\title{
PROGRAM OF THE
}

\section{MANUFACTURING ENGINEERING LABORATORY}

\section{5}

Infrastructural Technology, Measurements, and Standards for the U.S. Manufacturing Industries

U.S. DEPARTMENT OF COMMERCE Technology Administration National Institute of Standards and Technology Gaithersburg, MD 20899 



\section{PROGRAM OF THE}

\section{MANUFACTURING} ENGINEERING LABORATORY

\section{5}

Infrastructural Technology,

Measurements, and Standards

for the

U.S. Manufacturing Industries

U.S. DEPARTMENT OF COMMERCE Technology Administration National Institute of Standards and Technology

Gaithersburg, MD 20899

February 1995

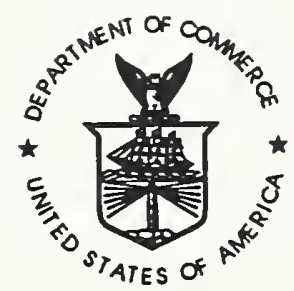

U.S. DEPARTMENT OF COMMERCE Ronald H. Brown, Secretary

TECHNOLOGY ADMINISTRATION Mary L. Good, Under Secretary for Technology NATIONAL INSTITUTE OF STANDARDS AND TECHNOLOGY

Arati Prabhakar, Director 


\section{Abstract}

The NIST Manufacturing Engineering Laboratory works with the U.S. manufacturing industries to develop and apply infrastructural technology, measurements, and standards to meet their needs. This report summarizes the resources, objectives, needs addressed, accomplishments, and plans for the projects carried out by the Manufacturing Engineering Laboratory in support of U.S. industry.

\section{Keywords}

infrastructural technology, manufacturing, manufacturing engineering, manufacturing technology, measurements, metrology, standards

\section{Disclaimer}

Certain commercial products are identified in this report to specify the work completely. Such identification does not imply recommendation or endorsement by the National Institute of Standards and Technology nor does it imply that the products mentioned are necessarily the best available for the purpose.

\section{For More Information}

Manufacturing Engineering Laboratory

National Institute of Standards and Technology

Building 220, Room B322

Gaithersburg, MD 20899-0001

Phone 301-975-3400

Fax 301-948-5668 


\section{Table of Contents}

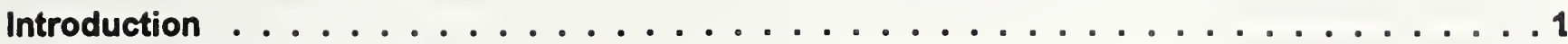

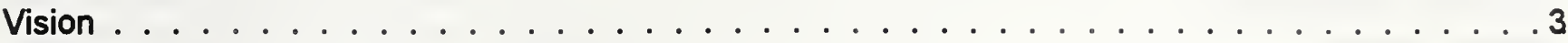

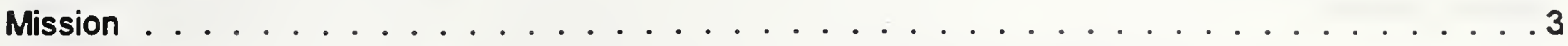

Goals . . . . . . . . . . . . . . . . . . . . . . . . . . 4

Customers. . . . . . . . . . . . . . . . . . . . . . . . . 5

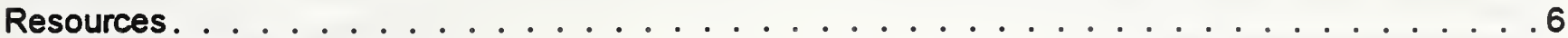

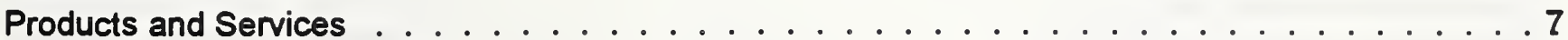

Evaluating Our Performance . . . . . . . . . . . . . . . . . . . . 7

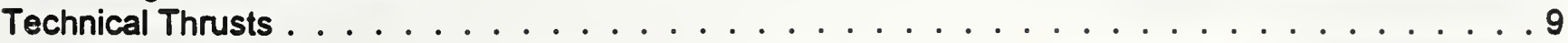

Project Descriptions . . . . . . . . . . . . . . . . . . . . . . . 11

Office of Manufacturing Programs . . . . . . . . . . . . . . . . . . . . . . . . . .

Collaboration With the Advanced Research Projects Agency . . . . . . . . . . . . . . . . . . . 16

NIST ManTech Program . . . . . . . . . . . . . . . . . . . . . . . . . 17

Technology Learning Modules . . . . . . . . . . . . . . . . . . . . . . . . . 19

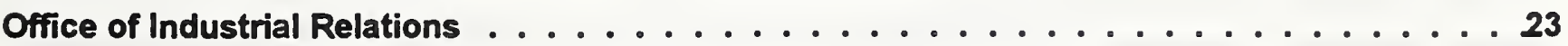

National Initiative for Product Data Exchange (NIPDE) . . . . . . . . . . . . . . . . . . . . .24

Precision Engineering Division . . . . . . . . . . . . . . . . . . . 27

Calibrated Surface Microscopy . . . . . . . . . . . . . . . . . . . . . . . . . 28

Calibration Research and Development . . . . . . . . . . . . . . . . . . . . . . . 30

Calibrations (SP-250) . . . . . . . . . . . . . . . . . . . . . 32

CMM Calibration Artifacts . . . . . . . . . . . . . . . . . . . . . . . . . 34

Collaboration in Dimensional Metrology With The Oak Ridge Centers For Manufacturing Technology

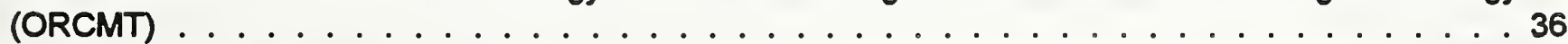

Complex Form Dimensional Metrology . . . . . . . . . . . . . . . . . . . . . . . . 38

Computational Metrology of Manufactured Parts . . . . . . . . . . . . . . . . . . . . . . . . .40

Development of Performance Evaluation Methodologies for Articulating Arm Coordinate Measuring

Machines

Diode Lasers For Length Measurement . . . . . . . . . . . . . . . . . . . . . . . . . .44

DOD Support . . . . . . . . . . . . . . . . . . . . . . . . . . 46

Figure and Finish Metrology For X-Ray Optics . . . . . . . . . . . . . . . . . . . . . 47

Hexapod Metrology . . . . . . . . . . . . . . . . . . . . . . . . . . . . . . 49

High-Accuracy CMM Development . . . . . . . . . . . . . . . . . . . . . 51

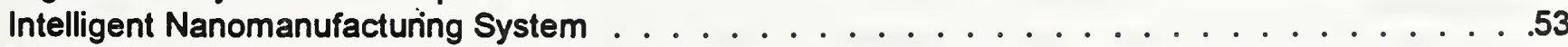

Laboratory Development . . . . . . . . . . . . . . . . . . . . . . . 56

Linewidth Correlation . . . . . . . . . . . . . . . . . . . . . . . . . 58

Long Length Laboratory . . . . . . . . . . . . . . . . . . . . . . . . . . . . 60

Metrology Education . . . . . . . . . . . . . . . . . . . . . . . . . 62

Molecular Measuring Machine . . . . . . . . . . . . . . . . . . . . . 64

Nanotechnology Competence Project . . . . . . . . . . . . . . . . . . 66

NIST Line Scale Interferometer Upgrading . . . . . . . . . . . . . . . . . . . 68

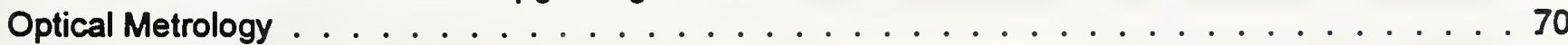

Optical Probe Metrology . . . . . . . . . . . . . . . . . . . . . . . . 72

Overlay Metrology . . . . . . . . . . . . . . . . . . . . . . . . . . . . . . . . . . . .74

Precision Machining of Advanced Materials . . . . . . . . . . . . . . . . . . 76

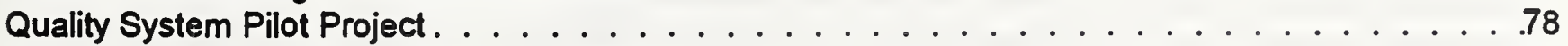

Scanning Electron Microscope Linewidth Metrology . . . . . . . . . . . . . . . . . . . . . . . .79 
Sematech Contract/nteraction . . . . . . . . . . . . . . . . . . . 81

SPM Tip Preparation and Charactenzation . . . . . . . . . . . . . . . . . 83

Surface Finish and Microform Measurements . . . . . . . . . . . . . . . . . . . .86

Ultraviolet Microscope . . . . . . . . . . . . . . . . . . . . . . 88

Wafer Flatness . . . . . . . . . . . . . . . . . . . . . . 90

Automated Production Technology Division . . . . . . . . . . . . . . .93

Acceleration And Shock Metrology . . . . . . . . . . . . . . . . . . . . . . . .94

Acoustical Metrology Services . . . . . . . . . . . . . . . . . . . . . . . . . .96

Artifact Mass To Watt Competence . . . . . . . . . . . . . . . . . . . . . . . . . . . .98

Enhanced Machine Controller . . . . . . . . . . . . . . . . . . . . . . . 100

Force Metrology . . . . . . . . . . . . . . . . . . . . . . . . 102

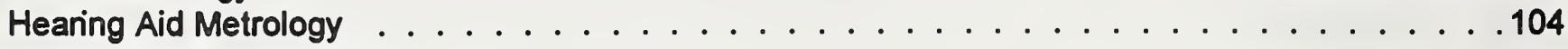

Mass Artifact Metrology . . . . . . . . . . . . . . . . . . . . . . 106

Materials Analysis of Ceramic Coatings On Metal Substrates . . . . . . . . . . . 108

Precision Machining . . . . . . . . . . . . . . . . . . . . . . . . . . . .110

Precision Machining of Advanced Materials . . . . . . . . . . . . . . . . 113

Process Modeling . . . . . . . . . . . . . . . . . . . . . . 115

Quality Control of Advanced Materials . . . . . . . . . . . . . . . . . . . . 117

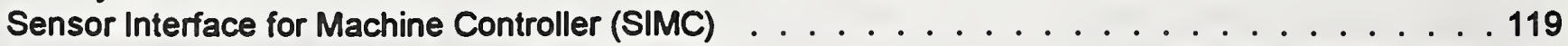

Sensor-based Manufacturing . . . . . . . . . . . . . . . . . . . . . . . 121

Spindle Characterization . . . . . . . . . . . . . . . . . . . . . . . . .123

Ultrasonic Calibrations Services . . . . . . . . . . . . . . . . . . . . . . . . . 125

Ultrasonic Transducer Development and Analysis . . . . . . . . . . . . . . . . . 127

Intelligent Systems Division . . . . . . . . . . . . . . . . . . . . . 129

Advanced Deburring And Chamfering System (ADACS) . . . . . . . . . . . . . . . . 130

Enhanced Machine Controller (EMC): The Next Generation of Factory Controllers . . . . . . . 132

Hexapod. . . . . . . . . . . . . . . . . . . . . . . . . . . . . . . 134

HPCC Virtual Factory Interface . . . . . . . . . . . . . . . . . . . . . . .136

IMI Robocrane Project . . . . . . . . . . . . . . . . . . . . . . . . . . . . . . 138

Next Generation Inspection System (NGIS) . . . . . . . . . . . . . . . . . . . . . . . . . 141

Operator Interfaces For Virtual And Distributed Manufacturing . . . . . . . . . . . . . . . . 143

Real-Time Control System Computer-Aided Control System Engineering Tool (RCT) . . . . . . 145

Reference Model Architecture/Joint Architecture . . . . . . . . . . . . . . . . . . . . . 147

Telerobotic Finishing of Aircraft Surfaces . . . . . . . . . . . . . . . . . . . . 149

Manufacturing Systems Integration Division . . . . . . . . . . . . . 151

Advanced Manufacturing Systems and Networking Testbed (AMSANT) . . . . . . . . . . . . 152

Agile Manufacturing Development of Castings . . . . . . . . . . . . . . . . . . . 155

Apparel Product Data Exchange Standard/Customer-Driven Apparel Manufacturing . . . . . . 157

Application Protocol Development Environment (APDE) . . . . . . . . . . . . . . . . . . . 160

APs For DOD And Industry . . . . . . . . . . . . . . . . . . . . . . . . 163

Computer Integrated Manufacturing Framework . . . . . . . . . . . . . . . . . 166

Computer-Aided Manufacturing Engineering . . . . . . . . . . . . . . . . . . 168

Dimensional Tolerancing and Computational Metrology . . . . . . . . . . . . . . . . . 170

Engineering Design Testbed . . . . . . . . . . . . . . . . . . . . . . . 173

Enhanced Integration of CAD With Design Support and Manufacturing Engineering Systems . . 175

Flexible Design-For-Assembly (DFA) Through Conceptual Assembly Modeling . . . . . . . . . 178

Industrial Fellowship Program-Black and Decker Manufacturing . . . . . . . . . . . . . . 180

Integration of Real-Time Scheduling And Shop Floor Data Collection . . . . . . . . . . . . 182 
Intelligent Processing of Metal Powders . . . . . . . . . . . . . . . . . . . . . . . . . . . . 184

Manufacturing Information Technology Transfer Project (MITT) . . . . . . . . . . . . . . . . . 185

Manufacturing Standards Development . . . . . . . . . . . . . . . . . . . . . . . . 187

Multi-Agent Manufacturing Systems . . . . . . . . . . . . . . . . . . . . . . . 190

National Industrial Information Infrastructure Protocols (NIIIP) . . . . . . . . . . . . . . . . 193

National PDES Testbed Program Office . . . . . . . . . . . . . . . . . . . . . . . . . . . 195

NIST/NADEP North Island Reverse Engineening Production System (REPS) . . . . . . . . . . . 197

Persistent Object Base (POB) Technology Evaluation For Engineering . . . . . . . . . . . . . . 199

Process Planning Applications . . . . . . . . . . . . . . . . . . . . . . . . . 201

Process Planning Testbed . . . . . . . . . . . . . . . . . . . . . . . . . . . . . . . . . . . 204

Rapid Response Manufacturing (RRM) Intramural Project . . . . . . . . . . . . . . . . . . . . . 206

Reference Model Architecture/Joint Architecture . . . . . . . . . . . . . . . . . . . . . . . . . 209

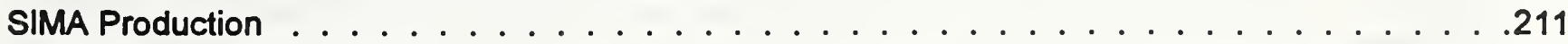

STEP Conformance Testing . . . . . . . . . . . . . . . . . . . . . . . 214

STEP Implementation Prototypes . . . . . . . . . . . . . . . . . . . . . . . . 216

Systems Integration For Manufacturing Applications (SIMA) Program . . . . . . . . . . . . . . . 218

Systems Integrating Manufacturing Applications (SIMA): Integration Project . . . . . . . . . . . 221

Virtual Enterprise For Custom, Therapeutic Footwear Manufacturing . . . . . . . . . . . . . . . 224

Cooperative Research and Development Agreements (CRADAs) . . . . . . . . . . . 227

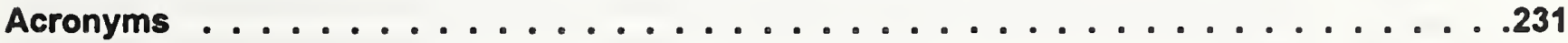




\section{Introduction}

The primary aim of a manufacturing enterprise is to deliver quality products that meet the needs of its customers. The primary aim of the Manufacturing Engineering Laboratory (MEL) is to work with its customers, the U.S. manufacturing industries, to develop and apply infrastructural technology, measurements, and standards to meet their needs.

Manufacturing is not just fabricating products from raw materials. Although the essence of manufacturing is transforming materials into products, modern manufacturing encompasses a wider variety of activities. Manufacturing activities start with product development planning, such as representing and exchanging knowledge about the product's form, dimensions and function, designing the product, and planning the production process.

Other manufacturing activities include controlling production machines and processes. Examples are handling materials, scheduling production, sensing and interpreting data before, during, and after production, and communicating between workers and machines. Finally, manufacturing activities include assembly, packaging, quality assurance, and marketing. Added to the activities of manufacturing, the issues of timeliness, cost effectiveness, safety, environmental friendliness, and reliability are critical factors in every manufacturing operation. As the leading federal laboratory for infrastructural technology, measurements, and standards for manufacturing, MEL supports a wide range of manufacturing activity areas and critical issues. MEL gives U.S. manufacturing industries tools that are used to improve efficiency and competitiveness.

Manufacturing is vital to the U.S. economy. Manufactured products represent approximately 19 percent (roughly $\$ 3$ trillion) of our gross national product. Manufacturing industries employ twenty million people, about 17 percent of the total workforce. Every 100 new manufacturing jobs creates an additional 64 nonmanufacturing jobs and supports an increase of over 200 workers. A healthy and robust manufacturing infrastructure that produces quality, customer-valued products, enables U.S. industry to compete successfully in international markets. A strong manufacturing infrastructure also allows the nation to sustain its economic growth, maintain a high standard of living, create jobs, and provide a strong national defense. By anticipating and addressing the needs of U.S. manufacturing industries for the next generation of physical and informational measurements and standards, MEL contributes to U.S. industruial competitiveness and economic prosperity.

Increased global competition is causing dramatic changes in the way products are manufactured. New manufacturing technologies are fueling the changes that are initiating a new industrial revolution. The rapidly changing competitive environment makes it necessary for U.S. industry to accelerate the development and application of advanced manufacturing technologies. The acceleration ensures the United States of future competitiveness in both national and international markets. MEL provides U.S. industry with state-of-the-art manufacturing architectures, models, data, and algorithms in advanced manufacturing technologies to help accelerate manufacturing technology development.

MEL's products are technology, measurements, and standards.

MEL supports the manufacturing technology infrastructure.

MEL contributes to U.S. industrial competitiveness and economic prosperity. 
MEL helps The Manufacturing Engineering Laboratory works with its customers to identify critical needs in meet

critical

industry

needs the advanced manufacturing technology infrastructure that supports U.S. industrial competitiveness. To address the critical needs, the Laboratory's activities are divided into four key thrusts: manufacturing systems integration, intelligent machines and systems, manufacturing metrology, and manufacturing processes and equipment. MEL's program consists of selected technical projects within these thrusts. The projects assist U.S. industry in developing necessary new technology, measurements, and standards.

This report describes MEL's vision, goals, resources, and customers needs. MEL pays special attention to how it measures the success of its programs.

The following project descriptions outline the resources, objectives, needs addressed, accomplishments, and plans for projects in the Laboratory. Five-year plans include the years 1995 through 1999. The project plans summarize the work of the Manufacturing Engineering Laboratory and provide $\mathrm{a}$ basis for building an even stronger program that will meet industry needs in the future. 


\title{
Vision
}

\author{
A world-class national research Laboratory \\ recognized as the primary resource \\ for infrastructural technology, measurements, and standards \\ for the U.S. manufacturing industries.
}

The Manufacturing Engineering Laboratory (MEL) is the leading federal laboratory for measurement-related research and development in manufacturing infrastructural technology. MEL's research and development leads to standards, test methods, and data that are crucial to industry's success in exploiting advanced manufacturing technology. Such technology can improve productivity and quality, reduce cost and time to market, increase profits, support higher wages, and lower the environmental impact of manufacturing operations.

While maintaining that vital and unique role, MEL has broadened its scope to encompass infrastructural technology. In cooperation with industry, MEL has become the federal government's key resource for supporting technology development in advanced manufacturing and for transferring manufacturing technology to industrial applications. MEL focuses on manufacturing supplier and user industries, and on industrial applications of advanced manufacturing technology to construction, transportation, environmental restoration, and health care. In this broader scope, MEL's work includes measurement, planning and control, communication, and methods for developing, representing, and communicating knowledge about products and processes.

\section{Mission}

To improve the competitiveness of U.S. manufacturing by working with industry to develop and apply infrastructural technology, measurements, and standards.

The Manufacturing Engineering Laboratory is unique because it serves the whole enterprise, in each of the manufacturing sectors, over the whole range of technologies. To carry out its mission, MEL:

Conducts research on manufacturing infrastructural technologies, Participates in manufacturing-related standards development, Provides measurement services to manufacturing industries, Provides manufacturing integration testbeds, Develops next-generation manufacturing metrology, and Collaborates with industry on new manufacturing technology. 


\section{Goals}

Through a strategic planning process, the Manufacturing Engineering Laboratory management established five goals for the Laboratory. The goals relate to traceability, measurements and standards, manufacturing architectures implementation, and customer satisfaction.

Traceability

Measurements and standards

\section{Manufac-} turing architectures

Implementation

\section{Goal 1: To establish MEL as the pinnacle of the traceability pyramid of physical and informational measurements for U.S. manufacturing products, processes, and services.}

The MEL research, development, and technology transfer programs embrace both physical and informational technologies. MEL maintains and makes accessible to industry traceability to national standards in length, mass, force, vibration, acoustic, and ultrasonic measurements, as well as to certain software testing systems and enterprise management tools.

\section{Goal 2: To anticipate and address the needs of U.S. manufacturing industry for the next generation of physical and informational measurements and standards.}

The Laboratory develops test and measurement techniques and provides calibration, measurement and test services to support industry needs. By monitoring the trends in requested services, consulting with industry on anticipated new requirements, and participating in new manufacturing technology development, MEL can forecast future industry measurement and standards needs. MEL also participates in private sector committees that develop formal documentary standards.

\section{Goal 3: To provide U.S. industry with state-of-the-art manufacturing architectures, models, data, and algorithms.}

MEL efforts in this area help create new generic architectures, such as those for machine controllers. MEL works to enable interoperability among manufacturing equipment and software tools and to anticipate necessary standards.

\section{Goal 4: To foster the development and implementation of advanced manufacturing systems, processes, and equipment.}

MEL efforts to foster the development and implementation of advanced manufacturing technology include the development of measurement techniques to characterize machines, and tools and their interactions with machined parts. MEL also works to develop the data, sensors, and models necessary for in-process gauging and controling. This reduces life cycle costs associated with man- 
ufacturing equipment by defining open, public domain specification and programing interfaces for equipment components.

\section{Goal 5: To improve customer satisfaction and MEL operational effectiveness.}

MEL continually seeks informal feedback from customers in daily interactions and more formally in workshops designed to solicit customer needs. Continuous improvement is pursued. Strategic planning, consensus building, and encouraging all staff to participate in decision-making are techniques used to spark improvements in MEL operational effectiveness.

\section{Customer Satisfac- tion}

\section{Customers}

The Manufacturing Engineering Laboratory has three types of customers: customers whom we directly assist, sponsors outside of NIST who fund our work, and oversight bodies who assess or evaluate the impact of our work. These customers represent industry, government, academia, standards organizations, consortia, technical societies, and the public. They include users of our services and products, and participants in our programs.

Oversight is through a formal chain and includes taxpayers, the Department of Commerce, the Office of Science and Technology Policy, the Office of Management and Budget, and Congress, as well as outside reviewing bodies such as the National Research Council.

MEL provides consultations, products, and services, including physical measurement services such as calibrations and standard reference materials. In exchange, the outside sponsors and users of our consultations, products, and services provide direct or in-kind financial support. During the years 1985 to 1993, funding from sponsors represented over half of the total MEL budget. These outside organizations, usually other government agencies, used the unique technical expertise of MEL scientists and researchers to enhance their own work, to meet their own goals, or to solve their measurement problems. However, for MEL to accept funding and agree to do the work, there are criteria that ensure mutual benefits. They include technical merit, potential for economic benefits, matching with MEL goals and priorities, meeting specific industry needs, availability of resources, and potential for collaboration and relationships with others.

MEL is proud of its reputation of responsiveness to its customers. By including customer satisfaction as one of its goals, MEL is demonstrating its commitment to serving those who can benefit from our work. 


\section{Resources}

The Manufacturing Engineering Laboratory receives its operating funds both from the NIST budget and from outside sources, mainly other government agencies. In fiscal year 1994, for the first time in ten years, funding from the NIST budget exceeded funding obtained from other sources.

MEL's total funding in fiscal year 1994 was $\$ 40,392,000$. Of this, $\$ 19,241,000$ came from the NIST budget and $\$ 13,270,000$ came from other government agencies. A smaller portion, $\$ 1,880,000$, came from NIST's Advanced Technology Program and Manufacturing Extension Partnership. The remainder of the budget was from reimbursable services such as calibrations, standard reference materials, the services of the Fabrication Technology Division, and from cooperative research and development agreements and miscellaneous expenses and income.

Source of Funding

NIST budget [Scientific and Technical Research and Services (STRS)]

Other government agencies (OA)

NIST Advanced Technology Program and Manufacturing Extension Partnership [Industrial Technology Services (ITS)]

Other [calibrations, standard reference materials, cooperative research and development agreements, miscellaneous expenses and income, and Fabrication Technology Division's services.
Amount (in thousands)

$\$ 19,241$

$\$ 13,270$

$\$ 1,880$

$\$ 6,001$

The human resources in the Manufacturing Engineering Laboratory are composed of permanent staff and guest researchers. Currently, there are 190 scientists and engineers, 36 technicians, 37 wage grade employees, and 45 support personnel, including clerical employees. In 1993, among the scientists and engineers, 29\% held PhDs, 34\% held master's degrees, and 37\% held bachelor's degrees. 


\section{Products and Services}

The Manufacturing Engineering Laboratory delivers products and services to its customers through communications, collaborations, demonstrations, equipment transfers, reimbursable services, and participation in voluntary standards organizations. Each of these mechanisms can be equally effective, depending upon the need that is being met. MEL communications include technical publications, presentations, and consultations. Important communication forums are conferences, workshops, and standards working groups where representatives from outside NIST discuss and develop action plans with us to meet industry needs. Attending meetings, visiting other organizations, and hosting visitors to our facilities contribute to communications.

Collaborations involve a wide range of joint activities. One type of collaboration is direct collaboration with outside partners on research and development projects. Testbeds are an effective way to collaborate with others on advanced technology and standards development and testing. Collaborations also include staff participation in standards organizations and professional societies. The enablers for direct collaborations are contracts, grants, cooperative research and development agreements (CRADAs), and guest researcher agreements. A new enabler will be the recently established industrial fellowship program.

Sometimes, collaborations lead to MEL installing hardware or software at a customer's or partner's location. Such installations serve to implement MEL-developed advanced technology quickly and to provide a test of the technology under actual operating conditions in a manufacturing environment.

Reimbursable services are the paid services that MEL provides, including calibration and fabrication services, and standard reference materials.

\section{Evaluating Our Performance}

The Manufacturing Engineering Laboratory sets its priorities, and evaluates its performance based upon the benefits realized by U.S. industry. Because of the variety and breadth of the work in MEL, the evaluation procedures must be flexible. Therefore, instead of specific criteria, a set of performance metrics is applied.

The performance metrics that form the basis of MEL's evaluation system are both qualitative and quantitative measurements of its economic and competitive impact. Performance metrics are made up of activity, progress, output, and significance metrics.

Activity metrics are measures of the size of the effort that led to a particular result and how many customers the result affected. Customers, interactions, staffing, and budget are included in activity metrics. The following are examples of information developed from activity-related measures that may be used to evaluate a project or assess a service.

Amounts of resources applied to the work

Number of interactions with customers

Amount of participation in consortia and standards organizations 
Time spent on cooperative research with industry and other federal agencies

Number of customers served and income generated

Use of unique facilities and testbeds by outside organizations

In-kind contributions by outside organizations

Progress Metrics are measures of achievement that indicate the status of a project or service. Progress metrics examine milestones and the results of internal and external reviews. Specific examples that apply progress metrics are:

Progress Metrics

\section{Output}

Metrics

Signifi-

cance

Metrics
Degree to which program plans are successfully executed

On-time achievement of milestones

On-schedule delivery of results

Decrease in time required for deliverables

Development of unique research facilities and testbeds

Success in attracting, developing, and retaining a diverse, world class staff

Positive feedback from National Research Council Assessment Panel

Output metrics are the quantitative measures of productivity. Typically, MEL measures its output by the numbers of countable actions, collaborations, or deliverables as shown in the following list.

Papers and reports published

Patents and licenses awarded

Technical achievements

Active CRADAs

Joint projects with other NIST laboratories and outside partners

Guest workers

Workshops and conferences

Standard reference materials produced

Calibrations and fabrication services performed

Significance metrics are the measures of the quality, value, and impact of the results on U.S. industry. The following examples show the way MEL measures significance.

Economic and competitive impact of technical results, patents, and licenses

Success in technology transfer to customers

Quality and relevance of technical output

Uniqueness and quality of research facilities, services and capabilities

Ability to provide critical advanced calibration, fabrication, and SRM services not available elsewhere

Ability to anticipate and establish critical SRM, calibration and fabrication services to meet new needs

Customer services compare well against a "best practice" benchmark

Number of companies claiming to be benefited by output

Degree of innovation

Leadership in outside activities

Awards and external recognition 
Education and experience level of staff

Distribution of staff among engineering and science disciplines

Diversity of staff

Quality of papers published

Number of invited papers and presentations

Press coverage

Results of the assessment panel and extent to which recommendations were followed

Results of surveys and impact studies indicating high quality or significant impact

\section{Technical Thrusts}

As part of its strategic planning and strategy implementing process, the Manufacturing Engineering Laboratory focuses on four technical thrust areas: Manufacturing Systems Integration, Intelligent Machines, Manufacturing Metrology, and Manufacturing Processes and Equipment. By focusing on the thrust areas, MEL is better able to concentrate its expertise in the most important areas to help U.S. manufacturers and to improve the manufacturing technology infrastructure.

\section{Thrust 1: Develop Interface Standards to Support a Fully Integrated Set of Manufacturing Systems That Demonstrate a Virtual Manufacturing Enterprise}

MEL addresses the information technology needs of manufacturers by concentrating on computer-integrated, electronically-networked manufacturing technologies and applications. Emphasis is on the development, implementation, testing, and dissemination of interface standards. The goal is a fully integrated set of interface standards to support a virtual manufacturing enterprise. The information technologies include integration frameworks, data representations, and data/knowledge exchange. The information technologies and applications are primarily product data exchange, design engineering, manufacturing systems engineering tools, and electronic commerce.

Manu-

In product data exchange, the work concentrates on the methods, tools, and conformance testing systems for application protocols that will be part of the new Standard for Exchange of Product Model Data (STEP). Design engineering and production systems work is on technologies and standards in support of environments for mechanical part production and apparel, and on systems integration to support those environments. Application areas includes the design of products, processes, and enterprises; planning and scheduling; process modeling; shop floor control; simulation; inspection; assembly; and machining.

The manufacturing systems engineering tools effort develops new technologies, methods, computer-aided tools, and standards for future engineering manufacturing systems. It develops engineering principles, design methodologies, and design tools for use in specifying, designing, building, testing, and evaluating both manufacturing engineering and real-time intelligent control systems.

Efforts in the area of electronic commerce address the development of technology and standards required to conduct commerce electronically and build an overall enterprise environment for manufacturing. 


\section{Thrust 2: Develop Performance Measures and Interface Standards to Support Industry Needs for Intelligent Systems and Sensor-Based Automation in Manufacturing}

Intelligent machine control is one of the most frequently mentioned technologies in surveys and lists of critical needs in manufacturing. Intelligent machines technology is a critical enabling component of advanced control systems for controlling machines, factories, processes, traffic, and vehicles. This thrust encompasses intelligent machines, open systems architecture, and simulation and modeling. These technologies are cross-disciplinary and foster collaboration among industry, universities, and government agencies.

\section{Intelligent Machines and} Systems

Manufacturing Metrology
Work on intelligent machines includes reference model architectures for intelligent controls, transformation of sensory data into models and knowledge databases, open systems architecture, simulation and modeling, development of metrics and performance measures, and standards. Plans for the work include demonstrating an integrated intelligent machine system testbed incorporating visual perception, force controlled manipulation, product and process models, simulation based reasoning, path planning, mobility, advanced operator interfaces, and development of engineering methods and computer-aided software engineering (CASE) tools.

The open systems architecture work seeks to improve the performance and functionality of manufacturing processes, machines, and tools. The work is developing interface standards for integrating commercial components from multiple suppliers. This enables modularity, extensibility, and portability of software across platforms.

Simulation and modeling efforts concentrate on validating methods, techniques, and technologies. These help management and technical personnel make better decisions about the design and control of manufacturing systems.

\section{Thrust 3: Address Industry Needs for Fast Reliable Measurements by Developing Measurement Systems and Standards}

The manufacturing metrology thrust incorporates research, development and services that provide more effective metrology support to U.S. manufacturing industries. Work under this thrust covers the chain of traceability from national standards through working standards to industrial process-control measurements, inspections and tests. The manufacturing metrology thrust focuses on dimensional and mechanical metrology, dimensional measurement inspection and test systems, nanotechnology, and advanced material processing manufacturing systems.

Dimensional and mechanical metrology work includes state-of-the-art calibration services and standard reference materials, as well as the research and development needed to provide them. The work covers the units of length and mass and the derived units of acceleration, sound pressure, dynamic displacement, sound reflectivity, and force.

Dimensional measurement inspection and test systems are the systems used by manufacturing industries for achieving and assessing the conformity of the dimensions of manufactured parts and assemblies to design tolerances. Sensor technology is addressed, as well as the processing of sensory data and the development of intelligent control algorithms. 
Nanometrology efforts deal with the standards and technology associated with measurement of dimensions which are nanometers in size. Activities include application of the molecular measuring machine for calibrations; research and development support; development and application of scanning probe microscopies; and calibrated artifacts for probe size.

Advanced material processing manufacturing systems are sensor-based computer-controlled automated systems that integrate material processing and material shaping operations for the manufacture of final discrete part products. This includes atomic scale processes that can be used to build-up increasingly larger multi-atom features.

\section{Thrust 4: Advance the State of the Art of High-Speed and High-Precision Manufacturing by Sensor-Based Metrology, Process Modeling, and Process Control}

The manufacturing processes and equipment thrust combines precision machining, nontraditional machining, manufacturing systems engineering tools, and fabrication services. Precision machining efforts work toward improving the accuracy of machine tools, coordinate measuring machines, and other machines that use sensor technology. These efforts include better characterization technologies for machines, processes, and tools and better integration of in-process and post-process measurement and control. The objective is to develop a science base for precision material removal and shaping processes and for sensor-based adaptive control of precision machining processes. In the long term, this will extend beyond metal cutting and forming to manufacturing with other materials.

\section{Manu- facturing Processes and Equipment} Nontraditional machining systems efforts aim to increase the flexibility of unconventional manufacturing processes and machine materials in specialty grinding, turning, milling, machining, casting, and stereo lithography.

Manufacturing systems engineering tools involves developing new technologies, methods, tools, and standards to implement computer-aided tools for the engineering manufacturing systems of the future. The objective is to investigate critical areas pertaining to engineering U.S. factories and to identifying and developing solutions for computer-aided factory engineering. This work accelerates the application of computer technology to the design and engineering of manufacturing systems.

Fabrication services provides design, fabrication, modification, and repairs to ultra-precise scientific instruments, apparatus, and equipment in support of NIST research and services.

\section{Project Descriptions}

The following sections contain descriptions of the projects in the Manufacturing Engineering Laboratory. These projects, combined with its action plan, respond to MEL's mission and goals.

The description of each project is in two parts. The first part is two pages of information on the project's resources, objectives, needs addressed, previous-fiscal-year accomplishments, and 
current-fiscal-year plans. The second part is a chart showing the planned schedule for major activities during fiscal years 1995 to 1999 . The acronym STRS represents scientific and technical research and services.

Under "Staff," the project leader's name is in capital letters. An asterisk identifies the staff members who work part time on the project.

The projects are grouped into the divisions and offices in the Manufacturing Engineering Laboratory. MEL is organized into two offices, four technical divisions, and the Fabrication Technology Division, as shown on the following organization chart. The technical divisions conduct almost all of the technical projects. 


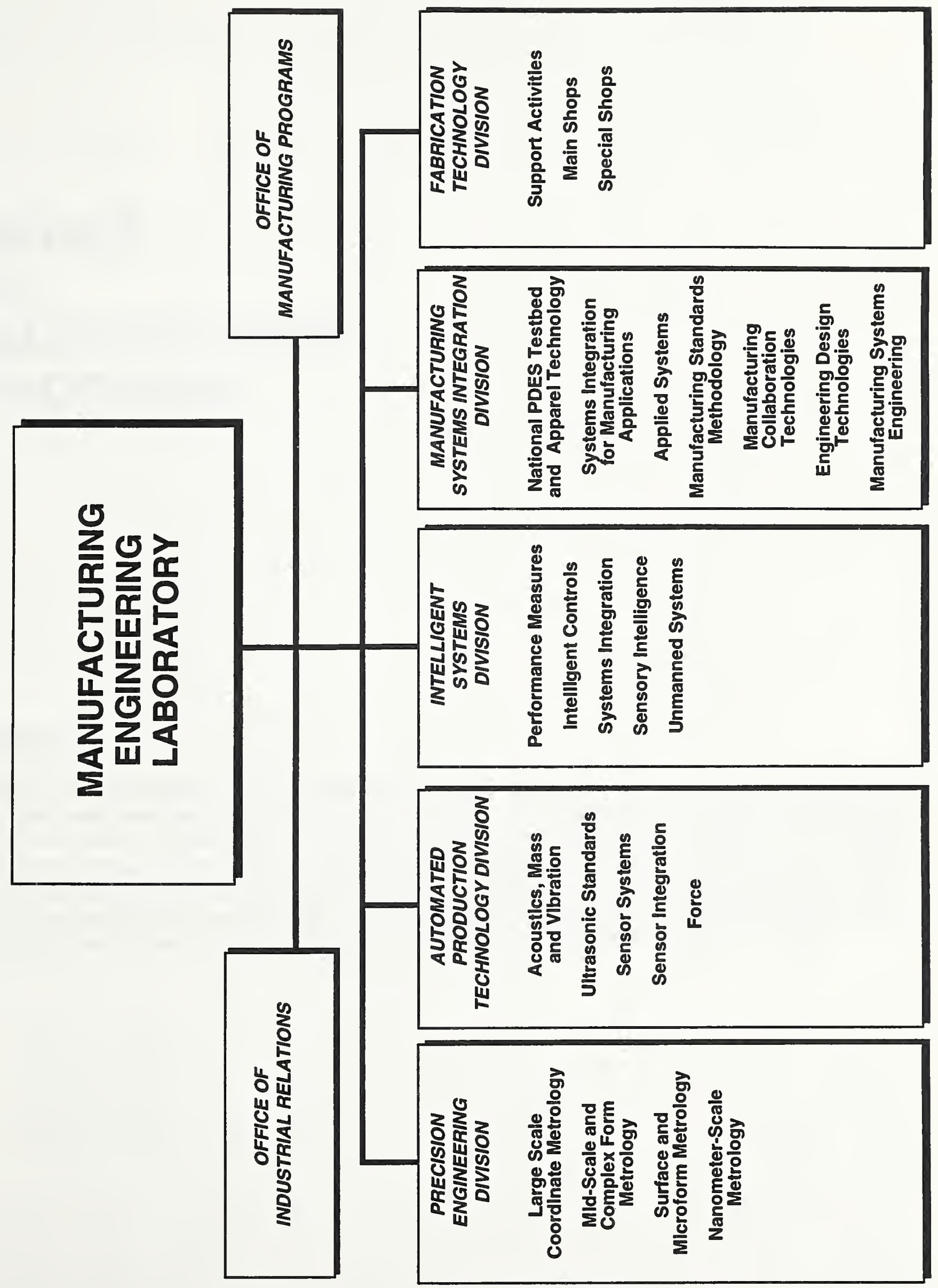




\section{OFFICE \\ OF}

MANUFACTURING

PROGRAMS

\section{MISSION:}

Manages cross-divisional, other-agency-sponsored research, development, and technology transfer within the Manufacturing Engineering Laboratory. Activities include proposal preparation and coordination, presentation to sponsors, negotiations with sponsors, maintenance of clear communications with sponsors, management of funded activities and reporting to sponsors; seeks out opportunities to implement technology from the Manufacturing Engineering Laboratory in actual manufacturing settings; develops linkages with other-agency-sponsored projects; and is one of the technology transfer agents of the Manufacturing Engineering Laboratory. 
Project Objective and MEL Thrust Supported: This project supports Manufacturing Engineering Laboratory efforts to work with other agencies in design and manufacturing.

Need Addressed: ARPA supports many projects to develop new tools for improving the integrated product and process development capabilities of Department of Defense manufacturers. ARPA seeks NIST support to help it identify keys areas for research, standards issues, and needed industry collaborations

Technical Approach: The project matches the knowledge within the Manufacturing Engineering Laboratory and other NIST laboratories with efforts funded by ARPA. NIST Personnel work with ARPA in the following ways:

- Technical Consulting. Serve as technical consultants to the ARPA sponsor, evaluating ARPA supported research, assessing commercial CAD/CAE/CAM systems and developments, and advising on standards-related issues.

- Programmatic Support. Support the ARPA sponsor in developing new programs for funding, and "white papers" to identify key issues to address national needs.

- Interagency Working Groups. Serve as a member of various interagency working groups. Several agencies are sponsoring research and development in the design and manufacturing arena.

- Specific Research. Perform research on a specific topic of mutual interest.

- Standards and Interface Issues. Identify and develop appropriate standards and system interfaces. One of the largest problems facing the development of the Design and Manufacturing systems is the issue of standards and interface issues.

FY 94 Accomplishments:

- Completed project Plan

- Coordinated MADEFAST design exercise for ARPA

- Developed Design White Paper for the National Science and Technology Council

- Represented NIST on the Agile Manufacturing Implementation Group.

- Identified new opportunities for NIST collaboration

\section{FY95 Plans:}

- Continue to support Manufacturing Automation and Design Engineering (MADE) project.

- Develop new activities between MEL and Simulation Based Design (SBD), Agile Manufacturing, IPPD for Vehicles, and other ARPA programs.

\begin{tabular}{|l|l|l|l|l|l|l||}
\hline $\begin{array}{l}\text { COLLABORATION WITH THE ADVANCED RESEARCH } \\
\text { PROJECTS AGENCY (ARPA) }\end{array}$ & FISCAL YEARS & 95 & 96 & 97 & 98 & 99 \\
\hline $\begin{array}{l}\text { Seek matches between NIST expertise and ARPA needs; } \\
\text { assist in initiating ARPA funding }\end{array}$ & & & & & \\
\hline $\begin{array}{l}\text { Coordinate long term MEL efforts such as NAMT with } \\
\text { external efforts in ARPA, NSF, DoE and the DOD }\end{array}$ & & & & & \\
\hline
\end{tabular}


Staff: (1.8 staff years) DAVID STIEREN, *Cheryl Albus, *Brenda Ray

Project Objectives and MEL Thrusts Supported: Formerly the NIST Automated Manufacturing Research Facility, this current program is a jointly sponsored, planned, and conducted array of individual technical projects. The staff above manages the program, selects the projects, assists in project management, interfaces with the Navy sponsors and industry, participates in DOD ManTech Program technical planning, and carries out other related activities. The NIST program manager for this effort acts as a technical and managerial liaison between MEL and the Navy ManTech Program. The projects within this program cover a wide range of computer integrated manufacturing technologies. These projects, which include both internal MEL work and contracted work, support all four MEL thrusts. Manufacturing Systems Integration, Intelligent Machines and Systems, Manufacturing Metrology, Manufacturing Processes and Equipment.

Need Addressed: This program serves the needs of the Navy ManTech Program by focusing on projects containing technical elements that will improve the capabilities or reduce the cost of Navy/DOD weapon systems production. The projects typically involve direct technical interaction with a Navy facility or contractor.

Technical Approach: This program supports nine active technical projects in FY 95. These projects deal with technologies ranging from enhanced control systems for machine tools, to integrated manufacturing engineering software tools, to advanced precision finishing systems. The projects leverage capabilities, expertise, and resources in MEL and the Navy to meet their objectives. The technical details of each of the projects are described separately.

\section{FY94 Accomplishments:}

- Transitioned the program from its AMRF status as a Navy Center of Excellence, to its current status as the NIST ManTech Program

- solved problems by focusing on projects that develop advanced manufacturing technologies that can be replicated in appropriate scenarios throughout DOD and the U.S. industrial base.

\section{FY95 Plans:}

- Operate the program to ensure the success of the individual technical projects.

- Develop the strategic plan for the program beyond FY 95 so that the program optimally meshes the objectives of MEL with those of the DOD ManTech Program.

Related Developments: NIST is no longer included in the Navy budget cycle for this program, which means that future year funding levels are uncertain. In addition, MEL is presently involved in the planning stages of the National Advanced Manufacturing Testbed (NAMT) that will be a new cross-cutting manufacturing initiative for MEL, and which is one of the active NIST ManTech projects for FY 95. The results of the NAMT planning effort will influence the future of this program. 


\begin{tabular}{|l|l|l|l|l|l|l|}
\hline NIST MANTECH PROGRAM FISCAL YEARS & 95 & 96 & 97 & 98 & 99 \\
\hline $\begin{array}{l}\text { Complete the NIST ManTech Program strategic plan } \\
\text { [Navy] }\end{array}$ & & & & & \\
\hline Complete on-going projects on schedule [Navy] & & & & & \\
\hline $\begin{array}{l}\text { Initiate new projects in accordance with the developed } \\
\text { strategic plan in accord with the NAMT effort [Navy] }\end{array}$ & & & & & \\
\hline
\end{tabular}




\section{Staff: (0.75 staff years) *DENVER LOVETT}

Project Objective and MEL Thrust Supported: The objective of this project is to develop a prototype module that can be used to deliver high performance manufacturing training for apprentice schools, small and medium size manufacturers, and community colleges, as well as school outreach programs in the metropolitan area. The two MEL thrust areas which this project supports are: (1) Manufact-uring Tools for Design and Manufacturing and (2) Manufacturing Processes and Equipment. This project supports MEL thrusts by fostering the implementation of advanced manufacturing systems, processes, and equipment. Small and medium manufacturing firms are often slow to adopt new technology because of extended implementation times associated with new technology and long training paths that are often ridden with frequent interruptions and set backs. High performance training systems provide greater productivity in the learning process and reduce one of the major barriers to the adoption of new technologies.

Needs Addressed: Many small manufacturers have gradually started to adopt new automation technologies in order to shorten manufacturing lead-time, to increase productivity and to improve product quality. One of the barriers they are facing is the shortage of a skilled workforce to work effectively with automation technologies. Due to planned obsolescence, the life spans of products are becoming shorter. This, in turn, often requires the implementation of new production systems to produce the next generation of products. This infusion of new production technology will require an enhanced training delivery system so that manufacturing personnel can be trained more effectively and more quickly. Small manufacturers and apprentice schools need high performance training systems that can reduce the training cycle and improve the quality of training. High schools and middle schools are searching for improved methods and learning technologies that can be used to merge science, math, and technology. The prototype module has been tested in both middle schools and high schools. This fall the testing began at the apprentice program at FOCUS-HOPE and Lancaster Area County/Willow Street Technical Schools.

The National Tooling and Machining Association, FOCUS-HOPE, and the Ray V. Watson Company have expressed a need for a high performance training system such as the TLM project and they are helping to form the industrial focus for the TLM project. In a broader sense, the public Law 103-227 "Goals 2000 : Educate America Act" mentions Department of Commerce as one of the departments that will assist the Secretary of Education in developing a long-range plan that supports the National Technology Policy. This is mentioned under Part C, Sections 231 and 232 of Public Law 103-227. In particular, NIST could provide laboratory-based technical assistance to the Office of Technology Education. Also, in the School-to-Work Opportunities Act (Public Law 103239, May 1994), there is need to support the intent of this law by developing innovative high performance training technologies. This project has launched a parallel effort of encouraging small research firms to participate in the research pertaining to high performance training systems. Several solicitations for Small Business Innovative Research (SBIR) were entered in the DOC SBIR booklet for FY 94 and FY 95.

Technical Approach: The project has provided a collaborative learning environment by assembling technologies that will allow remote access to high value resources by providing communication in the form of data, sound, and digital images transmission between NISTand the remote sites. The inputs to the system are groups of numerical control programs and the outputs are machined parts, digital images of the machining process, and instruction for improvements. The remote sites are electronically linked to NIST via modem.

The TLM project uses three-dimensional visual simulation to provide immediate feedback of programmed machining operations. The material removal process can be visually inspected and detail dimensional analysis of the material removal can be performed. This project uses commercially grade software that has been re-engineered to perform computer-based tutorial functions. Future improvements are to develop interfaces that would provide seamless integration and to enhance the multimedia functions of the simulation software. Ingenuity in designing projects for the TLM could significantly enhance the value of the TLM for learning math in a real-world setting. 
FY 94 Accomplishments:

- Selected four schools to participated in the TLM project. We implemented electronic data transmission between NIST and three of these schools.

- Completed 45 projects. NC programs were transmitted to NIST. Machine parts, digital images, and instruction for improvements were transmitted to the schools.

- Identified three potential industrial partners. These sites are FOCUS-HOPE, Affiliated Schools of the National Tooling and Machining Association, and the Ray V. Watson Company.

- Modules were distributed to two of the industrial beta-sites.

FY 95 Plans:

- Improve the efficiency of digital transmission by implementing more effective compression techniques.

- Upgrade TLM computers to provide more multimedia capability.

- Develop projects that will stimulate collaboration between schools and incorporate more multimedia features into the TLM software.

- Develop better interfacing capability in order to accomplish seamless data transfer between programs.

- Obtain funding support from Department of Education and Department of Labor.

Related Developments: The National Information Infrastructure (NII) is going to rapidly change the way we learn, work, and entertain. This project is a good candidate to demonstrate collaborative training on demand. The NII will make it easier to distribute these TLM modules and will facilitate data transfer between remote sites.

Today's manufactured products have shown explosive growth in complexity as increased functionality and new capabilities are incorporated into their designs. As the complexity of these products rise, so does the difficulty of training users in the operation and maintenance of these products. In addition, even as the functionality of the systems have increased, users are being asked to share more tasks and operate or maintain more systems. Therefore, users may focus on the operation of a particular type of system only during intermittent time periods, exacerbating and complicating efforts to use and maintain each system effectively.

To maintain proficiency, effectiveness, and a high level of productivity, users require both initial and sustained training. In addition, operators are confronted with multi-functional systems, complicated user interfaces, and information overload. The operator must integrate vast amounts of information in a short period of time and effectively manage the system for the highest quality and most reliable system performance. Hybrid computer-based training aids that inherently understand the operation and maintenance of these complex systems are required. 


\begin{tabular}{|c|c|c|c|c|c|}
\hline $\begin{array}{l}\text { TECHNOLOGY } \\
\text { LEARNING MODULES (TLM) }\end{array}$ & 95 & 96 & 97 & 98 & 99 \\
\hline Increase the number of TLM units from four to six [STRS] & - & & & & \\
\hline $\begin{array}{l}\text { Determine facets of learning, to be captured in the tutorial } \\
\text { for turning-operation [STRS] }\end{array}$ & & & & & \\
\hline $\begin{array}{l}\text { Develop requirements for three dimension simulation of } \\
\text { turning-operations and prepare solicitation for proposals } \\
\text { for NC tutorial for turning-center [STRS] }\end{array}$ & & & & & \\
\hline $\begin{array}{l}\text { Optimize for balance between speed of response, memory } \\
\text { storage, and quality of video, and audio; select } \\
\text { parameters to achieve optimization sampling rates } \\
\text { quantalization levels, encoding and decode parameters; } \\
\text { implement compression and decompression techniques } \\
\text { [STRS, DoEd] }\end{array}$ & & & & & \\
\hline $\begin{array}{l}\text { Upgrade TLMs to include more multimedia capability } \\
\text { [STRS, DoED] }\end{array}$ & & E & & & \\
\hline $\begin{array}{l}\text { Increase the number of TLM units in schools \& industrial } \\
\text { sites to } 18 \text { units [DoEdu \& DoL] }\end{array}$ & & & & & \\
\hline $\begin{array}{l}\text { Form CRDA's with prime produces of technology as } \\
\text { partners of this project and expand industrial participants } \\
\text { as user of TLM [STRS] }\end{array}$ & & $\Longrightarrow$ & & & \\
\hline $\begin{array}{l}\text { Transition from Technology Learning Modules to } \\
\text { Performance Support Systems (PSS) [STRS] }\end{array}$ & & & & & \\
\hline $\begin{array}{l}\text { Select manufacturing tasks for prototyping the PSS's [ } \\
\text { STRS, DoL] }\end{array}$ & & & $\square$ & & \\
\hline Develop design parameters for the PSS's [STRS, DoL] & & & 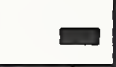 & & \\
\hline $\begin{array}{l}\text { Develop requirements to be used for procurement of } \\
\text { some of the PSS subsystems [STRS, DoL] }\end{array}$ & & & & & \\
\hline $\begin{array}{l}\text { Assemble, test and evaluate the effectiveness of two } \\
\text { prototype PSS [STRS, DoL] }\end{array}$ & & & & & \\
\hline
\end{tabular}




\section{OFFICE \\ OF \\ INDUSTRIAL \\ RELATIONS}

\section{MISSION:}

This office is responsible for the planning, development, coordination, and review of programs and activities within the manufacturing community that involve significant interaction with the U.S. industrial community. It also serves as a liaison to the Department of Commerce, Under Secretary for Technology, in advancing product data exchange efforts and supporting the National Initiative for Product Data Exchange. 
Title: NATIONAL INITIATIVE FOR PRODUCT DATA EXCHANGE (NIPDE)

Staff: (2 staff years) MEL: MERRILL M. HESSEL, Patricia Evans (temp), James Nell, Alan Tarica (temp), Melissa Zeltman; Other NIST: John Blair (Public Affairs), Ed Solomon (Physics); Private industry and other agency: William Conroy, Kathy Erickson, Gottlieb Fleig, Lance Horne, Chris Humphrey, Hank Noel, Ron Ruys, and Charles Stark.

Project Objective and MEL Thrust Supported: NIPDE was a three-year industry-government initiative designed to increase the visibility to the U.S. industrial community of Product Data Exchange (PDE) and to accelerate the development, implementation and delivery of the international standard STEP. Manufacturing Systems Integration.

The specific objectives of the NIPDE program were to:

- Develop programs to leverage and coordinate PDE activities

- Provide a central focus and impetus for product data exchange activities

- Establish NIPDE as a central PDE information source

-- Provide an electronic library for information about PDE objectives, schedules, milestones, plans, and status of the participating organizations.

-- Provide a remotely accessible electronic library of materials

- Coordinate with related U. S. activities

- Coordinate with international activities

Need Addressed: The NIPDE implementation plan was developed as an industry government initiative. The needs for exchange of product data information between $\mathrm{CAD}$ and other engineering systems are documented in this plan.

Technical Approach: The approach and milestones are clearly defined in the NIPDE implementation plan. A team of full time industry and government managers and engineers undertook the activities specified to meet the objectives. The progress of this effort was reviewed quarterly by both a Steering Committee and an Ad Hoc Senior Executive Level Board of industry and government personnel.

FY 94 Accomplishments:

- Broad Industry Participation

- Video (Distributed over 5000 copies)

- Articles and Speeches in Major Publications

- e.g. CALS Journal, Information Week, Aviation Week

- Press Packets with Industrial writeups

- Booths at Major Industry Expositions

- Information, slides and materials

- Product Data Exchange Conferences and Workshops

- The Electronic Library

- A server was established on the World Wide Web since June 1994

- It contains over 450 up-to-date Product Data Exchange project descriptions

- Monthly updates of projects and other materials

- Significant other information on PDE activities

- Between 4000 and 6000 accesses per week

- The NIPDE server points to other servers with PDE related information

- Capability Action Plans (CAP) initiated project to define PDE needs in critical areas

- A group of experts in the field defined these areas 
- They clearly defined scope of a specified capability

- The group prioritized set of functionality as required by the scope

- Projects (existing \& needed) mapped against ordered function list

- Identified missing elements (voids)

- Prepared a CAP Statement of Work Description

- Active CAP Areas and Participants

- Electronic Commerce of Component Information -- Allied Signal, Enterprise Integration Tech, NIST, Sandia

- Form Features -- Allied Signal, Arizona St Univ, GM, Northrop-Grumman, NCMS/RRM, RAMP, Raytheon

- Digital Mock Up - Chrysler, Ford, IBM, Lockheed

- Scientific/Engineering Data - Council of Library Resources, GM, IBM, NIST, Sandia Nat'l Labs

- Product Documentation -- Boeing, British Aerospace, GM, JCALS, NASA, Nat'l Semiconductor, Rockwell, Softquad

-Testing -- DISA, IPO Testing Project, ITI Michigan, PDES, Inc., NIST

- CAP's Being Initiated in FY 95

- Composites -- Boeing, GM, NCMS, SCRA

- Process Plants -- NIST, POSC, PlantStep

- Apparel -- NIST, SCRA, MTAC

- Master Plan Inputs and Mappings for Electronic Library and Software Tools

- Developed tool for inputting project data and outputting automated World Wide Web html code for the Electronic Library

- Tool database developed for query of information and available on disks for use on PCs

FY 95 Plans: Actual transition and institutionalization of NIPDE activities to the U.S. Product Data Association and the NIST IGES/PDES Office. Developed detail transition elements, defined transition schedules, assured readiness of tools, data, and processes. Transitioned the CAP activities to appropriate industry and government organizations.

Note: This program ends on March 1, 1995. All temporary NIST staff will terminate. The other NIST staff will work on other projects. The other staff will go back to their home institutions. 


\section{PRECISION ENGINEERING DIVISION}

\section{MISSION:}

Conducts research and development in precision-engineered length-metrology-intensive systems, both measuring and production machines. Provides delivery of industrially-important length-related measurements, standards, and infrastructural technology services in support of U.S. manufacturing's products and processes. Features of interest range in size from multiple meters to sub-nanometer and are measured by framed and frameless general and specialpurpose measuring probes, machines, and systems, employing the spectrum of optical, mechanical, electrical and quantum-mechanical phenomena, beginning with first-principles realization of the SI unit of length by means of stabilized lasers and displacement interferometry. 
Staff: (2.5 staff years) T. MCWAID, J. SCHNEIR, *R. Dixson, *J. Fu

Project Objective and MEL Thrust Supported: Project objective is to support high resolution surface microscopies used by U.S. manufacturing industries for micrometer scale metrology. Manufacturing Metrology

Need Addressed: Manufacturers of integrated circuits, opto-electronic devices, data storage media, and optical components use high resolution surface microscopy for quality and process control. Manufacturers require standards to verify proper instrument calibration and maintain process control. Uncalibrated measurements impact yield, process development costs, scaling from pilot lines to high throughput manufacturing, and correlation of product attributes with process models. Calibrated microscopy is an enabling technology for the manufacture of digitally based consumer products. This market, driven by the convergence of the information and entertainment industries, is projected to grow to three trillion dollars by the year $2002 .{ }^{1}$ In 1994 , the manufacture of microelectronic devices comprised a world market of $\$ 85$ billion.

Technical Approach: Atomic force microscopy (AFM) has evolved rapidly since its invention in 1986. AFM has revolutionized surface microscopy, allowing the acquisition of surface topography from both conducting and nonconducting surfaces with unprecedented lateral and vertical resolution. Indeed, AFM has demonstrated a lateral resolution of $0.3 \mathrm{~nm}$ and a vertical resolution of $0.01 \mathrm{~nm}$. To date, this microscopy has not been used by NIST for making traceable measurements. The cornerstone of this project is the development of an AFM with traceability to the wavelength of light in all three coordinate axes.

This "calibrated" AFM (C-AFM) will be used to calibrate pitch and height artifacts for use in U.S. industry. The instrument will calibrate pitch artifacts ranging in size from about $10 \mu \mathrm{m}$ down to $0.5 \mu \mathrm{m}$, or below, with an expanded uncertainty of $3 \mathrm{~nm}$. The calibrated AFM will calibrate height artifacts ranging from approximately $1 \mu \mathrm{m}$ down to $10 \mathrm{~nm}$, with an expanded uncertainty of $1 \mathrm{~nm}$.

Scanning electron microscopy (SEM) is used throughout industry. SEM is used for inspecting products for defects, contamination, and conformance to geometrical tolerances. Additionally, reliability personnel often rely on SEM to determine the cause of product failure. Accurate, reproducible SEM measurements are dependent upon the availability and use of magnification standards for microscope calibration.

Our mission includes the calibration of Standard Reference Material (SRM) 484, a magnification standard for SEMs. SRM 484 allows SEM operators to calibrate their instruments over magnifications ranging from $1000 \times$ to $20000 \times$. Seven previous issues of this popular SRM have been sold. The current issue, SRM $484 \mathrm{~g}$, will be calibrated this year. The project's current SEM will no longer support the dissemination of SRM 484 after SRM 484g. The electronics is obsolete, and the SEM must be replaced. Over 0.5 staff-years of repair has been required to date to prepare this SEM for calibration of SRM 484g. The Nano-Scale Metrology group has offered to make their Amray metrology SEM available to us for the calibration of future issues of SRM 484. We plan to accept this offer.

\section{FY 94 Accomplishments:}

- Designed, assembled, and performed initial performance tests on the C-AFM.

- $\quad$ Performed $3 \mu \mathrm{m}$ pitch measurements with $0.010 \mu \mathrm{m}$ expanded uncertainty.

\footnotetext{
${ }^{1}$ John Scully, former CEO Apple Computer (1992).
} 
- $\quad$ Performed $19 \mathrm{~nm}$ height measurement with $2 \mathrm{~nm}$ expanded uncertainty.

- Repaired SEM power-supply.

- Provided measurement support for two opto-electronics companies receiving ATP funding.

- Provided measurement support for VLSI Standards Inc., a leading manufacturer/marketer of industrial calibration artifacts.

- Surveyed over twenty five semiconductor manufacturers and equipment suppliers concerning calibrated surface microscopy requirements.

- Published seven articles in scientific journals and conference proceedings.

\section{FY 95 Plans:}

- Set up formal calibration facility using the C-AFM for the calibration of pitch/height artifacts: upgrade instrumentation; develop calibration data acquisition and analysis procedures; determine measurement uncertainty; calibrate pitch/height artifacts. The goal is $1 \mathrm{~nm}$ expanded uncertainty for height measurements and $3 \mathrm{~nm}$ expanded uncertainty for pitch measurements.

- $\quad$ Finish repair of SEM.

- Calibrate the SRM 484g SEM magnification standard.

- Provide AFM calibration support for Digital Equipment Corporation's efforts at front end-of-line and at line wafer metrology.

- Continue technical support of CRADA partners (Park Scientific Instruments, VLSI Standards Incorporated, and Optex Corporation).

\begin{tabular}{|c|c|c|c|c|c|}
\hline CALIBRATED SURFACE MICROSCOPY FISCAL YEARS & 95 & 96 & 97 & 98 & 99 \\
\hline \multicolumn{6}{|l|}{$\begin{array}{l}\text { Upgrade equipment and methods for C-AFM microscope } \\
\text { calibration services [STRS, SEMATECH] }\end{array}$} \\
\hline \multicolumn{6}{|l|}{$\begin{array}{l}\text { Characterize C-AFM microscope system performance and } \\
\text { measurement uncertainty [STRS, SEMATECH] }\end{array}$} \\
\hline \multicolumn{6}{|l|}{$\begin{array}{l}\text { Calibrate pitch/height artifacts for calibration of AFM } \\
\text { microscopes [STRS] }\end{array}$} \\
\hline \multicolumn{6}{|l|}{$\begin{array}{l}\text { Provide microscopy measurement support and } \\
\text { consultation for Uniphase, Park Scientific Instruments, } \\
\text { Optex, VLSI Standards, and other CRADA partners } \\
\text { [STRS] }\end{array}$} \\
\hline \multicolumn{6}{|l|}{$\begin{array}{l}\text { Calibrate SEM magnification standard (SRM 484g) } \\
\text { [STRS] }\end{array}$} \\
\hline \multicolumn{6}{|l|}{$\begin{array}{l}\text { Perform SRM } 484 \text { magnification standard calibration on } \\
\text { Nano-Scale Metrology group's SEM [STRS] }\end{array}$} \\
\hline \multicolumn{6}{|l|}{ Calibrate future releases of SRM 484 [STRS] } \\
\hline $\begin{array}{l}\text { Provide calibration support for at line front-end-of-line } \\
\text { AFM wafer microscopy at DEC and other integrated circuit } \\
\text { manufacturing companies [STRS] }\end{array}$ & & & & & \\
\hline
\end{tabular}


Staff: (1.65 staff years) JOHN STOUP, *Ted Doiron, *Howard Harary *Jay Zimmerman, *Jack Stone

Project Objective and MEL Thrust Supported: To improve the MEL dimensional measurement capabilities in the areas of length, form, diameter, and flatness. Manufacturing Metrology.

Need Addressed: NIST is required to provide traceability to physical and intrinsic national standards that insures standardization for the manufacturing industry. Pressure for improved dimensional measurement capabilities has been increasing with rapid technological advances in the manufacturing industry. Improvements in NIST measurement capabilities will have direct economic benefits for our calibration clients by allowing them into areas of design and research previously unapproachable due to measurement constraints.

Technical Approach: Using newly developed techniques and software, we will extend the capabilities of existing MEL dimensional calibration equipment to their practical limits. State-of- the-art statistical process control and environmental compensation and monitoring are NIST strengths in the field of dimensional calibration. Improvements in these areas should produce better accuracy with lower uncertainties for these measurements. Further improvements in these areas will be addressed by analyzing state-of-the-art equipment and processes that are currently available commercially. With cooperation from our calibration clients and equipment manufacturers, we will develop improved calibration services in several ways. We will procure new equipment and implement NIST measurement techniques and statistical process control to extend their capability. We will use state-of-the-art measurement principles to develop new equipment with improved accuracy and range. We will exploit existing commercial equipment in areas not originally intended for their use; i.e. the ZYGO phase stepping interferometer modified for gage block interferometry and dilatometry.

\section{FY 94 Accomplishments:}

- Developed a laser based micrometer for the absolute measurement of cylinders and wires. This instrument has improved accuracy over larger measurement ranges $(0-100 \mathrm{~mm})$.

- Improved long gage block calibrations by improving geometry and surface finish of NIST master gage blocks.

\section{FY 95 Plans:}

- Complete development of the artifact positioning system and micrometer enclosure for environmental control.

- Develop a cylindricity calibration with check standards and SPC using existing MEL calibration equipment.

- Analyze the performance of the Federal Formscan 3300 (on lease). Determine if the Formscan cylindricity measurement capabilities are comparable to the Talyrond based measurements.

- Analyze the performance of the Pratt \& Whitney Labmaster (on lease). Determine capability of performing NIST caliber measurements.

- Analyze AAMACS for implementation as a calibration instrument.

- Receive and begin research on the ZYGO phase stepping interferometer. Applications should include topographical flatness measurement, gage block interferometry, and dilatometry.

- Develop a method to measure gage block phase shift effects using a Strang Viewer based process. 


\begin{tabular}{|c|c|c|c|c|c|}
\hline $\begin{array}{l}\text { CALIBRATION RESEARCH } \\
\text { AND DEVELOPMENT }\end{array}$ & 98 & 96 & 97 & 98 & 99 \\
\hline \multicolumn{6}{|l|}{$\begin{array}{l}\text { Develop a full area flatness calibration (possibly up to } 300 \\
\text { millimeters in diameter) at lower uncertainties than the } \\
\text { current method [STRS, Calibration fees] }\end{array}$} \\
\hline \multicolumn{6}{|l|}{$\begin{array}{l}\text { Develop a form measurement calibration system } \\
\text { consisting of multiple equipment and procedures. Blend } \\
\text { this capability into all internal and external diameter } \\
\text { measurements to lower uncertainties in these areas by } \\
\text { minimizing part form error and positioning error terms in } \\
\text { the uncertainty statements [STRS, Calibration fees] }\end{array}$} \\
\hline \multicolumn{6}{|l|}{$\begin{array}{l}\text { Develop a dilatometry calibration service [STRS, } \\
\text { Calibration fees] }\end{array}$} \\
\hline \multicolumn{6}{|l|}{$\begin{array}{l}\text { Improve NIST gage block interferometry calibration by } \\
\text { upgrading existing Hilger interferometer and developing a } \\
\text { new system based on the ZYGO phase stepping } \\
\text { interferometer [STRS, Calibration fees] }\end{array}$} \\
\hline \multicolumn{6}{|l|}{$\begin{array}{l}\text { Improve the environmental control systems in all } \\
\text { interferometry equipment including gage blocks, cylinders } \\
\text { \& wires, spheres, and flatness [STRS, Calibration fees] }\end{array}$} \\
\hline \multicolumn{6}{|l|}{$\begin{array}{l}\text { Develop an angular measurement service based on a fully } \\
\text { mapped AAMACS for angle blocks, polygons, indexing } \\
\text { tables, optical encoders [STRS, Calibration fees] }\end{array}$} \\
\hline $\begin{array}{l}\text { Improve NIST long gage block interferometry by a } \\
\text { multicolor laser system using a new stabilized green laser } \\
\text { [STRS, Calibration fees] }\end{array}$ & & & & & \\
\hline
\end{tabular}


Staff: (4.7 staff years) ERIC STANFIELD, *Jay Zimmerman, *Bryon Faust, *Danny Taylor, *Dennis Everett, *Eddie Erber, *Ted Doiron, *John Stoup, *Mike Stocker

Project Objective and MEL Thrust Supported: To support industry by providing quality calibrations, traceability to national standards, and expert technical advice. Manufacturing Metrology.

Need Addressed: Target Customers: U.S. industry, other government agencies, foreign industries and laboratories. Target Customer Needs: high-accuracy calibration of dimensional artifacts, traceability to a national laboratory, technical guidance, and reasonable calibration turnaround time and price.

Technical Approach: Perform high-accuracy quality calibrations for private industry, government agencies, laboratories and international companies. This is accomplished by reporting parameter specific data with the lowest attainable uncertainty in a calibration report format which includes a NIST test number specific to each calibration.

FY 94 Accomplishments:

- Coordinated calibrations being performed at DOE Y-12 facility.

- Addressed the customer demand for Gear Related Calibrations.

- Completed Approximately 250 Calibration Orders.

- Received approximately $400 \mathrm{~K}$ in calibration revenue.

- Held the first dimensional calibration seminar which related to the customers' request for information on specific calibrations methods, uncertainty determination, and common sources of error.

- Documented several calibration procedures.

FY 95 Plans:

- Continue to improve current calibration methods and develop more accurate calibration methods.

- Offer gear-related calibrations.

- Begin developing a calibration laboratory quality system, which will help address turnaround time, price, and all customer quality related issues.

Related Developments: The growing popularity of ISO 9000 Standards in conjunction with ISO Guide 25 or ANSI Z540 in the United States. NVLAP performing laboratory accreditation to requirements which parallel ISO Guide 25 and ANSI Z540.

Both of the above will increase the number of calibrations performed by NIST (initially), the demand for new calibrations and/or dimensional standards, desire for lower uncertainties, and the demand for education. 


\begin{tabular}{|c|c|c|c|c|c|}
\hline CALIBRATIONS (SP-250) & 95 & 96 & 97 & 98 & 99 \\
\hline \multicolumn{6}{|l|}{$\begin{array}{l}\text { Replace Pulfrich Viewer with a ZYGO Interferometer for } \\
\text { performing optical flat calibrations [Calibration fees] }\end{array}$} \\
\hline \multicolumn{6}{|l|}{$\begin{array}{l}\text { Integrate the new laser based micrometer into thread wire } \\
\text { calibrations [Calibration fees] }\end{array}$} \\
\hline \multicolumn{6}{|l|}{$\begin{array}{l}\text { Maintain an average turnaround time of } 30 \text { days for all } \\
\text { standard calibrations [Calibration fees] }\end{array}$} \\
\hline $\begin{array}{l}\text { Develop a calibration laboratory quality system which will } \\
\text { be in full compliance with Guide } 25 \text { and ANSI Z540 } \\
\text { [Calibration fees] }\end{array}$ & & & & & \\
\hline
\end{tabular}


Staff: (2.0 staff years) BRUCE BORCHARDT, *Steve Phillips, *Greg Caskey, *Tyler Estler, *Dan Sawyer, *Trish Snoots, *David Ward

Project Objective and MEL Thrust Supported: To develop an interim test artifact and machine calibration techniques and devices for accuracy enhancement. Manufacturing Metrology.

Need Addressed: The Air Force recognized that the problem of CMM process control was critical when $95 \%$ of their CMMs failed their annual recalibration. Everyone who uses CMMs in production needs to check the machine's performance periodically. Otherwise, the machine might fail good parts or, even worse, pass bad ones. Existing test artifacts were too slow, heavy, and expensive and did not provide a full system check. A manufacturer of heavy equipment did a survey of all available artifacts and determined that none of them passed his criteria.

The full calibration of a CMM's geometry for the implementation of error correction is a very slow process when performed with traditional laser interferometers, electronic levels, and metrological fixtures. It may take 3 or 4 days to do the calibration. Since the accuracy of a CMM depends on the recalibration of the machine, the error correction procedure needs to be as rapid and simple as possible so that it can be done as often as needed.

Technical Approach: Improve speed: The most time-consuming part of a CMM calibration is the setup of the measuring instruments. If laser interferometers are used, they must be repositioned for each of the geometrical parameters used. Artifacts with high information density capability, like ball plates, must be repositioned many times to generate the necessary data. Each repositioning requires re-teaching the CMM the position of the artifact. The one-dimensional ball bar, also known as a ball step gage, can have high information density along one line and is capable of being repositioned so that the CMM can automatically find it.

Use a more practical artifact: Ball plates, which are currently used in CMM calibrations, are impractical because of high weight for even modest size. This is necessary because the supporting frame must be dimensionally stable under probing forces. A ball bar supported by a kinematic stand can be very lightweight, since the support will resist distortion under probing force. The ball bar also saves weight and complexity because it consists of only two balls with one calibrated center-to-center length. The negative side of this design is that it must be repositioned many times to gain the same information. This price is easily paid if the stand can be quickly relocated to a position known to within the seek distance of the CMM.

\section{FY 94 Accomplishments:}

- Designed and built general purpose ball bar stand system

- Brought to full production for sale the Interim Test Artifact for checking CMM accuracy at frequent intervals

- Wrote the ITA users manual

- Built and tested the automated ITA

- Deployed the ITA at Boeing Seattle, Boeing Wichita, Caterpillar, and Giddings \& Lewis

\section{FY 95 Plans:}

- Further deployment of the ITA at other high technical centers, including the Navy-Pomona base.

- Expand the ITA concept to the ball step gage, which holds the promise of CMM rapid geometry calibration. This is a necessary step in developingt a practical "virtual CMM" with complete information about machine behavior. This can generate the fundamental geometrical properties of 
a CMM under a specific set of conditions. The full implementation of the "virtual CMM"follows. The software for CMM measurement simulation can do an uncertainty prediction if it is given full information about the stability, reproducibility, and variability of the CMM's geometry, probing system, software and measurement algorithm.

\begin{tabular}{|l|l|l|l|l|l|l||}
\hline CMM CALIBRATION ARTIFACTS FISCAL YEARS & 95 & 95 & 97 & 98 & 99 \\
\hline Make calibrated ball bars an SRM [SRM] & & & & & \\
\hline $\begin{array}{l}\text { Develop ball step gage system for machines up to 1 } \\
\text { meter cube [OA] }\end{array}$ & & & & & \\
\hline $\begin{array}{l}\text { Do a full calibration for error correction in less than 4 } \\
\text { hours [OA] }\end{array}$ & & & & & \\
\hline $\begin{array}{l}\text { Predict CMM uncertainty for any measurement. Prove } \\
\text { that predicted CMM uncertainty is correct [Competency] }\end{array}$ & & & & & \\
\hline $\begin{array}{l}\text { Implement improved knowledge in National and } \\
\text { International Standards [STRS] }\end{array}$ & & & & & \\
\hline
\end{tabular}




\section{Title: COLLABORATION IN DIMENSIONAL METROLOGY WITH THE OAK RIDGE CENTERS FOR MANUFACTURING TECHNOLOGY (ORCMT)}

Staff: (0.4 staff years) ${ }^{*}$ DAVID STIEREN, *Ted Doiron, *Howard Harary

Project Objective and MEL Thrust Supported: To leverage the metrology capabilities available at ORCMT in support of enhancing PED's ability to deliver world-class precision measurement services for industry. Manufacturing Metrology.

Need Addressed: Documented needs of American industry for (previously unavailable) NIST calibration services for long step gages and end standards, certain two-dimensional reference standards, and the measurement of thermal expansion properties of standards.

Technical Approach: Establish and conduct a pilot project for the conduct of certain official NIST calibrations off-site from NIST at Oak Ridge, under PED metrological and administrative control, using ORCMT staff, facilities, and equipment. The pilot established in FY94 is continuing in FY95, and the expansion of the services provided under this effort is developing. Collaboration also involves daily interactions among the involved staff of PED and ORCMT for instrumentation development and control, laboratory facility development, and other consultative dialogue, particularly relating to temperature monitoring for metrology laboratories. Also leveraging this collaboration in the development of the technical criteria and procedural development of NVLAP Accreditation for Dimensional Metrology Laboratories.

\section{FY 94 Accomplishments:}

- Successfully established a new NIST calibration service for long step gages at ORCMT, with NIST management approval to conduct the service as a pilot effort.

- New pilot calibration service calibrated four step gage reference standards for American industry at ORCMT using the Moore M60 CMM, the measurement uncertainty of which was quantified and proven. Calibration service costs were $\$ 3000.00$, per calibration, turnaround times were about 30 days, and total two-sigma measurement uncertainties were 0.7 micrometers per meter or better.

- Conducted initial performance testing for new one-dimensional long waybed micrometer at ORCMT, which will be used for measurement of check standards at ORCMT.

- Progressed in the development of a dilatometer instrument at ORCMT for the measurement of the coefficient of thermal expansion for reference standards. Progression included development of thermostat system and automation of the instrument's data collection functions.

\section{FY 95 Plans:}

- Continue operation of joint calibration service pilot project.

- Expand pilot project services to include reference standards other than step gages, such as ball plates and/or grid plates in two dimensions.

- Validate performance of long waybed micrometer for calibration purposes to be used in conjunction with this collaboration.

- Complete development of dilatometer instrument.

Related Developments: The developmental efforts being conducted for the NIST Complex 3-D Metrology Laboratory involve close collaboration with ORCMT, and include the development of measurement capabilities for gear calibrations. These efforts include the ongoing construction of a new laboratory facility in Bldg. 220 at NIST, and the recent procurement of a new high-precision CMM by PED. The Center for Gear Metrology at ORCMT is a joint developmental effort occurring in conjunction with this collaboration. This is a TRP-funded 
three year program which runs through FY97.

\begin{tabular}{|c|c|c|c|c|c|}
\hline $\begin{array}{l}\text { COLLABORATION IN DIMENSIONAL } \\
\text { METROLOGY WITH THE OAK RIDGE } \\
\text { CENTERS FOR MANUFACTURING TECHNOLOGY } \\
\begin{array}{l}\text { (ORCMT) } \\
\text { FISCAL YEARS }\end{array}\end{array}$ & 95 & 95 & 97 & 98 & 99 \\
\hline $\begin{array}{l}\text { Continue operation of pilot calibration services as needed } \\
\text { by industry to augment and enhance PED precision } \\
\text { measurement capabilities [Oak Ridge Y-12 DOE Plant } \\
\text { plus customer calibration fees] }\end{array}$ & & & & & \\
\hline $\begin{array}{l}\text { Expand pilot calibration services for measurement of other } \\
\text { two- and three-dimensional reference standards, as } \\
\text { required by industry [Oak Ridge Y-12 DOE Plant plus } \\
\text { customer calibration fees] }\end{array}$ & & & & & \\
\hline $\begin{array}{l}\text { Develop/procure dilatometer instrument at NIST for use by } \\
\text { PED in the delivery of related calibration services [Oak } \\
\text { Ridge Y-12 DOE Plant plus customer calibration fees] }\end{array}$ & & & & & \\
\hline $\begin{array}{l}\text { Develop detailed annual plan for FY96 - FY } 99 \text { if required. } \\
\text { The detailed plan for FY95 is included in the PED } \\
\text { Statement of Work for FY95, which is being processed by } \\
\text { DOE ORCMT for the transfer of FY95 funding to PED } \\
\text { [Oak Ridge Y-12.DOE Plant plus customer calibration } \\
\text { fees] }\end{array}$ & & & & & \\
\hline
\end{tabular}


Staff: (2.1 Staff Years) HOWARD HARARY, *Edgar Erber, *Dennis Everett, *Ralph Veale, *David Stieren, *Ted Doiron

Project Objective and MEL Thrust Supported: To develop and extend the world-class dimensional measurement capabilities of MEL to forms with complex shapes (e.g. gears, turbine blades, propellers) in satisfaction of industry's advanced measurement needs. Manufacturing Metrology.

Need Addressed: Responds to an industry pull for the (re)establishment of NIST as the pinnacle of traceability for complex form 3-D artifacts for gear manufacturers and users (automotive, heavy equipment, aerospace, marine), and other industries. Traceability is a necessity if the gear industry is to maintain the quality and interchangeability of their parts and assemblies.

Technical Approach: Building on MEL existing expertise in the measurement of API thread gages, we will (1) expand our services to include other complex form artifacts and (2) lower the uncertainty for these measurements. A state-of-the-art high accuracy CMM in an environment with suitably tight temperature control $\left( \pm 0.1^{\circ} \mathrm{C}\right)$ is being installed. After commissioning of the CMM, we will develop a realistic error budget for 3-D measurements to assure traceability of measurements to the international standard of length. Measurement conditions and procedures will be continually tested and refined in an effort to reduce the uncertainty of the measurement process. We are working closely with our industrial clients through our relationship with ASME's Committee on Gear Metrology (COGM) and the American Gear Manufacturers Association (AGMA) to guarantee that the program addresses industry needs and to ensure customer satisfaction.

\section{FY 94 Accomplishments:}

- Began a Technology Reinvestment Project (TRP) program "The Deployment of a National Infrastructure for Gear Metrology." The partners include NIST, The American Society of Mechanical Engineers (ASME), the DOE Oak Ridge Center for Manufacturing Technology and Pennsylvania State University.

- Formed an industrial advisory committee sanctioned by ASME. The Committee on Gear Metrology (COGM).

- Let a contract for a new high-accuracy coordinate measuring machine (CMM) together with a suitable $(0.1 \mathrm{C})$ environment.

\section{FY 95 Plans:}

- Install, perform acceptance testing, and error-map a new high-accuracy CMM.

- Develop a measurement service, including total uncertainty, for gear master artifacts in cooperation with the DOE Oak Ridge/Y12. The initial service will be for master involute forms.

- Commence an international round-robin for gear artifacts.

- Begin complex form measurement needs assessment for the aerospace industry.

Related Developments: M\&M Precision Systems, a manufacturer of specialized gear measurement equipment, is currently funded by the ATP to improve their system's measurement capabilities by error mapping. 


\begin{tabular}{|l|l|l|l|l|l||}
\hline $\begin{array}{l}\text { COMPLEX FORM } \\
\text { DIMENSIONAL METROLOGY FISCAL YEARS }\end{array}$ & 96 & 96 & 97 & 98 & 99 \\
\hline $\begin{array}{l}\text { Extend the measurement services to master lead, flank } \\
\text { and pin artifacts [STRS] }\end{array}$ & & & & & \\
\hline $\begin{array}{l}\text { Enlarge service to the measurement of other complex } \\
\text { forms to meet the needs of the aerospace, automotive } \\
\text { and marine industries (e.g. turbine blades, airfoils and } \\
\text { propeller blades) [STRS plus calibration income] }\end{array}$ & & & & & \\
\hline $\begin{array}{l}\text { Integrate non-contact measurement technologies to } \\
\text { increase the speed and density of complex form } \\
\text { measurements [STRS, TRP, API] }\end{array}$ & & & & & \\
\hline
\end{tabular}


Staff: (3 staff years) Precision Engineering Division (821): TYLER ESTLER, *Steve Phillips, *Bruce Borchardt, *Greg Caskey; Factory Automation Systems Division (824): *Ted Hopp; Applied and Computational Mathematics Division (881): *Marjorie McClain, *Chris Witzgall; Statistical Engineering Division (882): *Keith Eberhardt, *Mark Levenson

Project Objective and MEL Thrust Supported: Develop rigorous point coordinate acquisition/analysis strategies which, coupled with machine and probe error models, will allow assignment of traceable uncertainties to measurements performed on coordinate measuring machines (CMMs). Manufacturing Metrology.

Need Addressed: In coordinate metrology, including more than 20,000 CMMs in US industry, there is no rigorous methodology to determine if part dimensions conform to design specifications, or to accurately estimate the statistical confidence of measurement results. As a consequence, all CMMs are considered uncalibrated and are not traceable per ISO definition. Since manufacturers have no way to assign realistic uncertainties to CMM measurements, in many cases they are forced to arbitrarily apply overly-conservative and costly ratios between part tolerances and the accuracies required of their measuring machines and NIST-calibrated artifacts. The ISO Guide to the Expression of Uncertainty in Measurement (1993) provides explicit rules for uncertainty computation in terms of error sources and sensitivity coefficients, given a model of the functional relationships between the quantity to be measured and the sources of uncertainty. For a modern computer-controlled CMM, the functional relationships are complex and often unknown. They involve convolutions of the spatial distribution of sampled points, each with its own cloud of uncertainty, with feature extraction algorithms that use various forms of optimization to estimate the locations and geometries of the features of interest. There is a strong industrial need for a systematic approach toward a generalized solution to this computational problem. Certainly, there is a large future competitive advantage for those manufacturers who can demonstrate defensible uncertainties in their CMM measurements of complex workpieces.

Technical Approach: NIST will develop integrated computational models of CMM measurement processes that build upon our significant accomplishments in mapping and software correction of quasi-static machine positioning errors. This work will include quantitative estimates of the size, and effect on measurement process uncertainty, of errors due to (1) point sampling strategies and their interactions with part form errors; (2) CMM machine and probe errors; (3) algorithm error in the extraction of part features from coordinate samples; and (4) variable errors due to thermal distortion, machine dynamics, and part-machine interactions. Important elements of this work include developing faster techniques for machine and probe error mapping and demonstration of a rigorous protocol for estimating the residual uncertainty of CMM measurements after correction for all known systematic errors. We will evaluate the Virtual CMM concept, estimating the measurement process uncertainty by random sampling of the error clouds associated with the point sample distribution, extracting the part features of interest using a robust fitting algorithm, and computing the resultant feature uncertainty by iteration of this procedure.

FY 94 Accomplishments:

- $\quad$ Published NISTIR on coupling of sampling strategy and circle fit uncertainty.

- Completed draft of paper on interaction of form error and sampling strategy for spheres.

- Completed draft chapter on CMM Performance Evaluation for a book on CM Machines and Systems.

- Led the formation of two new ANSI CMM Committees: ANSI B89.4.20: CMM Uncertainty and ANSI B89.4.21: Real Environments

- Initiated CMM probe error mapping project. 
FY 95 Plans:

- Publish paper on interaction of form error and sampling strategy for spheres.

- Devise and begin development of an error compensation model for touch-trigger CMM probe, with the goal of a residual error of less than $1 \mathrm{~m}$.

- Publish Users Manual for NIST-developed CMM Interim Testing Artifact.

- Demonstrate use of a novel ball step gauge for the rapid acquisition of CMM volumetric positioning errors.

- Publish completed book chapter on CMM Performance Evaluation.

Note: This Competence Project is funded through FY 98 only.

\begin{tabular}{|c|c|c|c|c|c|}
\hline $\begin{array}{l}\text { COMPUTATIONAL METROLOGY } \\
\text { OF MANUFACTURED PARTS }\end{array}$ & 95 & 96 & 97 & 98 & 99 \\
\hline \multicolumn{6}{|l|}{$\begin{array}{l}\text { Publish paper on interaction of form error and sampling } \\
\text { strategy for spheres [STRS] }\end{array}$} \\
\hline \multicolumn{6}{|l|}{$\begin{array}{l}\text { Publish completed book chapter on CMM Performance } \\
\text { Evaluation [STRS] }\end{array}$} \\
\hline \multicolumn{6}{|l|}{ Publish Interim Testing Artifact Users Manual [STRS] } \\
\hline \multicolumn{6}{|l|}{$\begin{array}{l}\text { Demonstrate software correction of lobing errors of a } \\
\text { touch-trigger probe [STRS] }\end{array}$} \\
\hline \multicolumn{6}{|l|}{$\begin{array}{l}\text { Demonstrate ball step gauge for rapid acquisition of } \\
\text { CMM error data [STRS] }\end{array}$} \\
\hline \multicolumn{6}{|l|}{$\begin{array}{l}\text { Research robustness issues in CMM feature extraction } \\
\text { algorithms [STRS] }\end{array}$} \\
\hline \multicolumn{6}{|l|}{$\begin{array}{l}\text { Research sampling strategies for extended list of part } \\
\text { geometric features [STRS] }\end{array}$} \\
\hline \multicolumn{6}{|l|}{$\begin{array}{l}\text { Evaluate validity of Virtual CMM concept using error- } \\
\text { mapped NIST machine [STRS] }\end{array}$} \\
\hline \multicolumn{6}{|l|}{$\begin{array}{l}\text { Integrate sampling strategy, algorithm selection, and } \\
\text { error-mapped CMM to test uncertainty computation for } \\
\text { selected geometric feature(s) [STRS] }\end{array}$} \\
\hline $\begin{array}{l}\text { Demonstrate mathematically defensible CMM uncertainty } \\
\text { computation on error-mapped CMM using traceable } \\
\text { NIST-calibrated artifact with known geometry [STRS] }\end{array}$ & & & & & \\
\hline
\end{tabular}




\section{Title: DEVELOPMENT OF PERFORMANCE EVALUATION METHODOLOGIES FOR ARTICULATING ARM COORDINATE MEASURING MACHINES.}

Staff: (0.55 staff years) GREG CASKEY, *Steve Phillips, *Bruce Borchardt, *Dan Sawyer, *Trish Snoots

Project Objective and MEL Thrust Supported: Develop methodologies for the performance evaluation of articulating arm coordinate measuring machines. Manufacturing Metrology

Need Addressed: The articulating arm coordinate measuring machine (ARCMM) is a relatively new configuration of measuring machine for which no current standardized performance test procedures exist. This project was begun after an ATP recipient, $2 \mathrm{~mm}$ Project Inc., requested that NIST investigate the prospect of using the ARCMM for a particular application. We project that an ANSI/ASME Standards working group will adopt this work for future publication as part of a national standard. The benefits of establishing a national standard for this technology are threefold: (1) it facilitates commerce by unifying terminology and performance specifications allowing prospective customers to compare available models equally; (2) it provides the user with a comprehensive set of performance assessment methods to assure their measurement process is under control; and (3) ultimately aids the articulating arm coordinate measuring machine manufacturers to improve their products.

Technical Approach: The starting point for this project is the application of the ANSI/ASME B89.1.12M1990 Standard "Methods for the Performance Evaluation of Coordinate Measuring Machines" to this technology. However, because this Standard was developed strictly for the evaluation of CMMs with three linear axes, only a portion of the tests apply to this particular CMM configuration. For these tests, we will establish the relative merit of the procedures, as well as develop modifications/enhancements that will maximize their effectiveness. Conversely, we anticipate performance issues for this class of CMM that are not addressed by the B89 suite of tests. In this case, new test methods will have to be developed. To facilitate this work, CRADA's will be established with several U.S. ARCMM manufacturers. Additionally, an ANSI/ASME Standards working group is being formed to investigate the performance assessment of the ARCMM, thus providing a natural audience for the research results.

FY 94 Accomplishments:

- Contacted and established CRADAs with the two principal U.S. ARCMM manufacturers to develop performance evaluation procedures.

- Provided input and feedback to a separate project on the development of artifacts and artifact mounting fixtures for application to the ARCMM.

- Applied the B89.1.12M-1990 Standard to one ARCMM manufacturer's machine. The results of this application led the manufacturer to change the quality assurance testing prior to shipping their machines.

- Consulted with ARCMM users from U.S. industry on testing procedures for these devices.

FY 95 Plans:

- Initiate the formation of an ANSI/ASME working group, within the B89.4 Committee, to address performance evaluation of ARCMMs.

- Apply the B89.1.12M-1990 Standard to an additional ARCMM from a second U.S. manufacturer of this technology.

- Seek user input on proposed test procedures and artifacts.

- Publish NIST Irs to the individual CRADA partners. These reports will contain the preliminary findings of the project. 
- Using the competence developed in the application of the B89 Standard to the ARCMM, develop a comprehensive performance evaluation program for the ARCMM.

- Report the findings of the NIST research to the ANSI/ASME working group on ARCMMs for review and comment.

- Publish a final report which can be used as a starting point for an American National Standard.

- Report to the ATP recipient, $2 \mathrm{~mm}$ Project Inc., on the feasibility of using the ARCMM for their specific application. 


\section{Staff: (2.0 staff years) LOWELL HOWARD, *Bill Penzes, *Fred Scire, *Jack Stone}

Project Objective and MEL Thrust Supported: To use emerging diode laser technologies to develop next generation length measurement tools. Manufacturing Metrology.

Needs Addressed: A disparate array of customers in the large scale manufacturing and semiconductor industries will be served by a variety of projects that address length measurement from the tens of meters to the picometer level. Large scale manufactures such as the aerospace, automotive and shipbuilding industries need improved ease of use for high accuracy measurement systems to lower the cost of quality control metrology. Semiconductor manufacturers working towards atomic sized critical dimensions will benefit by having higher accuracy SRMs made possible by adding traceable metrology to a variety of NIST calibration tools. Future NIST needs will be supported by building a competence base with diode laser systems for length measurement, which are already beginning to enter the commercial marketplace.

Technical Approach: Improve large scale manufacturing through the use of absolute interferometry systems based upon tunable diode lasers. Such systems can facilitate measurements of distances up to $50 \mathrm{~m}$ with an accuracy limited only by index of refraction uncertainties $(10 \mu \mathrm{m}$ or better at $10 \mathrm{~m})$. An absolute interferometer is tolerant of temporary signal loss, giving a flexibility not found in incremental type displacement systems. In a first design, $670 \mathrm{~nm}$ tunable diode laser will be used in conjunction with a fixed laser to achieve resolution similar to a displacement interferometer without the need to displace a mirror to effect a length measurement. Later designs will be incorporated into 3-D measurement systems and new index of refraction measuring techniques integrated into our system. Nano-scale measurements will be addressed by teaming frequency tracking Fabry-Perot interferometry with tunable diode lasers and newly available microwave measurement technology. The use of microwave technology permits Fabry-Perot interferometers of a practical size (10 to $25 \mathrm{~mm}$ ) allowing integration into piezoelectric actuators and calibration artifacts. Resolutions will be obtained in the picnometer domain with accuracy ultimately expected to reach tens of picometers or better. Ultimately, the system will be integrated into NIST SRM calibration tools for step height measurement and nano-scale metrology. Collaborations with Time and Frequency Division in Boulder are directed to developing diode laser sources suited to our purposes.

FY 94 Accomplishments: New start.

\section{FY 95 Plans:}

\section{Absolute Interferometer}

- Assemble interferometer and test-bed.

- Build or modify commercial fringe counting electronics.

- Identify problems and make modifications as needed.

Dynamic Displacement Artifact

- Complete metrology flexure stage and mirror assembly.

- Complete 19 bit high voltage programmer.

- Achieve phase-modulated servo locking of metrology cavity.

Source Development

- Test 2nd generation I2 stabilized laser.

- Manufacture 2 more I2 laser systems.

- Ongoing collaboration with Boulder on fast sweeping laser diode sources. 


\begin{tabular}{|c|c|c|c|c|c|}
\hline $\begin{array}{l}\text { DIODE LASERS } \\
\text { FOR LENGTH MEASUREMENT }\end{array}$ & 95 & 96 & 97 & 98 & 99 \\
\hline \multicolumn{6}{|l|}{ Build 1st prototype absolute interferometer [Competence] } \\
\hline \multicolumn{6}{|l|}{ Build 1st prototype DDA [Competence] } \\
\hline \multicolumn{6}{|l|}{$\begin{array}{l}\text { Test, troubleshoot and evaluate uncertainties } \\
\text { [Competence] }\end{array}$} \\
\hline \multicolumn{6}{|l|}{$\begin{array}{l}\text { Build } 2 \text { nd prototype absolute interferometer for use with } \\
\text { 3-D measuring systems [Competence] }\end{array}$} \\
\hline \multicolumn{6}{|l|}{$\begin{array}{l}\text { Integrate and test absolute interferometer with 3-D } \\
\text { measuring system [Competence] }\end{array}$} \\
\hline \multicolumn{6}{|l|}{$\begin{array}{l}\text { Build miniature DDA for Talystep and scanned probe } \\
\text { microscopes [Competence] }\end{array}$} \\
\hline \multicolumn{6}{|l|}{ Integrate DDA into SRM calibration tools [Competence] } \\
\hline \multicolumn{6}{|l|}{$\begin{array}{l}\text { Ongoing collaboration with Boulder on laser source } \\
\text { development [Competence] }\end{array}$} \\
\hline \multicolumn{6}{|l|}{ Industrial collaborations and dissemination [Competence] } \\
\hline $\begin{array}{l}\text { Investigate/Integrate new technologies as they become } \\
\text { available [Competence] }\end{array}$ & & & & & \\
\hline
\end{tabular}




\section{Title: DOD SUPPORT}

Staff: (0.75 staff years) BRUCE BORCHARDT, *Steve Phillips, *Dan Sawyer, *David Ward

Project Objective and MEL Thrust Supported: To assure that the Air Force and Navy have accurate CMMs and that their metrology personnel are educated about CMMs and the DOD facilities available. Manufacturing Metrology.

Need Addressed: Task 1: The Air Force primary standards laboratory has a critical need for an ultra high accuracy CMM. The tightening of tolerances on fixtures for new weapons systems makes traditional metrology unworkable. In addition, the calibration of standards for use by secondary standards laboratories makes faster and more accurate measurements imperative.

Task 2: The Navy needs to disseminate the use of CMMs to its metrology laboratories. Too many metrologists are unaware of the capabilities and potential of CMMs to solve their problems.

Technical Approach: Task 1: The requirements for the new CMM are only slightly beyond the state of the art in high accuracy CMMs. Therefore, the purchase of an enhanced machine from a top manufacturer is possible. The specifications, however, need to be very carefully written to assure the actual performance meets the needs. In addition, the test procedures demand the fabrication of specialized fixtures and objects and the devising of exactly detailed plans for the runoff.

Task 2: The education of metrologists requires speaking at conferences and writing manuals and technical papers, combined with one-on-one discussions and training as appropriate.

\section{FY 94 Accomplishments:}

Task 1:

- Wrote detailed specification and test procedure for purchase of Ultra High Accuracy CMM

- Designed and built test artifacts for the runoff of the machine

- Witnessed initial runoff at manufacturer's site Wrote report on runoff, including recommendations to manufacturer for next test

- Arbitrated discussions between manufacturer and Newark staff

Task 2:

- Presented paper at conference of American Society of Naval Engineers

- Sent CMM Interim Test Artifact to Pomona

FY 95 plans: (This is a short term project that is expected to end in FY 95.)

Task 1:

- Supervise CMM runoff at Newark AFB; assure that final tests pass

Task 2:

- Educate Navy experts in the proper use of CMMs, including interim tests and measurement algorithm selection

- Document current research

- Consult with users on the proper use of CMMs in measurement

- Work with Navy personnel to form the Navy CMM Metrology Center 
Staff: (1.9 staff years) C. J. EVANS, T. V. VORBURGER, *E. Marx, *J. Fu, *P. J. Sullivan (GW), *R. E. Parks (GW)

Project Objective and MEL Thrust Supported: The objective of the project is to develop traceable measurement techniques to measure deviations from the ideal form of aspheric optical substrates to be used in soft x-ray projection lithography (SXPL). Departures from the ideal form with spatial wavelengths ranging from a fraction of the X-ray wavelength $(13 \mathrm{~nm})$ to the full aperture of the part $(300 \mathrm{~mm})$ must be measured. In that range, figure error, comprised of the long spatial wavelength deviations, causes degradation of the image quality. The surface finish, comprised of the short spatial wavelengths, causes diffusely scattered light and degradation of contrast. Manufacturing Metrology.

Need Addressed: The continuing drive for ever smaller IC feature sizes means that the fundamental physical limits of lithography using transmissive optics and near visible illumination will be exceeded early in the next decade. SXPL is one attractive replacement technology and one in which the US currently has a technological lead; feature sizes below $0.1 \mu \mathrm{m}$ have been produced by SXPL over small field sizes in laboratory systems. Economic production, however, will require large field sizes and good optical efficiency, in turn requiring extremely accurate optical elements with superb surface finish. Companies attempting to make these optics do not have the measurement capabilities they need, and they cannot make what they cannot measure. These optics may be the heart of the next generation of lithography systems, themselves the machine tools of the silicon industry. That industry is worth $\$ 85$ billion per year.

Technical Approach: NIST work has shown that atomic force microscopes (AFMs) and visible phase measuring interferometers (PMIs) have the necessary resolution for finish and figure measurement, respectively. Commercially available instruments, as supplied, are insufficiently accurate. NIST has developed a calibrated AFM for establishing the traceability of optical surface finish measurements. The instrument has on-line calibration in the $x$ and $y$ directions using laser interferometry that will ultimately be accurate to $\pm 3 \mathrm{~nm}$. Calibration in the z-direction of $\pm 0.1 \mathrm{~nm}$ will be provided by a capacitance gauge, which in turn is calibrated off-line using laser interferometry. The instrument has been constructed and is undergoing initial shakedown. A number of useful measurements of surface finish standards have also been made.

PMIs can be extremely repeatable but do not currently have the absolute accuracy needed. Concepts for a system combining a PMI with high precision slideways have been developed and, over the next three years, will be implemented (in collaboration with an industrial vendor) in a new measurement capability, known as the NIST $\mathbf{X}$-ray Optics Calibration Interferometer (XCALIBIR). The goal is less than $1 \mathrm{~nm}$ PV uncertainty in measurement of aspheric optics up to $300 \mathrm{~mm}$ diameter with focal lengths up to 2 meters. To achieve this we will also need to be able to measure flat and spherical wavefronts to similar accuracies -- capabilities that are included in the new system's design.

\section{FY 94 Accomplishments}

- Developed user implementable techniques for assessing (and subsequently correcting for) systematic errors introduced by optical design, manufacture and assembly of commercially available PMIs when used to measure aspherics with reference to a spherical wavefront. Applied the technique to measurement of parts for AT\&T Bell Laboratories and for Tropel, Inc. Identified limitations in technique arising from incomplete knowledge of the optical system.

- Developed new methods for certification of errors in spherical wavefronts.

- Develop calibrated atomic force microscope and performed initial measurements.

- Performed finish measurement of an optical surface for five orders of magnitude of spatial wavelength 
with calibration in both the $\mathrm{x}$ and $\mathrm{y}$ directions.

FY 95 Plans:

- Complete specifications and initiate procurement of XCALIBIR.

- Demonstrate improvements in systematic error correction scheme for commercially available PMIs.

- Develop formulisms for calculation of $\mathrm{x}$-ray scattering from multilayers using AFM topography maps as input data. This will extend the direct application of three dimensional surface finish measurements to functional $\mathrm{x}$-ray optics in addition to calibration standards.

- Prepare publication of results on the calibrated surface finish measurements of the x-ray multilayer.

\begin{tabular}{|c|c|c|c|c|c|}
\hline $\begin{array}{l}\text { FIGURE AND FINISH METROLOGY } \\
\text { FOR X-RAY OPTICS }\end{array}$ & 95 & 98 & 97 & 98 & 99 \\
\hline \multicolumn{6}{|l|}{ Complete specification of XCALIBIR [STRS/Competence] } \\
\hline \multicolumn{6}{|l|}{ Procure XCALIBIR [DE] } \\
\hline \multicolumn{6}{|l|}{$\begin{array}{l}\text { Develop improved systematic error compensation scheme } \\
\text { for PMIs [STRS/Competence] }\end{array}$} \\
\hline \multicolumn{6}{|l|}{ Commission XCALIBIR as a calibration service [STRS] } \\
\hline \multicolumn{6}{|l|}{$\begin{array}{l}\text { Demonstrate an uncertainty of } \pm 1 \mathrm{~nm} \text { for measurement of } \\
\text { aspheric surfaces with XCALIBIR [STRS] }\end{array}$} \\
\hline \multicolumn{6}{|l|}{$\begin{array}{l}\text { Perform numerical calculation of } x \text {-ray reflectivity and } \\
\text { scattering using AFM maps from an } x \text {-ray multilayer as } \\
\text { input data [STRS] }\end{array}$} \\
\hline \multicolumn{6}{|l|}{$\begin{array}{l}\text { Compare calculated } x \text {-ray reflectivity and scattering with } \\
\text { measured results from SURF [STRS] }\end{array}$} \\
\hline \multicolumn{6}{|l|}{$\begin{array}{l}\text { Repeat the above experiments for several types of } \\
\text { multilayers and varying } x \text {-ray wavelengths [STRS] }\end{array}$} \\
\hline $\begin{array}{l}\text { Perform a profile measurement of an optical surface } \\
\text { spanning spatial wavelengths from } 2 \mathrm{~nm} \text { to } 100 \mathrm{~mm} \text { and } \\
\text { calculate the power spectral density function from these } \\
\text { data [STRS] }\end{array}$ & & & & & \\
\hline
\end{tabular}


Staff: (1.5 staff years) FRED RUDDER, *Greg Caskey, *Ron Hartsock, *Brian Scace, ${ }^{*}$ Trish Snoots

Project Objective and MEL Thrusts Supported: Develop metrology system to characterize the positioning accuracy of the AMTST Ingersoll Octahedral Hexapod machining center and a metrology system to provide enhanced positioning accuracy of the machining center. The characterization system shall apply to the class of machining centers based on the Stewart platform concept. The metrology system for enhanced positioning accuracy is specific to the Ingersoll configuration of the Stewart platform concept. Manufacturing Metrology.

Need Addressed: Machining centers based upon the Stewart platform concept promise to introduce a degree of precision machining productivity and production economy not possible with conventional machine tool structural configurations. The combination of structural rigidity, high-speed tool positioning, and full six-axis motion control are features that have drawn the attention of the automotive and aerospace industries and the tool, die and mold manufacturers. Since the machine configuration is not based upon fixed-axis mechanics but upon computationally-intensive servo-control algorithms, the need to perform tool position metrology for this class of machine tools is critical both for characterizing the positioning accuracy of the tool tip and evaluating the performance guarantees of such systems. Further, since the motion control is based upon feedback of linear displacement measurements and models of the Stewart platform kinematics the real-time metrology of this new class of machine tools is essential to realizing the performance potential. Precision material removal is an essential function of U.S. manufacturing industries and the potential for increasing productivity that is offered by Stewart platform machine tools will probably be an important element in maintaining U.S. manufacturing competitiveness.

Technical Approach: The project has two distinct objectives: develop metrology tools for directly characterizing tool tip positioning accuracy for the generic class of machine tools and implement on-machine metrology to enhance the positioning accuracy of the Ingersoll Hexapod system of the NIST Advanced Machine Tool Structure Testbed. To achieve the first objective we are implementing a metrology system to characterize, simultaneously, the six degrees of freedom motion of the tool tip as the machine tool performs a straight line vector move across its work volume. This metrology system is not machine specific and can be used for any particular implementation of the Stewart platform concept. The system uses a reference straight-edge, six LVDTs for straightness and angular motion, and a laser interferometer for linear displacement measurement. The second objective is long term and considers the specific configuration of the NIST Hexapod system. The current concept is to use a laser-based displacement measuring system to provide strut extension data in conjunction with an endof-strut PZT microactuator. Specific details of the configuration will be developed once the Hexapod strut fixture and the Hexapod machining center are delivered to NIST (winter-spring of 1995).

\section{FY 94 Accomplishments:}

- Developed concept for vector-motion metrology system for use in characterizing Stewart platform-based machine tools.

- Procured long-lead time items for metrology system.

- Procured precision one meter long straight-edge for metrology system.

- Initiated design of mechanical components for metrology system.

\section{FY 95 Plans:}

- Design and build tool-tip fixture for holding metrology system.

- Assemble and calibrate metrology system.

- Develop data acquisition software. 
- Develop designed experiments for machine characterization.

- Perform machine characterization metrology.

- Analyze metrology data.

- Report results of project at year-end.

\begin{tabular}{|l|l|l|l|l|l|l||}
\hline HEXAPOD METROLOGY FISCAL YEARS & 95 & 98 & 97 & 98 & 99 \\
\hline $\begin{array}{l}\text { Implement metrology systems and procedures for } \\
\text { characterizing positioning accuracy and controlling } \\
\text { motion of machine tools based upon the Stewart } \\
\text { platform concept [STRS, ATP, OA] }\end{array}$ & & & & & \\
\hline $\begin{array}{l}\text { Develop metrology system for characterizing tool tip } \\
\text { positioning accuracy for vector motion across work } \\
\text { volume [STRS, ATP] }\end{array}$ & & & & & \\
\hline $\begin{array}{l}\text { Design and assemble hardware and develop data } \\
\text { acquisition software for metrology system [STRS, ATP] }\end{array}$ & & & & & \\
\hline $\begin{array}{l}\text { Calibrate system and conduct designed experiments to } \\
\text { characterize positioning accuracy of NIST Hexapod } \\
\text { machine tool [STRS, ATP] }\end{array}$ & & & & & \\
\hline $\begin{array}{l}\text { Analyze metrology data and report results [STRS, ATP] } \\
\text { Report details of metrology system and procedures } \\
\text { developed to ASME Standards Committee B5: Machine } \\
\text { Tools-Components, Elements, Performance and } \\
\text { Equipment [STRS, ATP] }\end{array}$ & & & & & & \\
\hline $\begin{array}{l}\text { Develop concepts for implmentation of on-machine } \\
\text { motion control metrology system for NIST Hexapod } \\
\text { [STRS] }\end{array}$ & & & & & & \\
\hline $\begin{array}{l}\text { Implementation of on-machine metrology system for } \\
\text { NIST Hexapod [STRS, OA] }\end{array}$ & & & & & \\
\hline $\begin{array}{l}\text { Refinement and demonstration of on-machine metrology } \\
\text { system for NIST Hexapod [STRS, OA] }\end{array}$ & & & & & \\
\hline
\end{tabular}




\section{Staff: (1.45 Staff Years) TED DOIRON, *Jack Stone, *Mike Stocker}

Project Objective and MEL Thrust Supported: The objective is to support industry two dimensional measurements through calibration of grid plates, development of calibration algorithms, and by organizing interlaboratory comparisons. Manufacturing Metrology.

Need Addressed: There are needs for traceability for two dimensional measurements at two different scales. The large scale measurement systems make measurements at the 1-2 micrometer uncertainty level on artifacts up to one meter square. The artifacts include PC boards, arrays of resistors and capacitors and machined parts. These systems will be supported by calibrations of grid plates on the Moore M48 measuring machine.

The small scale measuring systems are used by the semiconductor industry. These systems have ranges up to $200 \mathrm{~mm}$ square and have repeatability in the $10-100$ nanometer range. Since NIST does not have an instrument with these capabilities, we are working toward standardizing measurement procedures and the development of an industry interlaboratory comparison system which would provide interim standards.

Technical Approach: For the large scale measuring machines the NIST M48 coordinate measuring machine (CMM) will provide calibration uncertainties in the $0.3-1.0$ micrometer range. These calibrations will be adequate for industry needs. To reach this goal, the M48 must become fully operational and calibrated. The calibration methods are well understood. The sensor will be a standard video based microscope, interfaced to an existing machine vision system. We will use the measurement algorithms developed for the Moore M5Z machine which made these calibrations until it was traded for the new machine.

NIST does not have an instrument to make state of the art measurements for the semiconductor industry. Our best measurement, in one dimension, is adequate for the current accuracy needs but is only a partial calibration. We will approach the problem in two different ways; by algorithm development and industry intercomparisons.

We plan to develop measurement algorithms which will allow the use of the one-dimensional NIST calibration along with multiple measurements in different orientations on the customers measuring machine to provide a complete check of the machine accuracy. Preliminary work, done as a graduate student thesis project, shows promise. We plan to continue the work, again working with university faculty and students.

The current funding level is not adequate to obtain a state-of-the-art measuring machine. In the following plan we assume that this will continue to be the case, and focus on cooperative efforts with industry metrology labs for algorithm testing. It is too early to actually predict the level of industry interest in this effort.

\section{FY 94 Accomplishments:}

- Developed the computer vision system and programmed it to measure the grid marks.

- Integrated this system into the measuring machine software and tested.

- Designed the microscope system and camera.

- Began the calibration of the M48.

- Took data on the $X$ axis motion and the $Y$ calibration.

- Obtained a test grid plate to use in the system tests.

\section{FY 95 Plans:}

- Calibrate M48 machine and begin calibration of industry grid plates. The uncertainty will be below 1.0 
micrometer. We will, as time permits, make system improvements to lower this figure, but the primary focus will be on customer calibrations.

- Contact the manufacturers of the 2D measuring machines used in the semiconductor lithography industry about arranging interlaboratory tests between their customers.

- Organize a meeting to design a grid plate compatible with as many machines as possible and use the interlaboratory test to assess the current industry performance. It is hoped that by comparing machines and discussing the results with the industry technical staff, we can organize a group to explore possible measures to provide an acceptable interim standard or procedure for these machines.

- Identify the very few research programs in this type of metrology.

- Contact a number of university faculty to explore possible collaborations. The collaboration among NIST, a university, and industry metrologists will be the main avenue for algorithm development.

Related Developments: Grid plate calibration problems are closely related to those of ball plate calibration. Ball plates are used as test standards for coordinate measuring machines. We are members of the ANSI/ASME committee on coordinate measurement standards and are in contact with our colleagues at the German standards bureau, PTB.

\begin{tabular}{|c|c|c|c|c|c|}
\hline $\begin{array}{l}\text { HIGH-ACCURACY } \\
\text { CMM DEVELOPMENT }\end{array}$ & 95 & 96 & 97 & 98 & 99 \\
\hline $\begin{array}{l}\text { Process improvement on M48; implement straightness } \\
\text { map; analyse industry grid plate round-robin; meet with } \\
\text { industry metrologists to formulate interim standard } \\
\text { artifact; explore use of industry machines for NIST } \\
\text { calibrations; test 2D measurement algorithms [STRS, } \\
\text { with EEEL] }\end{array}$ & & & & & \\
\hline $\begin{array}{l}\text { Upgrade M48 operating system and implementation of } \\
\text { calibration software on new system; implement intenim } \\
\text { standard for calibration of high accuracy 2D measuning } \\
\text { machines using standardized artifact and measurement } \\
\text { algorithm, traceable to NIST 1D measurements and } \\
\text { either NIST calibrations on industry machines or NVLAP } \\
\text { accreditation of industry machines; begin planning for } \\
\text { new one dimensional measuring machine to inerease } \\
\text { accuracy of selected lines on 2D grid plates [STRS, with } \\
\text { EEEL] }\end{array}$ & & & & & \\
\hline $\begin{array}{l}\text { Move M48 into new building; increase temperature } \\
\text { control to lower uncertainty of calibration system; } \\
\text { continue to implement and monitor } 2 D \text { interim standard } \\
\text { system; build new } 1 D \text { machine in new temperature- } \\
\text { controlled space in new ATF; develop new sensor } \\
\text { system for line setting. [STRS, with EEEL] }\end{array}$ & & & & & \\
\hline
\end{tabular}


Staff: (1.43 staff years) *J. DAGATA, *R. Dixon, *C. Evans, *J. Fu, *T. McWaid, *R. Polvani, *J. Schneir, *P. Sullivan, *V. Tsai, *T. Vorburger, *L. Howard, *J. Kramar, *M. Postek, *F. Scire, *R. Silver, *C. Teague, *J. Villarrubia, *A. Vladar

Project Objective and MEL Thrust Supported: To develop the capabilities to measure and fabricate nanometer-scale material structures which relate to the intrinsic atomic-scale properties of the material such that these structures are sufficiently robust and stable to be exchanged between NIST and its customers. Manufacturing Metrology.

Need Addressed: NIST is responsible for providing U.S. industry with standard reference materials which are used for the calibration of precision instruments and for establishing tolerances in discrete parts manufacturing. A two-to-twenty nanometer uniform step height reference standard which can be fabricated in a routine manner, calibrated by a NIST dimensional metrology activity, and supplied to industry fulfills a need which is not currently met by existing standard reference materials. There is an unmet need in industry for sub$\mathrm{nm}$ roughness standards. This project will investigate an integrated approach to the manufacture and certification of standard reference materials for these quantities as well as for linewidth and feature placement over areas up to $50 \mathrm{~mm} \times 50 \mathrm{~mm}$.

Technical Approach: Initially this project will develop an infrastructure for the integrated fabrication and calibration of nanometer-scale step-height and roughness standard reference surfaces. As a first step toward fabrication of these type artifacts, the production of atomically flat roughness standards will be investigated by developing an iterative approach to ultra smooth silicon wafer polishing combined with advanced surface passivation methods. Methods for conformably stabilizing the silicon surface so that its dimensional properties are unchanged by interaction with the environment and routine handling will be developed. This will enable characterization by NIST metrology activities such as the calibrated AFM and M3.

The first approach to the production of step height standards will rely on a combination of mechanical stress and thermal activation to generate controlled motion of dislocations along slip planes in a crystal sample. By controlling the dislocation density within the bulk and the motion of these defects, an initially smoothly polished or cleaved surface of the sample will become faulted over its entirety with a uniform step height equal to multiples of the Burgers vector of the crystal and, hence, to the lattice parameters. Coupling this activation process with thin film technology will make it possible to generate regular distributions of steps across an entire sample surface. For the practical realization of a step height reference standard covalently bonded semiconductors such as silicon, silicon-germanium, and III-V compound semiconductors offer particular advantages: Epitaxial growth is quite advanced, the preparation of extremely high quality surfaces with sub-tenth nanometer roughness is routine, and step heights of a few nanometers should be stable over time and under realistic handling conditions. It is possible to include several closely spaced heteroepitaxial layers in the epitaxial growth cycle. The relative movement of these marker layers can then be imaged by a suitable technique, such as cross-sectional transmission electron microscopy or scanned probe microscopy, to certify the step height topography in terms of the atomic lattice spacing of the material. Other materials systems such as barium fluoride, mica, quartz, and sapphire will be investigated for their suitability as step height standards as well.

FY 94 Accomplishments: New Start

\section{FY 95 Plans:}

- Fabricate and Calibrate Atomically Smooth Roughness Artifact. Develop iterated ultra smooth polishing and passivation of silicon (111) surfaces; Demonstrate stabilized surface; produce initial CAFM and M3 
measurements.

- Fabricate and Calibrate sub-20-nm Step Height Artifact. Design and fabricate stress fixture; study GaAs, silicon, and hep metal samples; produce initial CAFM and M3 measurements; integrate Controlled Ambient Facility and Ultrahigh Vacuum STM.

- Design appropriate transfer mechanism within DE constraints;

- Implement surface stabilization process in UHV STM preparation chamber.

- AFM tip characterization using sharp-edged artifacts and known geometry.

\begin{tabular}{|c|c|c|c|c|c|}
\hline $\begin{array}{l}\text { INTELLIGENT } \\
\text { NANOMANUFACTURING SYSTEM }\end{array}$ & 95 & 95 & 97 & 95 & 99 \\
\hline \multicolumn{6}{|l|}{$\begin{array}{l}\text { ROUGHNESS ARTIFACT (FABRICATE AND } \\
\text { CALIBRATE ATOMICALLY SMOOTH ROUGHNESS } \\
\text { ARTIFACT) }\end{array}$} \\
\hline $\begin{array}{l}\text { Develop iterated ultra smooth polishing and } \\
\text { passivation of silicon (111) surfaces [STRS] }\end{array}$ & $\infty$ & & & & \\
\hline Demonstrate stabilized surface [STRS] & $\mathbf{m}$ & & & & \\
\hline \multicolumn{6}{|l|}{ Perform CAFM and M3 measurements [STRS] } \\
\hline \multicolumn{6}{|l|}{$\begin{array}{l}\text { Evaluate processing scheme and long-term stability of } \\
\text { silicon (111) surfaces [STRS] }\end{array}$} \\
\hline \multicolumn{6}{|l|}{$\begin{array}{l}\text { STEP HEIGHT ARTIFACT (FABRICATE AND } \\
\text { CALIBRATE SUB-20-NM STEP HEIGHT ARTIFACT) }\end{array}$} \\
\hline Design and fabricate stress fixture [STRS] & - & & & & \\
\hline $\begin{array}{l}\text { Study and determine the suitability of GaAs, silicon, } \\
\text { and hcp metal samples [STRS] }\end{array}$ & $=$ & & & & \\
\hline \multicolumn{6}{|l|}{$\begin{array}{l}\text { Study and determine the suitability of barium fluoride } \\
\text { [STRS] }\end{array}$} \\
\hline \multicolumn{6}{|l|}{$\begin{array}{l}\text { Study and determine the suitability of reconstructed } \\
\text { silicon [STRS] }\end{array}$} \\
\hline \multicolumn{6}{|l|}{$\begin{array}{l}\text { Study and determine the suitability of cleavage planes } \\
\text { of stable crystals [STRS] }\end{array}$} \\
\hline \multicolumn{6}{|l|}{ Perform CAFM and M3 measurements [STRS] } \\
\hline \multicolumn{6}{|l|}{$\begin{array}{l}\text { Evaluate processing scheme and long-term stability of } \\
\text { above approaches [STRS] }\end{array}$} \\
\hline \multicolumn{6}{|l|}{ LINEWIDTH ARTIFACT } \\
\hline $\begin{array}{l}\text { Establish functional requirements for atom-based } \\
\text { linewidth standard based on experience with } \\
\text { roughness and step height artifacts [STRS] }\end{array}$ & & & & & \\
\hline
\end{tabular}




\begin{tabular}{|c|c|c|c|c|c|}
\hline $\begin{array}{l}\text { INTELLIGENT } \\
\text { NANOMANUFACTURING SYSTEM }\end{array}$ & 95 & 96 & 97 & 97 & 99 \\
\hline \multicolumn{6}{|l|}{$\begin{array}{l}\text { Design sample processing scheme for atomically } \\
\text { dimensioned linewidth standard [STRS] }\end{array}$} \\
\hline \multicolumn{6}{|l|}{ FEATURE PLACEMENT } \\
\hline \multicolumn{6}{|l|}{$\begin{array}{l}\text { Establish functional requirements for feature } \\
\text { placement standard based on experience with } \\
\text { linewidth artifacts [STRS] }\end{array}$} \\
\hline \multicolumn{6}{|l|}{$\begin{array}{l}\text { Design sample processing and calibration schemes } \\
\text { for feature placement standard [STRS] }\end{array}$} \\
\hline \multicolumn{6}{|l|}{ Develop methodology for feature placement [STRS] } \\
\hline \multicolumn{6}{|l|}{ SPM TIP FABRICATION AND CALIBRATION } \\
\hline \multicolumn{6}{|l|}{$\begin{array}{l}\text { Develop methods based on sharp-edged artifacts and } \\
\text { known geometry [STRS] }\end{array}$} \\
\hline \multicolumn{6}{|l|}{$\begin{array}{l}\text { Prescribe information required for extracting tip } \\
\text { geometry from experimental data [STRS] }\end{array}$} \\
\hline \multicolumn{6}{|l|}{$\begin{array}{l}\text { Fabricate high-aspect ratio SPM tips in ESEM and } \\
\text { characterize them with FI/FEM [STRS] }\end{array}$} \\
\hline \multicolumn{6}{|l|}{ INTEGRATION OF NANOMANUFACTURING CELL } \\
\hline \multicolumn{6}{|l|}{$\begin{array}{l}\text { Integrate Controlled Ambient Facility and Ultrahigh } \\
\text { Vacuum STM [STRS] }\end{array}$} \\
\hline \multicolumn{6}{|l|}{$\begin{array}{l}\text { Design transfer mechanism for coupling M3, ESEM to } \\
\text { CAF and UHV STM [STRS] }\end{array}$} \\
\hline \multicolumn{6}{|l|}{$\begin{array}{l}\text { Design and compile initial databases on manufacturing } \\
\text { processes, artifacts, and tips [STRS] }\end{array}$} \\
\hline $\begin{array}{l}\text { Demonstrate integrated Fabrication and Calibration of } \\
\text { atom-based artifacts [STRS] }\end{array}$ & & & & & \\
\hline
\end{tabular}




\section{STAFF: (1.0 staff years) BRIAN SCACE}

Project Objectives and MEL Thrusts Supported: The objective of the project is to provide PED and MEL personnel with solutions to physical environmental issues affecting reported research results. Manufacturing Metrology.

Need Adressed: The immediate target customers for project output are PED and MEL researchers. The target customers' technical needs vary with each specific problem addressed. An entire research facility, such as the PED Moore M48 facility, may be provided from concept through design, construction, and acceptance testing. In other cases, a specific problem area may be addressed such as retro-fitting an improved temperature controls or vibration isolation and damping. The project also provides for coordination and supervision of both in-house assets (Plant Division) and outside A\&E firms and contractors to complete construction or modifications to the researcher's satisfaction. The customer-project personnel are free to pursue other project goals in parallel with facility construction /modification. This results in a time savings while providing a laboratory environment within which best results may be attained.

Although this activity may be considered technical "support" in nature, it should be understood that, as manufacturing metrology continues to be developed and refined, the environment within which this is performed must also evolve. While the majority of the project's effort is directed internally (within MEL), its effect is felt indirectly with reported results from customer-projects to industry, as well as directly through such forums as NCSL.

TechnicalApprroach: As new levels of accuracy in manufacturing metrology are required by OAs and industry it is increasingly apparent that the current PED/MEL research facilities are obsolete. The project's approach to this issue is manifested in two forms.

The project works with PED/MEL researchers to upgrade individual facilities within the current General Purpose Laboratories (GPL). An example of this approach is removing a technically flawed vibration isolation system in Rms. B26/28 in Bldg. 220 and replacing it with a solid floor system of appropriate mass to eliminate amplification of incoming ground vibrations induced by vehicular traffic, footfall, and building mechanical systems. The resulting usable space was then renovated to accommodate 821.13's Surface Roughness SRM Calibration effort.

The project serves as MEL's input to the Capital Improvement of Facilities Project. The CIFP, part of the Office of Administration, is responsible for the construction of the Advanced Technology Laboratories (ATL) on both campuses and for complete renovation of selected GPLs. The project leader communicates directly with MEL researchers, recognized outside experts in the field of advanced facility design, contracted A\&Es, contractors, and the CIFP office to insure that MEL researcher's technical needs are addressed.

\section{FY 94 Accomplishments:}

- Completed Temperature Control Enclosure for the PED Moore M48 Coordinate Measuring Machine. This facility, in Rms. A12-14 Bldg 220, provides an environment about a large metrological frame with the following thermal specifications:

Room Volume Stability (single point)

Measurement Volume Stability

$20^{\circ} \mathrm{C} \pm 0.15^{\circ} \mathrm{C}$

Gradient within Room Volume

$20^{\circ} \mathrm{C} \pm 0.05^{\circ} \mathrm{C}$

Gradient within Measurement Volume

$0.20^{\circ} \mathrm{C}$

$0.05^{\circ} \mathrm{C}$ 
- Completed specification, design and contract award for construction of a Temperature Control Enclosure for PED Leitz Coordinate Measuring Machine of similar performance characteristics to the previous mentioned facility. Construction to be completed in FY 95.

- Completed retrofit of M-cubed facility with Direct Digital Control (DDC) of temperature in lieu of previous pneumatic system. This solution permits temperature control to setpoint $\pm 0.10^{\circ} \mathrm{C}$ single point stability.

- Project leader maintained working relationship with CIFP, Earl Walls (A\&E), HDR(A\&E), and CRSS Constructors (construction management) regarding MEL staff technical concerns with respect to the ATL project. This includes, but is not limited to, representing MEL on the ATL Technical Advisory Committee, representing PED during construction of the Vibration Isolation Testbed in Bldg 220 (while the building was occupied), serving on the Technical Evaluation Board for temperature control systems for the Temperature Control Testbed in Bldg. 226.

\section{FY 95 Plans:}

- Complete construction and commissioning of Temperature Control Enclosure for the PED Leitz CMM.

- Begin renovation of Complex Form Metrology space for PED

- Complete design phase of ATL as PED technical representative to CIFP. Begin renovation/construction of Large Object Metrology facility

Related Developments: The project leader has been appointed to the National Conference of Standards Laboratories (NCSL) Laboratory Facilities Committee and will be participating in the updating of the NCSL Recommended Practice RP-7 Laboratory Design.

\begin{tabular}{||l|l|l|l|l|l|l||}
\hline LABORATORY DEVELOPMENT FISCAL YEARS & 95 & 96 & 97 & 98 & 99 \\
\hline $\begin{array}{l}\text { Represent MEL regarding technical quality of ATL } \\
\text { [STRS] }\end{array}$ & & & & & \\
\hline $\begin{array}{l}\text { Design and construct retrofit of individual GPL technical } \\
\text { spaces per PED program requirements [STRS, OA] }\end{array}$ & & & & & \\
\hline $\begin{array}{l}\text { Coordinate fit-out of ATL space and preliminary } \\
\text { migration plan for elements of 821 and 822 displacing to } \\
\text { the ATL [STRS] }\end{array}$ & & & & & & \\
\hline
\end{tabular}


Staff: *J. VILlARRUBIA, ${ }^{*}$ S. Jones, ${ }^{*}$ M. Postek, ${ }^{*}$ J. Potzick, ${ }^{*}$ C. Teague, ${ }^{*}$ A. Vladar; ${ }^{*}$. Dixson, ${ }^{* J}$. Schneir, ${ }^{*}$ T. McWaid; *R. Allen, ${ }^{*}$ M. Cresswell, ${ }^{*}$ L. Linholm

Project Objective and MEL Thrust Supported: To improve linewidth measurement capabilities within PED and other related NIST groups through comparative experiments among practitioners of different measurement techniques. Manufacturing Metrology.

Need Addressed: NIST is responsible for providing linewidth SRM's and/or calibration services to meet the needs of U.S. industry. Presently, our only linewidth standards are optical photomask standards, the minimum linewidth of which is $0.5 \mu \mathrm{m}$ with a total uncertainty (using the new rules for uncertainty calculation) of $\sim 50 \mathrm{~nm}$. To support present and future semiconductor technologies, industry needs to measure sub-micron lines with uncertainties, as identified by SEMATECH, of $20 \mathrm{~nm}$ or better. The magnetic recording and photographic industries have gap width and grain size measurement requirements at approximately the same scale. NIST does not presently offer a linewidth measurement service or SRM with this level of accuracy.

Physical linewidth determination with any microscopic technique requires modeling of the probe/sample interaction in order to identify edge locations. One barrier to accurate linewidth determination has been acquisition of models in which we can have the required level of confidence. A second barrier is lack of consensus on the definition of linewidth.

Technical Approach: Linewidth measurement capabilities at NIST span several techniques, including optical, scanning electron, and scanned probe microcopies for physical linewidth as well as electrical techniques to measure the average width of conducting paths. This project seeks cooperative interactions among practitioners of the various techniques. This cooperation will include information exchange among practitioners of the various methods. It will also include design and eventual execution of experiments for cross-technique comparison of measurements.

A three to five page report will be produced for each method. This report will summarize perceived industry requirements, our present capabilities, issues/roadblocks to further progress, programs in place to address these obstacles, and perceived advantages and limitations of each techniques vis-a-vis the others. When compiled into a single document, these reports will serve two purposes. First, they will form the informational basis for designing experiments to address outstanding issues by employing complementary strengths of the various techniques. Second, they will serve as an educational document for those inside and outside of NIST who want to know the present status of linewidth measurements at NIST.

We will cooperatively design experiments to measure the same linewidth artifacts by two or more techniques. Experimental design will include all factors relevant to good measurement practice, including sample handling, definition of linewidth for purposes of this experiment, and a manufacturable linewidth artifact or artifacts measurable by multiple techniques. If possible, we will design a single artifact measurable by all of the methods. If this proves impractical, we might design several artifacts optimized for pair-wise comparisons linking all of the methods. We will seek industry cooperation in the fabrication of these artifacts. In parallel with efforts to design artifacts with desirable features, we will seek opportunities to begin measurements with specimens whether in hand or easily accessible, despite their less desirable properties. The goal of measurements on these artifacts will be to document any existing discrepancies between the methods. In the unlikely event that no such discrepancies are found, confidence in all of the techniques (including the probe/sample interaction models) would be significantly enhanced. In the more likely event of discrepancies, identification of the sources and remediation will enhance NIST's overall linewidth capabilities. 
FY 94 Accomplishments: New Start

\section{FY 95 Plans:}

- Compile a report summarizing, for each of our techniques, industry linewidth requirements, our present capabilities, work presently in progress, and issues/problems to be dealt with for further progress.

- Design linewidth artifact(s) for comparison of SEM, Optical, SPM, and Electrical linewidth determination.

- Create a working definition of linewidth.

- Complete some opportunistic measurements on easily available specimens.

- Begin procurement of artifact(s); need a manufacturer willing and able to supply a custom artifact for free (as part of a collaborative effort) or for an affordable price.

\begin{tabular}{|c|c|c|c|c|c|}
\hline LINEWIDTH CORRELATION & 95 & 96 & 97 & 98 & 99 \\
\hline $\begin{array}{l}\text { Compile a report documenting current status of linewidth } \\
\text { determination at NIST and identifying obstacles to further } \\
\text { progress [STRS] }\end{array}$ & $\mathbf{m}$ & & & & \\
\hline $\begin{array}{l}\text { Design linewidth artifact(s) for comparison of SEM, } \\
\text { Optical, SPM, and Electrical linewidth determination } \\
\text { [STRS] }\end{array}$ & & & & & \\
\hline $\begin{array}{l}\text { Perform opportunistic measurements on easily available } \\
\text { specimens [STRS] }\end{array}$ & & & & & \\
\hline Create a working definition of linewidth [STRS] & 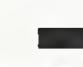 & & & & \\
\hline Procure artifact(s) designed above [STRS] & & $\boldsymbol{a}$ & & & \\
\hline $\begin{array}{l}\text { Measure artifact(s) linewidths via SEM, Optical, SPM, and } \\
\text { Electrical linewidth methods [STRS] }\end{array}$ & & & & & \\
\hline $\begin{array}{l}\text { Develop revised edge location models and/or linewidth } \\
\text { working definition to reconcile differences uncovered in } \\
\text { measurements [STRS] }\end{array}$ & & & & & \\
\hline $\begin{array}{l}\text { Test revised models/definitions by iterating the } \\
\text { procurement, measurement, and model revision steps } \\
\text { above [STRS] }\end{array}$ & & & & & \\
\hline $\begin{array}{l}\text { Develop one of the linewidth artifacts into a linewidth SRI } \\
\text { [OSRM] }\end{array}$ & & & & & \\
\hline
\end{tabular}


Title: LONG LENGTH LABORATORY

Staff: (0.55 staff years) ${ }^{*}$ CHARLES J. FRONCZEK JR., *Steve Phillips, *Greg Caskey, *Tyler Estler, *Ron Hartsock, *Trish Snoots, *David Ward

Project Objective and MEL Thrust Supported: Develop over the next four to five years a multi-functional calibration facility with the ability to determine one-dimensional length standards to an eventual accuracy of $0.25 \mu \mathrm{m}+0.4 \mu \mathrm{m} / \mathrm{m}$ over a range exceeding three meters. Manufacturing Metrology.

Need Addressed: Provide a basic and improved measurement service for geodetic level scales, ball bar standards and macrometrology scaling bars.

Developed in 1980, the Geodetic Scale Measurement Facility has an enormous potential for assessing large measuring tools. This system is the sole provider of calibration service to the U.S. surveying community. FY 1994 brought an increased number and variety of users requiring many mechanical and software alterations.

NIST's Interim Test Artifact program has received an astonishing response. This has produced a need for calibration of long end gauges and ball bars. Preliminary estimates suggest a requirement for over 100 ball bars per year. This service can be represented either as a Standard Reference Material or as a calibration service.

Five years ago, the formation of the ASPRS Coordinate Measuring Systems Committee (CMSC) promoted the use of conventional surveying equipment as frameless coordinate measuring machines. CMSC is welding together a community with diverse roles such as: aviation and automobile manufacturing and linear accelerator alignment. There is a significant need for calibrations of scaling bars as long as 3.5 meters.

Technical Approach: The Geodetic Scale Measurement Facility is based on a 20 -foot SIP comparator. This machine is well characterized and a logical foundation on which to base a multifunction Long Length Laboratory. The solution to these problems requires developing a totally automated and unified measurement system. An improved electro-mechanical design, modern environmental controllers, a new interferometer system, and a statistical analysis system will achieve this evolution. The basic concepts are defined. Most of the electromechanical system can be assembled by off the shelf purchases. A significant effort will be made in software development. New interfaces will probably have to be designed, developed, and built.

Since the design criteria require multifunctional operation, the development will be staged and reflect the user demand. Priority will be given as follows: (1) the ball bar; (2) the geodetic level; and (3) the macrometrology scale bar. However, provision will be made to allow ongoing calibration to continue. This facility will address the current and future needs of the large scale dimensional measurement community.

FY 94 Accomplishments: This is a FY 95 start up project.

\section{FY 95 Plans:}

- General design of LLL for an initial expected short term accuracy $0.5 \mu \mathrm{m}+0.7 \mu \mathrm{m} / \mathrm{m}$.

- Preliminary error analysis.

- Detailed design of interferometeric measuring system.

- Detailed mechanical design of ball bar measuring system.

- Purchase and machining of components.

- Assembly and integration.

- Software development. 
- Testing and verification.

- Error analysis and investigation of future directions.

- Evaluation of environmental controls.

\begin{tabular}{|c|c|c|c|c|c|}
\hline LONG LENGTH LABORATORY & 95 & 95 & 97 & 98 & 99 \\
\hline $\begin{array}{l}\text { Improve expected accuracy of ball bar measuring system } \\
\text { to } 0.3 \mu \mathrm{m}+0.5 \mu \mathrm{m} / \mathrm{m} \text {; Detailed mechanical design of } \\
\text { automated geodetic scale measuring system; detailed } \\
\text { design of electronic interfaces; purchase and machining of } \\
\text { components; assembly and integration; software } \\
\text { development; testing and verification; error analysis and } \\
\text { investigation of future directions; reevaluation of } \\
\text { environmental controls [STRS] }\end{array}$ & & & & & \\
\hline $\begin{array}{l}\text { Improve expected accuracy of ball bar measuring system } \\
\text { to } 0.25 \mu \mathrm{m}+0.4 \mu \mathrm{m} / \mathrm{m} \text {; investigate and design } \\
\text { macrometrology scaling bar; detailed mechanical design } \\
\text { of macrometrology scaling bar measuring system; } \\
\text { purchase and machining of components; assembly and } \\
\text { integration; software development; testing and verification; } \\
\text { error analysis and investigation of future directions } \\
\text { [STRS] }\end{array}$ & & & & & \\
\hline
\end{tabular}


Title: METROLOGY EDUCATION

Staff: (0.4 staff years) TED DOIRON, ${ }^{*}$ John Stoup, *Janet Land, *Ralph Veale

Project Objective and MEL Thrust Supported: Objective is to provide educational services to other laboratory staff. Manufacturing Metrology.

Need Addressed: There is almost no educational resource in dimensional metrology. Although there are three community colleges that offer two year associate degrees in metrology, none exists specifically in dimensional metrology, and no four-year programs exist at all.

Technical Approach: We have developed two different three-day seminars, one in the general principles of dimensional metrology and uncertainty budget development, and the other for gage block calibrations. We have offered two seminars per year recently, and have a large leftover demand. Because of space constraints, we plan to offer a two-day seminar in conjunction with the Measurement Science Conference, which is held annually in January in Los Angeles. We will offer one seminar at the NIST site in November or in the spring. Finally, we are developing half-day tutorials in specific topics.

To broaden our impact, we are working with a consortium of universities, government agencies, and industry representatives to prepare a TRP proposal for metrology education. The program will be led by North Carolina A\&T University and will use the resources and space of the university and the Department of Energy Y-12 facility to prepare a broad range of educational products. We envision a program which provides video tapes and written material, as well as on-site and off-site courses. These will be held at one site and broadcast to remote sites. Many of the consortium members have experience in distance education, and this program would simply expand their offerings.

\section{FY 94 Accomplishments:}

- Developed a new 3-day seminar and presented for the first time in November.

- Held the gage block seminar spring 1994, and a half day tutorial was given twice at the Measurement Science Conference last January.

- Developed 3-day seminar presented in November 1994.

- Conducted gage block seminar in spring 1994.

- Presented tutorial seminar at Measurement Science Conference in January 94.

\section{FY 95 Plans:}

- Continue developing the Dimensional Metrology Seminar and Gage Block Seminar. Prepare 2-day versions for the Measurement Science Conference.

- Poll customers and colleagues for topics of high interest for half day specialty seminars. The development of uncertainty statements is already a topic of considerable demand.

- Participate in formulating the TRP proposal for distance education in metrology. 


\begin{tabular}{|l|l|l|l|l|l||}
\hline \hline METROLOGY EDUCATION FISCAL YEARS & 95 & 96 & 97 & 98 & 99 \\
\hline $\begin{array}{l}\text { Develop cooperative program interaction with Canada and } \\
\text { Mexico [STRS and customer fees] }\end{array}$ & & & & & \\
\hline & & & & \\
\hline $\begin{array}{l}\text { Develop training program for Latin America [STRS and } \\
\text { customer fees] }\end{array}$ & & & & & \\
\hline $\begin{array}{l}\text { Seek funding to develop training program in dimensional } \\
\text { metrology for Latin American countries [STRS and customer } \\
\text { fees] }\end{array}$ & & & & & \\
\hline
\end{tabular}


Staff: (2.96 Staff years) *J. KRAMAR, *J. Dagata, *L. Howard, *J.Jun, *B. Penzes, *F. Scire, *J. Villarrubia, *C. Teague

Project Objective and MEL Thrust Supported: To develop a coordinate-measuring machine with subnanometer probe resolution and one nanometer total uncertainty within a measuring volume of $50 \times 50 \times 0.1 \mathrm{~mm}$. To use this instrument in the measurement and calibration of artifacts that will support industry -- particularly the semiconductor manufacturing industry -- in its needs for line width, pitch, and especially feature placement metrology. Manufacturing Metrology.

Need Addressed: The Molecular Measuring Machine (M3) Project was conceived and developed in direct response to NIST deficiencies in measurement capabilities that are projected to be a serious limiting factor in certain high technology industries. At the time the project was started, the minimum uncertainty in line spacing measurements at NIST was $10 \mathrm{~nm}$ for line spacings from 5 to $50 \mu \mathrm{m}$ and only $25 \mathrm{~nm}$ for line spacings of 1 to $50 \mathrm{~mm}$. Physical line width measurement uncertainties were about $50 \mathrm{~nm}$ for line widths ranging from 0.5 to 10 $\mu \mathrm{m}$. The U.S. precision optics and microelectronics industries have repeatedly requested that NIST reduce the measurement uncertainties of these quantities to the 0.1 to $1.0 \mathrm{~nm}$ range. These requests are motivated by the availability of commercial instruments with resolutions in the 100 to $10 \mathrm{pm}$ range, and by the increasingly smaller critical dimensions on all microelectronic circuit elements. As an example, the Semiconductor Industry Association road map is calling for line width measurement uncertainties (three sigma) of four atoms, i.e., one nanometer, by the year 2001 .

Technical Approach: Our response is to build the NIST Molecular Measuring Machine (M3), a state-of-theart, two-dimensional, coordinate-measuring machine designed to achieve $1 \mathrm{~nm}$ total uncertainty for point-to-point measurements over a $50 \times 50 \mathrm{~m}^{2}$ area while accommodating surface height variations of as much as $100 \mu \mathrm{m}$. The sensing probes are scanning tunneling and atomic force microscopes, which give an imaging resolution that extends to the atomic scale (sub-nanometer). The displacements are measured with a custom-built, state-of-the-art, heterodyne interferometer having a measurement resolution of $10 \mathrm{pm}$ with a $2 \mathrm{kHz}$ bandwidth. In order to achieve these metrological goals the instrument also incorporates a state-of-the-art temperature control system which maintains temperature stability to $100 \mu \mathrm{K}$ as well as an advanced seismic and acoustic vibration isolation system. This instrument will provide most of the aforementioned measurement capabilities and will be used to measure line spacing, line width, and feature-placement artifacts that can be used to calibrate the industries measuring machines. In addition to providing these metrological capabilities, M3 is also to be used as an exploratory tool in the rapidly growing field of nanotechnology.

\section{FY 94 Accomplishments:}

- Completed the assembly of M3 into its vacuum chamber.

- Rebuilt and improved the M3 interferometer optics: In attempting to clean the optic assemblies for insertion in ultra-high vacuum, some of the adhesive bonds failed. With care, it was possible to re-glue the optics with better alignment than they had previously had, thus improving the overall interferometer performance.

- Made the first measurements with M3, demonstrating the integrated functioning of all systems. This was a measurement of the line spacing of an array of chromium lines produced by the laser-focused deposition of neutral atoms (McClelland et al Science, Nov. 1993). M3 interferometrically scanned its tunneling microscope probe across 4700 lines over a distance of about $1 \mathrm{~mm}$, yielding an average spacing of 212.83 nanometers with an estimated standard uncertainty of 0.02 nanometers. This measured value corresponds with the theoretically predicted but previously experimentally unconfirmed value of 212.78 nanometers to within 0.05 nanometers. 


\section{FY 95 Plans:}

- Demonstrate the operation of $\mathrm{M} 3$ in a vacuum of $10^{3} \mathrm{~Pa}$.

- Improve the reliability of the M3 interferometer system to a mean-time-between-failures of one week.

- Produce an initial, crude error map for the fine-motion carriages and the superfine scanner.

- Draft a current capabilities and current error-budget document for M3.

- Demonstrate the integrated operation of an improved $\mathrm{Z}$ motor which includes a capacitance gage displacement sensor.

- Measure the X and Y pitches of a 2D holographic grating over a $1 \times 1 \mathrm{~cm}^{2}$ area.

- Measure line widths on artifacts that have been previously measured by optical microscopy and electrical resistance in order to enable a comparison between the techniques.

- Install an AFM probe and demonstrate its operation.

- Demonstrate the operation of the temperature control system in vacuum at a $1 \mathrm{mK}$ fluctuation level.

\begin{tabular}{|c|c|c|c|c|c|}
\hline MOLECULAR MEASURING MACHINE & 95 & 96 & 97 & 98 & 99 \\
\hline \multicolumn{6}{|l|}{$\begin{array}{l}\text { Upgrade all necessary sub-systems of } M 3 \text { to bring them } \\
\text { into full compliance with their advertised performance } \\
\text { specification goals. [STRS] }\end{array}$} \\
\hline \multicolumn{6}{|l|}{$\begin{array}{l}\text { Evaluate the tribological performance of candidate load- } \\
\text { beaning pads for use on the M3 diamond-turned } \\
\text { slideways. Then exchange the current pad/slideway } \\
\text { system for this improved combination. [STRS] }\end{array}$} \\
\hline \multicolumn{6}{|l|}{$\begin{array}{l}\text { Develop specific procedures for measuning the } \\
\text { repeatability of motion and for creating an error map of the } \\
\text { M3 coarse- and fine-motion carriages and apply these } \\
\text { procedures to improve the metrological capabilities. } \\
\text { [STRS] }\end{array}$} \\
\hline \multicolumn{6}{|l|}{$\begin{array}{l}\text { Calibrate existing artifacts and develop and calibrate new } \\
\text { artifacts that will be appropriate for transferring the } \\
\text { measurement capabilities of M3 to industry. [STRS, } \\
\text { OSRM, Fees] }\end{array}$} \\
\hline \multicolumn{6}{|l|}{$\begin{array}{l}\text { Design, install and test a six-degree-of-freedom, active, } \\
\text { vibration-isolation system for M3. [STRS] }\end{array}$} \\
\hline \multicolumn{6}{|l|}{$\begin{array}{l}\text { ncrease the versatility of } M 3 \text { by modifying the probe } \\
\text { system to include an atomic-force microscope. [STRS] }\end{array}$} \\
\hline \multicolumn{6}{|l|}{$\begin{array}{l}\text { Design and install a non-polarizing, heterodyne } \\
\text { interferometer system for use in M3. [STRS] }\end{array}$} \\
\hline $\begin{array}{l}\text { Refine the software and hardware control of M3 to make it } \\
\text { more user-friendly, i.e., more easily taught to new } \\
\text { operators, less prone to operator or system errors, and } \\
\text { more thoroughly documented. }\end{array}$ & & & & & \\
\hline
\end{tabular}




\section{Title: NANOTECHNOLOGY COMPETENCE PROJECT}

\section{Staff: (0.76 Staff Years) *J. DAGATA, *L. Howard}

Project Objective and MEL Thrust Supported: Develop a comprehensive understanding of nanofabrication needs and practices by working closely with members of EEEL on the fabrication and measurement of ultra-precise electrometer circuits based on single-electron-tunneling devices. Manufacturing Metrology.

Need Addressed: NIST needs to improve its ability to measure fundamental electrical constants and properties. The next generations of devices and circuits which will make this possible require critical control of structural dimensions on the nanometer scale. The development of routine fabrication methods for these circuits provides a well-defined test case for PED to confront the challenges of nanomanufacturing.

Technical Approach: Integrated processing within PED's controlled ambient facility and ultrahigh vacuum STM will be used to carry out the fabrication of critically dimensioned structures of functional electrical devices. The ability to perform electrical tests by AFM/STS of the structures prior to sending them to EEEL for full-scale evaluation is a key quality-control element of this approach.

\section{FY 94 Accomplishments:}

- Controlled ambient facility and its components designed, procured and delivered. Testing of completed system is now underway.

\section{FY 95 Plans:}

- Complete development of LabVIEW-based data acquisition system for AFM/STS (1/95-4/95).

- Fabricate silicon nanostructures by AFM-patterned oxidation (4/95-7/95).

- Design and test chip mask set and chip carrier (5/95-9/95). 


\begin{tabular}{||l|l|l|l|l|l||}
\hline \begin{tabular}{|l|l|l||}
\hline NANOTECHNOLOGY FISCAL YEARS \\
COMPETENCE PROJECT
\end{tabular} & 95 & 95 & 97 & 95 & 99 \\
\hline $\begin{array}{l}\text { Complete development of LabVIEW-based data } \\
\text { acquisition system for AFM/STS [Competence] }\end{array}$ & & & & & \\
\hline $\begin{array}{l}\text { Measure surface charge on insulating substrates using } \\
\text { AFM/STS and correlate with charge offset phenomena } \\
\text { [Competence] }\end{array}$ & & & & & \\
\hline $\begin{array}{l}\text { Fabricate silicon nanostructures by AFM-patterned } \\
\text { oxidation [Competence] }\end{array}$ & & & & & \\
\hline $\begin{array}{l}\text { Design and test chip mask set and chip carrier } \\
\text { [Competence] }\end{array}$ & & & & & \\
\hline $\begin{array}{l}\text { Demonstrate capability of using AFM/STS potentiometry in } \\
\text { conjunction with fabrication process to alter the resistance } \\
\text { of nanostructures in a controlled manner [Competence] }\end{array}$ & & & & & \\
\hline $\begin{array}{l}\text { Fabricate and characterize SET device structures } \\
\text { [Competence] }\end{array}$ & & & & & \\
\hline $\begin{array}{l}\text { Fabricate and characterize SET circuits with 5-10 devices } \\
\text { per circuit [Competence] }\end{array}$ & & & & & \\
\hline
\end{tabular}


Staff: (1.01 staff years) *WILLIAM PENZES, *John Beers, *Fred Scire, *Clayton Teague

Project Objective and MEL Thrust Supported: To maintain NIST capability for line scale measurements at a world-class level. Manufacturing Metrology.

Need Addressed: The line scale interferometer (LSI) serves a pivotal role in NIST measurements of the distance between two features - line scale measurements - for distances ranging from 10 micrometers up to 1 meter. It supports advanced measurement needs of the integrated circuit industry by providing calibrations of reticles for photo and X-ray masks, as well as line scale calibrations for optical line scale artifact manufacturers and manufacturers of various type of grid plates. Some of the US corporations often requesting ultra-high accuracy line scale measurements are IBM, ITT, Boeing Co, ACU-RITE, Corning, Inc., AMP, Iin. and Master Images. LSI remains the NIST reference for international practical comparisons of the meter. Finally, it serves as the NIST internal practical tie to the ISO definition of the meter for gage block measurements, ball-bar measurements, optical and SEM linewidth measurements and electrical test structure measurements.

This project addresses four areas of improvement: (1) increasing the line detector resolution, (2) upgrading of the data acquisition and control computer system and interfaces, (3) improvements in the resolution and accuracy of the displacement interferometer, and (4) improvements in the mechanical structure to permit simultaneous comparison of the wavelengths of two lasers. For the first area, the LSI presently uses a scanning photo-electric microscope capable of measuring scales with line width of 1 to 100 micrometers wide. Addition of a scanning capacitance line detector (SCLD) to the LSI will enable measurement of lines with widths as narrow as $10 \mathrm{~nm}$. The other improvements should be self explanatory when combined with the milestones and five-year plan.

Technical Approach: To develop a SCLD, a design based on a successful earlier NIST design is being built and tested. In this design the detector capacitor is placed in one leg of a carrier operated series resonant bridge. The sensitivity depends on the carrier frequency, the stand-off distance, the tip diameter, the detectable line width and the $\mathrm{Q}$ of the bridge components. The effect of all these parameters is currently being experimentally and theoretically investigated. Upgrading the data acquisition and control computer system will use a new highperformance PC, making all the necessary hardware modifications, redesigning the measurement procedure, rewriting the data acquisition and control software, installing a new data acquisition, data analyzing, instrument control and advanced graphic software. Interferometer improvements planned will include adoption of the phase measurement improvements from $\mathrm{M}$-Cubed and, after a careful design study, some means to overcome uncertainties from index of refraction effects.

\section{FY 94 Accomplishments:}

- Completed feasibility demonstration of scanning capacitance line detector using planned circuit design.

\section{FY 95 Plans:}

- Hardware:

1.Purchase a 56 inch long 1 inch Invar "I" beam and install into the LSI for the remote interferometer support.

2. Install the new laser mounting platforms at both sides of the LSI.

3. Modify the laser access hole at right end of the chamber by rerouting the internal copper piping.

4. Design, fabricate and instal kinematic mounts for the laser heads at both ends.

5. Improve the LSI housing by covering it with a laminate or other surface treatment.

6. Upgrade, if possible, the internal microscope lens system. 
- Instrumentation:

1. Procure a $486 \mathrm{DX} / 66$ computer for LSI..

2. Procure and install an A/D data acquisition board for the PC.

3. Procure and install an HPIB Interface board and install.

4. Hook up the reference PRT to the Keithley 2001 multimeter.

5. Connect all TC to the new Keithley 705 scanner and measure temperature with the Keithley 182 Nanovoltmeter.

6. Connect all peripheral instruments to the PC through IEEE-488 line.

7. Purchase a complete HP laser and interferometer system (laser head, counter, interferometer with reference, corner cube and beam bender).

\begin{tabular}{|c|c|c|c|c|c|}
\hline $\begin{array}{l}\text { NIST LINE SCALE INTERFEROMETER } \\
\text { UPGRADING } \\
\text { FISCAL YEARS }\end{array}$ & 98 & 96 & 97 & 98 & 99 \\
\hline \multicolumn{6}{|l|}{$\begin{array}{l}\text { Design, construct a Scanning Capacitive Line Detector } \\
\text { (SCLD) for the LSI based on discrate/hybrid electronics } \\
\text { [STRS] }\end{array}$} \\
\hline \multicolumn{6}{|l|}{$\begin{array}{l}\text { Install new temperature data acquisition and control } \\
\text { electronics for LSI [STRS] }\end{array}$} \\
\hline \multicolumn{6}{|l|}{$\begin{array}{l}\text { Rewrite LSI data acquisition and control computer } \\
\text { program [STRS] }\end{array}$} \\
\hline \multicolumn{6}{|l|}{$\begin{array}{l}\text { Design, construct a SCLD for LSI utilizing fully integrated } \\
\text { circuit electronics [STRS] }\end{array}$} \\
\hline \multicolumn{6}{|l|}{$\begin{array}{l}\text { Upgrade LSI computer and interfaces to peripherals } \\
\text { [STRS] }\end{array}$} \\
\hline \multicolumn{6}{|l|}{$\begin{array}{l}\text { upgrade LSI control electronics by converting all existing } \\
\text { prototype circuit boards to printed circuit boards [STRS] }\end{array}$} \\
\hline \multicolumn{6}{|l|}{$\begin{array}{l}\text { Design SRM (scales) for length standards which can be } \\
\text { measured by optical, electrical test structure and } \\
\text { capacitive sensing methods [STRS] }\end{array}$} \\
\hline \multicolumn{6}{|l|}{$\begin{array}{l}\text { Furbish the LSI with lodine Stabilized Laser to increase } \\
\text { measurement capability and accuracy. [STRS, MEL DIR.] }\end{array}$} \\
\hline \multicolumn{6}{|l|}{$\begin{array}{l}\text { Complete optical and mechanical modifications of the LSI } \\
\text { to enable dual wavelength comparison [STRS] }\end{array}$} \\
\hline \multicolumn{6}{|l|}{$\begin{array}{l}\text { Conduct design study to evaluate relative } \\
\text { advantages/disadvantages of using interferometer paths } \\
\text { in vacuum, controlled gas environment, and two color } \\
\text { index of refraction measurement [STRS] }\end{array}$} \\
\hline Implement choice of milestone "J" [STRS] & & & & & \\
\hline
\end{tabular}




\section{Staff: (0.46 staff years) ${ }^{*}$ JAMES POTZICK *Rick Silver *Carol Vezzetti}

Project Objective and MEL Thrust Supported: Project 1: Maintain quality of SRM 473 and its availability to industry. Project 2: Assess validity of Emulated Stepper Aerial Image Measurement (ESAIM) photomask linewidth metrology concept. Manufacturing Metrology

Need Addressed: Project 1: Accurate measurement and control of feature sizes on IC photomasks is critical to current and advanced IC manufacturing processes. This photomask linewidth SRM is the established standard for linewidth measurement among photomask vendors and users. We plan to meet the increasing customer demands for quality and numbers of SRMs with decreased calibration uncertainty.

Project 2: The IC industry needs greater photomask linewidth measurement accuracy than is (or ever will be) possible with a photomask SRM to meet the needs of future generations of ICs. As much as $40 \%$ of linewidth tolerance is presently consumed by metrology. A fundamentally different measurement approach is needed here.

Technical Approach: Project 1: Procure next batch of SRM 473 photomasks, inspect, calibrate using existing green light calibration system (or the UV microscope, when operational), maintain records, package and deliver to OSRM for sale.

Project 2: Photomask measurement must be understood in the larger context of photomask application, and this is the genesis of ESAIM. The purpose of a photomask is to project an image onto photo resist. In the Emulated Stepper Aerial Image Measurement concept the metrology tool is adjusted to emulate the optical system of the stepper to be used, and the end product of the measurement is the size of this emulated image, not the physical linewidth on the photomask. The effects of uncontrolled or difficult-to-measure mask attributes such as chrome edge profile, small defects, proximity effects, etc., are included on this measurement. Phase shift and other kinds of mask can be measured in the same way, with no change in tool or procedure. "Measure what the photomask does, not what it is." The remaining task is to estimate measurement uncertainty by analysis and modeling. Measurement accuracy is expected to improve by a factor of 3 or more.

\section{FY 94 Accomplishments:}

- Project 1: Wrote purchase specifications for SRM 473, evaluated bid proposals and issued a purchase contract. Prototype has been delivered and evaluated. Delivery of remainder is expected in January.

- Project 2: Presented ESAIM to industry. No fatal flaws were uncovered. Industry views are polarized, but SEMATECH seems to be interested. The only objections encountered concern the cost of changing a measurement process and of new tools. At least one appropriate tool is now on the market (originally designed for phase shift masks). The industry's needs will eventually force them to adopt this technique.

\section{FY 95 Plans:}

- Project 1: Ship newly calibrated SRM 473 to NPL for international intercomparison; accept theirs for measurement here; rewrite SP 260 for SRM 473; complete calibration and delivery of SRM 473 to OSRM; train technician for these and future calibrations as necessary, participate with NPL and PTB in measuring their proposed EEC $0.2 \mu \mathrm{m}$ linewidth standard.

- Project 2: Issue contract for optical analysis, modeling, and consultation in order to answer specific questions on the fidelity of stepper emulation in a measuring tool. Meet with contractor to discuss 
specifics; install aerial image simulation program on local computer; compare simulations with measurements on the UV Microscope for a reasonable and accessible range of parameters; issue report on findings and recommend practice in photomask.

\begin{tabular}{|c|c|c|c|c|c|}
\hline OPTICAL METROLOGY & 96 & 96 & 97 & 98 & 99 \\
\hline $\begin{array}{l}\text { Maintain software and hardware of green-light optical } \\
\text { system such that issuance of SRM } 473 \text { can meet all } \\
\text { customer demands [OSRM] }\end{array}$ & & & & & \\
\hline $\begin{array}{l}\text { Complete transition to calibrations with UV microscope } \\
\text { [OSRM] }\end{array}$ & & & & & \\
\hline $\begin{array}{l}\text { Maintain collaboration with EEC and other international } \\
\text { developments in optical linewidth measurement [STRS] }\end{array}$ & & & & & \\
\hline $\begin{array}{l}\text { Conduct studies to ascertain the potential uncertainty and } \\
\text { economic drawbacks of the stepper aerial image } \\
\text { emulation measurements [OMP] }\end{array}$ & & & & & \\
\hline
\end{tabular}




\section{Title: OPTICAL PROBE METROLOGY}

\section{Staff: (1.4 staff years) W. TYLER ESTLER, *Greg Caskey, *Bruce Borchardt}

Project Objective and MEL Thrust Supported: Develop techniques for performance characterization and calibration of non-contact CMM probes. Manufacturing Metrology.

Need Addressed: A consortium of U.S. auto makers known as $2 \mathrm{~mm}$ Inc. receives ATP funding to pursue high-accuracy dimensional metrology on automobile bodies and panels. In the most recent round of ATP proposals, a consortium led by the Ohio Aerospace Institute (OAI), including Chrysler Corporation, Eaton (a major manufacturer of truck transmissions), and Giddings \& Lewis, received an ATP grant to explore technologies related to the rapid, automated dimensional inspection of complex manufactured parts such as highaccuracy gears, turbine blades and rotors, and airfoils. The principal features of such a high-speed measuring system, as envisaged by $\mathrm{OAI}$ and their collaborators, include a machine-vision based pre-inspection module, a fast, dynamically stable coordinate measuring machine, a set of complementary non-contact probes, a two-axis positioning "wrist" assembly to enable surface-normal scanning, and a high-bandwidth controller to enable spatial coordinate data acquisition rates near 2000 points/second. Both of these consortia have approached NIST with the need for methods for characterizing the performance of non-contact scanning CMM probes.

Technical Approach: NIST will develop testing and calibration techniques for a set of non-contact CMM probes chosen in collaboration with $2 \mathrm{~mm}$ Inc. and OAI. These will consist of both optical and capacitance based devices. We will develop and implement robust methods for characterizing key sensor parameters such as working range, angular tolerance, and spot size. We will also address sensor response to changes in material composition, surface finish, and surface contamination due to oil films, and dust. NIST will also develop calibration artifacts and standardized testing procedures for dissemination to manufacturers and users of optical triangulation probes. NIST will collaborate with the ANSI/ASME B89.4.14 Working Group on noncontact probing technology.

\section{FY 94 Accomplishments:}

- Performed initial investigations into surface and sensor characteristics that affect the performance of optical triangulation noncontact sensors.

- Began developing performance test methodologies for optical triangulation probes in concert with ANSI/ASME Working Group B89.4.14.

- Developed, calibrated, and distributed artifacts to B89.4.14 members to evaluate the proposed tests.

\section{FY 95 Plans:}

- Begin developing non-contact sensor characteristic database to guide probe selection for end users.

- Evaluate optical triangulation probe sensitivity to surface finish variations typical of modern machining operations.

- Evaluate resolution, repeatability, and noise characteristics of several non-contact probes with a view towards estimating probe-related measurement uncertainty.

- Continue collaboration with ANSI/ASME Working Group B89.4.14 to refine non-contact probe test and evaluation procedures. 


\begin{tabular}{|l|l|l|l|l|l|l||}
\hline OPTICAL PROBE METROLOGY FISCAL YEARS & 95 & 96 & 97 & 96 & 99 \\
\hline $\begin{array}{l}\text { Develop noncontact sensor characteristic database to } \\
\text { guide probe selection for end users [ATP] }\end{array}$ & & & & & \\
\hline $\begin{array}{l}\text { Evaluate optical triangulation probe sensitivity to surface } \\
\text { finish variations typical of modern machining operations } \\
\text { [ATP] }\end{array}$ & & & & & \\
\hline $\begin{array}{l}\text { Evaluate resolution, repeatability, and noise } \\
\text { characteristics of several noncontact probes with a view } \\
\text { towards estimating probe-related measurement } \\
\text { uncertainty [ATP] }\end{array}$ & & & & & \\
\hline $\begin{array}{l}\text { Continue collaboration with ANSI/ASME Working Group } \\
\text { B89.4.14 to refine noncontact probe test and evaluation } \\
\text { procedures [ATP, STRS] }\end{array}$ & & & & & \\
\hline
\end{tabular}




\section{Staff: (1.01 staff years) *R. SILVER, *J. Potzick, *B. Larrabee, *C. Teague, *F. Scire}

Project Objective and MEL Thrust Supported: Design and implement an optical based overlay metrology system for the study and calibration of feature overlay on silicon wafers resulting from two or more patterning steps in IC fabrication. To design, procure, and calibrate Si based standards in support of overlay metrology. Manufacturing Metrology.

Need Addressed: NIST is responsible to the U.S. microelectronics industry for developing calibration standards in support of semiconductor IC production. With many fab lines turning out more than 2000 wafers per week and over 600 die per wafer, improvements in metrology can often improve yield which translates into substantial financial gains. Metrology issues are particularly critical in overlay measurement since the reduction in feature sizes of VLSI circuitry puts increasing demands on pattern placement of one level relative to another. This is widely recognized as one of the primary elements of concern in yield management. NIST currently offers no overlay standards; consequently, there is an immediate need for the development of overlay calibration instrumentation and standard artifacts.

Pattern placement of the various levels is typically monitored through a series of box in box patterns, each in a different plane. The overlay offset is determined by optical measurements of the box center lines where each box is in a different plane. Any misalignment in the overlay metrology system will translate into an artificial overlay offset, referred to as tool induced shift (TIS). Additionally, there are residual errors caused by asymmetries in the box in box edges or covering layers (resist) known as wafer induced shift. A set of standard artifacts and procedures needs to be developed to align overlay measurement systems and eliminate TIS. The aligned instruments must then be calibrated with standard artifacts to yield accurate overlay offsets.

Technical Approach: The technical strategy is divided into two segments: 1) instrumentational development, and 2) design and calibration of standard artifacts. The measurement system will be designed for maximum accuracy and repeatability (high throughput is not essential for the NIST calibration system). The system will be an optical reflection mode instrument, operational in either a bright field or confocal mode, with interferometry on three orthogonal axes also capable of monitoring the stage tilt. Additional instrumentational requirements are the option to scan the sample in any one of the three orthogonal axes, the ability to rotate the sample, and fully automated image recognition. Proper optical alignment in the z-direction is critical. Similarly, precise stage motion is essential to ensure that $\mathrm{z}$-axis focussing motion is decoupled from $\mathrm{x}$ - and $\mathrm{y}$-axis motion since this will also add an erroneous shift to the image.

The first aim of the NIST standards program is to develop better methods to characterize tool induced shift (TIS). The goal is to ensure that the overlay tool is operating within an appropriate TIS specification. This will be accomplished by the development of a "tool kit" with procedural and artifact standards to assist in alignment of the optical and mechanical elements of the overlay metrology system. These tools would allow calibration of residual X-and Y-motions during focusing in the Z-direction, adjustment and alignment of the illumination source, and calibration of the CCD pixels. Once the tool is aligned and TIS free, it may be used to characterize wafer induced shift of the test specimen.

Preparation of artifact standards for this purpose would be the second goal of the NIST program. Since user test patterns frequently have asymmetries in the edges and covering layers which are user specific, the NIST approach is to develop calibrated, wafer induced shift free standard artifacts. The edge geometry of these samples may be verified by SEM or AFM techniques. The final result would be wafer induced shift free standards for the calibration of TIS free optical overlay tools. 
FY 94 Accomplishments: New Start

\section{FY 95 Plans:}

- Complete the design of the reflection mode optical overlay metrology system.

\begin{tabular}{|c|c|c|c|c|c|}
\hline OVERLAY METROLOGY & 95 & 96 & 97 & 98 & 99 \\
\hline \multicolumn{6}{|l|}{$\begin{array}{l}\text { Complete construction and demonstrate full operation of } \\
\text { all optical and mechanical components [OMP, STRS] }\end{array}$} \\
\hline \multicolumn{6}{|l|}{$\begin{array}{l}\text { Write and install the software modules enabling electronic } \\
\text { feedback and control of stage motion, interferometric } \\
\text { position measurements, photometer optical intensities, } \\
\text { and CCD full field digital imaging [OMP, STRS] }\end{array}$} \\
\hline \multicolumn{6}{|l|}{$\begin{array}{l}\text { Complete image recognition software, full analog and } \\
\text { digital filtering, and internal graphics capabilities [OMP, } \\
\text { STRS] }\end{array}$} \\
\hline \multicolumn{6}{|l|}{$\begin{array}{l}\text { Develop modeling techniques for edge analysis and pitch } \\
\text { determination, in the reflection mode, necessary for } \\
\text { overlay measurements [OMP, STRS] }\end{array}$} \\
\hline \multicolumn{6}{|l|}{$\begin{array}{l}\text { Acquire overlay standards (both alignment and calibration) } \\
\text { for SRM certification [SRM Office] }\end{array}$} \\
\hline \multicolumn{6}{|l|}{$\begin{array}{l}\text { nvestigate effects of covering layers, resist, and material } \\
\text { thicknesses on apparent overlay shifts [STRS] }\end{array}$} \\
\hline $\begin{array}{l}\text { Participate in development of reflection mode optical } \\
\text { linewidth measurements and modeling techniques [OMP, } \\
\text { STRS] }\end{array}$ & & & & & \\
\hline
\end{tabular}


Staff: (2.4 staff years) C. J. EVANS, M. A. DONMEZ, *R. S. Polvani, *M. L. McGlauflin, *E. Whitenton, ${ }^{*}$ K. Harper, M. Davies (NRC Post-doc), *P. J. Sullivan (GW)

Project Objective and MEL Thrust Supported: The objective of the project is to develop manufacturing methods--including metrology and sensor feedback to open architecture controllers--to allow cost effective production of tight tolerance components in advanced, difficult to machine materials such as ceramics, crystals, and hardened steels. Applications include mechanical, optical and electronic systems ranging from bearings and turbine blades to space optics and magnetic memories. Manufacturing Metrology.

Need Addressed: There is an ever increasing trend to both tighter manufacturing tolerances and higher performance materials. Unfortunately, high strength wear resistant materials are also difficult to machine. For example, next generation turbine blades will be made from silicon nitride--and require complex, accurate forms with good surface finish and no machining-induced strength limiting defects. Machining costs are currently a high proportion of the total manufacturing cost, and must be reduced if advanced materials are to be cost competitive, yet defect density and surface finish must be controlled. Complex interactions between machine characteristics, tool and work materials, and process parameters must be understood as they provide the technological basis for manufacturing processes that will allow introduction of new products based on such materials. Improved grinding techniques will enhance the manufacturability of high-value-added, tight tolerance components. Potential industries impacted include aerospace, transportation, and mass storage.

Technical Approach: We aim to improve the state-of-the-art in ductile regime grinding and hard turning. Brittle materials behave in an apparently ductile manner under certain process conditions, allowing defect free ceramic surfaces to be diamond ground with fine grit wheels. Rapid wheel wear, however, means that continuous electrochemical dressing is required of the metal bond wheels; fundamental understanding of the dressing process, and its integration and control via an open architecture controller are required. Appropriate instrumentation will be developed to give sensory feedback for real time control of the grinding process as well. In higher stock removal processes, small variations in work material microstructure seem to have a substantial effect on removal rates; critical experiments will be performed to quantify and understand the basics of ceramic machinability and its variation. Loop stiffness and damping appear to have an impact on tool wear as well as surface integrity in hard turning; the new tools of non-linear dynamic analysis are being applied to understanding these effects. Chemical effects in tool wear need to be better understood.

\section{FY 94 Accomplishments:}

- Demonstrated effect of microstructure on surface characteristics of ground HIPped silicon nitrides.

- Developed predictive theory for chemical wear of single point diamond tools.

- Developed simple procedure for post-polishing diamond turned surfaces that eliminates the need for a finish cut on the diamond turning machine, reduces total production time, and produces an order of magnitude better surface finish without affecting diamond machined surface shape accuracy.

- Demonstrated that "ductile ground" silicon nitride has improved breaking strength.

\section{FY 95 Plans:}

- Complete High Stiffness Machining Research Test Bed and perform initial ceramics grinding evaluation tests.

- Demonstrate effect of spindle characteristics on hard turning on Moore \#3 based diamond turning machine.

- Evaluate surface characteristics and mechanical properties of electro-chemically assisted ductile ground 
silicon nitrides.

\begin{tabular}{|c|c|c|c|c|c|}
\hline $\begin{array}{l}\text { PRECISION MACHINING } \\
\text { OF ADVANCED MATERIALS }\end{array}$ & 96 & 96 & 97 & 96 & 99 \\
\hline \multicolumn{6}{|l|}{$\begin{array}{l}\text { Develop basic electrochemical theory for dressing } \\
\text { processes [STRS] }\end{array}$} \\
\hline \multicolumn{6}{|l|}{ Complete ceramics machinability studies [STRS/OA] } \\
\hline \multicolumn{6}{|l|}{$\begin{array}{l}\text { Evaluate stiffness and damping effect in hard turning } \\
\text { [STRS] }\end{array}$} \\
\hline \multicolumn{6}{|l|}{ Perform sensor evaluation for grinding control [STRS] } \\
\hline \multicolumn{6}{|l|}{$\begin{array}{l}\text { Implement one of the newly developed processes in a } \\
\text { production shop floor [STRS] }\end{array}$} \\
\hline $\begin{array}{l}\text { Establish the economic benefit derived from the shop floor } \\
\text { implementation described above. [STRS] }\end{array}$ & & & & & \\
\hline
\end{tabular}


Staff: (0.9 Staff Years) JANET LAND, *Eric Stanfield, *Ted Doiron, *Ralph Veale, *David Stieren

Project Objective and MEL Thrust Supported: The objective is to provide documentation for the Calibrations Laboratory based on conformance with ISO/IEC Guide 25. Manufacturing Metrology.

Need Addressed: The target customers are those companies that send their dimensional artifacts to NIST for calibration. NIST, through NVLAP, will begin to accredit calibration laboratories to the U.S. version of ISO Guide 25 (NCSL Z540-1). We intend to document our current quality system in the fashion of the international standard, which will provide us with adequate documentation for our own uses and act as a model for outside high-accuracy laboratories.

Technical Approach: Begin to create procedures based on current practices; document the current quality system, providing policies and objectives; and develop procedures for parts of the standard which we currently do not have formalized systems in place.

FY 94 Accomplishments: Began preliminary discussions concerning instituting policies and procedures for the calibration laboratory based on ISO/IEC Guide 25. Wrote draft procedures for customer information and calibration folder handling. Writing draft procedures for gage block and ring calibrations. Three staff members have attended classes on assessment techniques: ISO 9000 Lead Assessor Training (Doiron) and ISO 9000 Internal Assessment (Stanfield and Everett).

FY 95 Plans: Write the operating policies and procedures for this laboratory. The Group Leader is scheduled to attend ISO 9000 training session in February, 1995.

Related Developments: Group staff are scheduled to make first NVLAP assessments in dimensional area.

\begin{tabular}{|l|l|l|l|l|l|}
\hline QUALITY SYSTEM PILOT PROJECT FISCAL YEARS & 95 & 96 & 97 & 98 & 99 \\
\hline $\begin{array}{l}\text { Refine and implement the ISO/IEC Guide 25 for the } \\
\text { laboratory [STRS] }\end{array}$ & & & & & \\
\hline $\begin{array}{l}\text { Determine requirements for ISO Guide 25 certification and } \\
\text { begin writing procedures [STRS] }\end{array}$ & & & & & \\
\hline Write quality manual [STRS] & & & & & \\
\hline $\begin{array}{l}\text { Complete documentation of calibration procedures } \\
\text { [STRS] }\end{array}$ & & & & & \\
\hline $\begin{array}{l}\text { Achieve certification through inspection from accrediting } \\
\text { agency [STRS] }\end{array}$ & & & & & \\
\hline
\end{tabular}

NOTE: This project ends in July 1997. 
Staff: (1.96 staff years) *M. POSTEK, *A. Vladar, *S. Jones, *J. Lowney, *L. Carroll

Project Objective and MEL Thrust Supported: The SIA road map targets scanning electron microscopes as the metrology tool of choice for use in semiconductor production up through the year 2001. The objectives of this program are to develop standards, specifically those related to the measurement of linewidth, for the scanning electron microscope. This entails a multidimensional program including: understanding the function and signal generation in the SEM, developing NIST metrology instruments for the certification of standards, and developing the necessary artifacts and calibration procedures. Manufacturing Metrology.

Need Addressed: The manufacturing of present-day integrated circuits requires that certain measurements be made of the submicrometer structures composing the device with a high degree of precision. The accuracy of these measurements is also important, but more so to the development and pilot lines. The measurements of minimum feature sizes known as critical dimensions (CD) are made to insure proper device operation. NIST is responsible to U.S. industry for developing length intensive measurement capabilities and calibration standards. This project supports all aspects of this need since scanning electron microscopy is the major microscopical technique used for this submicrometer metrology. NIST addresses this need by providing (or is currently developing) standards and measurement techniques for these measurement instruments.

Technical Approach: The development of SEM linewidth standards is a multidimensional problem. This problem is being tackled through several thrusts fully supported by the semiconductor industry. The major areas(each with several sub areas) are described .

Standard Reference Material (SRM) 2090: Primary to SEM metrology is the calibration of the magnification of the instrument. SRM 2090 is an SEM magnification standard that will function at the low beam voltages used in the semiconductor industry and will have capability down to $0.2 \mu \mathrm{m}$ pitch. A prototype with $0.2 \mu \mathrm{m}$ lines and spaces was fabricated by the Nanofabrication Facility at Cornell University as a proof of concept and was used in a round robin study that clearly demonstrated the need for this standard. Texas Instruments was contracted to supply the standard with $0.1 \mu \mathrm{m}$ lines and spaces and has recently delivered 120 of these research artifacts.

Sharpness Standard: The performance characteristics of the SEM is extremely important to precise metrology. A new sharpness standard and evaluation procedure is being developed to monitor (or compare) SEM image quality. It is based on etched biphasic glass or an etching defect called "grass." NIST is working with Texas Instruments on its development, and with IVS on the use of a standard of this type in the SEM. The "ISAAC" system of SEM image analysis previously developed at NIST is being used to analyze the images obtained from the test samples delivered by Texas Instruments and measured at IVS under a CRADA.

Monte Carlo Modeling: Improvements are being made in the previously developed Monte Carlo computer model of beam-electron interaction with the sample that leads to a theoretical prediction of the SEM image profile of a feature. This model was originally developed to find edge location criteria for use in measuring the submicrometer features on $\mathrm{x}$-ray masks. The model has now been extended to include profiles of backscatteredelectrons as well as the original transmitted. Work is in progress to include secondary electron profiles, and to have up to three parallel lines (to study proximity effects), and to include 3-dimensional objects (such as vias). NIST is currently collaborating with METROLOGIX under a CRADA to include the characteristics of their SEM into the model for the purpose of verifying the model by comparing its results to actual experimental data.

\section{FY 94 Accomplishments:}

- Presented the results of the 1994 program and the allied Optical Linewidth Metrology Program to 
combined MEL and EEEL management.

\section{FY 95 Plans:}

- Complete the SEM metrology elements of the SEMATECH contract (4/95).

- Complete the design, construction and implementation of the NIST metrology instrument and begin to investigate the problems associated with the certification of SRM 2090 (4/95).

- Hold a follow-up to the NIST Workshop on "Electron Beam Interaction Modeling for Metrology and Microanalysis in the Scanning Electron Microscope." The follow-up will be held in collaboration with the 1995 Microbeam Analysis Society Meeting.

- Complete the ISAAC development and establish a user friendly algorithm for the measurement of SEM sharpness and document with a study of its performance (9/95).

- Pursue techniques for the cleaning of electron beam induced contamination from SEM samples such as SRM 2090. This is facilitated through the CRADA with ANATECH. This is a continuation of the FY 94 Director's Reserve program (9/95).

- Investigate SPM tip performance through direct monitoring with an SEM (contingent on the procurement of the SEM/SPM instrumentation from Topometrix).

- Continue the development sequence of the Monte Carlo Modeling - MONSEL - series and compare model data with actual SEM data. This is being facilitated through interaction with both Motorola and Digital Equipment Corporation production facilities under the SEMATECH contract and the Metrologix CRADA.

- Measure the AT\&T $x$-ray mask and SCALPEL mask with the SEM metrology instrument and compare to the electron beam model data.

\begin{tabular}{|c|c|c|c|c|c|}
\hline $\begin{array}{l}\text { SCANNING ELECTRON MICROSCOPE } \\
\text { LINEWIDTH METROLOGY }\end{array}$ & 95 & 96 & 97 & 98 & 99 \\
\hline \multicolumn{6}{|l|}{$\begin{array}{l}\text { Acquire production batches of SRM } 2090 \text { certify and issue } \\
\text { the standard [STRS, OSRM, OMP] }\end{array}$} \\
\hline \multicolumn{6}{|l|}{$\begin{array}{l}\text { Provide improved measurement methods for } x \text {-ray masks } \\
\text { and SCALPEL masks to support } x \text {-ray lithography [STRS, } \\
\text { OMP] }\end{array}$} \\
\hline \multicolumn{6}{|l|}{$\begin{array}{l}\text { Attempt comparative measurements between SEM and } \\
\text { SPM metrologies using the new combined instrument } \\
\text { [STRS, OMP] }\end{array}$} \\
\hline \multicolumn{6}{|l|}{$\begin{array}{l}\text { Improve the accuracy of thick layer metrology of photo- } \\
\text { resist structures using the application of Monte Carlo } \\
\text { modeling and associated experimentation }\end{array}$} \\
\hline \multicolumn{6}{|l|}{ Develop and issue thick layer SEM linewidth standard } \\
\hline \multicolumn{6}{|l|}{$\begin{array}{l}\text { Upgrade equipment and methods for large sample } \\
(300 \mathrm{~mm}) \text { metrology - SEM/SPM system [OMP, STRS] }\end{array}$} \\
\hline \multicolumn{6}{|l|}{$\begin{array}{l}\text { Acquire environmental microscope to facilitate the study of } \\
\text { specimen charging and high aspect SPM tip generation }\end{array}$} \\
\hline Move into the new ATL laboratories [STRS] & & & & & \\
\hline
\end{tabular}


Staff: (1.21 staff years) *M. POSTEK, *J. Dagata, *S. Jones, *J. Lowney, ${ }^{*}$ T.McWaid, *J. Potzick, ${ }^{*}$ R. Silver, *J. Schneir, *A. Vladar

Project Objective and MEL Thrust Supported: NIST received partial support from SEMATECH to collaborate in a program designated as "J93 - Phase 4 Consultation with NIST." This program began on or about January 1, 1994 and the primary program will end about March 15, 1995. The purpose of this program is for NIST to apply its metrology knowledge to selected SEMATECH lithography and metrology development activities. The targeted measurement technologies are: scanning electron microscope metrology, optical metrology, and scanned probe metrologies. This program is well within the charter and mission of NIST, and such collaboration is the best way for SEMATECH to achieve the key metrology objectives necessary for the success of current and future lithography programs at SEMATECH and its member companies. Manufacturing Metrology.

Need Addressed: The manufacturing of current integrated circuits requires that certain measurements be made of the submicrometer structures composing the device with a high degree of precision. The accuracy of these measurements is also important, but more so to the development and pilot lines. The measurements of minimum feature sizes known as critical dimensions (CD) are made in order to insure proper device operation. NIST is responsible to U.S. industry for the development of length intensive measurement capabilities and calibration standards. This project supports all aspects of this need. Optical metrology, scanning electron microscopy and scanned probe microscopies are the major microscopical technique used for this submicrometer metrology. NIST addresses this need by providing (or currently developing) standards and measurement techniques for these measurement instruments.

Technical Approach: NIST was given 60 working days, at the onset of this program, to: 1) survey the lithometrology needs of the domestic semiconductor industry, 2) summarize the results of this survey, and 3) propose projects for SEMATECH collaboration and funding in areas where NIST can bridge the identified gaps between the expressed needs and present capabilities. This was presented to SEMATECH and the member companies through a Project Proposal Report and they choose to fund several aspects of the program proposed. SEMATECH choose to fund programs in Scanning Electron Microscope Metrology (Development of SRM 2090, Sharpness Standard, Monte Carlo Modeling); Scanned Probe Microscopies (Calibrated AFM, Probe Modeling, Effects of Humidity) and Optical Microscopy (Development of the UV microscope).

\section{FY 94 Accomplishments:}

- Submitted Project Proposal to SEMATECH and the member companies. This resulted in the partial funding of the various programs currently in place and helped to ratify the NIST programs through industrial support.

- Submitted the Project Interim Report

FY 95 Plans:

- Submit the Project Final Report

- Continue of SEMATECH consultation

Related Developments: Continued SEMATECH OA funding is unlikely due to a fundamental change in the funding structure and direction of SEMATECH. However, it is imperative that NIST maintain a presence at SEMATECH functions due to the influence this organization has on the SIA and other semiconductor industry organizations. 


\begin{tabular}{|l|l|l|l|l|l|l|}
\hline SEMATECH CONTRACT/INTERACTION FISCAL YEARS & 95 & 95 & 97 & 98 & 99 \\
\hline $\begin{array}{l}\text { Complete deliverables related to the current SEMATECH } \\
\text { contract }\end{array}$ & & & & & \\
\hline $\begin{array}{l}\text { Continue interactions with SEMATECH and maintain a } \\
\text { NIST presence at necessary SEMATECH functions }\end{array}$ & & & & & \\
\hline
\end{tabular}


Staff: (1.01 staff years) ${ }^{*}$ R. SILVER, ${ }^{*}$ J. Villarrubia, ${ }^{* J}$. Dagata, ${ }^{*} \mathrm{C}$. Teague, ${ }^{*} \mathrm{M}$. Postek, ${ }^{*}$ A. Vladar, and *J. Kramar

Project Objective and MEL Thrust Supported: To develop means for reproducible preparation and direct characterization of SPM tips. To produce samples with canonically ordered surfaces on the nanometer length scale and to correlate the performance, in air and UHV, of well characterized probe tips on these surfaces with their performance in dimensional measurements. Manufacturing Metrology.

Need Addressed: NIST is responsible to U.S. industry for developing length intensive measurement capabilities and calibration standards in the nanometer scale regime. The new class of scan probes have unparalleled resolution and offer the most promise for meeting these needs of the microelectronics industry. However, before this enhanced resolution can be translated into precise, accurate dimensional measurement capabilities, these tools need to be fully calibrated. An often neglected aspect is the accurate characterization of SPM tips. NIST needs to develop reproducible means for the production and evaluation of SPM tips, such as the FIFEM, which will enable us to put an approximately $5 \mathrm{~nm}$ uncertainty on the geometrical shape of a tip with a $50 \mathrm{~nm}$ radius.

In all SPM techniques, tip properties (geometry and work function) are convoluted in the resulting image. The key to accurate metrology is to develop independent methods for the determination of tip geometry, models for the interpretation of imaging data which allow the determination of real feature dimensions, and the development of standard artifacts to verify the tip performance and surface reconstruction procedures. We need to fabricate tips of different shapes and materials to complete a comprehensive study on the relationship between fabrication processes and tip performance.

Technical Approach: The technical strategy is best broken into four thrust areas: 1) tip acquisition (in-house manufacturing or procurement), 2) direct geometrical tip characterization (FIFEM, SEM, new ideas), 3) characterization artifacts (atomically ordered surfaces, nanometer scale defined topography eg. linewidth samples, gold spheres), and 4) modeling (extract physical feature dimensions, determine tip geometry).

Due to the large number of tip types and available materials, we need to focus our efforts on particular tips (e.g. PtIr of different shapes). The strategy is to develop general tools for tip characterization but concentrate on a particular type of tip which can be used systematically and reproducibly for a specific type of measurement. We will develop an STM tip etching, field evaporation, and cleaning procedure which regularly yields stable W tips which produce atomic resolution on $\mathrm{Si}(7 \times 7)$ surfaces. We will acquire iron metallized AFM tips and develop the modeling procedures to provide an accurate means of measuring topographical features (eg. $100 \mathrm{~nm}$ linewidths or $1 \mathrm{~nm}$ step heights) in Si. The primary tools for direct tip characterization will be the FIFEM for 1 to $100 \mathrm{~nm}$ radii tips, and SEM analysis for larger tip features. We will determine which new methods (eg. TEM) can be developed to enhance the overlap region of these techniques.

A similar approach for sample preparation will be the general development of in-situ processing techniques but concentrate on the reproducible production of $\mathrm{Si}(7 \times 7)$ surfaces and $\mathrm{Si}(111)$ step and terrace structures. The use of these cananonical surfaces will enable us to delineate physical/chemical interactions between tip and specimen from pure geometrical interactions. In non-UHV environments, we will utilize the sample processing techniques and transfer vessel of the Controlled Ambient Facility (CAF). The second phase of sample preparation (longer term) is the development of in-situ stabilized surfaces which can be transferred to other measurement instruments. As a part of this phase, we will develop $\mathrm{Si}$ (111) linewidth features which have been etched and passivated, then stabilized by in-situ oxidation and measured with the UHV STM followed by subsequent measurement with mcubed and other collaborators. 
FY 94 Accomplishments: New Start

\section{FY 95 Plans:}

- Complete the design, construction, and implementation of the FIFEM in the UHV STM.

- Develop techniques in the UHV Prep Chamber for preparation of atomically ordered surfaces. These surfaces should have routinely achievable long range atomic order.

- Pursue the SPM tip modeling work, develop software for surface reconstruction given direct tip geometry and images, and facilitate easy data exchange between the acquisition systems and the computer modeling facility. Combine the experimental results with the modeling results and prepare a comprehensive summary report.

- Use SPM tip development and modeling interactively with the CAF. The CAF will provide sample preparation procedures and the Tip project will provide tip characterization. The results will be the correlation of tip performance with feature characteristics.

- Contingent on the procurement of the SEM/AFM instrumentation, additional feedback of AFM/STM tip performance by direct monitoring of tip stability by the SEM. SEM analysis of the probe tips, with or without the AFM present in the system.

\begin{tabular}{|c|c|c|c|c|c|}
\hline $\begin{array}{l}\text { SPM TIP PREPARATION } \\
\text { AND CHARACTERIZATION }\end{array}$ & 95 & 96 & 97 & 98 & 99 \\
\hline \multicolumn{6}{|l|}{$\begin{array}{l}\text { Complete construction and testing of the UHV FIFEM. } \\
\text { Implement modeling techniques which use the FIFEM } \\
\text { results to give direct geometrical characterization of SPM } \\
\text { tips [STRS] }\end{array}$} \\
\hline \multicolumn{6}{|l|}{$\begin{array}{l}\text { Develop techniques for controllable in-situ field } \\
\text { evaporation and ambient etching SPM tip preparation } \\
\text { [STRS] }\end{array}$} \\
\hline \multicolumn{6}{|l|}{$\begin{array}{l}\text { Prepare atomic artifacts, consistent with other PED } \\
\text { nanoscale projects, for tip characterization. Develop the } \\
\text { techniques necessary to stabilize these canonically } \\
\text { ordered, UHV prepared surfaces so they can be } \\
\text { transferred to other measurement facilities (m-cubed, } \\
\text { SEM, CAFM etc.) [STRS] }\end{array}$} \\
\hline \multicolumn{6}{|l|}{$\begin{array}{l}\text { Develop modeling techniques which yield upper and lower } \\
\text { bounds on tip sizes directly from imaging and compare } \\
\text { these results to geometrical sizes determined from FIFEM } \\
\text { and SEM. Improve the modeling capabilities as required } \\
\text { by experimental feedback [STRS] }\end{array}$} \\
\hline $\begin{array}{l}\text { Advance SEM measurement capabilities in coordination } \\
\text { with TEM and FIFEM to give accurate characterization of } \\
\text { SPM tip properties [STRS] }\end{array}$ & & & & & \\
\hline
\end{tabular}




\begin{tabular}{|l|l|l|l|l|l||}
\hline $\begin{array}{l}\text { SPM TIP PREPARATION } \\
\text { AND CHARACTERIZATION }\end{array}$ & & & & \\
\hline $\begin{array}{l}\text { Measure nanometer-scale, topographically defined } \\
\text { features with tips which have been well characterized, and } \\
\text { obtain dimensionally accurate measurements of the } \\
\text { features [STRS] }\end{array}$ & 98 & 96 & 97 & 98 & 99 \\
\hline $\begin{array}{l}\text { Design and certify standards for tip characterization based } \\
\text { on the results of the preceding experiments and } \\
\text { simulations [STRS, SRM] }\end{array}$ & & & & & \\
\hline $\begin{array}{l}\text { Investigate and develop new techniques for tip } \\
\text { characterization as they become available [STRS] }\end{array}$ & & & & & \\
\hline
\end{tabular}


Staff: (3.2 staff years) T. V. VORBURGER, *E. Marx, *T. B. Renegar, C. K. Rymes, *P. J. Sullivan (GW), J. F. Song

Project Objective and MEL Thrust Supported: To develop and maintain the measurement systems and physical standards that underpin industry's measurements of surface finish and microform, to support industry's efforts to develop national and international documentary standards in this area, and to lead worldwide standardization efforts in selected subareas. Manufacturing Metrology.

Need Addressed: The surface finish affects the function of a wide range of industrial products including mechanical parts, semiconductors, optics, ship hull surfaces, and roadways. The surfaces of these products must be specified and measured for surface finish. Since the surface finish topography of nearly all industrial parts is highly complex, the measurement of surface finish relies on detailed measurements of surface peaks and valleys, and statistical algorithms and sampling procedures to characterize them. NIST calibrations and measurement research are critical to maintain an accurate national measurement system for surface finish as are NIST contributions to standardization efforts to derive mutually agreeable and meaningful measurement results. An important part of this picture is accurate calibration of critical surface features including step height for the semiconductor industry and Rockwell indenter shape for the metals industry. The surface finish affects the operation of components in the $\$ 170$ billion auto industry (U.S.) and the $\$ 93$ billion aerospace industry (U.S.) as well as other mechanical systems. It figures in the manufacture of $\$ 85$ billion worth of integrated circuits (worldwide) and it affects the function of several $\$$ billion of optical components. Rockwell hardness is used as a materials characterization technique for a large fraction of $\$ 75$ billion worth of metal products (U.S.).

Technical Approach: We primarily use stylus-type profiling instruments to perform the calibrations of standards and direct tests of industrial components. These profiling instruments are calibrated with master artifacts calibrated by optical interferometry. As an example of our capabilities, the $2 \sigma$ uncertainty for our step height calibration is as small as $\pm 0.5 \mathrm{~nm}$ depending on the step height being calibrated. Using new techniques we are continuously upgrading either the hardware and software of these instruments or the calibration of our master artifacts or producing new standard reference materials (SRMs). We do these things to improve the accuracy, automation, and flexibility of our instruments and to meet new customer requirements. We also explore the use of light scattering as an alternative technique to profiling for characterizing the finish of certain types of components. During FY 95, our emphasis will be to develop surface-profile data analysis software that uses digital filtration to be consistent with ISO standards. We will also complete the documentation of our system for characterizing the tip geometry of hardness indenters in order to institute it as a calibration service.

\section{FY 94 Accomplishments:}

- Completed development of a system to measure the geometry of Rockwell C hardness indenters including the uncertainty analysis and prototype calibration reports. The $2 \sigma$ uncertainty in our measurement of the $200 \mu \mathrm{m}$ indenter tip radius is approximately $\pm 0.4 \mu \mathrm{m}$, by far the best in the world.

- Presented two talks on hardness indenter measurement at international conferences and published the associated papers for the proceedings.

- Completed the measurements and quality control checks for the certification of SRM 2073a, the second issue of a sinusoidal roughness standard with $3 \mu \mathrm{m}$ roughness average and $100 \mu \mathrm{m}$ spatial wavelength.

- Coordinated the completion of the draft of a set of nine standards for surface texture measurement for the American Society of Mechanical Engineers (ASME) Committee B46 on the Classification and Designation of Surface Qualities. 
FY 95 Plans:

- Pursue the approval and public review of the ASME B46 Standards collection.

- Develop a new data acquisition system for surface finish calibrations that includes digital, phase corrected filters in the software; perform the first surface finish calibration with the new system.

- Submit all documentation required for the institution of a new calibration service for hardness indenters.

- Complete the analysis and certification of SRM 2073a (uncertainty in the measured roughness to be approximately $2 \%-2 \sigma$ ).

- Complete a study for the Ballistic Missile Defense (BMD) Office on the requirements of optics metrology for BMD systems.

- Complete a study on the calculation of light scattered from a rough surface for an ongoing ATP Project being carried out by the Physics Optics Corporation.

- Improve the turnaround time of the surface finish and step height calibration service to 60 days.

\begin{tabular}{|c|c|c|c|c|c|}
\hline $\begin{array}{l}\text { SURFACE FINISH } \\
\text { AND MICROFORM MEASUREMENTS }\end{array}$ & 95 & 95 & 97 & 97 & 99 \\
\hline \multicolumn{6}{|l|}{$\begin{array}{l}\text { Initiate and complete the measurements and certification } \\
\text { of SRM } 2071 \mathrm{a} \text {, sinusoidal roughness specimen with } \\
0.3 \mu \mathrm{m} \text { roughness and } 100 \mu \mathrm{m} \text { spatial wavelength } \\
\text { [OSRM, STRS] }\end{array}$} \\
\hline \multicolumn{6}{|l|}{$\begin{array}{l}\text { Perform the first calibrations of Rockwell C hardness } \\
\text { indenters under the new calibration service [Calibration } \\
\text { fees] }\end{array}$} \\
\hline \multicolumn{6}{|l|}{$\begin{array}{l}\text { Complete the integration of a y-axis table into the } \\
\text { calibration system for surface roughness SRMs in order to } \\
\text { fully automate the surface sampling of these } \\
\text { measurements [STRS] }\end{array}$} \\
\hline \multicolumn{6}{|l|}{$\begin{array}{l}\text { Spearhead the development of a new international } \\
\text { standard for hardness that will be based on fundamental } \\
\text { metrology rather than hardness block intercomparisons } \\
\text { [STRS] }\end{array}$} \\
\hline \multicolumn{6}{|l|}{$\begin{array}{l}\text { Edit the ASME B46 Standards collection as required } \\
\text { preparatory to final publication [STRS] }\end{array}$} \\
\hline \multicolumn{6}{|l|}{$\begin{array}{l}\text { Develop and test a new hardness indenter calibration } \\
\text { system using optical techniques [STRS] }\end{array}$} \\
\hline $\begin{array}{l}\text { Continuously improve the accuracy and turnaround of the } \\
\text { existing surface finish and step height calibration service } \\
\text { [Calibration fees] }\end{array}$ & & & & & \\
\hline
\end{tabular}


Staff: (0.66 staff years) ${ }^{*}$ JAMES POTZICK, *Rick Silver, *Leon Carroll

Project Objective and MEL Thrust Supported: To complete construction and qualification of the NIST Scanning UV Microscope. Manufacturing Metrology.

Need Addressed: NIST Photomask Linewidth SRMs are the only traceable linewidth standards issued by NIST at this time. They are used worldwide to calibrate photomask metrology tools, and by the scanning probe microscope community. Present calibration uncertainty and linewidth range fail to meet industry needs in calibration accuracy and linewidth range.

Technical Approach: The present green-light optical calibration system is incapable of meeting these needs. The UV microscope is intended to replace that system. Some of the features of the UV instrument are: operation with UV as well as visible light sources to improve smallest measurable linewidth to $0.25 \mu \mathrm{m}$; structural design based on a Stewart platform for improved stability and lower vibration; use of a commercial computer-controlled $\mathrm{dc}$ motor/leadscrew scanning stage and $\mathrm{z}$-axis coarse focusing actuators for less vibration, improved stage motion control, longer scan range, more accurate feature positioning, and wider focus range; inclusion of a UV CID camera image monitor; replacement of the (former) slit aperture with a pinhole sampling aperture for raster scanning (instead of 1-dimension scanning).

Reduce calibration uncertainty by measuring in the UV where chrome is less transparent (and where the photomask will be used), and by reducing vibration. Use the longer scan range for calibrating the Optical Microscope Magnification Standard (new SRM). The pinhole raster scan will allow measuring tilt (wit measurement axis), taper, and curvature of photomask lines.

A successor to SRM 473 Photomask Linewidth Standard is planned, extending the linewidth range to $0.25 \mu \mathrm{m}$. There has been discussion of 1:1 steppers at $248 \mathrm{~nm}$ or $193 \mathrm{~nm}$ illumination, where this linewidth range will be needed, and all of our customers queried have indicated a desire for $0.25 \mu \mathrm{m}$ standard.

Extend the project to allow acquisition of through-focus aerial image data for comparison with modeling results.

\section{FY 94 Accomplishments:}

- Completed basic structure, illumination optics completed (except possibly for more intense UV source), imaging optics and alignment nearly completed.

\section{FY 95 Plans:}

- Obtain high resolution low noise UV and green light raster traces and compare.

- Install Z-axis position and tilt transducers and interface; install computer controlled coarse- and fine-focus.

- Prepare comprehensive computer flow chart for SRM calibrations.

- Write calibration program.

- Compare linewidth measurements on new and old systems; estimate uncertainty. 


\begin{tabular}{|c|c|c|c|c|c|}
\hline ULTRAVIOLET MICROSCOPE & 95 & 96 & 97 & 98 & 99 \\
\hline \multicolumn{6}{|l|}{$\begin{array}{l}\text { Obtain data necessary to characterize performance of } \\
\text { microscope and estimate uncertainty [STRS \& OMP] }\end{array}$} \\
\hline \multicolumn{6}{|l|}{$\begin{array}{l}\text { Develop and execute a plan for making transition from } \\
\text { performing photomask SRM calibrations on green-light } \\
\text { system to UV microscope [STRS \& OSRM] }\end{array}$} \\
\hline \multicolumn{6}{|l|}{$\begin{array}{l}\text { Adapt system to aerial image measurements and compare } \\
\text { with Spectel's simulations [STRS \& OMP] }\end{array}$} \\
\hline \multicolumn{6}{|l|}{$\begin{array}{l}\text { Conduct measurements for applications as they arise } \\
\text { [STRS] }\end{array}$} \\
\hline $\begin{array}{l}\text { Develop system to full state of operation to conduct } \\
\text { calibrations on Optical Microscope Magnification } \\
\text { Standards over the range of } 1 \text { to } 10,000 \mu \mathrm{m} \text { [STRS \& } \\
\text { OSRM] }\end{array}$ & & & & & \\
\hline
\end{tabular}


Staff: (2.6 staff years) C. J. EVANS, *M. L. McGlauflin, *E. Whitenton, *R. E. Parks (GW), *P. J. Sullivan (GW)

Project Objective and MEL Thrusts Supported: The objective of the project is to develop metrology and manufacturing methods for the production of smooth substrates for very large scale integrated circuits and to allow optimization of in-process chemo-mechanical planarization. Continuously decreasing integrated circuit feature sizes force down the acceptable wafer surface defect size, while productivity concerns are driving up the substrate diameter. Decreasing feature size is also focusing attention on silicon-on-insulator substrates as an alternative to bulk silicon. Manufacturing Metrology.

Need Addressed: Wafers need to be locally flat--over at least the die site--in many IC production processes. In others, particularly chemo-mechanical planarization, productivity may be increased if wafers are globally flat. In all these processes, wafers are mounted on a variety of chucks which can affect local and global flatness. Traceable metrology for flatness over $300 \mathrm{~mm}$ apertures is not available and, according to SEMATECH, is seen by wafer vendors as a fundamental constraint to introduction of $300 \mathrm{~mm}$ wafers. Improved metrology may lead to inherently flatter substrates which will be easier to polish to the required defect levels as wafer size increases. Improved production methods are also needed to bring down the costs of silicon-on-insulator (SOI) substrates. Either silicon or SOI substrates will be the feedstock for the IC industry which is worth $\$ 85$ billion per year.

Technical Approach: NIST work has shown that $10 \mathrm{~nm} 2 \sigma$ uncertainty flatness measurements can be made on $150 \mathrm{~mm}$ diameter substrates using current interferometers. Two routes will be taken to extend that performance: a modified Ritchey-Common configuration will be used on the existing NIST $150 \mathrm{~mm}$ aperture interferometer to extend its range to $300 \mathrm{~mm}$ diameter, with some minor loss of accuracy. In parallel, a new $300 \mathrm{~mm}$ aperture interferometer (XCALIBIR) with target uncertainties of the order of $1 \mathrm{~nm}$ is being developed for a range of applications including flatness (see separate MEL 1995 Project Description "Figure and Finish Metrology for X-ray Optics"). These interferometers will be used to evaluate a variety of chucking concepts, including adaptive chucks.

Given appropriate metrology, increased productivity in both the production of substrates and the in-process planarization steps requires both incremental improvements of current processes and evaluation of novel procedures. New combinations of chemical and mechanical processes will be evaluated for silicon-on-sapphire substrate production. New lap concepts will be evaluated. Use of adaptive chucks in planarization processes will be investigated. Close collaborations will be established with, amongst others, SOI substrate, stepper, and polishing consumables suppliers.

FY 94 Accomplishments: New start

\section{FY 95 Plans:}

- Demonstrate silicon polishing with low cost renewable lap

- Implement modified Ritchey-Common configuration on NIST interferometer

- Demonstrate high stock removal rate, low damage lapping of sapphire substrates

- Evaluate current industry and alternate chuck concepts. 


\begin{tabular}{|c|c|c|c|c|c|}
\hline WAFER FLATNESS & 96 & 96 & 97 & 98 & 99 \\
\hline \multicolumn{6}{|l|}{$\begin{array}{l}\text { Analysis and design for Ritchey-Common (R-C) } \\
\text { configuration [STRS] }\end{array}$} \\
\hline \multicolumn{6}{|l|}{$\begin{array}{l}\text { Procure and commission hardware for } \mathrm{R}-\mathrm{C} \text { configuration } \\
\text { [STRS/DE] }\end{array}$} \\
\hline \multicolumn{6}{|l|}{$\begin{array}{l}\text { Evaluate } 300 \mathrm{~mm} \text { chuck performance using R-C [STRS/ } \\
\text { CRADAs] }\end{array}$} \\
\hline \multicolumn{6}{|l|}{ Commission XCALIBIR as a calibration service [STRS] } \\
\hline \multicolumn{6}{|l|}{ Evaluate chuck concepts [STRS] } \\
\hline \multicolumn{6}{|l|}{$\begin{array}{l}\text { Design, fabricate and test adaptive chucks } \\
\text { [STRS/CRADAs] }\end{array}$} \\
\hline \multicolumn{6}{|l|}{ Perform silicon polishing with novel laps [STRS] } \\
\hline \multicolumn{6}{|l|}{$\begin{array}{l}\text { Perform sapphire polishing process development } \\
\text { [STRS/CRADA] }\end{array}$} \\
\hline $\begin{array}{l}\text { Develop planarization process using adaptive chucks } \\
\text { [STRS/CRADAs] }\end{array}$ & & & & & \\
\hline
\end{tabular}




\section{AUTOMATED \\ PRODUCTION \\ TECHNOLOGY \\ DIVISION}

\section{MISSION:}

Develops and maintains competence in integration of machine tools and robots and develops the interfaces and networks necessary to combine robots and machines into workstations and workstations into manufacturing cells; develops and maintains computer-assisted techniques for generation of computer code necessary for integration of machine tools and robots; develops and maintains competence in the processes and techniques necessary for manufacturing high accuracy parts; maintains competence in mass measurements, engineering measurements, and sensors, both static and dynamic, of force and force-related quantities, and other parameters required by the discrete parts industry; and with the nature of the measurement process and the transducers as well as the development, characterization, and calibration of transducers used in discrete parts manufacturing. 
Staff: $(2.6$ staff years $) *$ D. Eitzen, B. PAYNE, *D. Evans, ${ }^{*}$ C. Shoemaker

Project Objective and MEL Thrusts Supported: To provide US industry with the best possible measurement services in dynamic motion (vibration) metrology that industry needs and demands, to remain the recognized top of the traceability chain in sinusoidal and transient acceleration. To assist in applying this measurement capability to solve manufacturing needs such as accurate, fast actuator design. To provide special measurement expertise required by industry such as the evaluation of micromachined accelerometers. To assist US sensor manufacturers to build sensor test platforms for product development. To improve the realization and delivery of services for acceleration measurement. To harmonize national and international standards on accelerometer calibration and vibration measurement. Manufacturing Metrology.

Need Addressed: Through its physical measurement services, special measurements, consulting, and standards work (most notably committees of ASA and IEC) this vibration project impacts a very broad spectrum of manufacturing and production industries. Vibration measurements are used for environmental testing, diagnostics, product development, condition monitoring, process control, servo sensors, global positioning. . . Industry requirements are not being fully met in this metrology area; great accuracies and a wider range of frequencies are required. Some of the economic impacts involve very high volume. In the auto industry, which is but one example of a segment relying heavily on acceleration measurements, many tens of staff years are spent measuring accelerations on vehicles for air bag deployment systems and for ride control for a specific vehicle class. Delivery of systems in vehicles is measured in millions of units. Competitiveness and quality are obvious goals addressed by the project.

Technical Approach: The center of the approach is to maintain and significantly improve the accuracy and range of accelerometer measurement services, to continue our national and international standards committee work, and to undertake selected industrial measurement projects and DoD support when focused directly on our needs. For example the Supershaker work is largely funded by the Air Force (CCG) and is designed to provide us (and the Air Force) with a new generation of shakers for improved accelerometer calibration. One of the technical challenges in improving accelerometer calibrations is to develop "pure" mechanical acceleration; acceleration that is sensibly zero in all but one direction, is purely sinusoidal at a single frequency but adjustable over many orders in frequency and several orders in magnitude. The shakers currently used to try to generate these motions were designed several decades ago and need to be modernized. Another challenge is the accurate measurement of mounting element motion. Special interferometry will be the principle tool for determination of actual element motion and for servo inputs.

\section{FY 94 Accomplishments:}

- Delivered on the order of 80 reports of calibration on over 50 accelerometers.

- Initiated an agreement on intercomparison of shock calibration with NMRL, Japan.

- Completed the first generation Supershaker and began its performance evaluation.

- Supported international trade by training two Guest Researchers in vibration metrology.

FY 95 Plans:

- Complete 60-80 calibration reports on 40-60 accelerometers.

- Complete 1st phase of shock intercomparison with NRLM, Japan.

- Publish paper on initial performance evaluation of 1st generation Supershaker.

- Continue standards committee work in ASA and IEC; maintain chair in vibrations.

- Improve Supershaker performance and begin performance re-evaluation. 


\begin{tabular}{||l|l|l|l|l|l||}
\hline $\begin{array}{l}\text { ACCELERATION AND SHOCK FISCAL YEARS } \\
\text { METROLOGY }\end{array}$ & 95 & 96 & 97 & 98 & 99 \\
\hline $\begin{array}{l}\text { Continue to deliver calibration reports on vibration and shock } \\
\text { accelerometers. [OA] }\end{array}$ & & & & & \\
\hline $\begin{array}{l}\text { Continue standards development work through ASA and IEC; } \\
\text { maintain vibration chair. [STRS] }\end{array}$ & & & & & \\
\hline $\begin{array}{l}\text { Complete the development of prototype No. 1 of the advanced } \\
\text { accelerometer calibrator. [AF, STRS] }\end{array}$ & & & & & \\
\hline $\begin{array}{l}\text { Complete the MEL/CAML research on finite element analysis } \\
\text { model for application to shaker. [STRS, AF] }\end{array}$ & & & & & \\
\hline $\begin{array}{l}\text { Complete development of improved accelerometer calibration } \\
\text { for 2 k-20 kHz. [STRS, AF] }\end{array}$ & & & & & \\
\hline $\begin{array}{l}\text { Complete development of improved/new accelerometer } \\
\text { calibration for 20 k-40 kHz. [STRS] }\end{array}$ & & & & & \\
\hline $\begin{array}{l}\text { Complete development of improved accelerometer calibration } \\
\text { for 3 Hz to 1 kHz. [STRS] }\end{array}$ & & & & & \\
\hline
\end{tabular}


Staff: (1.9 staff years) *D. Eitzen, *D. Evans, V. NEDZELNITSKY, *R. Wagner

Project Objective and MEL Thrusts Supported: To provide US industry with the best possible measurement services for acoustical devices (particularly microphones) that industry needs and demands. To remain the recognized top of the traceability chain in free-field and pressure calibration of microphones. To provide special measurement expertise required by industry in developing revolutionary new sensors such as micro-machined silicon microphones and semiconductor tunneling hydrophones. To improve the realization and delivery of calibration services for acoustical quantities. Industry has been particularly demanding of services at higher frequencies. To harmonize national and international standards on acoustical instrumentation and microphone calibration. Manufacturing Metrology.

Need Addressed: Through its physical measurement services, special measurements, consulting, and standards work (extensive with ASA and IEC) this acoustic metrology project impacts a broad spectrum of US industries and concerns such as acoustic measurements for noise control and abatement, safety and health programs product development acceptance testing, condition monitoring, and object detection. Industry requirements are not being fully met in this metrology area; calibration services at higher frequencies is the most pressing need. Needs for measurements of electromagnetic interference effects on acoustical instrumentation are quickly escalating. Some of the economic impacts are very large. Acoustic measurements of new jet engine noise levels can have multi billion dollar impacts. Acoustic measurements in product development in the auto industry are extensive. National goals in health and safety are also very strongly affected.

Technical Approach: The center of the approach is to maintain and significantly improve the range of acoustical calibrations, to continue the extensive national and international standards committee work (including chairmanships and US delegation head), and rather critical and extensive special measurements for revolutionary sensor technologies. Benchmarking our measurement services is a part of the approach. Modernization and complete characterization of equipment is essential as is development of new measurement algorithms and signal processing techniques.

FY 94 Accomplishments:

- Delivered on the order of 50 calibration reports on a few number of microphones.

- Completed recalibration of NIST microphones by absolute reciprocity.

- Completed $\mathrm{PhD}$ in physics by one project staff

- Completed one invited paper, several invited talks, invited book chapter, and position papers for NAVLAP.

- Supported international trade by two extensive consultations in Thailand, training of two Guest Researchers.

- Completed microphone tests for NPL to diagnose their calibration problems.

- Performed special measurements for Horizon, Inc. and Draper Laboratory on developmental micromachined arrays and for Martin Marietta on a giant developmental towed array.

FY 95 Plans:

- Deliver on the order of 50 calibration reports.

- Continue standards leadership and development work.

- Benchmark $1 / 2$ inch microphone free field reciprocity calibration.

- Demonstrate how NIST microphone calibration data is an order of magnitude closer to model predictions than results of the recent European intercomparison.

- Make measurements on second prototype micromachined sensors for Draper Labs and Horizon, Inc. 
and on semiconductor tunneling hydrophone for NADC.

\begin{tabular}{|c|c|c|c|c|c|}
\hline ACOUSTICAL METROLOGY SERVICES FISCAL YEARS & 95 & 96 & 97 & 98 & 99 \\
\hline $\begin{array}{l}\text { Continue to deliver calibration reports on acoustical } \\
\text { instruments }[O A]\end{array}$ & & & & & \\
\hline $\begin{array}{l}\text { Continue leadership and harmonization of national and } \\
\text { international standards [STRS] }\end{array}$ & & & & & \\
\hline $\begin{array}{l}\text { Make special measurements on revolutionary sensors in } \\
\text { support of industry sensor development }[O A]\end{array}$ & & & & & \\
\hline $\begin{array}{l}\text { Complete development of acoustic calibration service to } \\
\text { double the current frequency range [STRS] }\end{array}$ & & & & & \\
\hline $\begin{array}{l}\text { Develop measurement service for effects of } \\
\text { electromagnetic interference on acoustical instruments } \\
\text { [STRS] }\end{array}$ & & & & & \\
\hline
\end{tabular}


Staff: (3.0 staff years) ${ }^{*}$ W. Crupe, ${ }^{*}$ B. Damazo, ${ }^{*}$. Davis, ${ }^{*}$ A. Donmez, ${ }^{*}$ D. EITZEN, ${ }^{*}$ J. Keller, ${ }^{*}$ R. Schoonover, New Hire

Project Objective and MEL Thrusts Supported: To develop a research competence needed to accommodate, transition, and interface between the artifact mass system and future prescription based on physical constants such as is embodied by EEEL's Watt experiment. The objective of the combined effort of EEEL's Watt experiment and this MEL project is to monitor the stability of Pt-Ir artifacts and eventually replace the mass artifact system, the last remaining fundamental unit defined by an artifact (an artifact with known instability at the highest levels of accuracy), with a prescriptional system based on physical constants. However, such a new system would leave the unit dissemination system even more dependent on air buoyancy corrections. Artifacts in controlled environments must be studied carefully. Manufacturing Metrology.

Need Addressed: The mass unit is fundamental to a broad range of manufacturing and producing industries. Some of the obvious segments include drug manufacturers, instrument manufacturers, and state weight labs. Further, the mass unit is fundamental to the definition derived for both mechanical and electrical metrology. This leads to a potential impact to clientele spanning virtually all manufacturing and technical communities. The unit of mass is the last remaining fundamental unit defined by an artifact, a situation that is at least inelegant. The artifact is also, at the highest levels, unstable in the time frame of months and years due to ad-or absorbed material and in the time frame of decades due to not understood mechanisms. The economic impact is obviously enormous and also includes such issues as engineering metrology, material accountability, equity in trade, and medicine and health. The fundamental issues are national and international.

Technical Approach: The technical strategy is to form a small team with competence in analytical physics, design of experiments, and experimental physics. The first task will be to transfer the detailed analytical and experimental knowledge base in mass measurements, corrections, and realization of the unit; particularly the knowledge base resident (a short time into the future) at NIST and BIPM. One key technical issue to be addressed is the larger correction for air buoyancy resulting from the new unit definition due to the fact that the Watt experiment generates a volumless force which is compared to an artifact with significant volume. This correction is approximately $150 \mathrm{mg}$ for $1 \mathrm{~kg}$ and the residual uncertainty is troublesome. This uncertainty requires that our present capability in the measurement of the density of solid objects and the density of air be significantly improved. This effort requires the use of a pressure chamber for the kilogram comparator so that constant, accurate, selected environments can be used. It also requires the design and use of two artifacts for air density measurement which will result in a direct measurement of air density. Another required improvement to the dissemination system needed to tie the new and artifact systems together is a dedicated system to measure the (weak) magnetic susceptibility of $\mathrm{kg}$ standards and an improved system for determining $\mathrm{kg}$ standard density. An improved understanding of artifact surface phenomena is also required. The other major element of this project is direct support of the Watt experiment itself. This includes newly designed artifacts for the experiment and input to the design of a new Watt balance.

FY 94 Accomplishments: (New start)

\section{FY 95 Plans:}

- Hire new staff member.

- Design and order pressure chamber.

- Recruit R. Davis from BIPM for temporary assignment at NIST.

- Order new balances for density and magnetic effects.

- Publish paper on new mass correction.

Related Developments: Progress on Watt experiment in EEEL and at NPL. 


\begin{tabular}{|c|c|c|c|c|c|}
\hline $\begin{array}{l}\text { ARTIFACT MASS TO WATT } \\
\text { COMPETENCE }\end{array}$ & 95 & 96 & 97 & 98 & 99 \\
\hline \multicolumn{6}{|l|}{$\begin{array}{l}\text { Complete magnetic susceptibility apparatus for measuring } \\
\text { mass standards [STRS] }\end{array}$} \\
\hline \multicolumn{6}{|l|}{$\begin{array}{l}\text { Complete apparatus for improved measurement of density } \\
\text { of } 1 \mathrm{~kg} \text { mass standards [STRS] }\end{array}$} \\
\hline \multicolumn{6}{|l|}{$\begin{array}{l}\text { Complete methodology and devices for direct } \\
\text { measurement of air density for mass correction [STRS] }\end{array}$} \\
\hline \multicolumn{6}{|l|}{ Complete mechanical input to new Watt balance [STRS] } \\
\hline \multicolumn{6}{|l|}{ Determine Watt artifact's mass to 0.01 ppm [STRS] } \\
\hline \multicolumn{6}{|l|}{$\begin{array}{l}\text { Complete practical understanding of } \mathrm{kg} \text { mass standard } \\
\text { stability [STRS] }\end{array}$} \\
\hline $\begin{array}{l}\text { Close loop on US prototype } 20 \text { mass standard and Watt to } \\
\text { within } 3 \text { pp [STRS] }\end{array}$ & & & & & \\
\hline
\end{tabular}


Staff: (6.1 staff years) *CHARLES YANG, *Brad Damazo, *Bob Gavin, *Louis Marchetti, *Lisa Fronczek, *Kang Lee, *Mahn Hahn, *Michael Huff, *Toni Savoy

Project Objective and MEL Thrust Supported: The objective of the program is to reduce life-cycle costs associated with machine tool controllers by defining an open, public domain specification and programming interfaces for controller components. The specification aims to stimulate third-party vendors to develop applications to improve machine tool performance, throughput, usability, and integrability while reducing cost. Intelligent Machines and Systems, Manufacturing Process and Equipment

Need Addressed: A strong, vigorous machine tool industry is critical to the U.S. manufacturing competitiveness in the international marketplace and to national security. The controller is a key component of the machine tool, since it determines the machine tool's capability. Traditional controllers have a number of disadvantages, such as long learning curve, lack of connectivity and integrability with sensors and widely available networks, and single-source supply for components. These difficulties result in high direct operating-costs and switching costs for machine tool users, and hinder the already arduous climb to agile, world class manufacturing. Open architecture technology has been identified as a solution to these problems by a variety of industrial sources, including the Partnership for Next Generation Vehicle (PNGV). With the needed specifications and programming interfaces for open controllers in place, third-party vendors can develop applications and components to enhance machine tool productivity. Learning curve can be drastically reduced by operator interfaces tailored to user familiarity. Programming incompatibility can be eliminated by modular, portable program interpreters. Integration can be facilitated through use of widely available platforms such as personal computers as hosts to controllers. Maintainability will be improved by multi-sourced components. Component costs can be reduced through leveraging volume across multiple industries.

Technical Approach: Retrofit and High-End EMCs, aimed toward their respective market segments, will be built to demonstrate EMC concepts. Implementations will include a variety of machine tools (e.g., mills, lathes, grinders) to validate interface generality. Sensor-based applications and off-the-shelf productivity enhancement applications will be implemented on the Retrofit EMC. Candidates from industry and government will be selected to serve as beta sites to provide production testing. Working systems will be developed at NIST prior to transfer to beta sites. A consortium will be established to facilitate collaboration with machine tool users, system vendors, and component vendors. The consortium input will guide EMC project goals.

FY94 Accomplishments:

- A Retrofit EMC on vertical milling machine. Research aimed toward machine enhancements and factory integration was conducted. Demonstrated integration of off-the-shelf, third-party CAD/CAM, shop management, and video applications. Off-the-shelf network applications were also demonstrated.

- Established the EMC Consortium, an industry consortium to guide the project goals for the EMC. Identified definition of Application Programming Interface as the key task for NIST.

- Collaborated with Motion Component Vendor to transfer enhanced controller technology to industry.

FY95 Plans:

- An EMC will be retrofitted to a 4-axis horizontal milling machine at GM Powertrain in Pontiac, MI. A customizable, Windows-based graphical user interface, interchangeable motion components, and sophisticated diagnostic module will be implemented. The implementation will allow switching control between the original controller and the EMC to demonstrate performance improvements. GM and NIST will evaluate EMC API for openness, modularity, and flexibility.

- A Retrofit EMC will be implemented on a turning center to verify EMC concepts. The EMC will be 
transferred to Watervliet Arsenal for production testing.

- Retrofit EMC will be transferred to Defense General Supply Center (DGSC) in Mechanicsburg, PA. DGSC will retrofit EMC at DoD sites.

- A Retrofit EMC will be implemented in a milling machine at McDonnell Douglas, St. Louis. High-speed milling will be implemented to demonstrate performance improvements. Factory networking will be implemented to demonstrate integration.

- A Retrofit EMC will be implemented at Portsmouth Naval Shipyard as part of production feasibility study. 
Staff: (6 staff years) *S. YANIV, ${ }^{*}$ T. Bartel, R. Peterson, R. Seifarth, ${ }^{*} \mathrm{~K}$. Yee, ${ }^{*}$ S. Ho, ${ }^{*}$ B. Crupe, ${ }^{*}$ C. Shoemaker

Project Objective and MEL Thrust Supported: To provide U.S. manufacturing industry, academia, Federal and state governments with the high-accuracy force measurement services that they need to remain competitive in both the national and world markets. To remain the top of the traceability chain in force measurements. To provide the National Conference of Weight and Measures, and the NIST Office of Weight and Measures with the technical support they need in legal metrology. To assure the compatibility of U.S. force metrology standards with those of other nations and of international standards with those of the United States. To improve the realization and delivery of services to industry. Manufacturing Metrology.

Need Addressed: Through its force measurement services, special tests, consulting and standards work (e.g., ASTM, OIML), the project supports the broadest possible spectrum of manufacturing industries, including aerospace, automotive, nuclear, chemical, electrical, and other industries. The project provides the means for the users of the force metrology program to assure traceability to national and international standards and contributes to quality and safety in manufacturing. In addition, through this project NIST performs as the technical arm of the National Conference of Weight and Measures for the National Type Evaluation Program for Load Cells, and provides industry a means to compete in international markets by demonstrating compliance with the requirements set forth by the Organization Internationale de Metrologie Legale (OIML) in R60-Load Cells.

Technical Approach: The force group plans to modernize the delivery of its services, upgrade present services where required, and refurbish the deadweight machines or primary national force standards. In addition, the group will continue its work with national and international standards groups to insure that barriers to world markets are minimized for U.S. manufacturers. To that end the group will continue to benchmark its capabilities against the national laboratories of other nations, and serve as the Technical Arm for both the National Conference of Weight and Measures and the NIST Office of Weight and Measures in the area of load cell testing. In this capacity, the project provides industry with the mechanism for obtaining Certificate of Conformance based upon environmental testing of load cells, and provides the intercomparison data required by the Office of Weight and Measures for negotiating mutual recognitions of test results agreements between the National Laboratories of various nations and NIST.

\section{FY 94 Accomplishments:}

- Performed over 1800 measurements for industry and delivered over 150 calibration reports.

- Performed intercomparison of load cell testing ( OIML R60) with a highly respected National Laboratory of a European Common Market country.

- Completed the development of hardware and software required to calibrate multiple load cell bridges simultaneously.

- Completed experimental study of load cell creep.

- Provided numerous consultations to U.S. manufacturers and other users of the service.

- Completion of Master degree by one staff member.

\section{FY 95 Plans:}

- Refurbish $25,000 \mathrm{lbf}$ deadweight machine

- Publish paper on load cell creep

- Continue participation in national and international standards

- Complete several hundred force measurements and prepare calibration reports in accurate timely fashion. 
- Provide consultations as needed to users of the force calibration and measurement service as needed.

- $\quad$ Report the results of intercomparison of OILM R60 load cell testing.

Related Developments: ISO activities in quality management (e.g., ISO 9000 standards, IEC Guide 25).

\begin{tabular}{|l|l|l|l|l|l|l||}
\hline FORCE METROLOGY FISCAL YEARS & 95 & 95 & 97 & 98 & 99 \\
\hline Refurbish 25,000 lbf deadweight machine [STRS] & & & & & \\
\hline Report results of OILM R60 intercomparison [STRS] & & & & & \\
\hline $\begin{array}{l}\text { Automate data acquisition and analysis for calibrations in } \\
\text { the 12 Mlb hydraulic testing machine [STRS, OPMS] }\end{array}$ & & & & & \\
\hline Refurbish 112,000 lbf deadweight machine [STRS] & & & & & \\
\hline Refurbish 300,000 lbf deadweight machine [STRS] & & & & & \\
\hline Refurbish 1,000,000 Ibf deadweight machine [STRS] & & & & & \\
\hline $\begin{array}{l}\text { Continue participation in national and international } \\
\text { standards work [STRS] }\end{array}$ & & & & & \\
\hline
\end{tabular}


Staff: (2.2 staff years) E. BURNETT, ${ }^{*}$ V. Nedzelnitsky, ${ }^{*}$ D. Eitzen, ${ }^{*}$ C. Shoemaker, ${ }^{*}$ D. Evans, ${ }^{*}$. Wagner

Project Objective and MEL Thrusts Supported: To provide the Department of Veterans Affairs (VA), (and the public, with evaluated data on hearing aids so that a rational match can be made between patient needs and available aids. To develop complex test methodologies, often extremely software intensive, necessary to test ever more complex sophisticated hearing aids. To provide the necessary standards support for hearing aids. To assist hearing aid manufacturers in the development of better aids. To communicate the results of these tests in a clear and open way. To provide acoustic and related technical support as needed by the VA and their suppliers. Manufacturing Metrology.

Need Addressed: Through special facilities and instrumentation, anthropomorphs, complex measurement algorithms, extensive software development, and sophisticated signal processing this hearing aid metrology project fulfills the health, information and support needs of the VA and supports the industrial development of improved aids by manufacturers. It also provides the public with useful needed health aid information. The VA is the largest purchaser of hearing aids and the need for test results for a rational aid selection criteria (developed by VA) is great.

Technical Approach: The center of the approach is the development of special facilities, instrumentation, complex measurement algorithms, software, and signal processing to provide valid measurements on diverse and constantly changing hearing aid devices. The approach also includes standards support for hearing aid technology, consulting with manufacturers, and technical support for the VA on measurement protocols and support for equipment purchases, e.g., audiology booths.

\section{FY 94 Accomplishments:}

- Completed development of new radically different test procedures for new generation of hearing aids.

- Evaluated several dozen new custom and "multi-focus" hearing aids.

- Completed report to the VA on shielding requirements and test procedures for hearing booths required for VA procurement.

- Completed technical report to VA on new procedures and evaluation results on hearing aids.

- Continued standards support work for hearing aid technology.

- Continued support for hearing aid manufacturers.

\section{FY 95 Plans:}

- Complete development of new radically different test procedures for new generation of hearing aids.

- Evaluate several dozen new hearing aids supplied by VA.

- Complete technical report to VA on new procedures and evaluation results on hearing aids.

- Continue standards support work for hearing aid technology.

- Continue support for hearing aid manufacturers. 


\begin{tabular}{|c|c|c|c|c|c|}
\hline HEARING AID METROLOGY & 95 & 96 & 97 & 98 & 99 \\
\hline \multicolumn{6}{|l|}{$\begin{array}{l}\text { Complete development of new radically different test } \\
\text { procedures for new generation of hearing aids [OA] }\end{array}$} \\
\hline \multicolumn{6}{|l|}{$\begin{array}{l}\text { Evaluate several dozen new hearing aids per year as } \\
\text { supplied by VA [OA] }\end{array}$} \\
\hline \multicolumn{6}{|l|}{$\begin{array}{l}\text { Complete technical report to VA on new procedures and } \\
\text { evaluation results on hearing aids }[O A]\end{array}$} \\
\hline \multicolumn{6}{|l|}{$\begin{array}{l}\text { Continue standards support work for hearing aid } \\
\text { technology }[O A]\end{array}$} \\
\hline \multicolumn{6}{|l|}{ Continue support for hearing aid manufacturers [OA] } \\
\hline $\begin{array}{l}\text { Provide needed acoustic consulting to VA and hearing aid } \\
\text { manufacturers }[O A]\end{array}$ & & & & & \\
\hline
\end{tabular}


Project Objective and MEL Thrusts Supported: To provide U.S. industry with the highest-accuracy services in mass metrology that industry needs and demands, to remain the recognized top of the traceability chain in mass. To assist in the realization of derived units such as force and pressure. To provide special measurement services required by industry such as solid density measurements, dead weight measurements, cask measurements, etc. To assure the compatibility of U.S. mass measurement with those of other nations and of international standards with those of the U.S. To improve the realization and delivery of mass measurement services and to conduct the applied research necessary to achieve these services. Manufacturing Metrology.

Need Addressed: The mass unit is fundamental to a broad range of manufacturing and producing industries. some of the obvious segments include drug manufacturers, instrument manufacturers, power companies, and state weight labs. Further, the mass unit is fundamental to the definition of derived for both mechanical and electrical metrology. This leads to a potential impact to clientele spanning virtually all manufacturing and technical communities. The economic impact is obviously enormous and also includes such issues as engineering metrology, material accountability, equity in trade, and medicine and health. The fundamental issues are national and international.

Technical Approach: The essential technical approach is to maintain and improve a core competence in the realization and dissemination of the unit of mass, in the measurement of density (solid, liquid, and air) and in the measurements leading to the realization of derived units such as force and pressure. In addition considerable effort must be performed with exacting accuracy and great care and the entire chain of realization of the unit and of the check and working standards must be maintained. This includes international benchmarking of our mass artifacts. The publication of papers on mass metrology is an important part of this strategy.

\section{FY 94 Accomplishments:}

- Prepared on the order of a hundred calibration reports on hundreds of weights.

- Completed recertification of the US prototype (20) kilogram (U.S. basic mass standard).

- Completed two projects for OSRM on density.

- Published five papers, 6 talks, and conducted three foreign workshops on mass measurement.

\section{FY 95 Plans:}

- Prepare on the order of a hundred reports on the calibration of hundreds of weights.

- Conduct special tests on dead weight machine components and pressure piston gage weights.

- Conduct special density measurements for industry and OSRM.

- Offer improved service for calibration of $1 \mathrm{~kg}$ masses about 4 times more accurate than previously offered.

- Through BIPM, begin benchmarking $1 \mathrm{~kg}$ mass through international intercomparison of $1 \mathrm{~kg}$ stainless steel standards. 


\begin{tabular}{|c|c|c|c|c|c|}
\hline MASS ARTIFACT METROLOGY & 95 & 96 & 97 & 98 & 99 \\
\hline \multicolumn{6}{|l|}{$\begin{array}{l}\text { Prepare on the order of a hundred reports on the } \\
\text { calibration of hundreds of weights [OA] }\end{array}$} \\
\hline \multirow{2}{*}{\multicolumn{6}{|c|}{$\begin{array}{l}\text { Publish papers on new developments in dissemination of } \\
\text { the mass unit [STRS] }\end{array}$}} \\
\hline & & & & & \\
\hline \multicolumn{6}{|l|}{$\begin{array}{l}\text { Participate in international standards work on mass } \\
\text { [STRS] }\end{array}$} \\
\hline \multicolumn{6}{|l|}{$\begin{array}{l}\text { Develop improved measurement service for weights } 100 \\
\mathrm{~g}-1 \mathrm{~kg} \text { [STRS] }\end{array}$} \\
\hline \multicolumn{6}{|l|}{$\begin{array}{l}\text { Develop improved measurement service } 1 \mathrm{~kg}-20 \mathrm{~kg} \\
\text { [STRS] }\end{array}$} \\
\hline \multicolumn{6}{|l|}{$\begin{array}{l}\text { Develop improved measurement service } 1 \mathrm{mg}-100 \mathrm{~g} \\
\text { [STRS] }\end{array}$} \\
\hline \multicolumn{6}{|l|}{$\begin{array}{l}\text { Screen customer } 1 \mathrm{~kg} \text { mass standards for magnetic } \\
\text { effects }[\mathrm{OA}]\end{array}$} \\
\hline \multicolumn{6}{|l|}{$\begin{array}{l}\text { Make improved measurements of density of customers } 1 \\
\mathrm{~kg} \text { mass standards }[\mathrm{OA}]\end{array}$} \\
\hline $\begin{array}{l}\text { Make more accurate direct air density measurements } \\
\text { resulting more accurate mass measurements for } \\
\text { customers } 1 \mathrm{~kg} \text { standards by a factor of } 4 \text { [OA] }\end{array}$ & & & & & \\
\hline
\end{tabular}


Project Objective: Develop the measurement technology necessary to aid industry in assessing and controlling the quality of its newly developed ceramic coatings for metals. Material modeling efforts and mechanical analyses will be complemented and correlated with ultrasonic measurements applicable to on-line process monitoring and control. The effects of porosity on the ceramic elastic moduli and the adherence of plasma-sprayed ceramic to metal substrate will be evaluated. Novel ultrasonic sensors and signature analyses will be developed to acquire the needed material property information. Manufacturing Processes and Equipment.

Need Addressed: The attractive wear and thermal resistance properties of ceramics has led to their development by industry as coating materials on metals for diverse applications, particularly at high temperatures. An especially significant usage is as a thermal barrier in high performance power plants, whether it be for automotive and aircraft engines, or for stationary electric generation units. Caterpillar is interested in coating their diesel engine cylinders. Pratt \& Whitney Aircraft has a program on the generation of nanolayered thermal barrier coatings. One specific material system of generic interest is plasma-sprayed ceramic coatings on steel and nickel-based super alloys, for usage in next-generation turbine blades. As a thermal barrier, a controlled level of porosity is desired. For wear resistance, however, porosity and cracking are disadvantageous. In the case of engine components experiencing large temperature excursions, the vertical micro-cracks ("crazing") which develop actually aid in sustaining the large thermal expansion differential between a ceramic coating and a metal substrate. It is important that the degree of porosity and micro-cracking be able to be evaluated and controlled for specific applications. Therefore, the focus of this work will be to develop a capability for modeling and measuring the level of porosity (and ideally microcracking), and assess its impact on the elasticity of ceramic coatings.

Technical Approach: A three-pronged effort will be made to evaluate and model specific material properties in ceramic coatings. Modeling efforts will address the separate effects of porosity and micro-cracking on the coating elasticity. Ultrasonic pulsed-wave techniques will be used to nondestructively assess the material properties based on back-scattered amplitude, attenuation, and sound velocity measurements. Mechanical tests will include measurements of the elastic modulus, plastic flow, hardness, and critical stress for fracture (toughness). Finally, section microscopy will be applied to assess sample pore distribution and micro-cracking for correlation purposes. The modeling work of Ed Fuller (MSEL) will be drawn on for an algorithm to characterize the microstructure generated in the plasma-spraying process, incorporating the material thermal expansion anisotropy, splat size and morphology, and texture. Finite-element-like codes will be developed to analyze the elasticity of both real and computer-simulated ceramic-on-metal structures, specifically including the effects of porosity and micro-cracking. Theoretical work will also address elastic wave scattering due to internal discontinuities such as pores and cracks. Ultrasonic measurements and analyses will be based on the scattering and propagation rate of pulsed elastic waves. Various techniques will be evaluated, with an emphasis on those that are applicable to on-line testing. MSEL personnel will perform mechanical tests exploiting a nanoindentation capability for material analysis. Instrumented nanoindentation techniques can determine several properties of bulk ceramic materials and coatings, including plastic flow and yielding, elastic modulus, and toughness.

FY94 Accomplishments: This is a new project; accomplishments on related work in a previous project include:

- Applying experimental surface-wave methods to assess ceramic subsurface damage due to the grinding process.

- Interpreting the echo amplitude reflection signals from ground and polished glass to evaluate nearsurface material properties for different grinding conditions. 
FY95 Plans:

- Correlate levels of ceramic porosity with ultrasonic wave amplitude and velocity (a measure of material elasticity).

- Relate echo-amplitude reflection signatures from the ceramic-metal interface to adherence quality between the ceramic and substrate.

- Compare ultrasonic wave speed measurements with model predictions by MSEL based on material morphology.

- Correlate nanoindentation data with ultrasonic data and use as input for enhancing finite-element models.

\begin{tabular}{|c|c|c|c|c|c|}
\hline $\begin{array}{l}\text { MATERIALS ANALYSIS OF CERAMIC COATINGS } \\
\text { ON METAL SUBSTRATES }\end{array}$ & 96 & 96 & 98 & 98 & 99 \\
\hline $\begin{array}{l}\text { Delineate the effects of micro-cracking and porosity on } \\
\text { ultrasonic wave signatures [STRS] }\end{array}$ & & & & & \\
\hline $\begin{array}{l}\text { Apply point source/point detection shcemes to more } \\
\text { effectively generate wave modes not accessible via } \\
\text { planar or focused insonification [STRS] }\end{array}$ & & & & & \\
\hline $\begin{array}{l}\text { Determine the critical model parameters representing the } \\
\text { ceramic morphology which principally impact the material } \\
\text { elastic wave speed [STRS] }\end{array}$ & & & & & \\
\hline $\begin{array}{l}\text { Further develop nanoindentation techniques to } \\
\text { corroborate ultrasonic values of the dynamic elastic } \\
\text { moduli as a function of porosity and microcracking } \\
\text { [STRS] }\end{array}$ & & & & & \\
\hline $\begin{array}{l}\text { Evaluate new sensor technology for generating "leaky" } \\
\text { surface (and/or layer) waves that may be applicable to in- } \\
\text { line process control [STRS] }\end{array}$ & & & & & \\
\hline $\begin{array}{l}\text { Interact with the industrial community and integrate their } \\
\text { inspection needs into the ultrasonic approach for material } \\
\text { quality assessment [STRS] }\end{array}$ & & & & & \\
\hline
\end{tabular}


Staff: (6.0 staff years) *A. DONMEZ, H. Bandy, *B. Damazo, ${ }^{*}$ D. Gilsinn, *M. Hahn, *K. Harper, *M. Kennedy, ${ }^{*}$ L. Marchetti, *N. Wilkin, W. Wyatt, *K. Yee

Project Objective and MEL Thrust Supported: The Precision Machining project fosters the development and implementation of advanced systems, processes, and equipment through the development of the basic infrastructural tools needed to control manufacturing processes, and produce products in a cost-effective and efficient manner. The objective is to develop methods to allow U.S. industry to improve the total control of their manufacturing processes in order to produce quality parts, and products. Manufacturing Processes and Equipment, Manufacturing Metrology.

Need Addressed: To compete effectively in global markets, U.S. industry needs to manufacture high precision products reliably, predictably and at competitive cost. This requires a high degree of control over the machining process, including the machines, tooling, and the inspection systems used in manufacturing. This "total control" strategy necessitates the characterization of all the elements involved in the machining process. This characterization process is time-consuming and can involve a few months to a year depending upon the machine features and the level of precision. The machining process, therefore, needs to be understood better than ever and all the factors influencing the precision of the product have to be taken into account. This project supports a broad spectrum of manufacturing industries, including the machine tool, aerospace, automotive and electronics industries.

Technical Approach: In collaboration with U.S. industry and the ATP, the precision machining project will investigate various components of the precision machining process and concentrate on methods to characterize machine tools and their interactions with workpieces. These are being investigated as follows: 1) To insure that APTD addresses the most urgent needs of industry, a series of industrial workshops will be sponsored. Findings from these workshops will be utilized to direct and refine the project long-term plan. 2) Apply the thermal characterization and error compensation technique to determine how to modify them in order to reduce the time consuming portions. 3) To address the time-consuming problem of characterization fast ball-bar and grid plate techniques are being developed. 4) Pre-process and Post-process information is being incorporated into algorithms so as to minimize the Pre-process characterization. 5) Preliminary algorithms to utilize Post-process data for closed loop control are currently being developed.

\section{FY94 Accomplishments:}

- First Precision Machining Workshop held.

- Characterization and thermal modeling of a piston turning machine accomplished.

- Real-time error compensation software for machine thermal errors developed and implemented on a piston turning machine.

- Cutting tests performed on a piston turning machine to verify machine thermal compensation models achieved $80 \%$ reduction in piston size variations machined over a period of a day.

- A restricted NISTIR was published describing the thermal compensation methodology in order to help industrial partners carry out similar modeling and error compensation.

- Designed and developed a new air bearing high speed linear actuator for piston turning applications.

- Based on our earlier work on real-time error compensation and our guidance with the ATP grant, a small company in Detroit (SMS) announced a thermally compensated turning machine in the last machine tool show in Chicago, a first in its class.

- Developed initial Post-process analysis algorithms and published a paper describing the techniques.

\section{FY95 Plans:}

- Evaluate the robustness of the piston turning machine error compensator methodology and software 
developed in FY94 by applying it to other piston turning machines built by Giddings \& Lewis.

- Develop tuned error compensation software that can be used for a series of machines in one product line.

- Evaluate ball bars and 2-D grid plates for fast characterization of machine tools.

- Fine tune the current Process-Intermittent software to incorporate descriptions of machined surfaces using splines or function fitting with bases functions such as Plus functions or B-splines for real-time compensation of process related errors in machining.

- Demonstrate the improved capability of Process-Intermittent control algorithms.

- Integrate the newly acquired CMM into the Post-Process control loop.

- Continue the leadership in the ISO to develop and implement the evaluation of thermal effects in machine tools as well as development of other machine tool metrology related standards.

- Continue participation in the development of performance evaluation standards for turning centers within the ASME organization.

\begin{tabular}{|c|c|c|c|c|c|}
\hline PRECISION MACHINING & 96 & 96 & 97 & 96 & 99 \\
\hline $\begin{array}{l}\text { Develop fast machine characterization techniques to } \\
\text { increase the cost effectiveness of real-time accuracy } \\
\text { enhancement using predictive machine tool models } \\
\text { [STRS, OA] }\end{array}$ & & & & & \\
\hline $\begin{array}{l}\text { Evaluate the robustness of fast characterization } \\
\text { techniques [STRS, OA] }\end{array}$ & & & & & \\
\hline $\begin{array}{l}\text { Develop process control techniques using Neural } \\
\text { Networks and expert systems models for machining } \\
\text { processes [STRS] }\end{array}$ & & & & & \\
\hline $\begin{array}{l}\text { Demonstrate closed loop machining based on the multi } \\
\text { loop control architecture defined during the earlier QIA } \\
\text { project to increase the quality of discrete part } \\
\text { manufacturing processes [STRS, OA] }\end{array}$ & & & & & \\
\hline $\begin{array}{l}\text { Extend the closed loop machining techniques and } \\
\text { algorithms to cylindrical grinding for the use of the } \\
\text { automotive industry. [STRS, OA] }\end{array}$ & & & & & \\
\hline $\begin{array}{l}\text { Develop a high speed machining testbed to investigate } \\
\text { high speed machining performance and increase the } \\
\text { accuracy of high speed machining for the aerospace } \\
\text { industry [STRS] }\end{array}$ & & & & & \\
\hline $\begin{array}{l}\text { Support the manufacturing industry infrastructure by } \\
\text { developing improved methods for machine tool metrology, } \\
\text { standards for evaluation of performance of various types } \\
\text { of machine tools and other manufacturing equipment } \\
\text { [STRS] }\end{array}$ & & & & & \\
\hline $\begin{array}{l}\text { Collaborate with industry in the development of an ISO } \\
\text { standard on the evaluation of thermal effects of machine } \\
\text { tools [STRS] }\end{array}$ & & & & & \\
\hline
\end{tabular}




\begin{tabular}{|l|l|l|l|l|l|l|}
\hline PRECISION MACHINING FISCAL YEARS & 95 & 96 & 97 & 98 & 99 \\
\hline $\begin{array}{l}\text { Collaborate with industry to develop a national standard } \\
\text { for the performance evaluation of CNC turning centers } \\
\text { [STRS] }\end{array}$ & & & & & \\
\hline $\begin{array}{l}\text { Investigate the use of advanced sensors in machining } \\
\text { applications and their integration to the control systems } \\
\text { [STRS, OA] }\end{array}$ & & & & & \\
\hline
\end{tabular}


Staff: (3.3 staff years) *C.J. EVANS, *M.A.Donmez, ${ }^{*}$ R.S. Polvani, *M.L.McGlauflin, ${ }^{*}$ E.Whitenton, ${ }^{*}$ K. Harper, *M. Davies, *P.J. Sullivan

Project Objective and MEL Thrust Supported: The objective of the project is to develop manufacturing methods -- including metrology and sensor feedback to open architecture controllers .- to allow cost-effective production of tight tolerance components in advanced, difficult to machine materials such as ceramics, crystals, and hardened steels. Applications include mechanical, optical and electronic systems ranging from bearings and turbine blades to space optics and magnetic memories. Manufacturing Metrology, Manufacturing Processes and Equipment.

Need Addressed: There is an ever increasing trend to both tighter manufacturing tolerances and higher performance materials. Unfortunately, next generation turbine blades will be made from silicon nitride, and require complex, accurate forms with good surface finish and no machining-induced strength limiting effects. machining costs are currently a high proportion of the total manufacturing cost, and must be reduced if advanced materials are to be cost competitive. Yet, defect density and surface finish must be controlled. Complex interactions between machine characteristics, tool and work materials, and process parameters must be understood as they provide the technological basis for manufacturing processes that will allow introduction of new products based on such materials. Improved grinding techniques will enhance the manufacturability of high-value-added, tight tolerance components. Potential industries impacted include aerospace, transportation, and mass storage.

Technical Approach: The project aims to improve the-state-of-the-art in ductile regime grinding and hard turning. Brittle materials behave in an apparently ductile manner under certain process conditions, allowing defect free ceramic surfaces to be diamond ground with fine grit wheels. Rapid wheel wear, however, means that continuous electromechanical dressing is required of the metal bond wheels; fundamental understanding of the dressing process, and its integration and control via an open architecture controller are required. Appropriate instrumentation will be developed to give sensory feedback for real time control of the grinding process as well. In higher stock removal processes, small variations in work material microstructure seem to have a substantial effect on ceramic machinability and its variation. Loop stiffness and damping appear to have an impact on tool wear as well as surface integrity in hard turning; the new tools of non-linear dynamic analysis are being applied to understanding these effects. Chemical effects in tool wear need to be better understood.

\section{FY 94 Accomplishments:}

- Demonstrated effect of microstructure on surface characteristics of ground HIPped silicon nitrides.

- Developed predictive theory for chemical wear of single point diamond tools.

- Developed simple procedure for post-polishing diamond turned surfaces that eliminates the need for a finish cut on the diamond turning machine, reduces total production time, and produces an order of magnitude better surface finish without affecting diamond machined surface shape accuracy.

- Demonstrated that "ductile ground" silicon nitride has improved breaking strength.

\section{FY 95 Plans:}

- Complete High Stiffness machining Research Test Bed and perform initial ceramics grinding evaluation tests.

- Demonstrate effect of spindle characteristics on hard turning on Moore \# 3 based diamond turning machine.

- Evaluate surface characteristics and mechanical properties of Electro-chemically assisted ductile ground silicon nitrides. 


\begin{tabular}{|c|c|c|c|c|c|}
\hline $\begin{array}{l}\text { PRECISION MACHINING } \\
\text { OF ADVANCED MATERIALS }\end{array}$ & 95 & 95 & 97 & 95 & 99 \\
\hline \multicolumn{6}{|l|}{$\begin{array}{l}\text { Develop basic electrochemical theory for dressing process } \\
\text { [STRS] }\end{array}$} \\
\hline \multicolumn{6}{|l|}{ Complete ceramics machinability studies [STRS/OA] } \\
\hline \multicolumn{6}{|l|}{$\begin{array}{l}\text { Evaluate stiffness and damping effect in hard turning } \\
\text { [STRS] }\end{array}$} \\
\hline \multicolumn{6}{|l|}{ Perform sensor evaluation for grinding control [STRS] } \\
\hline \multicolumn{6}{|l|}{$\begin{array}{l}\text { Implement one of the newly developed processes in a } \\
\text { production shop floor [STRS] }\end{array}$} \\
\hline $\begin{array}{l}\text { Establish the economic benefit derived from the shop floor } \\
\text { implementation described above [STRS] }\end{array}$ & & & & & \\
\hline
\end{tabular}


Staff: (3.7 staff years) *A. DONMEZ, ${ }^{*}$ M. Davies, ${ }^{*}$ D. Gilsinn, ${ }^{*}$ N. Wilkin, A. Ling

Project Objective and MEL Thrust Supported: To develop models of manufacturing processes and equipment for use in manufacturing pre-, post, and in- pocesses control and equipment development, and to provide U.S. industry with state-of-the-art manufacturing data, architecture, models and algorithms. Manufacturing Process and Equipment.

Needs Addressed: In the absence of adequate modeling tools for manufacturing processes and equipment, process control is almost nonexistent. This increases manufacturing cost significantly--a situation that makes it difficult for US industry to compete in world markets. The closest approximation to process control is the Statistical Process Control (SPC) technique used on the shop floor. Rather than controlling the process, SPC detects changes occurring in the manufactured parts and warns the operator that the fabricated product is out of tolerance. However, SPC does not provide an identification of what parameters need to be modified to bring the system within tolerance. Therefore, corrective actions must be undertaken by the machine operator after the fact based upon experience and/or common sense.

Technical Approach: A generic approach to manufacturing process modeling to achieve high-quality products involves several steps. These steps are (1) identifying critical parameters that define product quality, such as the dimensional tolerances, surface finish, strength, visual consistency, wear resistances, etc.; (2) identifying factors affecting these critical parameters; and, (3) establishing relationships between the factors and the parameters. These relationships can be described by deterministic tools such as kinematic, linear and nonlinear dynamics, and finite element models, or they can be described by statistical tools such as regression models. Another type of analytical tool that can be used for this purpose is neural network modeling. Since manufacturing processes are generally nonlinear, linear models that have been traditionally used to predict their performance produced limited success. Recent advances in signal processing for nonlinear dynamics systems combined with the development of better sensors provide a unique opportunity for improved characteriztion of manufacturing processes. Similarly, recent activities in neural networks research tools have opened new directions in modeling and controlling manufacturing processes and equipment. APTD has carried out some preliminary work using this tool to model machine-tool thermal behavior with success. We plan to elborate on our modeling methods with neural networks as an alternative modeling tool for a variety of manufacturing proceses. Statistical tools have been most commonly used techniques in manufacturing. Their use requires assumptions which may not be valid at all times. The applicability of some new techniques such as Principal Component Analysis (PCA) will be investigated. APTD work in this area has focused primarily on machining. APTD plans to extend, in collaboration with industrial partners, these models to other manufacturing processes such as injection molding, die casting, forming, grinding, and painting. To that effect, CRADAs will be formed with a variety of industries.

FY94 Accomplishments:

- The Neural Network thermal modeling results were documented as a NISTIR.

- A joint collaborative effort between APTD and CAML using the neural network thermal modeling technique was completed for a three axis mill.

- Potential industrial participants for injection molding research were identified

- A preliminary finite element analysis of the environmental impact on a diamond turning machine tool was completed.

FY95 Plans:

- Co-organize university-government-industry workshop on non-linear dynamics applications in manufacturing 
- Complete the parameter space characterization for dynamic modeling of turning.

- Develop nonlinear models for turning.

- Demonstrate the nonlinear dynamic response for turning.

- Apply neural network algorithms to part dimensional data to obtain information about machine behavior.

\begin{tabular}{|l|l|l|l|l|l|}
\hline PROCESS MODELING FISCAL YEARS & 95 & 96 & 97 & 96 & 99 \\
\hline $\begin{array}{l}\text { Statistically correlate the nonlinear dynamic model results } \\
\text { with measured surface characteristics [STRS] }\end{array}$ & & & & & \\
\hline $\begin{array}{l}\text { Implement a Neural Network algorithm in a process } \\
\text { control algorithm [STRS] }\end{array}$ & & & & & \\
\hline $\begin{array}{l}\text { Use the Neural Network control software in a } \\
\text { manufacturing process control application [STRS] }\end{array}$ & & & & & \\
\hline
\end{tabular}


Staff: $\left(2.5\right.$ staff years) ${ }^{*}$ G. BLESSING, ${ }^{* N}$. Hsu, *S. Fick, *M. Manley, *D. Xiang

Project Objective: Develop, test, and apply ultrasonic methods for industrial nondestructive testing and process control needs. This is in response to industrial sectors from sports to automotive to aerospace, who are increasingly turning to composite materials and structures for their high technology products. The matrix quantity in the new materials may be a polymer, ceramic, or metal. While a principal feature of these materials is their increased strength to weight ratios, they are very heterogeneous on a macro scale. This makes it difficult to control uniformity and quality and to detect discontinuities between and within composite layers. As a result, industry often turns to nondestructive ultrasonic evaluation methods to assess the integrity and quality of these complex materials. But present attempts to apply this technology have had limited success using off-the-shelf sensors, leading us to the development of new focused and point (spherical) transducer methods. Manufacturing Processes and Equipment

Need Addressed: Customer needs especially exist in the aerospace and parts manufacturing sectors. A CRADA is being developed with the Boeing Corporation to apply inspection methods to structural components seeking a correlation between ultrasonic signature and material performance. Several bearing manufacturers have also expressed keen interest in assessing the surface and sub-surface quality of their products. The bearing manufacturers in turn feed out into numerous major industrial sectors such as the automotive and those involved with both light and heavy machinery.

Technical Approach: Ultrasonic techniques previously applied to homogeneous materials will need modification for application to heterogeneous composites. Line-focusing techniques will be developed to define the direction of elastic wave propagation relative to the fiber reinforcement and/or texture in layered materials. Elastic anisotropies ranging from less than one to nearly fifty percent should be assessable.

FY94 Accomplishments: (This is an expanding thrust area that builds on the work of past projects.)

- The potential application of reflected ultrasound to assess bearing and engine-cam surface finish quality was demonstrated for manufacturers who finish-grind their production parts.

- Assisted Boeing, via a CRADA, with the analysis of their pulsed laser ultrasonic signatures obtained on aircraft skin materials.

- Collaborated with MSEL in ceramics grinding consortia, and made elastic measurements of silicon nitride and silicon carbide test materials undergoing development.

\section{FY95 Plans:}

- Assess elastic properties and adherence of ceramic layers to metal substrates.

- Interface new imaging software with ultrasonic hardware to enhance signal interpretation and echopattern recognition.

- Identify and obtain well characterized composite samples representative of the industrial community's interests.

- Establish new CRADA(s) for industrial partnerships to assure meaningful research and development directions are identified and pursued. 


\begin{tabular}{|c|c|c|c|c|c|}
\hline $\begin{array}{l}\text { QUALITY CONTROL } \\
\text { OF ADVANCED MATERIALS }\end{array}$ & 98 & 96 & 98 & 98 & 99 \\
\hline \multicolumn{6}{|l|}{$\begin{array}{l}\text { On the appropriate composite samples, make elastic } \\
\text { measurements of anisotropy, modulus, etc. [STRS] }\end{array}$} \\
\hline \multicolumn{6}{|l|}{$\begin{array}{l}\text { Extend wave propagation model using a Green's function } \\
\text { formalism to include nonhomogeneous materials media } \\
\text { [STRS] }\end{array}$} \\
\hline \multicolumn{6}{|l|}{$\begin{array}{l}\text { Correlate model predictions with experimental ultrasonic } \\
\text { results, first on matrix material, then on the fibrous- } \\
\text { reinforced composite plies [STRS] }\end{array}$} \\
\hline \multicolumn{6}{|l|}{$\begin{array}{l}\text { Assist industry in the data analysis of its ultrasonic } \\
\text { signatures obtained on structural materials, e.g. Boeing } \\
\text { composites [STRS] }\end{array}$} \\
\hline \multicolumn{6}{|l|}{$\begin{array}{l}\text { Interact with materials and nondestructive testing } \\
\text { communities engaged in composites research with } \\
\text { technical paper presentations, and manufacturing site } \\
\text { visits [STRS] }\end{array}$} \\
\hline \multicolumn{6}{|l|}{$\begin{array}{l}\text { Apply new transducer developments to pulse-echo } \\
\text { analysis of material near-surface damage, especially } \\
\text { occurring from ceramic and glass grinding processes } \\
\text { [STRS] }\end{array}$} \\
\hline \multicolumn{6}{|l|}{$\begin{array}{l}\text { Assess capability of acoustic emission (AE) techniques to } \\
\text { distinguish the basic material removal mechanisms } \\
\text { operative in ceramic grinding. Begin with single-point tool- } \\
\text { workpiece studies [STRS] }\end{array}$} \\
\hline \multicolumn{6}{|l|}{$\begin{array}{l}\text { Dependent on laboratory results of single-point tests, } \\
\text { implement AE sensor onto a grinding machine. [STRS] }\end{array}$} \\
\hline \multicolumn{6}{|l|}{$\begin{array}{l}\text { Analyze and correlate sensory data with various grinding } \\
\text { parameters of industrial interest. Develop and test } \\
\text { signature-analysis software to distinguish material } \\
\text { interface emissions from (background) machine noise. } \\
\text { [STRS] }\end{array}$} \\
\hline $\begin{array}{l}\text { With MEL and MSEL input, develop program for sensory } \\
\text { feed-back control of a real industry-like grinding process } \\
\text { [STRS] }\end{array}$ & & & & & \\
\hline
\end{tabular}


Title: SENSOR INTERFACE FOR MACHINE CONTROLLER (SIMC)

Staff: (2.96 staff years) $\quad$ *Lisa Fronczek, *Bob Gavin, *Vincent Lee, *KANG LEE, ${ }^{*}$ Toni Savoy, ${ }^{*}$ Charles Yang

Project Objective and MEL Thrust Supported: The objectives of the project are to develop a generic sensor interface that will allow the integration of sensor-based process control capabilities to open architecture machine tool controllers, and to implement the sensor/controller interface in a production machining center at the Portsmouth Naval Shipyard as a test-bed to test and validate specifications and functionality. Manufacturing Processes and Equipment, Intelligent Machines and Systems.

Need Addressed: The computerized numerical controller (CNC) machine tool is critical in the manufacturing of components for military craft and in support of the readiness of US defense forces, as well as in the US manufacturing industry. As the manufacturing community strives for greater product quality and manufacturing efficiency in order to maintain competitiveness, the ability to interface process sensors with CNCs in a cost effective manner has become increasingly important. The development of a generic sensor interface for machine tool controllers technology will impact well beyond the implementation at Portsmouth. For retrofit applications within the Navy, as well as the rest of DOD, and industry, SIMC will improve process control capabilities for environments not previously receptive to sensor integration. For new product applications, SIMC will facilitate new levels of capability for machine tools to integrate sensor types into the control. For sensor technologies, SIMC will provide the means for new and widespread applications of sensor-based manufacturing and process control. For discrete part manufacturing in general, SIMC provides the potential for an evolution in manufacturing process control. SIMC provides the potential for an advancement of machining capabilities for virtually any machine tool or process that could re-vitalize American manufacturing's ability to compete globally.

Technical Approach: NIST and Portsmouth Naval Shipyard have been working collaboratively on machine toolrelated projects for several years, and are presently working together to implement a NIST-developed EMC at Portsmouth on a Brown \& Sharpe VC 1000 vertical machining center. This machine and controller will serve as the platform for the integration of the sensor interface which will be developed in the SIMC project. A critical element for the success of the project is the plan for feasibility demonstration of the technology first at NIST, then the project demonstration at Portsmouth. Wide spread transfer of SIMC technology will take place through public domain documentation of generic interface specification. The work undertaken in this project is closely coordinated with the work performed in the sensor-based manufacturing project.

\section{FY95 Plans:}

- Work with industry and EMC project to define sensor interface.

- Design and develop application programming interface specifications for sensor to machine tool controller.

- Develop prototype and demonstrate application programming interface for sensor to machine tool controller.

- Document sensor/niachine tool controller specifications. 


\begin{tabular}{|l|l|l|l|l|l|}
\hline $\begin{array}{l}\text { SENSOR INTERFACE } \\
\text { FOR MACHINE CONTROLLER (SIMC) FISCAL YEARS }\end{array}$ & 98 & 96 & 97 & 98 & 99 \\
\hline $\begin{array}{l}\text { Develop sensor interface specifications for machine tool } \\
\text { controller [STRS, OA] }\end{array}$ & & & & & \\
\hline $\begin{array}{l}\text { Demonstrate sensor to machine tool interface in } \\
\text { production machine for beta site testing and validation } \\
\text { [STRS, OA] }\end{array}$ & & & & & \\
\hline $\begin{array}{l}\text { Draft generic application programming interface (API) } \\
\text { specifications for interfacing sensors and sensor bus with } \\
\text { control modules in open-architecture machine tool } \\
\text { controller [STRS, OA] }\end{array}$ & & & & & \\
\hline $\begin{array}{l}\text { Collaborate with industry and voluntary standardization } \\
\text { organization such as IEEE to develop sensor and control } \\
\text { interface specification for standardization [STRS] }\end{array}$ & & & & & \\
\hline \hline
\end{tabular}


Staff: (2.9 staff years) ${ }^{*}$ Gerry Blessing, *Lisa Fronczek, *Mike Huff, ${ }^{*}$ KANG LEE, ${ }^{*}$ Vincent Lee, *Matt Tolman

Project Objective and MEL Thrust Supported: The objectives of the project are to develop sensors, sensor interface specifications and standards, and to apply sensor, control technologies and closed-loop process control techniques to manufacturing systems to increase part precision, productivity, and cost efficiency. Manufacturing Processes and Equipment.

Needs Addressed: Sensor-based manufacturing involves the fusion of sensors, controls, and machines into an integrated system that can enhance the overall efficiency of manufacturing systems and advance manufacturing technology into a new era. The smart sensor market alone is over $\$ 500 \mathrm{M}$ and is one of the fastest growing industries. Yet the state-of-the-art is such that it is difficult to integrate sensors to equipment and very costly. Industry contacts indicate that manufacturers, users, and vendors of sensors, controllers, machine tools, and process equipment need solutions to ease the interfacing effort. National and international sensor and control interface standards are needed to address this problem. By working with industry and standard organizations in the development of sensor communication interfaces and protocols, sensor networking and bus architectures, control algorithms and methodologies, a closed-loop, sensor-based manufacturing paradigm can be achieved.

Technical Approach: In order to insure that APTD provides solutions to the most urgent needs of industry, it is anticipated that APTD will sponsor industrial workshops jointly with industry and standardization organizations such as IEEE and ISA. Priorities for the project will be based in part on these workshops findings. The project also develops specifications for sensor and control interface standards, and procedures to evaluate, test, and validate the standards. The project seeks to establish strategic alliances with industry partners to insure that research activities on infrastructure technologies for sensors and open-architecture machine tool controllers are responsive to industry needs. The work undertaken in this project is closely coordinated with the work performed in EMC and process modeling to maximum leverage of MEL resources.

FY94 Accomplishments:

- Cosponsored with IEEE First Workshop on Smart Sensor Interface Standards

- Cosponsored with IEEE Second Workshop on Smart Sensor and Transducer Communication Standards

- Published NISTIR 5507, "Portsmouth Fastener Manufacturing Workstation User's Manual"

- Published NISTIR 5549, "Portsmouth Fastener Manufacturing Workstation Technical Manual"

\section{FY95 Plans:}

- Sponsor workshops on sensor communication interfaces.

- Publish documentation on results and direction of the workshop.

- Collaborate with voluntary standardization organization to establish working group to develop sensor to microprocessor interface specification for standardization.

- Collaborate with standardization organization to establish working group to develop sensor networking specifications for standardization.

- Publish paper to disseminate information on draft sensor interface and networking specifications. 


\begin{tabular}{|c|c|c|c|c|c|}
\hline SENSOR-BASED MANUFACTURING & 95 & 95 & 97 & 98 & 99 \\
\hline $\begin{array}{l}\text { Collaborate with industry and voluntary standardization } \\
\text { organization such as IEEE to sponsor workshops on } \\
\text { sensor and control interfaces [STRS] }\end{array}$ & & & & & \\
\hline $\begin{array}{l}\text { Collaborate with IEEE to establish working group to } \\
\text { prepare draft sensor to microprocessor interface } \\
\text { specifications for standardization consideration [STRS] }\end{array}$ & & & & & \\
\hline $\begin{array}{l}\text { Collaborate with IEEE to establish working group to } \\
\text { prepare draft sensor network communication interface } \\
\text { specifications for standardization consideration [STRS] }\end{array}$ & & & & & \\
\hline $\begin{array}{l}\text { Interact with national standardization organization, } \\
\text { American National Standard Institute (ANSI) and } \\
\text { international standardization organization, International } \\
\text { Organization for Standardization (ISO) to establish } \\
\text { worldwide a set of sensor interface standards [STRS] }\end{array}$ & & & & & \\
\hline
\end{tabular}


Staff: (1.48 staff years) ${ }^{*}$ M. Davies, *A. DONMEZ, ${ }^{*}$ C. Evans, ${ }^{*} \mathrm{~K}$. Harper, ${ }^{*} \mathrm{~K}$. Yee

Project Objective and MEL Thrust Supported: The objective of this project is to develop the fundamental knowledge required to understand the relationship between measured spindle performance and manufactured part quality. Manufacturing Processes and Equipment, Manufacturing Metrology.

Needs Addressed: U.S. industry has an ever increasing need to produce high precision parts to remain competitive in global markets. Because the majority of manufacturing processes utilize spindles, the accuracy of these components is crucial. In depth study of the characteristics of a variety of spindle types and the relationship of those characteristics to performance in manufacturing will yield the data required to produce more accurate spindles.

Technical Approach: In order to improve spindle accuracy, a complete study of the geometric, thermal, and dynamic properties of several different types of spindles will be conducted. Analysis of the axis of rotation errors, thermal distortion, vibration modes, and non-linear dynamic effects will be carried out. The spindle types studied will include rolling element (tapered rollers) bearing, air bearing, and hydrostatic bearing spindles. Based on equipment availability, a ceramic spindle and an electro-magnetic bearing spindle will also be examined. Methodologies for spindle analysis developed in this effort will be made available to industry through publications and presentations in relevant forums. Correlations found between spindle characteristics and performance will also be presented to industry for their use in development of more accurate spindles.

FY94 Accomplishments:

- Completed geometric analysis of a rolling element bearing spindle.

- Carried out a characterization of the thermal distortion of the rolling element spindle.

- Completed dynamic characterization of the rolling element bearing spindle on a vibration isolated granite testbed.

- Collaborative work with SETCO/MLI/University of Florida was completed developing a high speed, high power spindle for milling aluminum aircraft components.

- Based on the results of geometric analysis, revision began on the B89 Axis of Rotation Standard.

\section{FY95 Plans:}

- Perform dynamic characterization of the rolling element bearing spindle on the machine base which will be used for all cutting tests.

- Conduct diamond turning cutting tests with the rolling element bearing spindle.

- Perform analysis of the surface produced by diamond turning with the rolling element bearing spindle.

- Correlate geometric and dynamic characteristics of the rolling element bearing spindle with surface features produced in diamond turning.

- Perform analysis of the surface produced by hard turning tests.

- Correlate geometric and dynamic characteristics of the spindle with surface features produced in hard turning tests.

- Conduct hard turning tests with an air bearing spindle.

- Conduct diamond turning tests with an air bearing spindle. 


\begin{tabular}{|c|c|c|c|c|c|}
\hline SPINDLE CHARACTERIZATION & 96 & 96 & 97 & 96 & 99 \\
\hline \multicolumn{6}{|l|}{$\begin{array}{l}\text { Perform dynamic characterization of the air bearing } \\
\text { spindle [STRS] }\end{array}$} \\
\hline \multicolumn{6}{|l|}{$\begin{array}{l}\text { Correlate surface features produced by both hard turning } \\
\text { and diamond turning with the dynamic characteristics of } \\
\text { the air bearing spindle [STRS] }\end{array}$} \\
\hline \multicolumn{6}{|l|}{$\begin{array}{l}\text { Compare performance of contact element bearing spindle } \\
\text { with performance of air bearing spindle in both diamond } \\
\text { and hard turning [STRS] }\end{array}$} \\
\hline \multicolumn{6}{|l|}{$\begin{array}{l}\text { Perform characterizations and cutting tests (as described } \\
\text { above) on hydrostatic spindle [STRS] }\end{array}$} \\
\hline \multicolumn{6}{|l|}{$\begin{array}{l}\text { Perform similar examinations of ceramic and } \\
\text { electromagnetic bearing spindles, based on equipment } \\
\text { availability [STRS] }\end{array}$} \\
\hline Comparisons of performance of various spindles [STRS] & & & & & \\
\hline
\end{tabular}


Staff: (0.8 Staff years) *G. BLESSING, *S. Fick, *J. Slotwinski

Project Objective: Deliver ultrasonic calibrations and respond to industrial requests for specific metrology tests in a timely way. A wide variety of industrial sectors periodically requests guidance and evaluation for material quality evaluation and sensor needs in product inspection and process control. Recent examples are from Abbott Laboratories to inspect for leakage in their IV pouches, StressTel Corporation to develop high precision glass reference artifacts for stress calibration, and a manufacturer of vehicular brake shoe pads for material quality assessment and adherence to substrate. Manufacturing Metrology.

Need Addressed: Industry has had a long-standing need and interest in ultrasonic nondestructive testing methodologies for process control and part inspection. While the present level of calibration requests on reimbursable dollars is low, we are retaining our capability to respond to industry's interests in three distinct areas of calibration. Two of these have resulted in the development of SRMs. The cyclical low being experienced for calibration demand is attributed to the lull in DOD and DOE activities. The three areas of calibration pertain to (i) ultrasonic reference block echo-amplitude measurements, (ii) power radiation measurements of transducer output, and (iii) sensitivity measurements of acoustic emission (AE) sensors as a function of elastic wave frequency.

Technical Approach: In the case of calibration (i) we deliver an evaluation of the echo-amplitude response from flat-bottom-hole reference artifacts in metal blocks that industry uses to calibrate the sensitivity of its ultrasonic systems to detect material flaws. The principal users are the aerospace and metals industries, e.g. Boeing, Lockheed, Alcoa, and Reynolds metals. In the case of (ii) NIST provides a measure of transducer power output radiation as a function of drive voltage so that the user may have a reference to calibrate the output levels of his system. SRM 1855 was developed as a well-characterized transducer transfer device to the medical community for the evaluation of their diagnostic and therapeutic system. These calibration reference data for example assure the safe delivery of patient sonograms. In the case of (iii), AE sensors are calibrated for their sensitivity to angstrom-level dynamic material surface displacements occurring in the $\mathrm{kHz}$ to $\mathrm{MHz}$ elastic wave frequency range. This technology is microscale application and analysis for fabricated materials of what happens on a macro scale with seismic waves. The broad industry involved with small and large pressure (gas and fluids) vessels, and storage tanks (oil, e.g.) is served with this calibration capability, defined by the ASTM E1 106 practice.

FY 94 Accomplishments:

- Delivered calibrations of ultrasonic reference blocks, medical-application transducers and AE sensors to industry.

- Documented mechanical and analytical details of the AE calibration procedure that is outlined in ASTM E1106 practice.

- Published NISTIR 5430 "Calibration of ASTM E127-Type Ultrasonic Reference Blocks," describing NIST procedural differences from ASTM practice.

- Chaired ASTM Committee E7.06.02 on ultrasonic reference block calibration methodology to provide leadership for industry's calibration needs in nondestructive testing.

\section{FY 95 Plans:}

- Provide ultrasonic calibrations of materials and sensors per industrial requests.

- Assist industry in the development of an ultrasonic stress measuring capability based on the new ASTM practice E1544.

- Present for review and possible ASTM ballot improvements in the precision of reference block calibrations.

- Publish a NIST Journal of Research paper describing the power radiation pressure measurement 


\begin{tabular}{|c|c|c|c|c|c|}
\hline ULTRASONIC CALIBRATIONS SERVICESISCAL YEARS & 95 & 95 & 97 & 98 & 99 \\
\hline $\begin{array}{l}\text { In collaboration with industry via ASTM E7.06 committee, } \\
\text { redefine precision limits for aluminum ultrasonic reference } \\
\text { blocks [STRS \& Industry ] }\end{array}$ & & & & & \\
\hline $\begin{array}{l}\text { Develop improved practices for reference block } \\
\text { methodology, esp. including more sensitive ceramic PZT- } \\
\text { type transducers to replace present usage of quartz } \\
\text { transducers [STRS] }\end{array}$ & & & & & \\
\hline $\begin{array}{l}\text { Continue participation in national and international } \\
\text { standards committee activities (ASTM, IEEE, ISO, etc.) via } \\
\text { balloting, round-robin tests, and holding appropriate chairs } \\
\text { [STRS] }\end{array}$ & & & & & \\
\hline $\begin{array}{l}\text { Develop scenario to replace material reference artifacts } \\
\text { with a model-based analytical approach for ultrasonic } \\
\text { calibration in the nondestructive testing field [STRS] }\end{array}$ & & & & & \\
\hline $\begin{array}{l}\text { Develop improved and automated sensor evaluation } \\
\text { scanning system to assess transducer behavior and } \\
\text { quality [STRS] }\end{array}$ & & & & & \\
\hline
\end{tabular}


Staff: (2.2 staff years) ${ }^{*}$ G. Blessing, ${ }^{*}$ S. Fick, ${ }^{*}$ N. HSU, *M. Manley, *J. Slotwinski, ${ }^{*}$ D. Xiang, *

Project Objective and MEL Thrust Supported: Develop and analyze new ultrasonic transducer designs to meet industry's expanding inspection needs of more complex materials and structures. During such development, in-use and off-the-shelf available transducers will also be studied for comparison and an evaluation of their limitation. The transducer analysis will take advantage of an established deconvolution capability previously developed within the group. Manufacturing Processes and Equipment

Need Addressed: In an ultrasonic system there are several principal components including the electronic pulser to drive a transducer, the transducer itself acting as transmitter and sensor, and the receiving amplifier. In addition, there is the effect of the material (and its internal scatterers) on the elastic waveform generated. The system is only as strong as the proverbial weakest link, and it has been our experience in the ultrasonics group that this weakness is often the transducer. As a result, both experimental and analytical investigations are crucial in order to understand what the transducer is doing in two transduction processes: (a) when the transducer acts as a transmitter converting the electric energy into mechanical wave energy, and (b) when as a receiver it converts the elastic wave echo back into an electrical representation. Without detailed knowledge of these transduction processes, the waveform signatures cannot be properly interpreted. The material and process-monitoring conditions we attempt to evaluate and control can then only be partially understood.

Technical Approach: In-use transducers will be scanned for their mechanical output. New transducers will be designed and fabricated for specific materials measurements, e.g. anisotropy in fibrous composites and textured metals. A Green's function deconvolution approach will be used to analyze the waveforms to be expected, and comparisons made with experimental results. One may analyze the problem in the following three-step process:

(i) transduction of the driving electrical pulse; (ii) wave propagation through a material medium; and (iii) transduction of the received mechanical wave back into an electric signal whose signature we attempt to interpret. If we fully understand parts (i) and (ii) of the process, we can use ultrasound to study material properties in (iii), and monitor the manufacturing process. This is our goal in this project.

\section{FY94 Accomplishments:}

- Generic analytical results were obtained predicting the behavior of various waveforms propagating in solid materials, and presented to the IEEE International Ultrasonics symposium. Other labs in France, Japan, Taiwan, and the US have picked up on the work seeking collaboration.

- The contributions of a visiting scientist with experience in transducer design were sought and invited to work with the ultrasonics group at NIST.

- The quartz transducer used in ASTM-type calibration of ultrasonic reference blocks was evaluated for its spatial output, and compared with past performance over 15 years.

- Using a deconvolution analysis for laser-generated and laser-detected elastic waves, Boeing was aided in understanding the operation and capability of a remote-sensing system.

\section{FY95 Plans:}

- Pursue new transducer designs utilizing versatile polymeric piezoelectric films to fabricate curved geometry transducer faces for controlled focusing.

- With known drive voltage signals, predict the behavior of transducers to generate the desired mechanical waveforms.

- Apply transducers with spatially asymmetric output to study the elastic anisotropy of composite and ceramic materials.

- Increase the transducer evaluation capability of two independent mechanical scanning systems by 
adding rotation and translation degrees of freedom to one, and increasing the translation extension of another.

\begin{tabular}{|l|l|l|l|l|l||}
\hline \hline $\begin{array}{l}\text { ULTRASONIC TRANSDUCER } \\
\text { DEVELOPMENT AND ANALYSIS }\end{array}$ FISCAL YEARS & 95 & 96 & 97 & 98 & 99 \\
\hline $\begin{array}{l}\text { Apply analytical deconvolution techniques to better } \\
\text { understand the electric/mechanic transduction process for } \\
\text { ultrasonic sensors [STRS] }\end{array}$ & & & & & \\
\hline $\begin{array}{l}\text { Accomplish mechanical scanning improvements for spatial } \\
\text { investigations of transducer output [STRS] }\end{array}$ & & & & & \\
\hline $\begin{array}{l}\text { With industrial requirements input and within the context of } \\
\text { ASTM, assist in developing a replacement standard for } \\
\text { the quartz transducer used in E127 [STRS] }\end{array}$ & & & & & \\
\hline $\begin{array}{l}\text { Assist industry in specific sensor needs, e.g. the detection } \\
\text { of solids in a slurry flowing through a pipe, for application } \\
\text { to process control [STRS] }\end{array}$ & & & & & \\
\hline $\begin{array}{l}\text { Document and present results of transducer development } \\
\text { to appropriate technical review forums [STRS] }\end{array}$ & & & & & \\
\hline $\begin{array}{l}\text { To complement the effort in the development of extended } \\
\text { sources, establish the attributes and limitations of point } \\
\text { source/point detection sensor technology [STRS] }\end{array}$ & & & & & \\
\hline $\begin{array}{l}\text { Continue with the development of polymeric PVDF } \\
\text { transducer elements not only as pulse-echo devices, but } \\
\text { also as small-element sensors [STRS] }\end{array}$ & & & & & \\
\hline $\begin{array}{l}\text { Develop acoustic emission pick-up sensors for the } \\
\text { requirement of high fidelity detection in the grinding of } \\
\text { ceramics and metals [STRS] }\end{array}$ & & & & & \\
\hline $\begin{array}{l}\text { Expand database of scanned medical transducer devices } \\
\text { for feedback esp. to the diagnostic community [STRS] }\end{array}$ & & & & & \\
\hline \hline
\end{tabular}




\section{INTELLIGENT SYSTEMS DIVISION}

\section{MISSION:}

Strives to enhance U.S. industrial competitiveness through the development and application of intelligent systems technologies; develops and maintains competence in intelligent machines and systems, robotics, real-time sensory-interactive control, open-system architectures, software development techniques, simulation and modeling, and methods for intelligent system design and testing; conducts research in techniques for planning and control, world modeling, sensory processing, and interactive graphics for operator interface; works with industry, universities, and other government agencies to implement pre-commercial prototype open-system architecture, intelligent control systems for a wide variety of applications; applies artificial intelligence techniques to real-time sensory-interactive control for computer-integrated manufacturing systems; supports other NiST laboratories and other government agencies in applications of intelligent systems with high national priority, such as construction, environmental clean-up, transportation systems, mining, and military applications; develops reference model open-system architectures for intelligent control systems; develops methodologies for design and implementation of intelligent control systems; develops methods and tools for software development and testing; develops and tests measures of performance for intelligent control systems, robots, and intelligent machines; and supports the development of new standards for intelligent machine systems, robots, and automated manufacturing systems. 
Staff: NIST (1.3 staff years) KEITH STOUFFER, *Bob Russell; UTRC (2.6 staff years)

Project Objective and MEL Thrust Supported: The objective of this program is to develop the interface standards and performance measures for advanced robotic deburring and chamfering (finishing) systems. Manufacturing Processes and Equipment.

Need Addressed: Pratt \& Whitney, as well as industry as a whole, has a great need to automate the finishing process for parts. Manual finishing of parts is very time consuming, inconsistent, and prone to errors that can damage an expensive part beyond repair. Manual deburring and chamfering operations account for approximately $35 \%$ of the final cost associated with the manufacture of product parts. Annual deburring operation costs are currently estimated at $\$ 3.9$ billion nationwide. The price for manual deburring manifests itself in the time required to machine a part at the bench, the cost of a thorough inspection following the bench, the possible subsequent rework and sometimes even the component scrap. Cumulative trauma disorders (most notably carpel tunnel syndrome) can result in high health care costs and lost labor. Automation will largely reduce or eliminate these problem areas.

Technical Approach: The ADACS workstation consists of a robot carrying an active tool, and a servo positioning table. A six axis Cincinnati Milacron T3-646 is used as a macro positioning device to carry a two-degreeof-freedom force sensing tool. The tool has a carbide rotary cutter positioned at the tip. This Chamfering and Deburring End-of-arm Tool (CADET), which is mounted to the T3-646 flange, incorporates actuators and force sensors to provide control over cutting forces and tool stiffness at the part edges. The servo table is used as a part fixturing and manipulation device. Each device is controlled separately and is coordinated under the control of the system supervisor using the NIST-developed hierarchical Real-time Control System (RCS). RCS allows feedback from a variety of sensors to be easily integrated with the control of the robot, accommodating for robot inaccuracies which may result from off-line programming. A Computer Aided Design (CAD) graphical user interface allows the user to graphically select which edges are to be chamfered and specify the machining parameters (feed rate, chamfer depth, direction of cut, etc.) to obtain the required chamfer on each edge. ADACS is a joint project between NIST, the Navy ManTech Program, United Technologies Research Center (UTRC), and Pratt \& Whitney. The AMRF is responsible for the development of the advanced CAD-directed, sensor-based control system which coordinates the operations of the robot, deburring tool, and fixturing table. UTRC is responsible for the development of the deburring process model and fabrication of an enhanced deburring tool, the Chamfering and Deburring End-of-arm Tool (CADET). Pratt \& Whitney is scheduled to install a prototype chamfering and deburring cell at their East Hartford plant upon completion of the project. Finishing costs are expected to be reduced by $50 \%$ and rework rates are expected to be reduced to nearly $0 \%$. Tolerances on the finished edges will be less than $\pm 0.1 \mathrm{~mm}$.

FY 94 Accomplishments: (The ADACS project was not funded during FY 94.)

- Presented the conference paper "ADACS - An Automated System for Part Finishing" at IECON '93 Maui, Hawaii, November 15-19, 1993.

- Presented several proposals to the Navy for continued funding of the project.

- Received funding for the project at the end of September.

FY 95 Plans:

NIST:

- Develop geometric transforms for trajectory planner such as arcs and Non-Uniform Rational B-Splines (NURBS).

- Develop a standard protocol for the data transfer from the CAD user interface to the trajectory generator via RCS.

- Develop user interface with CAD to extract necessary edge information for each feature. 
- Develop hierarchy of control with the CAD system.

- Develop feature processing with UTRC.

- Prepare technical plan for commercial production of the CADET.

- Develop enhancements for Deneb's Telegrip software.

- Integrate the CADET into the ADACS workstation.

- Prepare technical plan for transfer of technology to Pratt \& Whitney.

- Prepare NISTIR summarizing the technology development of the ADACS.

UTRC:

- Select processing procedures to be used to process Pratt \& Whitney part in end-of- contract system demonstration.

- Design and develop specifics of ADACS Real-time Control System (RCS) architecture.

- Define suite of RCS communications for ADACS layers and system components.

- Develop processing modes for processing part features.

- Integrate CADET with CAC machine.

- Integrate process models into Process Controller.

- Prepare technical plan for commercial production of the CADET.

- Prepare technical plan for transfer of technology to Pratt \& Whitney.

Related Developments: NIST and UTRC, working in cooperation with several tool and control manufactures, are assembling a plan to commercially produce the ADACS CADET tool and control system. 
Staff: (3.85 staff years) JAMES ALBUS, *Frederick Proctor, *Elena Messina, *Wendell Wallace, ${ }^{*}$ Tsungming Tsai, *John Michaloski, *Steven Legowik, *Robert Russell, *Keith Stouffer, *Sandor Szabo, *David Coombs, and *Tom Kramer

Project Objective and MEL Thrusts Supported: The object of the program is to reduce the life-cycle cost of machine tool controllers by developing public domain open system interface standards and interchangeable software, and to demonstrate the open system on machines for two user groups: retrofit and high-end. Intelligent Machines and Systems, Manufacturing Process and Equipment

Need Addressed: In 1980, nearly half of the world's machine tools were manufactured in the U.S. Today, the U.S. market share has fallen to $10 \%$. Since machine tool technology is considered critical for both civilian and military uses, it is important to recapture some of this market. The controller is the critical component of a machine tool which can change its capabilities. Currently, competition is based on hardware. The EMC project will shift the controller from hardware to software, an area where the U.S. still has a commanding lead. The benefits include reduced: 1) life cycle costs, 2) training costs, since the operator interface can be customized around user familiarity, 3) maintenance costs due to multi-vendor sourcing, lead time for components, and inventory reduction, and 4) integration costs. Other benefits include: 1) a large pool of potential developers providing innovative technology, 2) more flexible controllers producing higher quality parts at lower cost, 3) improved performance, 4) shorter part programs resulting from using non-uniform rational B-splines (NURBS) as a representation for specifying paths, and 5) improved safety by using a tool identification system to verify tool selection.

Technical Approach: Public domain open system interface standards and interchangeable software will be developed to allow machine tool builders to construct a baseline controller, extend an initial set of components with new ones, modify the controller to handle new applications, access low-level functions and data, and improve machine diagnostics. An operational Enhanced Machine Controller (EMC) is being developed and tested. The EMC will consist of the Host Machine Executive (HME), which is the Computer Numerical Control (CNC) "main program," including the basic controller components, e.g., trajectory generator, servo interface, part program interpreter, operator interface, and Programmable Logic Controller (PLC). Support software will include a toolkit to allow a user to easily configure a system and select appropriate components. The toolkit will support the simulation of the candidate controller so that the designer can ensure the system meets specification before purchasing any components.

The EMC concept will be demonstrated by building two controllers aimed at different market segments: the retrofit user and the high-end user. For each controller implementation, a working system will first be developed at NIST. Then, the controller will be field tested at a minimum of two beta sites in a real production environment.

In order to work closely with machine tool users, machine tool builders, and control component manufacturers, a collaboration consortium will be established though a Cooperative Research and Development Agreement (CRADA). Each member's requirements and needs will be taken into account during the course of the project through regular meetings and interactions.

\section{FY94 Accomplishments:}

- A shop floor implementation using a vertical milling machine, which is oriented toward machine tool enhancements, provides empirical evidence of machine tool enhancements, e.g., thermal and geometric error correction. This is complemented by a lab development controller which concentrates on software engineering to develop generic interfaces for an open system architecture. These systems are currently running version 0 code. This will be improved and released as the open system software. 
FY95 Plans:

- An EMC will be retrofit to a 4-axis milling machine at the GM Powertrain prototype shop. The EMC will have a customizable, Windows-based Graphical User Interface, interchangeable components (such as motion control boards), and a sophisticated diagnostics module. This system will be used to validate the benefits of the NIST specification for an open architecture controller. Together, GM and NIST will evaluate the openness, modularity, and flexibility of the EMC architecture and API's.

- The EMC project will continue to provide leadership to the DOE Technologies Enabling Agile Manufacturing (TEAM) Intelligent Closed Loop Controller Project. This is a national effort aimed at producing standard specifications for open architecture controllers.

- $\quad$ NIST will collaborate with industry partners to deliver an EMC integrated with a high-end multi-axis machine tool at Boeing. NIST will supply the API definitions and provide technical guidance. The actual implementation of the Boeing EMC will be performed by industrial vendor-partners, thus validating the API's scalability to a high-end system, and beginning the deployment of API's within the vendor community.

\begin{tabular}{|c|c|c|c|c|c|}
\hline $\begin{array}{l}\text { ENHANCED MACHINE } \\
\text { CONTROLLER (EMC) }\end{array}$ & 95 & 96 & 97 & 98 & 99 \\
\hline Install EMC at GM powertrain plant & 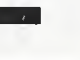 & & & & \\
\hline Test and evaluate EMC at GM & & & & & \\
\hline Transfer EMC technology to Trellis, Boeing & & & & & \\
\hline $\begin{array}{l}\text { Develop application protocol interfaces (APIs) for open } \\
\text { system architecture }\end{array}$ & & & & & \\
\hline Develop national and international standards for APIs & & & & & \\
\hline Integrate EMC into NAMT and other MEL projects & & & & & \\
\hline
\end{tabular}


Staff: (1.45 staff years) ALBERT J. WAVERING, *Tom Wheatley, *Joe Falco, *Bob Bunch, *John Michaloski

Project Objectives and MEL Thrusts Supported: This program establishes the Advanced Machine Tool Structures Testbed (AMTST) through the installation of the Octahedral-Hexapod, test strut, and related laboratory hardware and software; supports our commitment to making the AMTST a site for collaborative research by working with industrial partners who wish to perform machining, metrology, and other tests on the Hexapod; develops an Enhanced Machine Controller (EMC) for the Hexapod; and achieves micrometer-scale positioning repeatability and accuracy. Manufacturing Processes and Equipment.

Need Addressed: By the year 2000, tolerances for discrete parts are projected to decrease from $7.5 \mu \mathrm{m}$ to $1 \mu \mathrm{m}$ for the most demanding normal machine tool based production. This includes a vast array of parts for the motor vehicle, construction equipment, aerospace, and electronic component industries. Furthermore, on-machine inspection of these parts will require accuracies which are 4-10 times better than the manufacturing tolerance. A new class of machine tools based on the Stewart platform concept (such as the Octahedral-Hexapod) has the potential to meet these increasingly demanding tolerance requirements at a reasonable cost. U.S. machine tool manufacturers are currently a step ahead of foreign competitors in the development of this technology. If sufficient progress can be made quickly enough in establishing parallel machines as viable tools for precision manufacture, it could alter the entire future of the machine tool industry world wide. The NIST work, in collaboration with industrial partners, will provide critical assistance to the U.S. machine tool industry to help take advantage of this opportunity to regain a major part of the market share which has been lost to foreign manufacturers over the past two decades.

Technical Approach: In addition to planning and coordinating the installation of equipment for the AMTST, this project has three related objectives. The first is the development of an Open Architecture controller for the Hexapod based on the EMC. This controller will provide software modularity and interfaces required to implement performance enhancing modifications such as the addition of microactuators and laser-based feedback metrology, and thermal error compensation. In time, this controller will be network-linked to distant sites to allow remote operation from non-NIST facilities. This will facilitate the second objective, which is to work with machine tool user organizations on joint projects. This experience gives them first-hand experience with Stewart platform machine tool technology allowing educated decisions regarding the application of these machines in their own plants. The third objective is to work with the Precision Engineering Division to develop microactuation and laser metrology hardware enhancements for the Hexapod machine (see the PED Hexapod Metrology project description) and integrate them into the NIST controller. With appropriate control algorithms, these modifications are expected to make micron-scale positioning of the spindle platform possible. Throughout this project, ISD will be working closely with PED, the Ingersoll Milling Machine Company, and other industry partners to share results and make use of ATP developments. A workshop will be held to provide an additional opportunity for industrial partners to visit the Advanced Machine Tool Structures Testbed and to solicit suggestions and comments regarding research directions.

\section{FY 94 Accomplishments:}

- Held Workshop on Advanced Machine Tool Structures: Research directions (at NIST).

- Held competition and awarded contract for Octahedral-Hexapod machine tool and additional strut for Advanced Machine Tool Structures Testbed.

- $\quad$ Performed planning required for AMTST equipment installation.

- Made progress toward identifying industrial partners interested in pursuing joint projects related to the Hexapod.

- Developed concept for prototype microactuator system.

- Procured critical components for microactuation system (for the test strut). 
FY 95 Plans:

- Perform detailed design of microactuator retrofit for a single strut.

- Work toward adapting EMC controller for use with Octahedral Hexapod.

- Train NIST personnel to operate the Hexapod machine.

- Install Hexapod machine and test strut in AMTST.

- Install and integrate prototype single-strut microactuator and metrology systems.

- Participate in collaborative machining and metrology tests.

- Conduct performance tests of enhanced test strut.

- Conduct second workshop on Advanced Machine Tool Structures Research.

- Develop demonstration of micron-scale control of single strut on test stand.

- Write NISTIR on microactuator and metrology system enhancements for single strut.

\begin{tabular}{|l|l|l|l|l|l||}
\hline HEXAPOD FISCAL YEARS & 95 & 96 & 97 & 98 & 99 \\
\hline $\begin{array}{l}\text { Establish the AMTST (install equipment, obtain training, } \\
\text { etc.). [STRS, ATP] }\end{array}$ & & & & & \\
\hline Develop EMC-based controller for single test strut. [STRS] & & & & & \\
\hline $\begin{array}{l}\text { Develop, integrate, and evaluate prototype microactuator } \\
\text { system for a single strut. [STRS, ATP] }\end{array}$ & & & & & \\
\hline $\begin{array}{l}\text { Participate in machining and metrology tests with CRADA } \\
\text { partner(s). [STRS] }\end{array}$ & & & & & \\
\hline $\begin{array}{l}\text { Report details of single strut enhancements and results of } \\
\text { evaluation tests. [STRS, ATP] }\end{array}$ & & & & & \\
\hline $\begin{array}{l}\text { Develop EMC controller for complete Hexapod machine. } \\
\text { [STRS] }\end{array}$ & & & & & \\
\hline Test and evaluate Hexapod EMC controller. [STRS] & & & & & \\
\hline $\begin{array}{l}\text { Integrate Hexapod controller into NIST Virtual } \\
\text { Manufacturing system to provide network-linked remote } \\
\text { operation. [STRS] }\end{array}$ & & & & & \\
\hline $\begin{array}{l}\text { Integrate and evaluate microactuator and metrology } \\
\text { enhancements for the full machine. [STRS] }\end{array}$ & & & & & \\
\hline $\begin{array}{l}\text { Report details and results of EMC controller } \\
\text { implementation and enhancements. [STRS] }\end{array}$ & & & & & \\
\hline $\begin{array}{l}\text { Add thermal control and/or compensation to Hexapod. } \\
\text { [STRS] }\end{array}$ & & & & & \\
\hline $\begin{array}{l}\text { Develop control algorithms for advanced applications, } \\
\text { such as force control for on-machine deburring and } \\
\text { finishing. [STRS] }\end{array}$ & & & & & \\
\hline
\end{tabular}


Staff: (0.8 staff years) *ERNEST W. KENT, *Joseph Falco

Project Objective and MEL Thrusts Supported: The objective is to develop a system combining aspects of teleoperation and simulation which will enable remote operators to plan, debug, and execute, in real time, robot and other machine operations at remote manufacturing sites. This work will explicitly focus on the interchangeability of virtual and remote operations, demonstrate and evaluate remote planning and control of machines at multiple sites using a variety of types of operation, and evaluate capabilities and limitations of virtual planning of remote operation, develop proposed standards for software and communications interfaces for remote and virtual operations. Manufacturing Process and Equipment, Manufacturing Systems Integration.

Need Addressed: Increased specific customer needs and rapid technology innovation are prompting a major shift in the way U.S. manufacturers must design, develop, and deliver quality products to the marketplace. Often, in today's manufacturing industry, the components making up an enterprise are geographically dispersed. A system is needed that will allow members of an enterprise including design, production and administrative facilities, to control and monitor distributed manufacturing systems.

Technical Approach: A Virtual Factory (VF) Interface is being developed to test concepts of virtual and remote manufacturing. The system will enable remote operators to plan, debug, and execute, in real time, robot and other machine operations at remote manufacturing sites. A testbed consisting of four networked geographically dispersed installations is being integrated to demonstrate distributed VF systems. Industry nodes to this network are now in the process of being established. These VF concepts are also being used as a distributed research tool by providing an environment for small companies and universities to remotely access NIST's advanced manufacturing testbeds (i.e., Enhanced Machine-tool Controller (EMC), Hexapod Machine Tool)

\section{FY94 Accomplishments:}

- Established a baseline hardware and software configuration for a connection into a Virtual Factory Network.

- Demonstrated its functionality by remotely controlling a Robotic workcell at Sandia National Laboratory, New Mexico from NIST, Maryland using a supervisory graphical interface.

\section{FY95 Plans:}

- Install and integrate a centralized VF operator station in the AMSANT lab.

- Integrate NIST system to demonstrate a networked four-installation demonstration of distributed VF systems at DOE labs in Sandia, Oak Ridge, and Richland, Oregon.

- Integrate Sandia GISC with NIST EMC controllers, define interfaces between graphics system and controller, implement application-specific graphic components.

- Improve upon VF technology to provide an explicit 2D interface.

- Develop VF operator stations for a NIST application (e.g., mini-mill). 


\begin{tabular}{||l|l|l|l|l|l||}
\hline HPCC VIRTUAL FACTORY INTERFACE FISCAL YEARS & 95 & 96 & 97 & 98 & 99 \\
\hline Develop a virtual gear factory (Eaton) & & & & & \\
\hline Develop a virtisal engine block line (GM) & & & & & \\
\hline Develop guidelines for a virtual factory application & & & & & \\
\hline
\end{tabular}


Staff: (3.75 staff years) ROGER BOSTELMAN, Adam Jacoff, *Rick Norcross, *Ken Goodwin, *Ed Amatucci, ${ }^{*}$ Chuck Giauque, *Wendell Wallace, *Tsung-Ming Tsai, *Kimberly Anderson, *Jason Marcinkoski, and *Mollie Sourwine

Projects Objective and MEL Thrusts Supported: Use the Robocrane for an Intelligent Machine Testbed to study and implement standards for such machines and for future study of attached hardware/software systems by installing the following: 1) state-of-the-art Controller Area Network Amplifiers (CANamps) providing an efficient servo loop control mechanism, and 2) an Enhanced Machine Controller (EMC). This will equip the RoboCrane to serve as a testbed for open system architecture controller standards. Work with industry and other government agencies to achieve application in field uses. These uses include temporary highway bridge construction, an Air Transportable Expeditionary Crane, and an apparatus (TETRA) for long-line suspended load stabilization in a manufacturing environment. Intelligent Machines and Systems; Manufacturing Systems Integration.

Need Addressed: There are a large number of field operations that are inherently hazardous to human operators and riggers. Tightened environmental enforcement is requiring remote operations to remove humans from dangerous situations, including highway bridge and causeway construction, paint stripping, cargo handling, structural steel erection, radioactive and toxic waste handling, and unexploded ordnance assessment and remediation. The construction industry has one of the highest rates of job injuries of all major industries. Back injuries account for about half of all safety related costs.

The NIST RoboCrane is a revolutionary advance in crane technology. It transforms the crane from a device for simply lifting and placing heavy loads, to a device for precisely manipulating objects and/or maneuvering power tools with position and force control in all six degrees of freedom.

Typical cranes cannot control sway and/or rotations due to environmental perturbations and crane movements. NIST's novel approach, utilizing Stewart Platform technology, significantly reduces these motions and provides six degree-of-freedom control of the suspended load in a simple teleoperated or autonomous control mode. Advanced RoboCrane systems will support NIST's goals in improving industry competitiveness through faster, safer, and increased control of crane loads. Intuitive RoboCrane control requires little training, and enhances worker performance.

Specific customers such as crane manufacturers and construction contractors could benefit from stabilized and maneuverable crane loads for rapid bridge construction equating to $\$ 15 \mathrm{~K}$ per day savings over project duration. Manufacturers of large products such as aircraft, ships, bridges, railroad rolling stock, construction equipment, and farm machinery could benefit from stabilized and maneuverable crane loads for safe, rapid, and inexpensive large scale manufacturing capabilities. U.S. Marine Corps and military crane manufacturers could benefit from a lightweight and flexible gantry design with stabilized and maneuverable crane loads for a multitude of military applications in an expeditionary theater. Nuclear/toxic waste handling facilities, large scale manufacturing and assembly facilities, palletized cargo storage depots, steel erection fabricators, and remote site construction companies could benefit from stabilized and maneuverable crane loads for safe, rapid, and inexpensive large scale manufacturing capabilities.

Technical Approach: Develop robotic systems for large scale, machining, assembly, forming, and finishing. Integrate controls, sensors, world models, software development tools, and operator interface enhancements. Validate and test intelligent systems software architectures. Actively seek to transfer technology to companies for commercial uses. Investigate potential applications in cooperation with other agency and industrial partners. 
FY 94 Accomplishments:

- Designed and procured necessary CANamps for future upgrade of servo control. Designed and installed tension sensors in-line with winch cables in preparation of lower platform force control. Developed graphical control using a commercially available IGRIP simulation package. Performed lateral stiffness and weight lift experiments and compared these to a finite element model for analysis and extrapolation to larger or smaller scale versions of the RoboCrane.

- Through a Marine Corps contract, designed and developed models of a conceptual air transportable expeditionary RoboCrane and compared to multiple gantry designs. Compared current inventoried military equipment to show a lighter, yet similar lift capacity RoboCrane system with multiple applications. Prepared a report and presented results to the Marine Corps as a final contract task.

- Designed a prototype TETRA apparatus using state-of-the-art solid modeling CAD software (Pro/Engineer). Constructed the prototype and attached it to an existing NIST bridge crane for the purpose of investigating multi-cable suspension techniques at depths of up to 75 feet. The current prototype is being used to perform static (non-hoistable) load stability tests in order to quantify the passive stability of the system at a variety of suspension depths.

\section{FY 95 Plans:}

- Work with crane manufacturers to design, develop, and market a bridge construction RoboCrane and temporary bridge system.

- Modify the RoboCrane testbed by installing CANamps, an Enhanced Machine Controller; implementing a standard Real-Time Control System Architecture, and installing a graphics user interface using IGRIP software.

- Work with Marine Corps to develop a military version of RoboCrane.

- Further develop TETRA: install winches on the lower platform to allow active control of suspended loads; implement an EMC controller, joystick input device and remote teleoperative capability; demonstrate remotely controlled (manless) cargo acquisition, stable cargo transfer and accurate cargo placement at suspension depths of up to 75 feet.

\begin{tabular}{|c|c|c|c|c|c|}
\hline IMI ROBOCRANE PROJECT & 95 & 95 & 97 & 98 & 99 \\
\hline $\begin{array}{l}\text { Develop a conceptual design and transfer the technology } \\
\text { to crane manufacturers and/or contractors for large-scale } \\
\text { construction; develop an Intelligent Machine Testbed for } \\
\text { implementation of advanced hardware and software } \\
\text { systems; analyze various components of the } \\
\text { Expeditionary RoboCrane; develop a 25-ton capacity } \\
\text { container mobilizer concept and model; develop actively } \\
\text { controlled prototype TETRA: Load Acquisition and } \\
\text { Stabilization System and demonstrate effectiveness in } \\
\text { long-line cargo handling; perform active stabilization } \\
\text { experiments along with cargo acquisition and placement } \\
\text { testing and publish results. }\end{array}$ & & & & & \\
\hline
\end{tabular}




\begin{tabular}{|c|c|c|c|c|c|}
\hline IMI ROBOCRANE PROJECT & 95 & 96 & 97 & 98 & 99 \\
\hline $\begin{array}{l}\text { Study interface standards for modular control systems for } \\
\text { state-of-the-art, large scale manufacturing capabilities; } \\
\text { use the system for scalable, cable suspended } \\
\text { expeniments as needed for other crane type projects; } \\
\text { advance the graphical user interface to allow semi- } \\
\text { autonomous control and master slave/off-line } \\
\text { programming control; monitor crane usage based on } \\
\text { marketplace feedback, determining system flaws and } \\
\text { potential control system upgrades; work with Building and } \\
\text { Fire Research Laboratory (BFRL) on construction } \\
\text { automation initiative retrofit NIST High Bay bridge crane } \\
\text { with full-scale TETRA system to improve cargo handling } \\
\text { capabilities and fully test TETRA system during actual } \\
\text { cargo handling applications (maximum mass of } 30 \text { metric } \\
\text { tons); develop relationship with crane manufacturer to } \\
\text { include TETRA modifications into their product. }\end{array}$ & & & & & \\
\hline \multicolumn{6}{|l|}{$\begin{array}{l}\text { Implement an operator interface system including } \\
\text { cameras, monitors, and remote sensing capability; } \\
\text { develop interface specifications and control algonithms to } \\
\text { automate specific hazardous work site applications; work } \\
\text { with Building and Fire Research Laboratory (BFRL) to } \\
\text { integrate RoboCrane into construction site databases and } \\
\text { metrology systems; work with industry for production and } \\
\text { installation into manufacturing industries and develop } \\
\text { measurements and standards based on marketplace } \\
\text { feedback. }\end{array}$} \\
\hline \multicolumn{6}{|l|}{$\begin{array}{l}\text { Implement fully autonomous control algorithms to be } \\
\text { controlled via remote sites for virtual manufacturing } \\
\text { capability combined with operator interface feedback. }\end{array}$} \\
\hline $\begin{array}{l}\text { Work with industry to address RoboCrane mobility control } \\
\text { to allow maneuverability over a much broader work } \\
\text { volume using a standard path planner and based on } \\
\text { previous mobility control studies performed at NIST; link } \\
\text { mobility control to remote site efforts and develop interface } \\
\text { standards for mobile systems. }\end{array}$ & & & & & \\
\hline
\end{tabular}


Title: NEXT GENERATION INSPECTION SYSTEM (NGIS)

Staff: (2.24 staff years) MARTIN HERMAN, *Sandor Szabo, *Tsai-Hong Hong, *Marilyn Nashman, *William Rippey

Project Objective and MEL Thrusts Supported: This project will demonstrate an integrated coordinate metrology system that uses multiple advanced sensors to obtain two orders of magnitude increase in coordinate measurement throughput. The integrated system will use an enhanced open architecture controller to control the inspection process on a coordinate measuring machine. Manufacturing Metrology, Intelligent Machines and Systems.

Need Addressed: Manufacturers in the automotive and aerospace industries need fast, efficient, accurate, and flexible methods for measuring the geometry of mechanical parts, particularly complex parts (e.g., transmission housings, air foils, turbine blades, engine valve bodies and seats, dies and molds). This will provide the ability to tie in metrology to process control. Benefits will include increased productivity, increased manufacturer throughput, reduced inventories required, and accelerated time-to-market. It will allow U.S. manufacturers to respond with lightning speed to the identification of new markets and meeting new market demands before foreign competitors do.

Technical Approach: NIST will develop sensor processing and control technologies that will allow Coordinate Measuring Machines to be used must more efficiently than with touch trigger probes. The speed and density of data acquisition can be greatly increased with the use of advanced sensors, such as optical, analog touch, and analog capacitance probes. However, such sensors cannot be used without the appropriate controllers to position them at appropriate points and scan them over surfaces. We propose to incorporate a public domain open architecture controller which will allow users and equipment manufacturers to interface new sensors and devices, to modify the controls to improve performance, and to add new features in response to changing requirements or new technologies.

\section{FY 94 Accomplishments:}

- Implemented an initial version of the three lowest hierarchical levels of the NIST open architecture controller.

- Integrated the following two probes into the system: an Automated Precision, Inc. 3-D analog touch probe and an ExtrudeHone analog capacitance probe.

- Demonstrated the ability to scan surfaces using closed loop feedback on probe data, while servoing on probe height, using each of these probes.

- Demonstrated real-time data collection of machine axis and sensor data during the scans, along with automated recording of the data to text files after each scanning pass.

- Integrated cameras and vision processing hardware into the system.

- Demonstrated vision processing algorithms to extract straight edges of machined parts and overlay them on live imagery. Demonstrated ability to track a moving touch probe and overlay it on the live imagery.

- Demonstrated an operator interface using a Granite hand-held terminal device.

\section{FY 95 Plans:}

- Receive and integrate sensor interface modules from API and ExtrudeHone for their probes, and from Sensor Adaptive Machines, Inc. for its laser triangulation probe, and demonstrate sensor-servoed surface scanning with them.

- Demonstrate integration of vision with an analog probe for surface scanning. Vision will provide "look-ahead" expectations about the positions of straight edges to help provide for smooth control of the scanning probe.

- Demonstrate ability to latch sensor data with machine scales. 
- Modify current NGIS controller to be more compatible with NIST Enhanced Machine Controller (EMC): (a) add EMC communications software, (b) add timing synchronization software, (c) modify current NGIS controller to conform to EMC interfaces, (d) extend EMC operator interfaces to support NGIS controller.

- Port NGIS controller to PC. Maintain a dual testbed with a VME controller and a PC controller, and a capability to quickly change the machine from one controller to the other.

- Demonstrate integration of vision with analog probe to handle surface scanning near non-linear edges. Edges due to holes, grooves, etc. will be extracted and used to control probe motion near these edges.

- Begin work with Wizdom Systems to integrate the PC-based EMC/NGIS controller into their PARADYM-31 product.

Related Developments: We are a member of the National Center for Manufacturing Sciences (NCMS) Next Generation Inspection System (NGIS) consortium, and have been doing work in concert with the consortium. The second phase of the NCMS program, planned to begin in FY 95, will involve NIST transferring NGIS technology to several members of the consortium. The NIST controller and NIST control algorithms will be transferred to Ford Motor Company and Brown \& Sharpe. Also, the NIST controller will be commercialized through Wizdom Systems, Inc.

\begin{tabular}{|l|l|l|l|l|l||}
\hline $\begin{array}{l}\text { NEXT GENERATION FISCAL YEARS } \\
\text { INSPECTION SYSTEM (NGIS) }\end{array}$ & 95 & 96 & 97 & 98 & 99 \\
\hline $\begin{array}{l}\text { Port the NIST NGIS/EMC controller to the PC environment } \\
\text { for easier technology transfer; demonstrate sensor- } \\
\text { servoed scanning of NGIS probes over curved and } \\
\text { complex surfaces; demonstrate the integration of vision } \\
\text { with the NGIS probes; transfer NIST technology to Ford } \\
\text { and other NCMS NGIS sites. [STRS] }\end{array}$ & & & & & \\
\hline $\begin{array}{l}\text { Integrate CAD-based inspection capability into the NIST } \\
\text { system. [STRS] }\end{array}$ & & & & & \\
\hline $\begin{array}{l}\text { Work with Wizdom Systems to integrate the NGIS/EMC } \\
\text { open architecture controller into their Paradym-31 } \\
\text { software product. [STRS] }\end{array}$ & & & & & \\
\hline $\begin{array}{l}\text { Develop software for integration into factory quality control } \\
\text { systems. [STRS] }\end{array}$ & & & & & \\
\hline $\begin{array}{l}\text { Demonstrate construction and modification of CAD models } \\
\text { based on sensor data. [STRS] }\end{array}$ & & & & & \\
\hline
\end{tabular}


Staff: (1.55 staff years) *ERNEST KENT, *Tsungming Tsai, *Michael Roche, *Nicholas Tarnoff, *Joseph Falco

Project Objective and MEL Thrust Supported: The Operator Interfaces for Virtual Manufacturing project develops human interfaces for virtual and distributed manufacturing systems employing HPCC technology. This includes developing methods to collect and present relevant information at an appropriate level of abstraction for interactively examining remote operations and representations, and cooperatively controlling remote systems. Manufacturing Systems Integration.

Need Addressed: The issue addresses human interface standards for control of distributed and simulated manufacturing systems as developed in a laboratory setting for the AMSANT facility. The focus is not only on remote interaction with shop-floor equipment, but also on interfaces for development, management and control of plant and operations at a variety of levels, such as shop-floor supervisor, production foreman, plant manager, production executives, facility designers, and consultants. The general problem is to collect and present the relevant information at the appropriate level of detail and in the most efficient possible format to a variety of remote decisionmakers, and to allow them to interactively examine remote situations and cooperatively control the remote environment.

Technical Approach: Among the significant problems to be addressed are: what kinds of information should flow across the interface, what is the best data format for maximizing operator bandwidth, and what existing and foreseeable interface technologies can best deliver this information? We are attacking these issues through: 1) industry workshops and questionnaires to clarify user needs, 2) definition of standard interfaces between manufacturing databases and operator display systems (in consultation with other SIMA projects), 3) test and evaluation of interface technologies on testbed systems in the AMSANT, and 4) implementation of selected technologies within the AMSANT as interfaces into SIMA projects.

\section{FY94 Accomplishments:}

- Held a joint workshop August 9, 1994, for industry manufacturing experts, VR technology experts, and human factors experts, to define real-world needs and requirements for information, human factors requirements of interfaces, and applicable technologies. Understand user pull and technology push. The results of the questionnaire and the proceedings have been published as NISTIRs.

- Planned and established an operator interface/visualization laboratory for VR-lab equipment. Completed initial facilities plans for space remodeling and network connectivity. Installed a SGI Onyx machine that will become part of the AMSANT network to provide access to databases of all SIMA projects through AMSANT for provision of advanced operator interfaces.

- Implemented initial manufacturing operator interface (moved forward from FY95 milestones). Demonstrated the graphical interface into the real-time database of a simulated gear-manufacturing operation in September 1994. This demonstration included 3D (non-stereo) visualization of the factory facility, in-depth visualization of operation of various workstations such as milling machines, robots, and materials-delivery, graphical and text/numeric presentation of current and planned status, schedules, command queue, inventory, and similar operational information.

\section{FY95 Plans:}

- Implement second-level development of manufacturing operator interface by fully separating display and database functions. Define an initial data/display interface standard.

- Bring AMSANT real-time visualization laboratory on line, with VR and other advanced visualization and interface technologies.

- Contract for study of human factors requirements. 
- Contract for development of multi-user shared environment technology using text-based virtual reality. Make operational using gear-factory simulation database.

- Contract for installation of advanced, graphics-based, immersive VR displays. Make operational using gear-factory simulation database.

\begin{tabular}{|l|l|l|l|l|l|l||}
\hline $\begin{array}{l}\text { OPERATOR INTERFACES FOR VIRTUAL } \\
\text { AND DISTRIBUTED MANUFACTURING FISCAL YEARS }\end{array}$ & 95 & 95 & 97 & 98 & 99 \\
\hline Install operator interface station in AMSANT & & & & & \\
\hline Install operator interface for remote Hexapod & & & & & \\
\hline Install operator interface for RoboCrane & & & & & \\
\hline $\begin{array}{l}\text { Install operator interface for construction site integration } \\
\text { (BFRL) }\end{array}$ & & & & & \\
\hline Develop operator interface standards & & & & & & \\
\hline
\end{tabular}




\section{Title: REAL-TIME CONTROL SYSTEM COMPUTER-AIDED CONTROL SYSTEM ENGINEERING TOOL (RCT)}

Staff: (1.75 staff years) JOHN HORST, Hui-Min Huang, Elena Messina, Tom Kramer, Nicholas Tarnoff, John Micholoski, Will Shackleford, *Contractor

Project Objective and MEL Thrusts Supported: We intend to develop a specification for a graphical user interface tool (RCT) that automates the development of large-scale control system designs according to the RCS reference architecture and design method. The RCT specification will be used to develop a request for proposal for commercial development of the RCT. We will monitor the performance of this contract. For experimentation, we plan to develop a prototype RCT in-house. This project relates to MEL goals in the following ways: 1) The development of open architectures and methods for the design and maintenance of real-time control systems has been identified as a critical need in manufacturing. The Intelligent Systems Division (ISD) of NIST has long been working on such an architecture and methodology (i.e., RCS). The absence of graphical-based design tools accompanying RCS has hindered its transfer to the commercial sector. 2) The development of component-based software has been identified as a NIST ATP focus area. This project will contribute to the development of component-based software for real-time control systems by clearly defining and realizing generic modular software components in an RCS design.

Need Addressed: Control systems integrators, users, and vendors need to decrease development times of largescale, multi-platform control systems for manufacturing. They also need open architecture standards to allow plugand-play compatibility of components such as controllers and sensors. It is our experience that engineers developing large-scale control systems have greatly benefited from the RCS approach to control system design. The creation of a software development tool based on RCS would greatly accelerate the transfer of the RCS technology to control systems integrators, users, and vendors and would contribute to increased manufacturing efficiency, quality, and productivity.

Technical Approach: Tools generally support methodologies either explicitly or implicitly. Consequently we found no commercial tool fully satisfactory for RCS development. Therefore, we argue the need to have a tool developed to our specifications. The choice of a graphical user interface (GUI) tool is evident, since software code development is increasingly being done via GUIs. Such tools reduce system development time and automate many of the code development details unrelated to the application. The RCS CACSE tool (RCT) we are planning to develop would automate much of the process of large-scale control system development, allowing the developer to focus on the application.

Because NIST is neither positioned nor chartered to maintain software, we plan to interest control system software vendors to develop the RCT based on our specifications rather than develop the tool solely in-house. The RCT specifications developed in FY1995 are to form the basis for a request for proposal that would be awarded in FY96. Contract supervision will follow the award. In order to better guide contract development and supervise contract performance, we plan to develop some prototype tool components in-house.

\section{FY94 Accomplishments:}

- Analyzed a wide variety of commercially available tools to see if any of these tools would allow control system development according to the RCS approach, to learn, through the features of each tool, what the control systems developers require in such tools, and to develop a feature list for the potential development of a tool like that proposed under this project.

- Tentatively concluded that no existing commercial tool will provide an appropriate platform for the dissemination of the RCS technology.

- Continuing to investigate the use of some commercially available tools for developing RCS applications. 
FY95 Plans:

- Generate a precisely defined, unambiguous specification of the RCS architecture and design process based on existing documentation.

- Form the basis for the development of an RCS CACSE tool (RCT) specification using the Real-time Control System.

\begin{tabular}{|c|c|c|c|c|c|}
\hline $\begin{array}{l}\text { REAL-TIME CONTROL SYSTEM } \\
\text { COMPUTER-AIDED CONTROL SYSTEM } \\
\text { ENGINEERING TOOL (RCT) } \\
\end{array}$ & 95 & 96 & 97 & 98 & 99 \\
\hline $\begin{array}{l}\text { Use the RCT specification as the basis for a request for } \\
\text { proposal to fund the development of RCT by a commercial } \\
\text { software vendor. [STRS] }\end{array}$ & & & & & \\
\hline Award the contract; supervise the contract. [STRS] & & 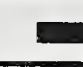 & & & \\
\hline $\begin{array}{l}\text { Develop prototype tool components in-house in order to } \\
\text { better guide contract development and supervise contract } \\
\text { performance. [STRS] }\end{array}$ & & & & & \\
\hline $\begin{array}{l}\text { Test the tool on division projects as it becomes available. } \\
\text { [STRS] }\end{array}$ & & & & & \\
\hline
\end{tabular}


Staff: (2.5 staff years) HARRY SCOTT, Tom Kramer, Kate Senehi, Hui-Min Huang, Nicholas Tarnoff, Alex Meystel

Project Objective and MEL Thrusts Supported: The purpose of this project is to develop a detailed design of a Reference Model Architecture for intelligent control of manufacturing processes; to demonstrate, validate and evaluate the NIST reference model architecture through analysis and performance measurements of a simulated and prototype implementation; to provide U.S. industry with state-of-the-art manufacturing architectures and models, to foster the development and implementation of advanced manufacturing systems, and to anticipate and address the needs of U.S. manufacturing industry for the next generation of advanced manufacturing systems and standards. Manufacturing Systems Integration.

Needs Addressed: The lack of a formal, consistent control architecture with a factory-wide scope is evidenced by characteristics of current implementations and their shortcomings. These include implementation of islands of automation exhibiting a low level of integration because of the absence of a common system architecture design model, functionality limited by the inability to integrate the components of multiple developers as the result of proprietary or non-standard interfaces, minimal reusable software components leading to higher cost, arbitrary differences in implementation techniques because a common model is not followed, and a lack of common development tools because of the differences among various architectural approaches. The development of the reference model architecture for intelligent control of manufacturing systems will directly address these needs. A common architecture will promote a higher level of integration and the standardization of subsystem interfaces. Further, since the architecture will no longer be a "moving target," the potential for software reuse is greater, as is the likelihood of creation of development tools that are useful across many applications. The results are cost savings in development and implementation of intelligent control systems for manufacturing.

Technical Approach: Following on a feasibility study completed in FY93 and the draft joint architecture design developed in FY94, the joint architecture will be refined and a manufacturing application implemented and demonstrated. A workshop on architecture issues is planned in FY95 and a consortia will be sought to identify architectural issues. Discussions will continue with potential industrial partners who have manufacturing facilities suitable for modeling and control under the joint architecture in simulation and as a prototype implementation. The selected facility will be modeled and operated under the joint architecture in simulation, using visualization methods developed under the HPCC Operator Interface Program, and using simulation tools, or extensions to existing tools, developed jointly by NIST and commercial tool vendors. Based on the study of Computer Aided Control System Engineering (CACSE) tools completed in FY94, development of the required tools will begin, and a first version of a CACSE tool will be demonstrated.

\section{FY94 Accomplishments:}

- Conducted a feasibility study that reviewed various architectures and considered the concept of incorporating various aspects from them.

- Introduced an initial version of the architecture through a draft document that addressed preliminary definitions. This draft serves as an overview of the architectural framework for the proposed architecture, a description of key aspects of the functioning of the architecture and a formal model of some portions of the architecture.

- Exploration of potential industry partnerships.

\section{FY95 Plans:}

- Complete detailed functional specification and architectural model using NGIS and EMC/Monarch systems as sources of specific implementation characteristics. 
- Fully specify message suite for operation and startup/shutdown.

- Develop server controllers for material handling and tool management functions.

- Complete factory model and operational scenarios for first implementation.

- Implement factory model in simulation.

- Host workshop on architecture issues.

- Build real-time, scheduled, and transition controller types; develop required graphical support of controller user interfaces.

- Develop/integrate CASE components appropriate for joint architecture.

- Develop configuration management and scripts.

- Identify and implement application specific non-generic work elements.

- Integrate contractor-developed communication tool with implementation.

- Create process and production plans for first implementation.

- Develop/Integrate data base and create necessary resource files for first implementation.

- Integrate developed components in first implementation.

\begin{tabular}{|c|c|c|c|c|c|}
\hline $\begin{array}{l}\text { REFERENCE MODEL ARCHITECTUREJJOINT } \\
\text { ARCHITECTURE } \\
\text { FISCAL YEARS }\end{array}$ & 95 & 96 & 97 & 98 & 99 \\
\hline $\begin{array}{l}\text { Seek industrial partners with suitable factories for } \\
\text { emulation/control. [OA] }\end{array}$ & & & & & \\
\hline $\begin{array}{l}\text { Host workshop on architecture issues and seek } \\
\text { consortium to work toward national/international standard } \\
\text { for reference model architecture. [OA] }\end{array}$ & & & & & \\
\hline Develop design of first version of joint architecture. [OA] & & & & & \\
\hline Determine factory application for first implementation. [OA] & & & & & \\
\hline $\begin{array}{l}\text { Develop first, partial implementation and integrate with } \\
\text { factory emulation. [OA] }\end{array}$ & & & & & \\
\hline Develop data to support first implementation. [OA] & & & & & \\
\hline $\begin{array}{l}\text { Develop complete implementation of joint architecture. } \\
\text { [OA] }\end{array}$ & & & & & \\
\hline $\begin{array}{l}\text { Integrate CASE components to support implementations } \\
\text { of joint architecture systems. [OA] }\end{array}$ & & & & & \\
\hline $\begin{array}{l}\text { Document the initial implementation of the joint } \\
\text { architecture. [OA] }\end{array}$ & & & & & \\
\hline $\begin{array}{l}\text { Prepare report on the complete implementation of the joint } \\
\text { architecture. [OA] }\end{array}$ & & & & & \\
\hline $\begin{array}{l}\text { Prepare report on CASE support tools used and needed. } \\
\text { [OA] }\end{array}$ & & & & & \\
\hline
\end{tabular}


Staff: (0.5 staff years) ALBERT J. WAVERING, *Tom Wheatley, *Keith Stouffer, *Bob Russell, *John Michaloski

Project Objective and MEL Thrust Supported: Study the implementation of telerobotic surface and edge finishing for aircraft depot tasks, based on the Unified Telerobotic Architecture Project (UTAP) architecture and interfaces. Manufacturing Systems Integration.

Need Addressed: The Aircraft Directorate at the San Antonio Air Logistics Center (SA-ALC) is responsible for maintenance on the C-5 airframe, including such tasks as paint stripping and repainting, part cleaning, surface finishing of panels, skin repair of engine cowls, and sealing and de-sealing of fuel tanks. Telerobotics has been identified as a key enabling technology for improving the productivity of a wide range of aircraft maintenance tasks. A manipulator under telerobotic control augments the cognitive skills of the human operator with the precision and consistent performance of a machine. However, an impediment to the widespread implementation and use of telerobotic technology for depot maintenance tasks has been the lack of a well-defined, modular software architecture and standard interfaces to facilitate the integration of system components and to provide a consistent operator interface. To improve the efficiency of implementing telerobotic applications, SA-ALC sponsored a preliminary study (performed by JPL) to develop a proposal for a generic telerobotic control system architecture. During FY 94, Advanced Cybernetics Group, Inc. (ACG), JPL, and Trellis joined NIST in defining the interfaces for the architecture. The next step is to validate these UTAP interfaces for one or more depot maintenance applications. In this project, aircraft surface and edge finishing applications will be investigated to evaluate the UTAP architecture and interfaces, and to bring them closer to implementation at SA-ALC and potentially other ALC's and commercial aircraft maintenance facilities.

Technical Approach: The two related applications which have been selected to study the usefulness of the UTAP architecture and interfaces are edge finishing and surface finishing. NIST will investigate the application of UTAP specifications to edge finishing (deburring) by following the UTAP arrangement of software modules and message definitions in developing the Advanced Deburring and Chamfering System (ADACS). Since NIST does not have significant expertise in robotic surface finishing, a subcontractor will be funded to develop a surface finishing demonstration built around a UTAP compliant controller. Telerobotics experts at JPL will assist NIST in evaluating the design and final implementation of the operator interface and other aspects of the demonstration system built by the subcontractor.

\section{FY 94 Accomplishments:}

- Developed and published initial UTAP interface specification document (with JPL and others).

- Funded feasibility studies of recommended architecture, and interfaces (performed by subcontractor ACG).

- The UTAP architecture and interface work performed to date has had significant impact beyond the Air Force applications at SA-ALC. It is influencing the Next Generation Controller (NGC) project, since it has been suggested to use the UTAP interface definitions as a specific starting point for an NGC implementation. The UTAP documents may also be considered as a starting point for an AIAA space robotics architecture standards document.

\section{FY 95 Plans:}

- Map ADACS functional architecture into UTAP to evaluate the suitability of the UTAP architecture and interfaces for edge finishing.

- Map ADACS interfaces into UTAP.

- Reorganize ADACS control system code and make other modifications as necessary to achieve 
compliance with UTAP.

- Fund development of surface finishing demonstration system (external contract).

- Fund evaluation of operator interface design and finished product (external contract).

- Identify deficiencies in the UTAP architecture and interface specifications and suggest modifications that address the deficiencies.

\begin{tabular}{|l|l|l|l|l|l||}
\hline $\begin{array}{l}\text { TELEROBOTIC FINISHING FISCAL YEARS } \\
\text { OF AIRCRAFT SURFACES }\end{array}$ & 95 & 96 & 97 & 98 & 99 \\
\hline $\begin{array}{l}\text { Develop ADACS implementation of UTAP controller for } \\
\text { edge finishing application. [OA] }\end{array}$ & & & & & \\
\hline $\begin{array}{l}\text { Fund development of surface finishing demonstration. } \\
\text { [OA] }\end{array}$ & & & & & \\
\hline $\begin{array}{l}\text { Report details and results of UTAP implementations, and } \\
\text { provide specific recommendations for modifications. [OA] }\end{array}$ & & & & & \\
\hline $\begin{array}{l}\text { Provide technical assistance to organizations pursuing the } \\
\text { application of UTAP to other projects. [OA] }\end{array}$ & & & & & \\
\hline $\begin{array}{l}\text { Participate in implementation of surface finishing } \\
\text { applications at SA-ALC. [OA] }\end{array}$ & & & & & \\
\hline $\begin{array}{l}\text { Participate in the development of UTAP implementations } \\
\text { for other depot maintenance tasks and further refine } \\
\text { architecture document and interface specifications for } \\
\text { national and international standards. [OA] }\end{array}$ & & & & & \\
\hline
\end{tabular}




\section{MANUFACTURING SYSTEMS INTEGRATION DIVISION}

\section{MISSION:}

Provide a focus for national research and development of the infrastructural technologies and standards required for the implementation of virtual enterprises in a manufacturing environment. 


\section{Staff: (2.0 staff years) ${ }^{*}$ Newton Breese, ROB DENSOCK, *Deborah Nickerson Fowler}

Project Objective and MEL Thrusts Supported: The objective of the AMSANT project is to provide a distributed, multinode facility at NIST that will enable collaborative development of technologies and standards to support distributed and virtual manufacturing enterprises through an advanced computing and communications infrastructure. Manufacturing Systems Integration.

Need Addressed: The AMSANT project will address the high performance computing and communications needs of the SIMA and NAMT programs. High performance computers and communications are necessary building blocks to effectively integrate the various applications within a distributed virtual manufacturing enterprise and to promote new forms of collaborative engineering and electronic commerce. The AMSANT facilities will house special purpose, high-performance computers equipped with high speed networking capabilities that will be used by NIST researchers and external collaborators to develop new manufacturing technologies and standards. The AMSANT network will provide an interface to external testbeds across the United States that will team with NIST to develop, refine, test, and transfer advanced manufacturing technologies and associated applications. The AMSANT project will also investigate effective, low cost networking solutions that are needed to interface with small and medium sized manufacturing facilities.

Technical Approach: A thorough requirements analysis was conducted in order to determine what the AMSANT project needed to provide in terms of computing resources, networking capabilities, application software, laboratory space, and demonstration facilities. In response to the requirements analysis, an initial AMSANT facility and supporting computing and communications infrastructure were designed.

The AMSANT network is centered around the latest development in high speed networking; Asynchronous Transfer Mode (ATM). ATM was chosen for its speed (155 Mbps dedicated bandwidth to each station) and its ability to effectively support voice and video applications such as desktop video conferencing and virtual reality applications. Switched ethernet will be used to support slower systems that cannot drive the ATM. ISDN and high-speed modems will be investigated for dial-up access to the AMSANT network. As collaborative partners are identified, dedicated wide area communications links will be installed. These links will connect NIST technology testbeds with external manufacturing testbeds to support a variety of distributed manufacturing scenarios.

The AMSANT high performance computing base is centered around a Sun SPARCcenter 2000 Multi-processor Unix Server. This server will house the most of the necessary applications as well as documentation and data files. A Sun SPARCserver 1000 house the extensive repositories of externally available information and will support a wide variety of interfaces to that information in order to support efficient technology transfer. Other systems within the AMSANT facility include several SGI Onyx and Indigo II systems, several Sun SPARCstation 20 systems, and several Pentium PCs.

Many types of application software will be installed on the AMSANT servers including information engineering tools, integration tools, engineering applications, document publishing tools, code development tools, and information dissemination tools.

The AMSANT facility(s) will serve as a working laboratory that industrial collaborators and NIST researchers can utilize as well as serve as a demonstration site to show proof-of-concept for the research and development activities at NIST. The first such AMSANT facility will be constructed in the Metrology building at NIST. The facility will house the AMSANT servers, the ATM networking equipment, and fifteen high performance 
computers. One room in this facility will be dedicated to research in virtual reality applications and techniques for use in the Operator Interfaces project. The facility will contain large overhead monitors, an electronic whiteboard, a TV and VCR, an overhead projector, printers, and several tables to support daily research activities as well as demonstrations.

A yearly requirements analysis will be conducted throughout the life of the AMSANT project to assure that the AMSANT continues to provide an adequate and appropriate computing and communications infrastructure.

\section{FY 94 Accomplishments:}

- Performed AMSANT requirements analysis.

- Designed initial facility and network.

- Constructed initial facility in Metrology building at NIST.

- Procured furnishings for facility.

- $\quad$ Procured ATM networking equipment from Fore Systems.

- Began procurement of new AMSANT computing equipment.

FY 95 Plans:

- Install, configure, and test new computer systems and networking equipment.

- Install new applications software.

- Establish ATM connections to CSL, CAML, and ATDnet.

- Install and test desktop video conferencing software at NIST and across ATDnet.

- Investigate ISDN and high-speed modem equipment.

- Conduct yearly AMSANT requirements analysis.

- Complete Installation of AMSANT furnishings.

Related Developments: The AMSANT project of MEL teamed with CSL and CAML to pioneer an ATM backbone network at NIST and to connect NIST to the ATDnet. The ATDnet is a Washington area ATM test network that connects several government agencies. These network connections will allow for better communications within NIST and allow us to test the usefulness of ATM in the wide area.

\begin{tabular}{|c|c|c|c|c|c|}
\hline $\begin{array}{l}\text { ADVANCED MANUFACTURING SYSTEMS AND } \\
\text { NETWORKING TESTBED (AMSANT) FISCAL YEARS }\end{array}$ & 95 & 96 & 97 & 98 & 99 \\
\hline $\begin{array}{l}\text { Complete construction of first AMSANT node including } \\
\text { hardware and software [STRS] }\end{array}$ & & & & & \\
\hline $\begin{array}{l}\text { Establish ATM connections to CSL, CAML, and ATDnet } \\
\text { and test the benefits of ATM [STRS] }\end{array}$ & & & & & \\
\hline $\begin{array}{l}\text { Design and construct second AMSANT node to support } \\
\text { Engineering Design testbed. Apparel Manufacturing } \\
\text { project, and National PDES Testbed [STRS] }\end{array}$ & & & & & \\
\hline $\begin{array}{l}\text { Install communications links to remote testbeds (DoE } \\
\text { TEAM, NIIIP, GE Casting) [STRS] }\end{array}$ & & & & & \\
\hline $\begin{array}{l}\text { Develop a comprehensive network management system } \\
\text { to manage AMSANT and MSID networks [STRS] }\end{array}$ & & & & & \\
\hline
\end{tabular}




\begin{tabular}{|c|c|c|c|c|c|}
\hline $\begin{array}{l}\text { ADVANCED MANUFACTURING SYSTEMS AND } \\
\text { NETWORKING TESTBED (AMSANT) FISCAL YEARS }\end{array}$ & 95 & 96 & 97 & 98 & 99 \\
\hline \multicolumn{6}{|l|}{$\begin{array}{l}\text { Expand the development environment supported by } \\
\text { AMSAMT to include other research and demonstration } \\
\text { facilities at NIST that are seamlessly connected via ATM } \\
\text { [STRS] }\end{array}$} \\
\hline \multicolumn{6}{|l|}{$\begin{array}{l}\text { Migrate proven computing and networking technologies to } \\
\text { the desktop of NIST researchers [STRS] }\end{array}$} \\
\hline \multicolumn{6}{|l|}{$\begin{array}{l}\text { Increase the number of communications links to external } \\
\text { testbeds to } 10 \text { [STRS] }\end{array}$} \\
\hline \multicolumn{6}{|l|}{$\begin{array}{l}\text { Upgrade the design of other NIST computing labs based } \\
\text { on the AMSANT design in order to allow cooperative } \\
\text { research among the NIST laboratories [STRS] }\end{array}$} \\
\hline $\begin{array}{l}\text { Test and evaluate new computing and networking } \\
\text { technologies that will benefit manufacturing [STRS] }\end{array}$ & & & & & \\
\hline
\end{tabular}


Project Objective and MEL Thrust Supported: To assist General Electric with the development and technology transfer of a prototype agile virtual manufacturing process development environment for high quality sand-molded castings. Maufacturing Systems Integration.

Need Addressed: Manufacturing process development is the largest time and cost element for new product introduction. The manufacturing process development phase covers all work performed to reach a production ready state for a new product design. Current and future market needs along with fierce global competition require major reductions in the manufacturing process development time and cost without quality compromise. Direct speed-up and enhancement of current manufacturing process development activities will not be sufficient to guarantee the competitiveness of U.S. industry. The basic structure doing manufacturing process development will have to be changed into a virtual one that taps into the best internal and external resources available and utilizes a new operational mechanism that provides major speed and cost advantages.

One of the longest manufacturing development cycles is that for steel castings which can be as long as two years. This project addresses renewing and revitalizing the current castings acquisition process for a casting supplier and its sub-tier suppliers and service providers. The project will focus on increasing the manufacturing agility for steel castings that are made using sand molds.

Few software tools supporting casting manufacturing agility are available, and fewer still speak to each other except in their own proprietary languages. As a result, casting manufacturing processes are developed through a loosely coupled activities where humans provide the integration, coordination, and most of the information content. These systems lack the agility to respond to the challenges of endless unanticipated changes in product design and market needs.

Technical Approach: The project will utilize integration technologies and functional technologies to address the critical need for agile manufacturing development of castings. The integration technologies will include leveraging the use of the NII infrastructure and services to streamline communications between all the life-cycle perspectives required to produce castings. Active document technology which enable rich electronic technical data packages capturing design and manufacturing intent will also be used to facilitate the ease with which specifications are produced, reviewed, and extended.

The functional technologies to be employed are necessary to accelerate and enhance the performance of each stage of the casting manufacturing process development phase. These technologies include those supporting castings producibility analysis, process and pattern design, pattern prototyping, pattern fabrication, process and tooling validation, and networked manufacturing services.

To facilitate technology dissemination, the casting project participants will work with NIST to establish a testbed for castings manufacturing process development technologies. The AMSANT facility at NIST will serve as repository for the specifications and prototype software interfaces developed as part of the project. AMSANT will also serve as a vehicle for testing and demonstrating virtual castings development processes.

FY94 Accomplishments: (new start)

\section{FY95 Plans:}

- Develop casting design specification templates

- Develop methodology to create/communicate design specifications 
- Develop casting manufacturability database and interfaces

\begin{tabular}{|c|c|c|c|c|c|}
\hline $\begin{array}{l}\text { AGILE MANUFACTURING DEVELOPMENT } \\
\text { OF CASTINGS } \\
\text { FISCAL YEARS }\end{array}$ & 98 & 96 & 97 & 98 & 99 \\
\hline Establish optimized castings design process [ARPA] & & & & & \\
\hline $\begin{array}{l}\text { Establish enhanced pattern design/fabrication/validation } \\
\text { methodologies [ARPA] }\end{array}$ & & & & & \\
\hline $\begin{array}{l}\text { Define requirements for scale-up to heavy castings } \\
\text { [ARPA] }\end{array}$ & & & & & \\
\hline $\begin{array}{l}\text { Establish virtual casting development process testbed at } \\
\text { NIST [ARPA] }\end{array}$ & & & & & \\
\hline
\end{tabular}


Title: APPAREL PRODUCT DATA EXCHANGE STANDARD/CUSTOMER-DRIVEN APPAREL MANUFACTURING

Staff: (2.5 staff years) ${ }^{*}$ Jeane Ford, TINA LEE, *Howard Moncarz, ${ }^{*}$ Mike Read, ${ }^{*}$ Summer Student

Project Objective and MEL Thrusts Supported: The objective of this five-year project is to develop the Apparel Product Data Exchange Standard (APDES) and to develop the Customer-Driven Apparel Manufacturing (CDAM) environment for the APDES implementation. APDES, a STEP-based apparel standard, is a set of comprehensive specifications to support computer integration of the apparel product life cycle. Manufacturing Systems Integration, Intelligent Machines and Systems.

Need Addressed: The apparel industry is one of America's largest manufacturing industries, shipping \$128 billion of apparel and textile products in 1990 and providing over $10 \%$ off all manufacturing jobs, particularly for women and minorities. The industry in the U.S. faces fierce competition from imported products. The percent market penetration for apparel imports has gone from $28 \%$ in 1980 to $66 \%$ in 1992 . The industry requires special attention.

The apparel industry is in a transition from a labor-intensive, manually operation base to a more competitive technology base. New technologies have impacted the entire process of designing, producing, and distributing apparel. However, most machinery manufacturers are only concerned with optimizing their own equipments and there are no industry accepted guidelines for information transfer within the apparel manufacturing enterprise. The industry is becoming more aware of the need for integration standards. This project will be a formal and active standards-development effort in support of computer integration of the apparel product life cycle.

Technical Approach: In recent years, NIST has been working on developing APDES. We have established a framework for extending STEP to apparel application areas. We have identified fifteen application areas for the effective computer integration of the information required to operate an apparel manufacturing enterprise. We have also specified a prototype Application Protocol (AP) for Ready-to-Wear Pattern Making, one of the identified application areas, using the STEP methodology.

To best serve the American apparel industry, we plan to integrate the initial prototype AP of the Ready-to-Wear Pattern Making into STEP. We also plan to develop APs for the entire set of application areas that we have identified. We will use the prototype AP of Ready-to-Wear Pattern Making as a strawman for a formal STEP AP. The STEP AP of Ready-to-Wear Pattern Making can then be used as the model for developing APs for other application areas. The APs will be developed in full conformance with ISO guidelines for formal STEP AP development.

We plan to demonstrate the implementation of the first prototype AP, as well as other APs when completed, in an APDES/ CDAM environment. The plan for the CDAM implementation is to create a testbed for advanced apparel design and manufacturing that is field operational. In other words, the separate components required that will create the "virtual enterprise" will be located at actual field sites, such as the Defense Personnel Service Center and an apparel manufacturer. Those separate field sites will be integrated within the APDES/CDAM environment and the total system will be referred to as the testbed. The implementation will be done in steps to show incremental progress toward the ultimate, full-fledged operational testbed. The initial proof-of-concept implementation will require relatively minor roles from a smaller number of participants, but the framework will be created with the intent to accommodate more participants, more technology components, and successively greater functionality of each component and the entire system.

FY 94 Accomplishments:

- Completed a literature survey and published the NISTIR 5365, A Bibliography on Apparel Sizing and 
Related Issues, that collects sizing and its related areas references for the quick use of apparel researchers. Several organizations including the American Society for Testing and Material (ASTM) and Virginia Polytechnic Institute are using this reference material.

- Investigated types of body dimensions that are needed for the fit and manufacture of garments and patterns. Published the NISTIR 5411 entitled Body Dimensions for Apparel that provides a suggested list of data requirements for the conducting of future body measurements surveys and for the development of new or improved sizing standards for apparel. The body dimensions list is being used by the Institute for Standards Research of ASTM to help develop a new apparel sizing standard for women.

- Participated in the 1994 Bobbin Show, that was held September 27-30 in Atlanta, GA. Bobbin is a major manufacturing trade show and the largest in the world for the apparel and sewn products industry. About 900 exhibitors showcased their latest products and services at the Show. The APDES poster was part of DLA exhibit. The theme for the DLA exhibit was Customer Driven Apparel Manufacturing: Research to Reality. It featured the major DLA research projects. NIST's APDES project was one of the projects presented in the DLA's 8-minute video presentation and was included in the DLA brochure for distributing at the show.

- Published a journal article, "CALS Technologies Applied to the Fiber/Textile/Apparel Industry", in CALS/Enterprise Integration Journal. It provides an overview of the advances being made in the Fiber, Textile, and Apparel industry with EDI and STEP. The article enables national recognition of NIST's APDES standard development effort.

- Developed four proposals to submit to DLA's newly launched R\&D program: Apparel Research Network (ARN). NIST has been recognized as an influence role in ARN.

- Established an on-going dialog with leading apparel CAD companies and introduced to them the APDES concept.

\section{FY 95 Plans:}

- Develop and submit the candidate AP summary for Ready-to-Wear pattern making to ISO for approval as a new AP project.

- Define APDES/CDAM environment including top level "to be" architecture and top level "prototype implementation" architecture.

- Identify participants in the prototype implementation and pursue R\&D agreements.

- Analyze current environment of participants.

- Demonstrate the first phase of the APDES/CDAM implementation.

- Develop long-term APDES/CDAM project plan.

\begin{tabular}{|l|l|l|l|l|l||}
\hline $\begin{array}{l}\text { APPAREL PRODUCT DATA EXCHANGE } \\
\text { STANDARD/CUSTOMER-DRIVEN } \\
\text { APPAREL MANUFACTURING }\end{array}$ FISCAL YEARS & 98 & 96 & 97 & 98 & 99 \\
\hline $\begin{array}{l}\text { Complete the AP of Ready-to-Wear Pattern Making as a } \\
\text { STEP International Standard [DLA, STRS] }\end{array}$ & & & & & \\
\hline $\begin{array}{l}\text { Conduct workshops and develop plan to enable APDES } \\
\text { environment for CDAM [DLA] }\end{array}$ & & & & & \\
\hline $\begin{array}{l}\text { Establish and publish APDES/CDAM environment } \\
\text { including "prototype implementation" architecture and "to } \\
\text { be" architecture [DLA, STRS] }\end{array}$ & & & & & \\
\hline
\end{tabular}




\begin{tabular}{|c|c|c|c|c|c|}
\hline $\begin{array}{l}\text { APPAREL PRODUCT DATA EXCHANGE } \\
\text { STANDARD/CUSTOMER-DRIVEN } \\
\text { APPAREL MANUFACTURING } \quad \text { FISCAL YEARS }\end{array}$ & 96 & 96 & 98 & 98 & 99 \\
\hline $\begin{array}{l}\text { Demonstrate APDES/CDAM environment. (Phase 1: } \\
\text { proof-of-concept implementation using current } \\
\text { ready-to-wear pattem making technology, Phase 2: } \\
\text { prototype implementation with made-to-measure } \\
\text { technology, Phase } 3 \text { : pilot implementation with new design } \\
\text { technology and made-to-measure technology) [DLA, } \\
\text { STRS] }\end{array}$ & & & & & \\
\hline $\begin{array}{l}\text { Establish and manage roadmap and planning model for } \\
\text { the entire set of apparel APs [DLA, STRS] }\end{array}$ & & & & & \\
\hline $\begin{array}{l}\text { Establish and lead ISO apparel working group and provide } \\
\text { support to apparel AP develop team [STRS] }\end{array}$ & & & & & \\
\hline $\begin{array}{l}\text { Develop and promote the entire set of apparel APs to } \\
\text { STEP International Standard (IS) status [STRS] }\end{array}$ & & & & & \\
\hline
\end{tabular}


Title: APPLICATION PROTOCOL DEVELOPMENT ENVIRONMENT (APDE)

Staff: Josh Lubell, *MARY MITCHELL, Lisa Phillips, ${ }^{*}$ Chris Stillwell, ${ }^{*}$ Peter Wilson

Project Objective and MEL Thrust Supported: This project accelerates the development of STEP and to aid Application Protocol developers in creating AP specifications more efficiently, with higher quality and at a lower cost. Manufacturing Systems Integration.

Need Addressed: Our initial customers are from within the standards organizations along with industrial partners that are necessary to validate the specifications. In particular, the results of this work will be used by groups that are developing STEP: the International Organization for Standardization (ISO) and the U.S. IGES/PDES Organization (IPO). We have identified potential industrial partners and specific standards projects to review our project requirements and goals. There is a close interaction with the PDES, Inc. consortium which is promoting the creation of new STEP Application Protocols (APs) (APs are the focus of STEP implementations), and promoting AP implementation by vendors. We have identified several ISO STEP AP projects that view this project as critical to their success in progressing their AP and with which a close interaction will be maintained throughout the development project (AP223 led by CTC in Johnstown, PA, AP210 led by PDES, Inc. and AP214 led by ProSTEP in Germany). The Department of Defense funded PAS-C project to develop an AP for use of composite materials has been another interaction. As the project matures collaborations with various software suppliers will be established (SoftQuad - SGML Tools, STEP Tools Inc. and PDIT are the first of these). Current practices for AP development require extraordinary labor expenditures on behalf of AP developers to define the requirements of an $\mathrm{AP}$ and to deliver them into a finished AP document.

Technical Approach: This project will establish an integrated suite of software tools to assist STEP Application Protocol (AP) development. These software tools will interact with a central information registry at NIST consisting of STEP related documents and data, much of it represented in SGML. The process of developing acceptable international AP specifications requires that development teams identify what information is appropriate to the AP, model that information, verify that the information models are correct, identify how this information will be satisfied by STEP standardized information model constructs, identify test criteria for implementations of the AP, and describe all of these components in a document of mandated format. The APDE will provide and integrated toolset to support each of these process steps.

The APDE project will be addressed in phases. During the first phase, emphasis is placed on specifying remote access services (RAS) to the existing APDE toolset, establishing the AP document in a standards based format (SGML), and evaluating the commercial tools needed to complete and augment the APDE tools. The second phase will provide an implementation of RAS, provide an integrated environment for all of the tools, populate the AP information base(s), complete the SGML environment, and begin the environment to support AP implementation. The last phase will focus on completion of the AP implementation environment, prototype implementation support tools, and have identified outside organizations to support the functionality. The long term APDE strategy is to maintain a STEP information repository of information, models, metrics, analysis, and currently available tools for use by the STEP development and implementation communities.

FY94 Accomplishments:

- Analyzed third-party software, focusing on SGML tools for developing an author/editing/publishing environment, and AP information repository (APIB) database.

- Conducted user requirements workshops (i.e. Greenville IPO/ISO meeting, etc.) and surveys, prioritized needed tool capabilities for FY95 plan of work (NISTIRs).Acquired, installed, and pilot use of SGML and database tools completed. Selected OpenText Database, SoftQuad Editing, FastTag document conversion, and Hammer publishing tools for customization.

- Validated SGML STEP Integrated Resource (IR) Document Type Description (DTD), initiated DTD. 
DTD accepted by ISO SC4 editing committee (Document N43). Documented STEP document style, obtained agreement on document structure and required text, and released interium Latex style files (needed until SGML editing environment released/adopted by STEP editors)

- $\quad$ Tagged four STEP IRs.

- Developed SGML AP DTD, initiated DTD validation. DTD submitted by ISO SC4 editing committee.

- Documented Remote Access Services (RAS) requirements, state of the practice, and capabilities to information and service offerings to support initial implementation of RAS. (NISTIR and conference proceedings)

- Implemented initial Remote Access Services (RAS) for APDE, made available via EXPRESS server.

- Demonstrations at IPO/ISO meeting, NII conference (paper available), NIIIP (ARPA TRP project) Reference Architecture meeting.

FY95 Plans:

- $\quad$ SGML environment paper completed and published in SGML '94 proceedings.

- APDE Architecture paper completed and ready for publication.

- Tag AP and complete validation of DTD for AP's. Enhance DTDs to simplify tag names and tagging/modify tagged documents appropriately. Populate the AP information base with remaining STEP parts (initial release parts)

- Customize and integrate a STEP SGML environment by customizing the interface to SoftQuad Author/Editor; providing SGML database storage and retrieval capability by customizing query and viewer interfaces; automating document tagging for Latex and WordPerfect formats using Flex/Bison for Latex and FastTag for WordPerfect, specifying SGML-to-LaTeX mapping, implementing mapping with Hammer, and supporting printing of graphics as publication tools; and referencing the path generation tool.

- Integrate other APDE tools with the APIB

- Demonstrate APDE and APIB capabilities at CALS Expo'95, IPO/ISO meeting

\begin{tabular}{|c|c|c|c|c|c|}
\hline $\begin{array}{l}\text { APPLICATION PROTOCOL DEVELOPMENT } \\
\text { ENVIRONMENT (APDE) } \\
\text { FISCAL YEARS }\end{array}$ & 95 & 96 & 97 & 98 & 99 \\
\hline $\begin{array}{l}\text { Produce on-line information repository (APIB) containing } \\
\text { SGML-encoded IS STEP IRs and Part } 203 \text { that will } \\
\text { contain Parts } 11,21 \text {, and } 22 \text { with non-SGML tagging and } \\
\text { will be developed using text retrieval software from Open } \\
\text { Text; implement software to aid in tagging STEP } \\
\text { documents in SMGL; extend current APDE user interface } \\
\text { to make full use of APIB; publish document describing } \\
\text { recommended APDE architecture; conduct alpha testing } \\
\text { with one or two AP teams; implement software tool for } \\
\text { translating SGML-tagged STEP documents into LaTeX for } \\
\text { electronic preview and publishing }\end{array}$ & & & & & \\
\hline
\end{tabular}




\begin{tabular}{|c|c|c|c|c|c|}
\hline $\begin{array}{l}\text { APPLICATION PROTOCOL DEVELOPMENT } \\
\text { ENVIRONMENT (APDE) }\end{array}$ & 95 & 95 & 97 & 98 & 99 \\
\hline $\begin{array}{l}\text { Develop STEP-smart SGML document editing software for } \\
\text { AP developers to use; publish document discussing APIB } \\
\text { architecture and software integration issues; produce } \\
\text { users manual; improve support for building mapping table; } \\
\text { establish NIST APIB server for entire STEP community; } \\
\text { package APDE client software and make available as a } \\
\text { distribution; produce document planning transition from } \\
\text { SOLIS to APIB }\end{array}$ & & & & & \\
\hline $\begin{array}{l}\text { Support tools for activity model development, including } \\
\text { IDEFO and IDEF1X modelers; add groupware for } \\
\text { configuration management, workflow; develop access } \\
\text { control mechanisms so that users can safely modify APIB } \\
\text { documents; add context-sensitive on-line help; establish } \\
\text { metrics for tracking use of STEP and progress toward its } \\
\text { development; expand architecture to allow for multiple } \\
\text { servers }\end{array}$ & & & & & \\
\hline $\begin{array}{l}\text { Transition to NIST-maintained service with a site } \\
\text { administrator; add conformance testing capability; add } \\
\text { more tools for supporting STEP implementors since, by } \\
\text { now, there will be a large body of completed APs }\end{array}$ & & & & & \\
\hline $\begin{array}{l}\text { Make APDE a permanent service serving as the online } \\
\text { repository for STEP and tool environment for AP } \\
\text { developers and implementors }\end{array}$ & & & & & \\
\hline
\end{tabular}


Staff: (1.2 staff years) *JESSE CRUSEY, *Jeane Ford

Project Objective and Mel Thrust Supported: The National PDES Testbed initiated a project in FY94 to identify DoD and industrial requirements for ISO 10303, Standard for the Exchange of Product Model Data (STEP), Application Protocols. With a goal to address dual-use priorities and benefits, the initial effort has been focused on the development of a suite of STEP Application Protocols for Digital Technical Product Data Packages. The overall objective of this project is to significantly improve the requirements process for STEP Application Protocol and drive the development and validation of APs to meet both Government and industry priorities. Manufacturing Systems Integration.

Need Addressed: The target customer group for this project includes both government agencies and commercial enterprises ranging from large corporations and small suppliers. Currently DoD/other Agencies and industry receive and archive technical data for products and systems in varying forms, e.g., drawings, computer models, databases, micro-film. Vast amounts of technical data are controlled by numerous differing standards. Separate standards are used by Government agencies and within the commercial arena. Lengthy cycle times, data integrity and redundancy issues, non-value added operations and high costs characterize the many processes which are involved in managing technical product data packages.

The community of thousands of large corporations, government facilities and small companies must establish a national and global infrastructure to process and manage electronic product data among business partners. The challenge is to address the specific requirements of each sector and to respond with new ways of doing business, cost-effective/affordable systems and the establishment of dual-use standards and specifications.

Technical Approach: Commercial industries and DoD consider STEP a key enabling technology to accomplish the transition from hard copy based data to a digital form of technical information for a product. The standard specifies how to represent all element of product data in digital form and how to share this information among business partners in the form of physical files and databases. STEP specifies more than just the geometry and shape characteristics of a part or product. The standard includes other information such as configuration management, tolerances, materials properties, and conformance classes for various engineering design representations.

A STEP Application Protocol (AP) provides standardized sets of information applicable to the exchange of data required to support a specific application use of the data. This project will develop a suite of STEP APs to enable the exchange and use of technical product descriptions for supporting acquisition, production, engineering and product support. This data collectively defines the design configuration and procedures required to ensure adequacy of product performance. It consists of all application technical data, such as drawings, parts lists, specifications, standards, operational parameters, quality assurance provision and packaging details. The initial scope will support the common core set of requirements shared by the users of Industry Product Data Packages and DoD Technical Data Packages. This core set of requirements will be derived from high demand informational elements within specific life cycle functions and commodity sectors identified through workshops with Government and industry.

\section{FY94 ACCOMPLISHMENTS:}

- Formed joint team from NIST, Air Force, and PDES, Inc. This alliance has merged three separate efforts with similar statements of work and common goals into one. Both the expertise of each member as well as the independent funding sources are being leveraged to accomplishment a level of effort that no one partner could do alone. Several Navy Program Offices are currently expressing interest in joining the team and contributing funding.

- Applied first stage capabilities of electronic Requirements Management System to capture and analysis 
requirements for TDP AP gathered from user community. This system will provide Groupware techniques to improve the requirements process for STEP development activities.

- Conducted first DUAL-USE REVIEW BOARD meeting and presented project to IPO/SO and other industrial associations. The expansion of the initial requirements from $\mathrm{DoD}$ to include commercial needs enables this project to truly represent dual-use environments and enable one set of standards for technical product data packages to be used nationally and internationally by both Government and industry.

- Defined Preliminary Data Description Exchange (DDE) Flle Specification. This specification provides a complete description of the contents of a complex data package consisting of multiple TDP elements, multiple files and formats. It provides metafile data for an EDI transaction giving processing information and reference data.

- Published Technical Development Plan for TDP AP Core, Initial Requirements Document, Planning Model and STEP Group 1 AP Document, yielding headstart to ISO standardization. This project has established a close interface to the Air Force F-22 Program. The F-22 will utilize the results of this TDP AP project in their specification regarding Digital Product Data management. Liaison to commercial projects are beginning through PDES, Inc.

\section{FY 95 PLANS:}

- Complete Interim ARM Validation Report for TDP Core.

- Use requirement management system to complete and consolidate requirements from industry and government

- Rapid prototype critical ARM UoFs

- Develop AIM for the TDP Core

- Validate Data Description Exchange for the TDP COre.

- Hold second Dual Use Review Board meeting

- Convene supplier base workshops

- Publish Recommended Practices Guidelines

- Develop TDP Core Test Criteria

- Publish implementation plan and initiate pilot implementation projects (two in industry and two in government operations)

Related Developments: NIST, the Air Force ManTech PAS-C Program and PDES, Inc. have teamed in an effort to develop and deploy a suite of APs to enable a STEP-based Technical Data Package environment for both government and commercial products. This team is closely aligned with the Advanced Weapons System (AWS) and F-22 Digital Product Data efforts. Liaison with the Navy JEDMICS Program, Navy RAMP and projects at the Naval Surface Warfare Center, Crane Division, are in place. A Dual-Use Review Board has been established including representation from DoD services, Air Logistics Centers, Federal Aviation Administration, aerospace and automotive corporations, vendors, and small suppliers. 


\begin{tabular}{|l|l|l|l|l|l||}
\hline APs FOR DOD AND INDUSTRY FISCAL YEARS & 96 & 96 & 97 & 98 & 99 \\
\hline $\begin{array}{l}\text { Bring Core TDP Application Protocol to STEP IS } \\
\text { (International Standard) status [DOD, STRS, INDUSTRY] }\end{array}$ & & & & & \\
\hline $\begin{array}{l}\text { Expand TDP AP Suite to add features and conformance } \\
\text { classes Technical Product Data Representations, } \\
\text { Commodity Types, Product Producer Functions, and } \\
\text { Product User Support Functions [DOD, STRS, } \\
\text { INDUSTRY] }\end{array}$ & & & & & \\
\hline $\begin{array}{l}\text { Initiate series of Pilot Implementations including: } \\
\text { Aerospace, Automotive, Air Force Air Logistics Center, } \\
\text { and Navy RAMP facilities [DOD, STRS, INDUSTRY] }\end{array}$ & & & & & \\
\hline $\begin{array}{l}\text { Establish Parts Acquisition Workcell at NIST to } \\
\text { demonstrate and development application of TDP AP in } \\
\text { small supplier base [STRS, NAVY] }\end{array}$ & & & & & \\
\hline $\begin{array}{l}\text { Develop link between TDP Data Definition Exchange Flle } \\
\text { concept and EDI technology [STRS] }\end{array}$ & & & & & \\
\hline $\begin{array}{l}\text { Complete TDP AP Suite as STEP International Standard } \\
\text { STRS, DOD, INDUSTRY] }\end{array}$ & & & & & \\
\hline
\end{tabular}


Title: COMPUTER INTEGRATED MANUFACTURING FRAMEWORK

Staff: (1.1 staff years) *Neil Christopher, *Steve Osella, *SELDEN STEWART, * Evan Wallace, *Jim St. Pierre (EEEL)

Project Objective and MEL Thrust Supported: To foster the development, standardization, and adoption by industry of an object-oriented framework for manufacturing applications. Manufacturing System Integration.

Need Addressed: SEMATECH, a consortium of major US semiconductor manufactures, has asked NIST to participate in its project to develop a CIM Application Framework for semiconductor manufactures by assisting in: generalizing the Framework to a broader class of manufacturing; standardizing the Framework; promoting the Framework in industry, and developing conformance test methods and test suites. The economic potential in the semiconductor industry alone is in the hundreds of millions of dollars in reduced integration costs for new fabrication facilities and shorter lead times for getting to market. Other areas of manufacturing would benefit from reuse of the framework in their own manufacturing domain. A successful framework would make U.S. industry more productive and more competitive in world markets.

Technical Approach: Based on the success of the Microelectronics Manufacturing Science and Technology (MMST) project by member-company Texas Instruments, SEMATECH initiated a project to take those results and develop an open framework for the use of manufacturing companies and their suppliers. The new framework is object-oriented and based on the Object Management Group's Common Object Request Broker Architecture (OMG/CORBA). NIST works with SEMATECH on the OMG Special Interest Group on Manufacturing (MfgSIG) to promote the Framework, and on the Common Facilities Task Force and ORB Task Force to standardize the Framework. NIST works with SEMATECH to validate and test the formal specifications, and to develop new formal methods of description and testing for the Framework. The current goal is a completely revised version 2.0 of the Framework by early 1996 with trial implementations, based on work in progress, in 1995 . Conformance testing procedures are planned for 1996.

\section{FY 94 Accomplishments:}

- Participated in the Standards Strategic Planning Workshop of the Semiconductor Equipment and Materials International.

- Created an online, electronic form of version 1.0 (later updated to 1.1) of the Specification. This made the it possible to browse the central document in this project through the world-wide web.

- Helped SEMATECH reorganize the OMG MfgSIG.

- Participated in reference implementation development.

\section{FY 95 Plans:}

- Hold a joint workshop with industry participation.

- Test formal, interface definition language (IDL) specifications with commercial object request broker tools.

- Publish first annual report and recommendations.

- Hold a joint Workshop with supplier companies.

Related Developments: The progress of OMG in defining and adopting CORBA 2.0 is of vital importance to this project. Since the Framework is based on CORBA, its success as a standard and in supporting software products is key to the success of the SEMATECH Framework. Other consortia, most notably the National Industrial Information Infrastructure Protocols (NIIIP), have programs of work that are synergistic with our program. NIIIP's goal is to combine Internet, OMG, and STEP technology into a virtual enterprise. The SEMATECH Framework has been proposed as a pilot project for the second year of NIIIP. 
After the Framework has been adopted as a common facility by OMG, the next step in standardization would be at the ISO level through TC184/SC5.

The agreement with SEMATECH is for a three year plan that goes to March 1997. Work beyond that date is technically quite reasonable, especially in conformance test development, formal specification of semantics, and international standardization, which are all typically long-term activities.

\begin{tabular}{|c|c|c|c|c|c|}
\hline $\begin{array}{l}\text { COMPUTER INTEGRATED } \\
\text { MANUFACTURING FRAMEWORK }\end{array}$ & 98 & 96 & 97 & 98 & 99 \\
\hline \multicolumn{6}{|l|}{$\begin{array}{l}\text { Develop roadmap and recommendations for industry to } \\
\text { adopt and use the Framework [STRS/SEMATECH] }\end{array}$} \\
\hline \multicolumn{6}{|l|}{$\begin{array}{l}\text { Revise the Framework to eliminate programming } \\
\text { languages dependencies [STRS/SEMATECH] }\end{array}$} \\
\hline \multicolumn{6}{|l|}{$\begin{array}{l}\text { Develop conformance testing strategy and methods } \\
\text { [STRS/SEMATECH] }\end{array}$} \\
\hline \multicolumn{6}{|l|}{$\begin{array}{l}\text { Develop and install a Framework test environment in the } \\
\text { AMSANT [STRS/SEMATECH] }\end{array}$} \\
\hline \multicolumn{6}{|l|}{$\begin{array}{l}\text { Integrate commercial and research manufacturing } \\
\text { applications into the test environment using the } \\
\text { Framework [STRS/SEMATECH] }\end{array}$} \\
\hline \multicolumn{6}{|l|}{$\begin{array}{l}\text { Investigate methods for formal specification of the } \\
\text { semantics of the Framework, e.g. state machines, agents, } \\
\text { VDM, and Z [STRS/SEMATECH] }\end{array}$} \\
\hline \multicolumn{6}{|l|}{$\begin{array}{l}\text { Adopt Framework as a standard through OMG and ISO } \\
\text { [STRS/SEMATECH] }\end{array}$} \\
\hline $\begin{array}{l}\text { Develop testing methods and suites of tests } \\
\text { [STRS/SEMATECH] }\end{array}$ & & & & & \\
\hline
\end{tabular}


Staff: (3 staff years) *Al Jones, *CHARLES MCLEAN, *Swee Leong, *Shaw Feng, 2 new hires

Project Objective and MEL Thrust Supported: The overall goal of the project is to lower manufacturing costs, reduce development and delivery times, and improve product quality through the development and use of advanced manufacturing engineering tools. The project will develop an integrated tool kit which can be used to plan part production and accurately predict product quality and process performance before a job is released to the shop floor. Other project objectives include the development of a process capabilities database, a functional definition of the manufacturing engineering process, and an integrated tools architecture. Manufacturing System Integration.

Need Addressed: Integrated computer-aided manufacturing engineering environments are needed by internal DoD manufacturing sites, primes and subcontractors, and non-defense commercial manufacturing facilities. Although many software tools are currently available for manufacturing engineers, they do not work together and cannot be readily integrated. This lack of integration significantly diminishes the productivity of manufacturing engineers, reduces the quality of their work, and increases the time it takes to plan the production of a part or an assembly. Examples of these tools include: producibility analysis software, process planning systems, and simulation/modeling packages. Data generated by these tools is not guaranteed to produce a correct part the first time. New integrated engineering environments (i.e., tool kits) must be developed to solve this problem. For widespread implementation, environments must be based primarily upon the integration of commercially-available engineering tools.

Integrated engineering tool kits would increase the productivity of engineers performing producibility analyses, designing manufacturing systems, evaluating quality costs, and conducting design trade-off studies. A recent study indicated that improved manufacturing and industrial engineering support tools could save the Department of Defense about \$300 million per year ("Manufacturing Systems Strategic Plan," Report of the Manufacturing Systems Committee, DoD Manufacturing Science and Technology Program, March 1993). The benefits realized from this project will be applicable to Defense as well as civilian manufacturing.

Technical Approach: The project will assess industry needs, with respect to manufacturing engineering tools and tool integration. It will develop architectures, interfaces, and databases for integrating engineering tools environments. Prototype integrated engineering tool kits will be constructed from commercial products. Process capability study procedures, process feature sets, data base structures, and reference databases will be developed. Solutions will be validated at industry sites. The principal elements of the technical approach are: 1) identify and address critical industrial needs through collaboration, 2) develop solutions to engineering tool integration problems, 3) construct prototype environments using commercial products, 4) validate results through industrial testing of system implementations, 5) specify and promote needed industry standards, and 6) facilitate the rapid commercialization of new technology.

\section{FY 94 Accomplishments:}

- $\quad$ Prepared technical plans for Manufacturing Engineering Tool Kit.

- Identified industrial collaborators for tool kit project.

- Conducted two CAME industry workshops (business process re-engineering tool kit and process capabilities database).

- Prepared draft white paper on Computer-Aided Manufacturing Engineering Program.

- Procured baseline software systems (initial set) for tool kit environment.

\section{FY 95 Plans:}

- Procure computer workstation for manufacturing engineering tool kit. 
- Procure remainder of baseline tool kit software systems.

- Demonstrate baseline (non-integrated) tool kit environment.

- Prepare architecture and technical specifications for tool kit.

- Award contracts/grants for tool kit development/extensions.

- Develop initial manufacturing engineering functional model.

Related Developments: Texas Instruments and Hughes Missile Systems Group have asked the CAME Project to participate in their bid for an ARPA TRP Affordable Multiple Missile Manufacturing Project. NIST participation is in the area of engineering tools, specifications, and technologies.

The DOD Joint Advanced Strike Technology (JAST) Program has indicated that they will sponsor CAME tool kit development in FY96 as a part of their Manufacturing and Producibility Program.

\begin{tabular}{|l|l|l|l|l|l||}
\hline $\begin{array}{l}\text { COMPUTER-AIDED } \\
\text { MANUFACTURING ENGINEERING FISCAL YEARS }\end{array}$ & 98 & 96 & 97 & 98 & 99 \\
\hline Develop tool kit requirements, designs, etc. [OA] & & & & & \\
\hline Install systems, develop extensions, and integrate [OA] & & & & & \\
\hline Test, demonstrate, and document tool kit environment [OA] & & & & & \\
\hline Define process capability methods, feature sets, etc. [OA] & & & & & \\
\hline Conduct process capability studies at industry sites [OA] & & & & & \\
\hline Design and implement process capability database [OA] & & & & & \\
\hline Define manufacturing engineering reference model [OA] & & & & & \\
\hline Develop integrated tools architecture [OA] & & & & & \\
\hline
\end{tabular}




\section{Staff: (2.5 staff years) TED HOPP, Cathleen Diaz, *David Rosenfeld}

Project Objective and MEL Thrust Supported: The objective of this program is to establish a common technical basis for tolerancing, metrology, and measurement traceability of complex dimensional characteristics in the discrete parts industry. To reduce industry inspection costs, assure quality of manufactured parts, and provide traceability through the NIST Algorithm Testing and Evaluation Program for Coordinate Measuring Systems. To continue deployment of NIST's Algorithm Testing System (ATS) for evaluating the performance of data analysis software embedded in coordinate measuring systems. To support the establishment of national standards based on the ATS, development of new tolerancing technology, measurement methods, inspection algorithms, and standards for complex, high-precision parts. Manufacturing Metrology.

Need Addressed: The dimensional metrology community, users, vendors, and manufacturers of coordinate measuring systems (CMS) need formal mechanisms for testing and evaluating the performance of data analysis software embedded in CMSs. ATEP-CMS will help industry reduce inspection costs, improve procurement methods, and decrease measurement uncertainties, while providing traceability of measured results to national standards. Addressing complex geometries, providing tighter coupling between product design and process design, and providing the means to increase the use of statistical tolerancing challenge the field of dimensional tolerancing. Characterizing data analyses underlying coordinate metrology systems in basic metrological principles and developing algorithm objectives for advanced tolerance verification provides industry with dimensional and metrological methods not available in the past. The Dimensional Tolerancing and Computational Metrology Program will support national goals for ASME Research Committee on Dimensional Tolerancing and Metrology. Additionally, the draft national standard, ASME Y14.5.1, Mathematical Definition of Dimensioning and Tolerancing Principles, and the draft national standard, ASME B89.4.10, Methods for Performance Evaluation of Coordinate Measuring System Software are supported by this program. Furthermore, this program supports the U.S. and international standards communities efforts to improve coordination of the standards in these areas.

Technical Approach: NIST is providing the ATEP-CMS Special Test Service to industry by performing CMS software tests and evaluations consistent with emerging national standards. NIST will establish a research consortium to carry out work identified by the national research agenda on dimensional tolerancing and metrology. The program will specify requirements for data analysis algorithms and develop new reference software implementations of the algorithms. NIST will collect data on process characteristics and study interaction of part deviations, coordinate sampling plans, and data analysis methods in order to characterize measurement uncertainty from coordinate measurements. NIST will also develop performance metrics and assessment methods for the new algorithms and design algorithm testing tools based on these metrics and integrate tools into an algorithm testing environment.

\section{FY94 Accomplishments:}

- Developed the first U.S. test of the software component of length-measurement systems, the NIST Algorithm Testing and Evaluation Program for Coordinate Measuring Systems (ATEP-CMS). ATEPCMS was approved as a NIST Special Test Service to test orthogonal-distance regression fitting software for seven geometry types: lines, circles, planes, spheres, cylinders, cones, and toruses.

- Completed Version 2 of the NIST Algorithm Testing System (ATS). The ATS is the testing tool used for testing and evaluating CMS software in the ATEP-CMS. Version 2 of the ATS implements graphical display capabilities, calculates and displays estimation of uncertainties, and provides sophisticated test data generation capabilities to design, test, and run multiple experiments.

- Published: NISTIR 5374, "A Process for Selecting Standard Reference Algorithms for Evaluating Coordinate Measurement Software", NISTIR 5366, "Concept for an Algorithm Testing and Evaluation 
Program at NIST", Testing of Coordinate Measuring Systems Software, 1994 NCSL proceedings, "Computational Metrology", Manufacturing Review, Vol. 6, No. 4, pp. 295-304, ASME, NISTIR 5501, "The Sensitivity of Three-Point Circle Fitting."

FY95 Plans:

- $\quad$ Provide and manage the ATEP-CMS Special Test Service.

- Initiate Standard Reference Algorithm (SRA) selection process

- Identify, develop, and incorporate new fitting algorithms in the ATS

- Develop and publish strategic plan for NIST/University/Industry

- Organize workshop on industry priorities

- Publish: NIST Special Test Service: The Algorithm Testing and Evaluation Program for Coordinate-Measuring--Systems; Algorithm Testing and Evaluation Program for Coordinate Measuring Systems: Long Range Plan; Algorithm Testing and Evaluation Program for Coordinate Measuring Systems: Testing Methods; Performance Measures for Geometric Fitting in the NIST Algorithm Testing and Evaluation Program; User's Guide for the Algorithm Testing System Version 2.0, Section I- Getting Started; User's Guide for the Algorithm Testing System Version 2.0, Section II- Reference

Related Developments: Proposed Draft ISO Standard: Method for Testing Software for Computing Gaussian Substitute Elements in Co-ordinate Metrology, Maurice Cox, National Physical Laboratory, Teddington, Middlesex. This proposed international standard specifies a method for testing software used for computing substitute geometric elements from coordinate measurements.

The Physikalisch-Technische Bundesanstalt (PTB) offers a service to test CMS software by comparing results for test data sets to results obtained from reference software.

\begin{tabular}{|l|l|l|l|l|l||}
\hline $\begin{array}{l}\text { DIMENSIONAL TOLERANCING AND } \\
\text { COMPUTATIONAL METROLOGY }\end{array}$ FISCAL YEARS & 95 & 96 & 97 & 98 & 99 \\
\hline $\begin{array}{l}\text { Provide ATEP-CMS service to industry [OA-Calibrations] } \\
\text { Identify and implement objectives for additional fitting } \\
\text { algorithms [STRS] }\end{array}$ & & & & & \\
\hline $\begin{array}{l}\text { Incorporate the SRA selection process for reference } \\
\text { algorithms incorporated in the ATS [ STRS] }\end{array}$ & & & & & \\
\hline $\begin{array}{l}\text { Publish strategic plan for NIST/University/lndustry [STRS] } \\
\text { Organize and hold workshop on industry prionities and } \\
\text { publish results [STRS] }\end{array}$ & & & & & \\
\hline $\begin{array}{l}\text { Establish consortium on Dimensional Tolerancing and } \\
\text { Metrology [STRS] }\end{array}$ & & & & & \\
\hline $\begin{array}{l}\text { Initiate contracts on Chebyshev fitting and exact anithmetic } \\
\text { algorithms [STRS] }\end{array}$ & & & & & \\
\hline $\begin{array}{l}\text { Complete MOU with NSF in area of computational } \\
\text { geometry for manufacturing [STRS] }\end{array}$ & & & & & \\
\hline
\end{tabular}




\begin{tabular}{||l|l|l|l|l|l||}
\hline $\begin{array}{l}\text { DIMENSIONAL TOLERANCING AND FISCAL YEARS } \\
\text { COMPUTATIONAL METROLOGY }\end{array}$ & 95 & 95 & 97 & 98 & 99 \\
\hline $\begin{array}{l}\text { Publish performance models and metrics for tolerance } \\
\text { evaluation software [STRS] }\end{array}$ & & & & & \\
\hline $\begin{array}{l}\text { Make available software testing for tolerance evaluation } \\
\text { functions [STRS] }\end{array}$ & & & & & \\
\hline $\begin{array}{l}\text { Define tolerancing and measurement methods for } \\
\text { sculptured surfaces [STRS] }\end{array}$ & & & & & \\
\hline $\begin{array}{l}\text { Publish framework for tolerancing, metrology, and } \\
\text { standards [STRS] }\end{array}$ & & & & & \\
\hline $\begin{array}{l}\text { Establish new national standards for statistical and } \\
\text { complex-surface tolerancing [STRS] }\end{array}$ & & & & & \\
\hline $\begin{array}{l}\text { Establish new national standards for performance } \\
\text { evaluation of inspection systems for complex surfaces } \\
\text { [STRS] }\end{array}$ & & & & & \\
\hline $\begin{array}{l}\text { Provide measurement support for complex-surface } \\
\text { inspection systems [STRS] }\end{array}$ & & & & & \\
\hline
\end{tabular}


Title: ENGINEERING DESIGN TESTBED

Staff: (1.0 staff year) RAM D. SRIRAM, *Peter Hart

Project Objective and MEL Thrust Supported: To provide an environment for facilitating leading edge research and development in design technology and standards that will increase the competitiveness of the U.S. engineering industry. Manufacturing Systems Integration.

Needs Addressed: Engineering design plays a significant role in the product development process. The decisions made during engineering design stage have a considerable impact on the life cycle costs. Various studies indicate that errors made during early design stages tend to add exponential costs to the final product. To effectively compete in the global markets, the U.S. industry should produce quality goods at a competitive price. To do so would involve taking appropriate measures to produce innovate and robust designs, which should include all information needed for other engineering tasks. The engineering testbed is an initiative aimed at addressing technology and standards issues in engineering design. The various needs and benefits provided by the engineering design testbed are outlined below.

Need: Small design and manufacturing companies do not have adequate capabilities to exploit the national information infrastructure. This impedes their ability to compete effectively in national and international market.

Benefit: Small design companies will have access to various kinds of design expertise, and they will be able to sell their services through the information highway. This will also attract multinational companies to invest in the U.S. supplier base.

Need: Current CAD systems do not have proper mechanisms for incorporating the rationale behind design decisions. This results in considerable rework and potential manufacturing disasters.

Benefit: Encoding of design rationale will help keep track of how and why engineering decisions are made. This will result in rework reduction and conflict mitigation in team design.

Need: Lack of access to adequate design histories (both product and process) results in duplication of effort and costly delays, resulting in non-optimal design schedules.

Benefit: Work in product and process modeling will aid in developing standards for representing design information. This will help in developing a repository of design case studies, which can be accessed by the industry, resulting in reduced product life-cycle times.

Need: Many companies are not using the state of the art tools in engineering design. This results in inferior designs, which cannot compete in local and global markets.

Benefit: Our expertise in various aspects of design, such as robust design techniques, computer-aided conceptual design support, will be used to facilitate technology transfer to the industry.

Technical Approach: Help identify the information access needs of small to mid-size design companies and work with commercial vendors (such as Spectragraphics and Autocad) to address these issues. Participate in various national initiatives on design to help in standardization of design product and process models, with a particular focus on collaborative design. Participate in the development of appropriate storage structures for design case studies (or application notes). Work closely with both industry and other government agencies in helping with design related needs of these agencies.

FY 94 Accomplishments: New start. 
FY 95 Plans:

- Lead research activities related to engineering design, in particular Design Process Modeling, Design Rationale, and Design for Assembly.

- Install prototype systems that demonstrate new technologies.

- Participate in standards activities that support technology development efforts for engineering design representation.

- Develop close links with industry, universities, and government agencies. Study at least one large scale design activity, such as aircraft design, to assess the information modeling needs for collaborative design.

- Conduct workshops for assessing needs of small designers (i.e., suppliers) for accessing information resources.

\begin{tabular}{|c|c|c|c|c|c|}
\hline ENGINEERING DESIGN TESTBED & 95 & 96 & 97 & 98 & 99 \\
\hline \multicolumn{6}{|l|}{$\begin{array}{l}\text { Lead research activities related to engineering design, in } \\
\text { particular Design Process Modeling, Design Rationale, } \\
\text { Virtual Design Environments, Design for Environment, and } \\
\text { Desian for Assembly [STRS] }\end{array}$} \\
\hline \multirow{2}{*}{\multicolumn{6}{|c|}{$\begin{array}{l}\text { Install prototype systems that demonstrate new } \\
\text { technologies [STRS] }\end{array}$}} \\
\hline & & & & & \\
\hline \multirow{2}{*}{\multicolumn{6}{|c|}{$\begin{array}{l}\text { Participate in standards activities that support technology } \\
\text { development efforts for engineering design representation } \\
\text { [STRS] }\end{array}$}} \\
\hline & & & & & \\
\hline \multicolumn{6}{|l|}{$\begin{array}{l}\text { Study at least one large scale design activity, such as } \\
\text { aircraft design, to assess the information modeling needs } \\
\text { for collaborative design [OA, STRS] }\end{array}$} \\
\hline \multicolumn{6}{|l|}{$\begin{array}{l}\text { Conduct workshops for assessing needs of small } \\
\text { designers (i.e., suppliers) for accessing information } \\
\text { resources [STRS] }\end{array}$} \\
\hline \multicolumn{6}{|l|}{$\begin{array}{l}\text { Help at least one small business (design company) in } \\
\text { utilizing the national information infrastructure [STRS] }\end{array}$} \\
\hline \multicolumn{6}{|l|}{$\begin{array}{l}\text { Conduct research on object-oriented database needs for } \\
\text { engineering design [STRS] }\end{array}$} \\
\hline \multicolumn{6}{|l|}{$\begin{array}{l}\text { Interact with industry to provide support for effective } \\
\text { design practices [STRS] }\end{array}$} \\
\hline \multicolumn{6}{|l|}{$\begin{array}{l}\text { Develop educational and training programs related to } \\
\text { collaborative design [STRS] }\end{array}$} \\
\hline $\begin{array}{l}\text { Demonstrate a prototype virtual and distributed design } \\
\text { environment, with cooperation from other divisions at NIST } \\
\text { [STRS] }\end{array}$ & & & & & \\
\hline
\end{tabular}




\section{Title: ENHANCED INTEGRATION OF CAD WITH DESIGN SUPPORT AND MANUFACTURING ENGINEERING SYSTEMS}

Staff: KEVIN LYONS, *Peter Hart, *Michael Pratt

Project Objective and MEL Thrusts Supported: Enhance the interoperability and performance of design systems through identification of functional, data, and integration requirements, and development of prototype system extensions and enhancements which implement HPCC and integration technology solutions. Manufacturing Systems Integration

Within this broad scope, the project will be focused on achieving results in the following two areas; 1) understanding of the design process and how design systems aid in product design (process modeling), and 2) data exchange mechanisms between CAD (Computer Aided Design) and design support (e.g., Analysis, Virtual Reality) and manufacturing engineering systems (MES) such as process planning. The project's benefit to industry are a result of addressing the needs specified below.

Need Addressed: Many industries are struggling to identify new methods to remain competitive with U.S. and foreign companies. Design processes have received little attention yet are of significant importance to the industrial product realization process. Effective engineering design is key to matching the company's product to its customer demands and to providing improved quality, reduced costs, and reduced time to market. Specific needs related to project focus are further discussed below.

CAD-to-design support and manufacturing engineering systems - The emergence of new design support systems has introduced interoperatability issues in that these new systems are not tightly coupled with current $C A D$ applications. An example of this is VR (virtual reality) systems which are being viewed as a natural extension or enhancement to current $C A D$ systems, yet today very different methods to visualize and manipulate the underlying product model are used. This results in data and information that can not be shared by other engineering and manufacturing systems. This incompatibility is highlighted when engineers, working with a product model within a VR application, generate important information that assists in defining assembly processes or results in modifications to the product model. In addition to these concerns, successful application of new design support tools and technologies in industry where significant impact can be shown, is lacking. Until these barriers are addressed and solved there is little likelihood of industries acceptance of these tools and technologies.

Process Modeling - To assist in achieving more effective engineering and manufacturing processes, new methods and techniques are needed to increase companies understanding of their current processes. Without this, the implementation of new processes is severely hampered, and, no metrics to evaluate the performance of the new process (versus previous method) is available. Other problems facing industry are: a) the need to develop models that also serve as a first step in the identification of areas that support concurrent engineering activities by recognizing key areas to support data exchange, industry can focus on areas that provide maximum return on their investment $\}$; b) the need to develop models that accurately represent the design and manufacturing process companies which would enable them to serve as a basis for supporting workflow applications.

Technical Approach: As specified in the objective section, there are two areas which are within scope of this project and these are addressed by the following tasks: 1) Develop process and information models to: a) increase understanding of current process and document, b) support documentation of process representations required to define design and manufacturing processes, c) assist in development of integration mechanisms, and d) assist and support prediction of performance for proposed processes; 2) Extend and enhance design system utility by incorporating enhanced functionality/features/information to demonstrate how these technologies can be applied to real design and manufacturing needs today and in the future.

Process Modeling, Simulation, and Analysis - To assist in coordinating project activities, understanding the existing 
manufacturing processes (and documenting), and measuring project results; a product realization process (PRP) model representing the product design, planning, and production scenario will be created. In addition, other information models will be developed as appropriate to assist in design integration efforts.

Integration of $\mathrm{CAD}$ with support and manufacturing engineering systems - An issue that is facing design technologies is the exchange of information between CAD and other systems. This project will develop a prototype information exchange mechanism to demonstrate the transfer of data created in a $C A D$ environment to other manufacturing systems (e.g., process planning system) utilizing state-of-the-art support technologies. The project will explore a variety of data types with the initial effort aimed at the creation of trajectory, component orientation information (process data), swept volumes, and assembly sequencing data that can be merged with the part representation. The use of "state of the art" commercial applications allows for focus on

\section{FY 94 Accomplishments:}

- Participated in developing SIMA background document

- Produced functional data and integration requirements document

- Selected, installed, and tested initial design systems

- Developed Product Realization Process (PRP) computer models with simulation capabilities

- Demonstrated missile seeker brassboard prototype for NASA mid-size satellite development

\section{FY 95 Plans:}

- Produce process models defining the product realization process.

- Develop scenario for representing industry needs in design

- Develop information models for use in developing data exchange mechanisms for CAD to design support tools and manufacturing systems

- Demonstrate current state-of-the-art solutions

- Conduct panel discussion at Concurrent Engineering Conference on enterprise process modeling. 


\begin{tabular}{|c|c|c|c|c|c|}
\hline $\begin{array}{l}\text { ENHANCED INTEGRATION OF CAD WITH DESIGN } \\
\text { SUPPORT AND MANUFACTURING ENGINEERING } \\
\text { SYSTEMS } \\
\text { FISCAL YEARS }\end{array}$ & 95 & 95 & 97 & 95 & 99 \\
\hline $\begin{array}{l}\text { Demonstrate current integration capability for design, } \\
\text { planning and production applications, which serves } \\
\text { primarily as a baseline for measuring success of future } \\
\text { developments and cycle tests; present "to-be" integration } \\
\text { scope with milestones. }\end{array}$ & & & & & \\
\hline $\begin{array}{l}\text { Demonstrate Pro-Engineer to PART process planning } \\
\text { application integration with feature mapping; discuss } \\
\text { limitations of current approaches such as direct } \\
\text { translation; demonstrate use of design support system } \\
\text { such as virtual reality with limited interoperability with CAD } \\
\text { system; demonstrate data exchange through use of } \\
\text { neutral files, API's (Application Programming Interfaces) in } \\
\text { limited capacity, and direct translators; develop models } \\
\text { using STEP standards such as AP203; identify desirable } \\
\text { extensions relating to emerging technologies; report } \\
\text { detailing recommendations for standards to support } \\
\text { industry needs; document recommendations for the } \\
\text { development of new standards where they do not exist } \\
\text { (e.g., no effort in developing umbrella standard for support } \\
\text { of AP's that include features) and can make maximum } \\
\text { impact for industry }\end{array}$ & & & & & \\
\hline $\begin{array}{l}\text { Initiate creation of testbed within AMSANT that combines } \\
\text { design, process planning, and production domains and } \\
\text { demonstrates the capabilities of the system. Modify, as } \\
\text { necessary to meet the needs of specific industries that } \\
\text { have expressed an interest in assisting NIST with applied } \\
\text { research efforts; achieve a better understanding of } \\
\text { accuracy issues. Implement incremental prototype } \\
\text { solutions to address and document recommendations to } \\
\text { overcome accuracy barriers }\end{array}$ & & & & & \\
\hline $\begin{array}{l}\text { Work with industries that have expressed a strong interest } \\
\text { in serving as a production testbed for NIST information } \\
\text { technology systems; support the installation of systems } \\
\text { within industry and continue refinement of systems to } \\
\text { meet user needs. }\end{array}$ & & & & & \\
\hline $\begin{array}{l}\text { Continue work with industries and expand efforts to } \\
\text { promote a pilot installation; support industry partners } \\
\text { through demonstrations, documentation, and } \\
\text { presentations. }\end{array}$ & & & & & \\
\hline
\end{tabular}



MODELING

\section{Staff: (1.0 staff year) GERARD J. KIM}

Project Objective and MEL Thrust Supported: The primary objective of this project is to develop a methodology for integrating assembly knowledge during various design stages, and ways to customize the method to different design domains in a flexible and systematic manner. Manufacturing Systems Integration.

Need Addressed: Integrated Product/Process Design (IPPD) is an engineering approach that integrates activities from product concept through production and field support, using a multi-functional team to simultaneously optimize the product/process development and agile manufacturing. For example, Design-for-Assembly (DFA) is one of many such design criteria that emphasizes designing products for simple or less expensive assembly operations. Most computer-supported DFA methods are practiced in a form of comparative analysis (by employing some kind of a scoring system) of finished products instead of (re)designing products. This still falls short of the objective of IPPD which, in part, is to allow designers "generate" different design alternatives.

Such inadequacy stems, first, from lack of computational support for conceptual modeling of designs, and in particular, assemblies, in current CAD systems. Representing and reasoning about conceptual design is crucial to IPPD, because, when integrated with appropriate tools, it allows for prediction of wrongful design decisions beforehand, and is computationally a better platform for exploring different design alternatives and performing redesigns.

Secondly, there is an inherent computational difficulty in extracting, from CAD models, features or information necessary and useful for DFA and redesign: namely, DFA characteristics and design intent. In most cases, DFA characteristics are not well represented in CAD data, and, for a general design domain, very difficult to derive because it requires complex geometric processing and reasoning about the design context. On the other hand, design intent is also very important for validating redesign suggestions, but usually undocumented and lost. Even with design history capture capability, certain design information will still go undocumented because they are simply common sense. In a restricted design domain, however, above difficulties can be assessed to a certain degree by taking advantage of the conceptual modeling framework and domain knowledge.

Technical Approach: Previously, a model of DFA redesign, and an interactive computer-aided DFA tool called REV-ENGE (from REVerse ENGineering) have been developed. The central idea of REV-ENGE was to achieve DFA redesign by reverse engineering, i.e. by acquiring/inferring the design process, then replaying and modifying the design process rather than "patching up" the result of the final design. The theory of redesign in REV-ENGE can be easily extended to formally specify a framework to model conceptual assemblies. Taking advantage of domain knowledge to assess the computational burden essentially amounts to building design system for the chosen domain. This corresponds to customizing the framework with required domain knowledge, and this process will shed light on the knowledge acquisition process, important for later technology transfer.

The design system is envisioned to be a state-based automata, and the implementation will, therefore, involve defining a design state (and objects that constitute the design state such as the artifact, design intent, etc.), design operators (transfer functions), and design rules appropriate for the chosen domain. The definition of design states forms the basis for representation of conceptual design and assemblies. The definition of design operators and design rules form basis for making gradual refinement of the given design. For visual feedback, each design operators will be associated with a domain dependent shape representation.

The next step is to implement a DFA analysis method suitable for use with evolving designs. That is, in comparison to the conventional DFA methods, where the analysis is performed upon a final design, DFA rules should evaluate choices of design operators as design proceeds. This allows detection and resolution of "less desirable" design 
decisions in early design stages, and thus enables designers to assess more fundamental design problems.

To correctly apply DFA rules, design intent must be taken into consideration so that unnecessary design problems are not identified. In addition to representing design intent system by text and classifying them according to certain taxonomy, semantics of design intent must be understood at least to some extent so that designers can be prompted, on demand, to enter the information more easily.

\section{FY94 Accomplishment:}

- Performed literature search

- $\quad$ Ported REV-ENGE to NIST

- Made improvements to REV-ENGE and Restructuring of Code for future needs

- Become familiar with CAD systems (IDEAS, ProE)

- Integrated Assembly Planner with REV-ENGE

- Submitted journal article "Interleaving Assembly Planning and Design for Concurrent Engineering" (IEEE Trans. Assembly Task and Planning)

- Selected domain (remote controls)

- Redefined and Formulated research plans

\section{FY 95 Plans:}

- Customize REV-ENGE for remote control domain and document the process

- Formalize a theory for conceptual assembly modeling

- Extend REV-ENGE for assembly modeling

- Investigate relationships between assembly modeling and assembly analysis

- Extend case-based redesigner for visual feedback

- Interface to a CAD system (IDEAS Open Architecture)

- Publish report

- Demonstrate system 


\section{Staff: (0.4 staff years) *SIMON FRECHETTE}

Project Objective and MEL thrusts Supported: MEL recently established an Industrial Fellows Program, based upon the NIST Industry Fellows Program. MEL staff members are encouraged to pursue temporary assignments in industry. The Manufacturing Systems Integration Division (MSID) will assign a staff member to work at the Black and Decker Corporate Engineering Headquarters in Towson, Maryland on a part-time basis for a period of six months. Black and Decker is interested in working with NIST to identify and implement improved manufacturing integration technologies at their production facilities. Black and Decker managers would like to leverage on NIST work in this area. Black and Decker will gain valuable expertise and insight in the areas of integration and standards implementation. NIST will gain valuable knowledge, experience, and resources which can be applied to MSID programs. This fellowship will enable MSID programs to build an extremely valuable, long-term relationship with an industrial partner. Forming this type of relationship will demonstrate NIST's commitment to cooperating with industry to develop and implement new technologies based on industry needs. Manufacturing Systems Integration.

Need Addressed: The purpose of this proposed effort is to provide MSID expertise in those areas that will benefit an industrial partner and to acquire information and expertise from the industrial partner that can be applied to MSID programs. Mr. Don Elson, V.P. Technology, Black and Decker Corporation met with representatives from NIST MSID on January 13, 1995 at Black and Decker's Towson facility. Mr. Elson expressed his eagerness to work with NIST and Black and Decker staff cited manufacturing systems modeling and manufacturing standards implementation as two primary areas where NIST assistance would have great impact. MSID proposes to work with Black and Decker to model manufacturing systems as part of Black and Decker programs related to work flow management and engineering change orders. MSID will also provide assistance in implementing existing standards and provide information on emerging standards relating to manufacturing. In addition, the MSID industrial fellow will serve as a conduit to other expertise and information at NIST including those outside of the MEL, e.g., advanced materials, electrical measurements, Manufacturing Extension Program services, etc.

Technical Approach: MSID will work with the industrial partner to identify the functional areas, activities, data, engineering tools, and systems integration required for taking new product designs into production. An MSID staff member will work at a facility as an industrial fellow on a part time basis to identify and understand application integration requirements, model the manufacturing engineering activities as performed at this facility, and acquire example product and process data. This information will be used by MSID programs to guide the development of an architecture for manufacturing engineering as well as develop and integrate manufacturing software tools.

FY 94 Accomplishments: New project.

\section{FY 95 Plan:}

- Establish a Cooperative Research and Development Agreement (CRADA) with Black and Decker.

- Develop a detailed project plan for the industrial fellowship, including milestones, deliverables, timeline, management responsibility, and assignments.

- Issue weekly status reports that summarize activities and technical achievements.

- Develop a manufacturing engineering activity model for use in system integration development efforts.

- Collect examples of product data (part design, assembly, and materials specifications) and process 
data (process plans, facility layouts, scheduling data, etc.) and other product lifecycle information for use in SIMA development efforts

- Issue a final report that summarizes the experiences of the industrial fellow during this assignment, draws conclusions, and makes recommendations for follow-on activities.

- Ensure that SIMA project staff are aware of industry operations and requirements, and that the industry partner is aware of available technology solutions. 


\section{Title: INTEGRATION OF REAL-TIME SCHEDULING AND SHOP FLOOR DATA COLLECTION}

\section{Staff: (0.75 staff years) *AL JONES, *Chuck McLean, *Swee Leong}

Project Objective and Mel Thrust Supported: The main objective of this project is the development of a generic interface specification and a data exchange specification which can be used to demonstrate the integration of real-time scheduling tools with shop floor data collection tools. Manufacturing Systems Integration.

Need Addressed: During the last 10 years, many U.S. manufacturing facilities have invested in computer-based shop floor scheduling and data collection systems. These data collection systems have made it possible to gather data about the events on the shop floor almost as soon as they happen. A recent study conducted at Purdue University estimated that shop floor throughput could be increased by as much as $30 \%$ by integrating scheduling tools with these data collection tools. Such an integrated system would provide the capability to analyze and react to problems deduced from this data in real-time. This will decrease the cost and increase the likely on-time delivery of DoD procurements. This project will make it possible to develop the standards to build such an integrated system from a wide range of commercial products.

Technical Approach: The project will focus on developing methods for integrating scheduling with shop floor data collection and improving the real-time, functional capabilities of the next generation of scheduling software tools. Achieving integration will require the development of new interface and information standards. Interface standards will specify the feedback information that is needed by scheduling. This feedback information is available from many different sources including barcode readers, shop floor data collection systems, and the emerging "open architecture" machine tool controllers. Information standards will specify how this feedback is actually stored and retrieved. NIST will work with industry, vendors and the international standards community to develop those standards. Once the effectiveness of these candidates has been demonstrated, NIST will work with the national and international bodies to develop a set of interface standards.

The availability of this feedback from shop floor data collection systems provides the impetus for improving the realtime, adaptive capabilities of the next generation scheduling software. Providing those capabilities will necessitate the development of new techniques to solve job shop scheduling problems. These techniques have been under development for the past two years by NIST and Ohio University. The approach for this project will be to complete that development and then integrate these results into two existing simulation-based schedulers so they can generate schedules and respond to problems in real-time. After this has been successfully demonstrated, we will demonstrate that the feedback from the shop floor data collection systems can be used to generate new schedules whenever they are needed (error recovery). NIST will work with vendors and academia to develop and demonstrate these new techniques. Once the effectiveness of these techniques has been demonstrated, NIST will work with vendors to bring those techniques into their next generation products.

It is difficult to attach exact dollar figures to these impacts across all US manufacturing, but a recent study gives some approximate measures. According to a recent DoD study, Shop Floor Labor and Manufacturing Support account for roughly 53\% of total company cost. The FY93 President's budget includes \$54B for procurement. Of this total, approximately $\$ 26 \mathrm{~B}$ went to cover these costs. The study further estimated that improvements in the shop floor integration, simulation, and scheduling methodologies could result in costs savings on the order of $\$ 2 \mathrm{~B}$.

FY 94 Accomplishments: New start

\section{FY 95 Plans:}

- Complete analysis of ongoing academic scheduling research

- Develop reference architecture 
- Complete assessment of commercial scheduling and data collections tools

- Identify vendor, user, and DoD collaborators

- Acquire commercial software tools

- Develop interface and exchange specifications

Related Developments: This is related work in scheduling and simulation in the SIMA production project.

\begin{tabular}{|l|l|l|l|l|l||}
\hline $\begin{array}{l}\text { INTEGRATION OF REAL-TIME SCHEDULING AND } \\
\text { SHOP FLOOR DATA COLLECTION FISCAL YEARS }\end{array}$ & 95 & 95 & 97 & 98 & 99 \\
\hline $\begin{array}{l}\text { Complete analysis of ongoing academic scheduling } \\
\text { research [STRS, NAVY] }\end{array}$ & & & & & \\
\hline Complete new real-time scheduling research [STRS] & & & & & \\
\hline $\begin{array}{l}\text { Complete assessment of commercial scheduling and data } \\
\text { collections tools [STRS, NAVY] }\end{array}$ & & & & & \\
\hline $\begin{array}{l}\text { Procure commercial software tools and acquire training } \\
\text { [STRS, NAVY] }\end{array}$ & & & & & \\
\hline Complete modifications to commercial software [NAVY] & & & & & \\
\hline $\begin{array}{l}\text { Demonstrate integration at NIST using specifications } \\
\text { [STRS] }\end{array}$ & & & & & \\
\hline Demonstrate integration at industrial sites [NAVY] & & & & & \\
\hline $\begin{array}{l}\text { Complete integration of new scheduling techniques into } \\
\text { commercial software [STRS, NAVY] }\end{array}$ & & & & & \\
\hline Develop reference architecture [STRS, NAVY] & & & & & \\
\hline Develop integration architecture [STRS, NAVY] & & & & & \\
\hline $\begin{array}{l}\text { Develop interface and exchange specifications [STRS, } \\
\text { NAVY] }\end{array}$ & & & & & \\
\hline
\end{tabular}


Staff: (0.5 staff years) *STEPHEN A. OSELLA

Project Objective and MEL Thrust Supported: The Intelligent Processing of Metal Powders project was organized to investigate the process of inert gas-metal atomization and to develop an automatic control system capable of controlling the size distribution of metal powder particles produced in such a system. The research has involved the disciplines of metallurgy, fluid dynamics, thermodynamics, optics, signal acquisition and processing, control theory, and artificial intelligence. The project team consisted of a number of groups in various divisions of NIST.

Need Addressed: Metal powder manufacturing is attractive due to the capability for near-net shape processing with desirable physical and mechanical properties. Research has shown that the properties of metal powders are highly correlated with the size of the particulate for many alloy systems. The project is part of an overall industrial consortium of powder producing and consuming companies which are interested in progressing the state-of-the-art in metal powder production technology. The consortium was organized to provide a framework for the development and dissemination of this technology.

Technical Approach: The incomplete physical understanding of the powder formation process precludes the formulation of an adequate first-principles model. In an effort to obtain some understanding in this area, dimensional analysis techniques were employed to reduce the number of process parameters affecting the production of powder. As a result of this analysis, four independent dimensionless groups were proposed as the factors which characterize the powders produced in this type of atomizer. Experiments were designed to determine the effects of the four factors on particle size distribution and were carried out using the Supersonic Inert Gas-Metal Atomizer (SIGMA) system. The experiments were conducted using argon as the gas media and Inconel 625 as the alloy system. The result of these experiments was a model which correlates SIGMA process parameters with various particle size distribution statistics.

\section{FY 94 Accomplishments:}

- Developed through experimentation a correlation model relating the gas-to-metal ratio (a process parameter proved to be influential to particle formation) to statistics of particle size distribution (e.g., median particle size).

- Completed a particle-size control system that was successfully demonstrated to the consortium member companies.

FY 95 Plans: (This is the final year of a four year project which will not continue after this fiscal year.)

- Develop an IBM-compatible reference version of the particle-size control system to assist in the transfer of technology to consortium member companies.

Related Developments: This project is part of a larger NIST program in IPM that includes staff from MSEL and CSTL. 
Title: MANUFACTURING INFORMATION TECHNOLOGY TRANSFER PROJECT (MITT)

Staff: (2.8 staff years) Manish Butani, *Peter Hart, *Don Libes, *Julie Parker, *MICHELLE POTTS, *Steven Ray, *Bill Regli

Project Objective and MEL Thrust: To provide a coordinated and focused infrastructure of the emerging tools, technologies and growing electronic networks resulting from the information exchange revolution currently underway to empower American industry with readily-available information bases containing up-to-date manufacturing research developments and practices and to facilitate information sharing and collaboration opportunities. Manufacturing Systems Integration

Need Addressed: American industry is demanding easier and faster access to government manufacturing research developments. The MITT project was established to meet these increasing challenges by providing appropriate information dissemination and computer-mediated collaboration tools to other SIMA projects, thereby amplifying the availability of MEL's research developments to the manufacturing community at large. Easily accessible repositories of manufacturing research information provide valuable resources for large and small manufacturing firms alike and support the national goal of providing a populated national information network.

Technical Approach: The MITT project was designed to be a three year project. The first year's efforts (FY 94) concentrated on building an infrastructure of available tools and servers for information dissemination and populating a manufacturing research repository. The second year's efforts will concentrate on teaming with SIMA and other MSID research projects to apply these tools and services to improve communication and technology transfer of their results to the manufacturing and standards communities. Investigations will also begin on the application of emerging technologies such as computer-mediated collaboration, enhanced searching and information discovery capabilities to facilitate SIMA activities. The third year's efforts will focus on building an Internet-based collaborative laboratory environment to catalyze the teaming of NIST with industry to solve key industrial manufacturing problems. Support of the information dissemination infrastructure and information repositories developed by this project will also be transitioned to support facilities within NIST where appropriate.

\section{FY 94 Accomplishments:}

- Put on line a prototype suite of authoring, searching and retrieval tools.

- Available servers: ftp, gopher, wais, http, email archive servers, MSID internal http

- Available file transfer protocols: gopher, wais, ftp, http, email, kermit

- Available clients: www browsers (including Mosaic), gopher, veronica, jughead, email, wais

- Available client interfaces: www browsers, gopher, email, wais

- Available authoring tools/aids: HotMetal, WP styles, emacs routines

- Information bases: appropriate information bases made available via gopher and wais

- Most MSID manufacturing research papers on-line via ftp and http

- Wrote functional description of the server/tool suite written.

- Completed state-of-the-practice report on information dissemination methods. Available on line through WWW.

- Put on line collection of linked hypertext documents describing MSID work to the public.

- Put on line internal-access collection of hypertext documents facilitating information exchange among MSID staff.

- $\quad$ Published NISTIR 5453, "How to Utilize FASD's Information Services."

- Produced outline for user training course materials. 
FY 95 Plans:

- Expand MSID's on-line manufacturing information repository (public and internal).

- Refine external server system security arrangements while upgrading computer server machine and its operating system, in conjunction with the MEL AMSANT facility.

- Resolve repository data redundancy issues when using multiple distribution mechanisms.

- Prototype the application of computer-mediated collaboration tools in the area of manufacturing process planning.

- Establish collaboration with other organizations to enhance effectiveness of MSID's on-line manufacturing information repositories.

- Provide training for in-house users of information dissemination systems and authoring tools to facilitate the population of MSID's web.

\begin{tabular}{|l|l|l|l|l|l||}
\hline $\begin{array}{l}\text { MANUFACTURING INFORMATION TECHNOLOGY } \\
\text { TRANSFER PROJECT (MITT) }\end{array}$ & & & & \\
\hline $\begin{array}{l}\text { Augment integrated information dissemination tool/server } \\
\text { suite [STRS] }\end{array}$ & & & & & \\
\hline $\begin{array}{l}\text { Facilitate the population of MSID's manufacturing } \\
\text { information repository [STRS] }\end{array}$ & 95 & 96 & 97 & 98 & 99 \\
\hline $\begin{array}{l}\text { Develop prototype of computer-mediated collaboration } \\
\text { tools for a focussed SIMA application [STRS] }\end{array}$ & & & & & \\
\hline $\begin{array}{l}\text { Establish an Internet-accessible Collaborative Laboratory, } \\
\text { in conjunction with another SIMA project [STRS] }\end{array}$ & & & & & \\
\hline
\end{tabular}


Staff: Bradford Smith, *Allison Barnard, *Jessy Crusey, *Sharon Gray, *MARY MTCHELL, ${ }^{*}$ Cramona Randall, Ellen Trager, Joan Wellington, *Guest Researcher (Bill Conroy; after March 1 Sharon Kemmerer)

Project Objective and MEL Thrust Supported: To ensure the timely development and processing of manufacturing standards with the quality, integrity, and completeness required to support industrial needs. Manufacturing Systems Integration.

Need Addressed: Industrial use of computers in the design, manufacture and product support demands the frequent sharing of database information. This effort targets the development of neutral data exchange standards such as the Standard for the Exchange of Product Model Data (STEP), the Product Data Exchange Using STEP (PDES) and a new approach to representing Part Library information (PLIB). The effort also is responsible for the production integrity of existing standards such as the Initial Graphics Exchange Specification (IGES).

Technical Approach: This effort is responsible for the technical leadership of a dynamic US domestic effort within the IGES/PDES Organization (IPO) and the corresponding worldwide standardization effort under the International Organization for Standardization committee ISO TC184/SC4. As such it leverages the collective resources from 435 experts in 26 participating and 9 observing nations of ISO plus the efforts of 7 worldwide industrial consortia known as STEP Centers.

NIST provides the technical infrastructure towards the development and implementation of these critical manufacturing standards. It is also the international repository and configuration management site for digital product standards. The repository had over 10,000 FTP accesses in FY94 and hundreds of mail server accesses each month. Among the many services offered, NIST maintains STEP on-line document access, maintains a repository of unique STEP entity names and ensures correct and consistent use of the EXPRESS language.

AP integration and interoperability is a serious barrier to the success of STEP, yet there is an inadequate allocation of industry resources to make progress on this serious issue. NIST provides leveraged resources to put operational procedures in place to minimize resource requirement and maximize national and international technical expertise in manufacturing standards development.

\section{FY 94 Accomplishments:}

\section{IGES:}

- Defined technical content of Version 5.3 which was approved as an ANSI standard.

- Approved IGES piping application protocol as an ANSI standard.

- Established transition strategy from IGES to STEP.

\section{STEP:}

- Completed ballotting and editing on 2100 pages of initial release document.

- Approved and submitted initial release for ballot as an ANSI standard.

- Supported 93 development projects and processed 27 Committee ballots.

- Managed circulation of documents and ballots to 430 experts in 22 countries.

- Completed ballotting on 13 Committe Draft parts to extend STEP functionality.

- Arranged 3 ISO standards meetings (hosting 2 with the IPO in the US).

- Hosted 12 workshops on STEP technology to educate and disseminate information to industry. (One session was re-broadcasted by satellite to multiple sites.) 
- Designed and implemented a project management and scheduling system.

- Produced a Quality Manual for developing AIC and ATS documentation.

\section{FY 95 Plans:}

IGES:

- $\quad$ Publish ANSI IGES Version 5.3

- Complete IGES Version 6.0 with EXPRESS description of entity schemas

- Establish electronic document archive for IGES

STEP:

- Provide the Chairman and Secretariat for this International Standards committee.

- Improve the quality, speed and summarization of committee balloting.

- Update STEP supplementary directives and associated style files.

- Edit and prepare camera ready production of International Standards.

- Publish STEP as an American national standard.

- Disseminate status of approximately 100 projects to 460 experts in 22 countries.

- Establish operational means for STEP Implementors' Forum and establish Email exploder for building STEP implementors' agreements.

- Initiate fullscale use of the STEP SEDS error reporting system.

- Build international consensus on policies and procedures.

- Expand STEP on-line document access, maintain repository of unique names and ensure correct and consistent use of EXPRESS.

IPO:

- Provide Chairman support of the national standards committee.

- Support National PDE Electronic Library transitioned from NIPDE.

- Establish and actively exploit IPO strategic affiliations.

- Develop meeting mentoring program, identify newcomers by interest, assign leading technical experts to newcomer in field of interest, and establishing metrics to measure success of program.

- Prepare news briefs and press releases.

- PLIB: Establish mirror archive for ISO 13584 documents on parts library.

- Process draft specifications through international ballot process. 


\begin{tabular}{|c|c|c|c|c|c|}
\hline $\begin{array}{l}\text { MANUFACTURING STANDARDS } \\
\text { DEVELOPMENT }\end{array}$ & 98 & 96 & 97 & 98 & 99 \\
\hline $\begin{array}{l}\text { Publish ANSI IGES Version 5.3; complete technical work } \\
\text { on IGES Version 6.0; make operational STEP } \\
\text { Implementation Forum; publish the } 12 \text { documents of the } \\
\text { STEP Initial Release; adopt STEP as an ANSI national } \\
\text { standard; make digital form available }\end{array}$ & & & & & \\
\hline $\begin{array}{l}\text { Develop strategy for integration of STEP, PLIB and } \\
\text { electronic data interchange; incorporate AP development } \\
\text { tools to reduce cost and time; publish STEP AP capability } \\
\text { for sheet metal, drafting and electronics; finish the SDAI } \\
\text { as an international standard for a data access interface; } \\
\text { publish IGES Version } 6.0 \text { as a data migration path to } \\
\text { STEP }\end{array}$ & & & & & \\
\hline $\begin{array}{l}\text { Demonstrate initial competence for managing PLIB data; } \\
\text { achieve integration of form features, tolerancing and } \\
\text { parametrics }\end{array}$ & & & & & \\
\hline $\begin{array}{l}\text { STEP and PLIB standards integrated for building } \\
\text { construction and electronics; develop capability for } \\
\text { capturing and tracking requirements definition in the } \\
\text { standard; reach consensus on technical approach to long- } \\
\text { term arehiving }\end{array}$ & & & & & \\
\hline $\begin{array}{l}\text { Develop a strategy to enable applications-specific, } \\
\text { functional-requirements-driven data sharing as needed } \\
\text { and when needed among business partners; automatically } \\
\text { generate APs and their abstract test suites as needed to } \\
\text { meet requirements }\end{array}$ & & & & & \\
\hline
\end{tabular}




\section{Staff: (2.0 staff years) *NEIL CHRISTOPHER, *Shaw Feng, *Don Libes, *Steve Osella}

Project Objective and MEL Thrusts Supported: The objective of the Multi-agent Manufacturing System project is to collaborate with industry to conduct research into manufacturing software systems which adapt to variable manufacturing conditions and which can be easily reconfigured by non-programming experts to support new manufacturing processes. Manufacturng Systems Integration, Intelligent Machines and Systems.

Need Addressed: U.S. manufacturing industry seeks to increase its competitiveness by increasing the quality of its products, reducing product development times, and by increasing the agility of its operations. Software systems for engineering design, planning, scheduling, and control have become a very significant part of industry's push to increase its competitiveness. Unfortunately the cost of software development, deployment, and maintenance is becoming a significant portion of operation costs. This project addresses the need for manufacturing software which is able to solve complex problems, is easily reconfigured to suite new processes, and has low development, deployment, and maintenance costs.

Technical Approach: This project addresses industry's needs through work in five areas 1) development of fundamental formalism for agent system structure, 2) a multi-agent manufacturing system development environment, 3) prototype multi-agent manufacturing systems, 4) a library of reusable software agents, and 5) standardization of the appropriate developments.

This project's industry collaborators, faced with shorter product development cycle times and variable market demands, have chosen manufacturing execution systems as the first target application of this project. Manufacturing execution systems help to determine sequence and timing of operations on the factory floor but increased variability in factory load and product mix invalidates many traditional approaches embodied in these systems. Recent research indicates that multi-agent manufacturing execution systems could be constructed to schedule and balance factory loads. Multi-agent systems are made of multiple software components that cooperate with each other to manage problem complexity by decomposing the solution to the problem. That is, instead of having a single decision maker, multi-agent systems propose a collection of decision makers who individually are concerned with a far reduced problem domain. Future target applications of multi-agent systems include those in engineering design and in process planning.

In order to lower development and maintenance costs development tools and libraries of reusable software agents will be designed and prototyped. It is intended that experts in a particular manufacturing domain use these tools to reconfigure systems and create new systems without employing software programming specialists.

The fundamental concepts for the structure of agents and multi-agent systems must be widely understood and the application of some of these concepts must be standardized in order to maximize cost savings to industry. This project will pursue where appropriate standardization of the results of the work in multi-agent manufacturing applications and support systems.

\section{FY 94 Accomplishments:}

- Participated in the NCMS manufacturing industry workshop on "Principles of Responsible Agent Systems".

- Hosted lecture on the subject of Complexity and Autonomous Agent Behavior.

- Evaluated the potential for the use of the NIST Expert Control System Shell as a component of a development environment for multi-agent manufacturing systems.

- Reviewed technical literature 
FY 95 Plans:

- Establish CRADAs with industry collaborators.

- Develop scenario for operation and deployment of multi-agent manufacturing execution system.

- Develop reference model for multi-agent manufacturing execution system.

- Develop scenario for reuse of software components in multi-agent manufacturing systems.

- Create proof of concept prototype for multi-agent software development system.

- Create proof of concept multi-agent manufacturing execution system.

- Create proof of concept software component reuse library for multi-agent systems.

- Hold technology transfer demonstrations and publish FY 95 report.

Related Developments: Related work in the use of multi-agent systems to manufacturing problems is being initiated at several major industrial sites and research institutions. Workshops and conferences are no longer an anomaly.

\begin{tabular}{|l|l|l|l|l|l||}
\hline $\begin{array}{l}\text { MULTI-AGENT FISCAL YEARS } \\
\text { MANUFACTURING SYSTEMS }\end{array}$ & 95 & 96 & 97 & 95 & 99 \\
\hline $\begin{array}{l}\text { Write technical papers on the structure of multi-agent systems } \\
\text { [ATP] }\end{array}$ & & & & & \\
\hline $\begin{array}{l}\text { Write technical papers on development tools and reuse of } \\
\text { multi-agent system software.[ATP] }\end{array}$ & & & & & \\
\hline $\begin{array}{l}\text { Develop proof of concept prototype manufacturing system } \\
\text { and development tools [ATP] }\end{array}$ & & & & & \\
\hline $\begin{array}{l}\text { Write technical papers on opportunities for standardization of } \\
\text { aspects of multi-agent systems. [STRS] }\end{array}$ & & & & & \\
\hline $\begin{array}{l}\text { Extend proof of concept prototypes to become industry pilots. } \\
\text { [STRS] }\end{array}$ & & & & & \\
\hline $\begin{array}{l}\text { Develop metrics for the performance off multi-agent systems. } \\
\text { [STRS] }\end{array}$ & & & & & \\
\hline $\begin{array}{l}\text { Initiate standards activities and pursue opportunities for } \\
\text { national repository of reusable software agents [STRS] }\end{array}$ & & & & & \\
\hline $\begin{array}{l}\text { Pursue application of multi-agent systems to engineering } \\
\text { design and process planning problems. [STRS] }\end{array}$ & & & & & \\
\hline $\begin{array}{l}\text { Develop conformance testing service for multi-agent system } \\
\text { components. }\end{array}$ & & & & & \\
\hline $\begin{array}{l}\text { Develop industry pilot applications of multi-agent design and } \\
\text { planning systems. [STRS] }\end{array}$ & & & & & \\
\hline
\end{tabular}




\begin{tabular}{|l|l|l|l|l|l|l||}
\hline \hline $\begin{array}{l}\text { MULTI-AGENT } \\
\text { MANUFACTURING SYSTEMS FISCAL YEARS }\end{array}$ & 95 & 96 & 97 & 98 & 99 \\
\hline $\begin{array}{l}\text { Further development in learning and adaptation of multi-agent } \\
\text { systems. [STRS] }\end{array}$ & & & & & \\
\hline $\begin{array}{l}\text { Pursue development of wide area problem solving systems } \\
\text { based on multi-agent systems. [STRS] }\end{array}$ & & & & & \\
\hline
\end{tabular}


Staff: Peter Denno, *MARY MITCHELL, K.C. Morris, *David Sauder,

Project Objective and MEL Thrust Supported: To foster the development of technology enabling industrial virtual enterprises and the adoption of STEP in the operation of industrial virtual enterprises. Manufacturing Systems Integration.

Need Addressed: The NIIIP Consortium, funded through an ARPA TRP award, is a consortium of various manufacturers, technology providers and universities. NIST is participating in its project to develop, demonstrate, and transfer into wide-spread use the technology to enable industrial virtual enterprises. A virtual enterprise is a temporary consortium of companies which come together to share costs and skills to exploit fast-changing opportunities. The technology of NIIIP industrial virtual enterprises is expected to provide the following benefits: a) enable enterprise teaming on an ad hoc basis; b) provide a means for rapid reaction to business opportunities; c) enable concurrent engineering practices, through the use of shared data representations and workflow management technology; and d) allow organizations to overcome inhibitors to information accessing, sharing and communicating through the use of STEP, OMG object technology and Internet standards.

Technical Approach: Using a spiral development process the NIIIP Consortium will deliver a) a reference architecture; b) toolkits which are the building blocks of an instantiated reference architecture; c) research prototypes that may include other projects where NIST has involvement, such as the SEMATECH Manufacturing Framework and the National PDES Testbed; and d) pilot demonstrations. In the development of these deliverables NIIIP will adopt and converge existing standards and technology from STEP, OMG CORBA and theWorkflow Management Coalition. NIST is providing direction and implementation of components of a toolkit to bind the STEP Standard Data Access Interface (ISO 10303 Part 22) to OMB CORBA IDL. The development of this capability is key to the NIIIP goal of providing data sharing and STEP information modeling in the context of a NIIIP industrial virtual enterprise.

The NIIIP is initially planned as a two-year program (phase four) ending in FY 96.

\section{FY 94 Accomplishments:}

- Participated in spiral development cycle 0 NIIIP Reference Architecture Short

\section{FY 95 Plans:}

- Document and contribute to a chapter regarding NIIIP adopted computing standards to the NIIIP Reference Architecture Long Document.

- Contribute to Spiral Development Cycle 1 NIIIP STEP Toolkit Definition.

- Track status of SDAI/IDL binding proposals from ISO/TC184/SC4 Working Group 7.

- Extend the NIST STEP class library to support level 2 implementation of STEP part 22 and validate the $\mathrm{C}++$ binding.

- Demonstrate Cycle 1 NIIIP STEP Toolkit.

Related Developments: The progress of OMG in defining and adopting CORBA 2.0 is important to this project. The development of CORBA ORB products and object services conforming to this standard are essential to development of key components of NIIIP including the NIIIP STEP toolkit. 


\begin{tabular}{|c|c|c|c|c|c|}
\hline $\begin{array}{l}\text { NATIONAL INDUSTRIAL INFORMATION } \\
\text { INFRASTRUCTURE PROTOCOLS (NIIIP) FISCAL YEARS }\end{array}$ & 95 & 96 & 97 & 98 & 99 \\
\hline $\begin{array}{l}\text { Support level } 2 \text { implementations of STEP part 22; } \\
\text { demonstrate Cycle } 2 \text { NIIIP STEP Toolkit; describe NIIIP } \\
\text { SDAI bindings to databases interfaces (IDL); define Cycle } \\
3 \text { STEP Toolkit; demonstrate Cycle } 3 \text { STEP Toolkit meets } \\
\text { validation suite requirements; contribute to NIIIP Phase } \\
\text { Two Plan }\end{array}$ & & & & & \\
\hline
\end{tabular}


Staff: *Allison Barnard, *Jesse Crusey, *Clarence Johnson, *JEANE FORD, *Mary Mitchell, (See individual projects for technical staff listing)

Project Objective and MEL Thrust(s) Supported: The National PDES Testbed (NPT) Program Office is responsible for managing and providing administrative support to the projects which are funded as part of the NPT. These projects consist of both DoD sponsors and NIST internal funding sources. The objectives of the NPT are: to accelerate the development and deployment of STEP-based product data environments in U. S. industry and Government operations; to reduce development cycle time and costs associated with STEP development and deployment; and to leverage the work of industry, government agencies, universities and consortia through joint project teams and technology transfer activities. Manufacturing Systems Integration.

Need Addressed: The exchange of and application of digital product data is complex and costly. For a number of years the United States along with an international community of researchers have been developing a standard for the exchange of product model data (STEP-ISO 10303) and the enabling technologies to facilitate computer-based technical information management. This effort itself is a challenging undertaking requiring thousands of staff-hours of a worldwide team of engineers, computer scientists, and administrators. The National PDES Testbed was established to provide support through testing services, software toolkits for developers, technical consultation, and direct participation in DoD and industry sponsored STEP efforts. Additional needs for the establishment of a network-assessable STEP Application Protocol Development Environment and SGMLbased electronic repository are being meet.

TECHNICAL APPROACH: The National PDES Testbed is comprised of a number of difference projects and joint developments efforts with industry and other Government sponsored programs. These projects are individually described under the titles:

Applications Protocol Development Environment

STEP Implementation Prototypes

APs for DoD and Industry: Technical Data Package AP Suite and Requirements Management System STEP Conformance Testing Service

The technical approach is three-fold: support the developers of the STEP standard with pre-commercial toolkits, on-line STEP services and repositories, training and consulting; participate directly on development teams and in joint implementation pilots projects; and provide technology transfer between related NIST projects and STEP activities.

The Application Protocol Development Environment is facilitating the development of quality STEP Application Protocols (APs) by providing an integrated, STEP-tailored software environment for AP development. APDE goals include: improvement of AP developer productivity by $40 \%$ and improvement in the quality of APs throughout the STEP process; better communications among STEP developers and users; automation and remote access to STEP development toolkits,. The APDE contains six modules corresponding to the phases of STEP AP development process. These modules access a central library, the Application Protocol Information Base (APIB). This on-line repository facilitates reuse of sharable resources (i.e., documents, data models and test data) to develop additional application which share a common framework. SGML is being used in the APIB with data type description being populated with the integrated resources and application protocols from incremental STEP ISO releases. The APIB provides multi-user access and configuration control of STEP documents, data models in EXPRESS and test suites.

The STEP Implementation Prototypes project is working with pilot projects to focus on STEP implementation, 
data sharing and interoperability issues. This project combines forces with Tank Automotive Command (TACOM) and the Automotive Industry Action Group (AIAG) on a Pilot project to assess the benefits and practical requirements for adoption of STEP technology throughout the supply chain (including small and medium size companies). The requirements of incorporating STEP into existing business practices specifically to improve contractor/supplier relationships and reduce engineering changes.

The Application Protocols for DoD and Industry project is defining the requirements and supporting the development of STEP APs to meet DoD and dual-use priority needs. Current focus is on electronic transaction of Dual-Use Technical Data Packages and the development of a Suite of APs for Technical Data/"Build-To" Packages to exchange and share product definition data among the Government, contractors and suppliers.

NIST, the Air Force and PDES, Inc. have teamed in this effort to develop and deploy a Suite of APs to enable a STEP-based Technical Data Package environment for both Government and commercial products. Proposals are underway to add the participation of and liaison with the JEDMICS Program, Naval Surface Warfare Center Electronic Product Digital Definition Set project, Advanced Weapon System (AWS), and F-22 Digital Product Data efforts. Pilot implementations are planned with the aerospace, automotive and small supplier communities.

In addition, a Requirements Management System (RMS) is in development to support requirements definition, validation and traceability activities for STEP Application Protocol development teams and the Application Protocol Development Environment. This project will a provide a taxonomy, data templates and software environment for managing the STEP Planning Model. The Technical Data Package AP project is using the RMS to gather, analysis and manage end user requirements.

The STEP Conformance Testing Service is providing early conformance testing capabilities to vendors as these new products are under development. This allows vendors to "build-in" conformance prior to market test and deployment. The high level of automation for conformance testing is designed to keep the costs low and the cycle times short.

Major accomplishements for FY 94 and plans for FY 95 through FY 99 are specified in individual project plans.

The National PDES Testbed program shares joint projects with the SIMA program. 
Staff: (1.0 staff years) *SIMON FRECHETTE, *Kevin Jurrens

Project Objective and MEL Thrust Supported: The primary objective of this project is to reduce the cost of replacement aircraft components by providing the capability to reverse engineer these components when no other replacement method is available. The Reverse Engineering Production System will be used to manufacture replacement parts for naval aircraft. This project will provide the production capability and systems integration necessary to manufacture replacement honeycomb sections faster, more efficiently, and more accurately than is possible with the current manual methods. This technology will provide NADEP NI with the capability to develop CAD models of replacement parts by optically scanning existing parts to obtain dimensional data. This data will be used to generate the control programs required to manufacture the replacement parts. Intelligent Machines and Systems.

Need Addressed: The Naval Air Depot North Island (NADEP NI) in San Diego, CA is responsible for the repair and maintenance of naval aircraft. Many of these aircraft require replacement of damaged or worn out components. In many cases, replacement components (especially structural components) must be custom manufactured. The original tooling and manufacturing data for these components are rarely available. Either this data was never purchased from the aircraft manufacturer, or the data is in a proprietary form which is not compatible with existing systems. One method to reproduce this data is to measure an existing part to reverse engineer the part design data.

Technical Approach: An optical scanning system coupled with an advanced CAD/CAM system is an effective and efficient means of obtaining the data required to manufacture replacement components when none of the original manufacturing data is available. An optical scanning system provides the ability to "map" (digitize) the surface and features of a part and supply this data to a CAD/CAM system. Part designs, tooling (fixture) designs, and numerical control (NC) part programs are generated from the completed CAD part model. New parts are produced using available manufacturing equipment. The Reverse Engineering Production System (REPS) will consist of an optical measurement system (OMS), a CAD/CAM system, computer workstations, a file server, a local area network (LAN), and two 5-axis NC machine tools. The system will also include an NC fabric cutter used to process composite fabric patches. NIST will develop detailed specifications for each component of the system. These specifications will contain detailed integration and data transfer requirements to insure system-tosystem compatibility.

\section{FY 94 Accomplishments:}

- Completed Gerber composite fabric cutter upgrade. Gerber system has been returned to production. DNC communications link with Command-1000 CAD/CAM system operational. All existing control programs have been converted to the new format and new storage media.

- Completed machine tool performance assessment.

- Awarded upgrade contract to Dayton Machine Tool Co. 8/94. Machine shipped to Dayton facility in Dayton, $\mathrm{OH}$ 9/94. Completion and installation scheduled for $6 / 95$.

- Revised Optical Measurement System technical specifications. OMS procurement on-hold pending resolution of additional project funding and resolution of NAVAIR CAD-2 contract.

- Completed initial specifications for CAD/CAM systems. Final specifications pending resolution NAVAIR CAD-2 contract.

- Completed Local area network installation. DNC link between C-100 controller and Command-1000 $\mathrm{CAD}$ system is operational. Factory network interface installed.

- Performed Investigation of Optical Measurement Systems. The REPS project has performed an extensive state-of-the-art survey of commercially available optical measurement systems. Systems were evaluated 
with respect to variables such as accuracy, speed, work volume, ease of use, communications capability, and cost.

FY 95 Plans:

- Identify CAD/CAM systems from NAVAIR CAD-2 contract

- Investigate available optical measurement system technology

- Finalize optical measurement system technical specification

- Issue optical measurement system solicitation

- Negotiate and award optical measurement system contract

- Perform acceptance testing for 5 axis core carver upgrade

- Perform acceptance testing of optical measurement system

- Perform Final system integration

\begin{tabular}{|c|c|c|c|c|c|}
\hline $\begin{array}{l}\text { NIST/NADEP NORTH ISLAND } \\
\text { REVERSE ENGINEERING PRODUCTION } \\
\text { SYSTEM (REPS) } \\
\text { FISCAL YEARS }\end{array}$ & 96 & 96 & 97 & 96 & 99 \\
\hline $\begin{array}{l}\text { Identify CAD/CAM system hardware and software from } \\
\text { NAVAIR CAD-2 contract. [NAVAIR] }\end{array}$ & & & & & \\
\hline $\begin{array}{l}\text { Investigate available optical measurement system technology. } \\
\text { [NAVAIR] }\end{array}$ & & & & & \\
\hline $\begin{array}{l}\text { Finalize optical measurement system technical specification. } \\
\text { [NAVAIR] }\end{array}$ & & & & & \\
\hline Issue optical measurement system solicitation. [NAVAIR] & & & & & \\
\hline $\begin{array}{l}\text { Negotiate and award optical measurement system contract. } \\
\text { [NAVAIR] }\end{array}$ & & & & & \\
\hline $\begin{array}{l}\text { Perform acceptance testing for } 5 \text { axis core carver machine tool } \\
\text { upgrade. [NAVAIR] }\end{array}$ & & & & & \\
\hline $\begin{array}{l}\text { Perform acceptance testing of optical measurement system. } \\
\text { [NAVAIR] }\end{array}$ & & & & & \\
\hline Perform Final system integration. [NAVAIR] & & 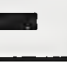 & & & \\
\hline
\end{tabular}


Title: PERSISTENT OBJECT BASE (POB) TECHNOLOGY EVALUATION FOR ENGINEERING

Staff: *Peter Denno, *Josh Lubell, *MARY MITCHELL, *KC Morris, *David Sauder,

Project Objective and MEL Thrust Supported: To facilitate the transition of Persistant Object Base (POB) technology from research to industrial implementation for the supported application areas of manufacturing and engineering. Manufacturing Systems Integration

Needs Addressed: NIST is being asked to support ARPA in: 1) focusing POB research into manufacturing and engineering application areas and 2) transferring the technology into standards activities and user communities. Additional users of NIST results include other ARPA POB developers, such as Texas Instruments. Incorporation of the standard into pilot implementations of technology will help move the emerging POB technology into industrial implementation and provide feedback into the related standard.

The development of new technology is proceeding at a pace faster than industry is able to absorb and faster than applicable information standards can be developed. The POB evaluation project is attempting to head off the divergence of new technology from the standards and from industrial implementations.

The lag time between technology development and standards has been viewed as a necessary evil under the assumption that standards should only be formed for a mature technology. But due to the rapid pace of development of new technology, this lag time has become unacceptable. By the time a standard is created, the underlying technology is often out-dated. By developing the standards in parallel with emerging technology, it is anticipated that the resulting standard will be suitable for the up-coming generation computing systems.

Data management technology for engineering and manufacturing lags behind its counterpart for business applications. The POB project serves to validate the applicability of the new data management technology for these applications and for information systems which use the emerging data standard STandard for the Exchange of Product Model Data (STEP).

Technical Approach: NIST began developing software for ISO 10303 (unofficially known as STEP) in 1988. STEP supports the sharing of engineering and manufacturing data related to product development. The STEP Standard Data Access Interface (SDAI) is an emerging application program interface for engineering and manufacturing data. NIST-developed software for the implementation mechanisms defined in STEP provides a basis for SDAI implementations.

NIST has been participating in the development of SDAI and has been working with the ARPA-funded POB system from Texas Instruments, called the Open Object Oriented Database (OODB). The NIST software is being enhanced to provide an SDAI/C++ interface to the Open OODB.

This approach provides early feedback into both the research and standards communities on the compatibility as well as the quality of their respective products. The experience gained enables the identification of barriers to information sharing for the engineering and manufacturing communities. Participation on standards committees and with the ARPA research community provides opportunities to promote solutions to the uncovered barriers and to encourage needed coordination. In addition, the availability of NIST software enables researchers in industry and academia to experiment with STEP without a significant investment of time and money, allowing people to build experience with and provide input into the emerging standard. 


\section{FY 94 Accomplishments:}

- Contributed to the development of SDAI, and to the ANSI Object Information Management committee's analysis of object languages.

- Validated the second release of the Open OODB (alpha release 0.2 ) by integrating the system with NISTdeveloped software for STEP.

- Installed the Open OODB releases $0.1,0.2$, and $0.2+$ patches. Many of the patches were implemented as a direct result of our testing.

- Ported the STEP Class Library to work with the Open OODB preprocessor (ppCC.) This port provided a realistic and extensive test for ppCC. For instance, one of the things that we uncovered was problems with the use of $\mathrm{X}$-windows libraries together with persistent classes. Even though the X-window structures were not persistent they need to be preprocessed because they are used to present persistent data. Ours was the first application to attempt using X-windows with the Open OODB. Another thing we had problems with was making the $\mathrm{CH}$ union construct persistent.

- Provided input to TI on our requirements for the second release of Open OODB.

- Developed and categorized a set of abstract test suites for POB systems and initiated testing on TI's Open OODB.

- Developed a set of test cases based on the STEP Class Library for putting STEP data into the Open OODB and retrieving it. In doing this we uncovered a number of trouble areas dealing with things ranging from the representation of real data types to constructor dependencies. The most complex test case at this point will load a STEP exchange file into the database and write out an exchange file from the database.

- Evaluated the Open OODB for use in another project called PDES Evaluation Project. (Funding for this evaluation came from the Joint-services program for Flexible Computer Integrated Manufacturing (JFCIM).)

- Developed a design for using our software to interactively import STEP exchange files into the Open OODB, thus making the data persistent, and to interactively access data sets from the database.

\section{FY 95 Plans:}

- Participate in the POB research program and related standards activities including ISO 10303 (STEP) and the ANSI Object Information Management committee.

- Enhance NIST software including the EXPRESS to $\mathrm{C}++$ translator and associated libraries to support the proposed SDAI/C + binding using the Open OODB. There is a significant amount of work to do on this task. In particular,

- The STEP Class Library user interface needs to be expanded to take advantage of the database functionality.

- Develop a user-friendly demonstration.

- Complete the SDAI implementation.

- Document changes to our software.

- Document project experiences. 
Staff: (2.4 staff years) *Shaw Feng, *Susan Hoffman, *Michael Pratt, *STEVEN RAY, *Bill Regli

Project Objective and MEL Thrust: The objective of this project is to improve the capabilities and integration of manufacturing planning applications. This will be addressed in three ways: the specification of a series of information and process models and communication protocols needed by planning systems; the implementation of these specifications as part of an integration activity using commercial planning system software; and the development of a repository of information supporting the research, development and integration of future planning system applications. Manufacturing Systems Integration.

Need Addressed: There are two principal obstacles impeding the successful adoption of integrated manufacturing process planning technology by American industry. The first is the lack of infrastructure and standards to allow the integration of process planning subsystems with each other, and with external engineering and production functions. The second obstacle is the fragmentation of the process planning research and development community, including industrial engineering staff, commercial system developers, and academic researchers. This disconnect unnecessarily hampers communication among interested parties. The intent of this project is to address the first problem, while a related project, the Process Planning Testbed, addresses the second.

Commercial system vendors, systems integrators, and industrial manufacturers have all expressed a desire for NIST to play an active role in establishing an integration infrastructure for manufacturing planning systems. Some evidence of this interest is manifested in the form of three active CRADAs with this project, with other companies expressing interest in forming additional CRADAs'.

Typically, none of the customers of this project has a vested interest in precisely how his or her systems interchange information, other than the ease with which the systems can be integrated. Thus, NIST has both the mandate and the ability to put in place a series of representation and communication specifications to which a variety of engineering systems can conform. Adoption of technically complete specifications will significantly ease the job of systems integrators, drastically reduce the cost of integration for manufacturers, and increase the market for commercial software vendors, especially in the small and medium sized manufacturing sector. On a broader scale, the use of this technology will allow more rapid response of American manufacturers to changing product and market needs, which will let them remain competitive while responding to these changes.

Technical Approach: The process planning applications project will tackle the barriers to integration of process planning systems into the larger engineering context by focussing on the two communication mechanisms among systems. First, the information shared between the planning functions and other engineering functions such as design, scheduling and production will be identified, formally modeled, and implemented as a series of databases. Access to these databases will be via accepted or emerging standard mechanisms such as SQL (Structured Query Language) or SDAI (Standard Data Access Interface). Example models include product data, process plan data, and manufacturing resource data. Second, the "dialogue" between the planning function and other engineering functions, both "upstream" and "downstream" will be formally characterized. Specifications for a formal communications protocol will be defined and tested by means of prototype implementations. Both of these technical tasks will be validated by building prototype integrated environments which include several commercial process planning systems. Present plans call for implementations using the PART system by ICEM,

1 Boeing Helicopter and McDonnell Douglas have both expressed interest in collaborating with this project. 
the MultiCAPP system by International Technegroupe, Inc., and the METCAPP system by the Institute of Advanced Manufacturing Sciences Inc.

\section{FY 94 Accomplishments:}

- Collaborated on a SIMA background study document, which documents industry needs in the area of manufacturing systems integration, defines the initial project focus in detail and sets the technical direction for project efforts. The report also describes the principal types of product realization software applications now in use, reviews moves toward integration within the manufacturing industry, discusses relevant research trends in the field of product realization, and surveys standards which may be applicable to the work of the SIMA project.

- Defined an activity model of manufacturing process planning, as a first step toward a standard process model. This model drew upon past efforts to model process planning, including a study funded by CAM-I (Computer Aided Manufacturing, International), and several university studies. This process model will be used to identify the necessary messages within a communication protocol to and from the process planning function.

- Identified suitable collaborators to ensure adequate technology transfer of project results. To date, three CRADAs are active which involve work within this project, with: a) International Technegroupe, Inc., who has donated their commercial process planning system, MultiCAPP, and will collaborate on developing open interfaces to their system; b) Advanced Databases, Inc., an object-oriented database vendor, who will collaborate on sharing information among engineering applications via emerging standard access mechanisms; c) American Heuristics, Inc., a custom software developer and system integrator, who will collaborate on process planning application software development. In addition, collaborations have been established with related in-house projects, such as the Rapid Response Manufacturing (RRM) project funded by the Advanced Technology Program, and the Computer Aided Manufacturing Engineering project funded by the Navy Manufacturing Technology Program.

- Researched and procured additional software identified as critical to the project. In particular, the PART process planning system, sold by ICEM, represents an important commercial implementation of generative planning capability, and it was purchased for use within this project.

\section{FY 95 Plans:}

- Define process plan representation model, building upon earlier work with ALPS (A Language for Process Specification).

- Collaborate (with the RRM project) on the definition of manufacturing resource models to support process planning.

- Collaborate (with the SIMA Design Applications project) on the definition of an Engineering Process Model, which will drive the specification of a communication protocol between process planning and design functions.

- Collaborate (with other SIMA projects) on prototyping databases, based upon the models defined above.

- Collaborate (with CRADA partners and vendors) on the integration of several commercial process planning systems by means of the neutral database and communication protocol implementations.

- Collect industrial data describing product data, process plans, and manufacturing resources, to populate the databases described above. Build repository of realistic data for use by collaborators and the research and development community. 
Related Developments: ISO TC184/SC4/WG3 is sponsoring the development of ISO 10303-49, Process Structure and Properties, which will support the representation of process plans. When this model becomes a standard, serious attention will be given to incorporating this representation into our integration approach.

\begin{tabular}{|l|l|l|l|l|l|l||}
\hline PROCESS PLANNING APPLICATIONS FISCAL YEARS & 96 & 96 & 97 & 96 & 99 \\
\hline Refine process plan activity model [STRS] & & & & & \\
\hline Refine plan representation model [STRS] & & & & & \\
\hline Implement refined representation model [STRS] & & & & & \\
\hline $\begin{array}{l}\text { Establish Process Planning Collaborative Laboratory } \\
\text { [STRS] }\end{array}$ & & & & & \\
\hline $\begin{array}{l}\text { Participate in standardization efforts re. process planning } \\
\text { [STRS] }\end{array}$ & & & & & \\
\hline $\begin{array}{l}\text { Develop integration conformance tests for process } \\
\text { planning [STRS] }\end{array}$ & & & & & & \\
\hline
\end{tabular}




\section{Staff: (0.8 staff years) *STEVEN RAY, *Shaw Feng, *Visiting researchers}

Project Objective and MEL Thrust Supported: To provide a research-enabling environment dedicated to the development of technology and standards in the area of manufacturing process planning. Manufacturing Systems Integration.

Need Addressed: Manufacturing process planning is now recognized as one of the functions critical to achieving an integrated engineering and production process. Indeed, it serves as the bridge between the engineering domain and the manufacturing shop floor. Tackling the integration of these applications demands collaboration as the complexity and scale of the problems expand. In many areas, engineers have either used generic tools and technology, or developed their own tools, to meet their specific needs. This has been difficult, as funding for tool development by numerous projects is redundant, and often the building of tools is not seen as necessary to the accomplishment of project goals. A more explicit partnership between manufacturing engineers and computer scientists can inspire development of computing technology that better meets the needs of the manufacturing research and development community. The Process Planning Testbed Project ${ }^{2}$ seeks to foster this partnership by assembling supporting tools, sample data, and contributed planning systems at a single, nationally accessible location at NIST.

Technical Approach: The project has been attacking this problem along four avenues: information services; workshops; a laboratory for testing and integration; a collaborative research program. Information services were put in place to allow the diverse process planning community to easily communicate with one another. Components of the service include electronic mailing lists, an on-line focussed bibliographic citation database, and information available via the World Wide Web. Three workshops have been held, bringing together various constituencies (vendors, users, researchers) involved in manufacturing planning. The ultimate aim is to create a "Collaboratory" (collaborative laboratory) dedicated to process planning research and development ${ }^{3}$. This project has not been funded since FY 93, and is subsisting on a small amount of carryover funds. Because of this, the project is currently focussing its resources on collaborations with visiting researchers and postdoctoral candidates.

\section{FY 94 Accomplishments:}

- Upgraded an object-oriented database engine and supporting interface and translation tools, which support a network-accessible graphical process plan editor. This editor allows developers on the Internet the ability to experiment with advanced representation structures which are feeding into current process plan standardization activities.

- Expanded the bibliographic citation database $e^{4}$ to over 800 references. This resource supports ongoing peer review of the process planning literature by the R\&D community, a service not possible with a conventional library.

\footnotetext{
${ }^{2}$ Ray, S.R. and Feeney, A.B., "A National Testbed for Process Planning Research," NISTIR 5169 , 1993.

${ }^{3}$ The term "collaboratory" is defined and presented in "National Collaboratories - Applying Information Technology for Scientific Research," National Academy Press, Washington, D.C. 1993

${ }^{4}$ Feeney, A.B., "User's Guide to the On-Line Bibliographic Reference System for the NIST Process Planning Testbed," NISTIR 4891, 1992.
} 
- Expanded the process planning repository to include sample product designs and experimental process planning systems.

- Collaborated with related NIST programs to assemble suites of software tools to accelerate the research and development activities within industry and academia. These last two activities have received strong endorsement by industrial and academic developers, as they greatly reduce the amount of startup work required of them in their own projects.

\section{FY 95 Plans:}

- Secure suitable sponsorship of this effort. Targeted funding levels are roughly $\$ 300-400 \mathrm{~K}$.

- Host two or three visiting researchers under external sponsorship to tackle problems common to all system developers, in the areas of representation, architectures and integration.

- Pending funding, host a workshop which would for the first time bring together the participants and conclusions of the prior three workshops 5 .

\begin{tabular}{||l|l|l|l|l|l||}
\hline \hline PROCESS PLANNING TESTBED FISCAL YEARS & 95 & 96 & 97 & 98 & 99 \\
\hline $\begin{array}{l}\text { Sponsor nationwide workshop series designed to improve } \\
\text { sharing of industrial needs and technical solutions [STRS, } \\
\text { OA] }\end{array}$ & & & & & \\
\hline & & & & & \\
\hline $\begin{array}{l}\text { Establish Process Planning Collaborative Laboratory } \\
\text { [STRS, OA] }\end{array}$ & & & & & \\
\hline
\end{tabular}

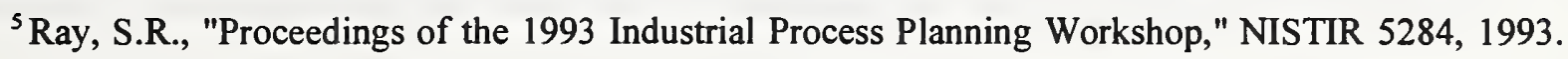




\section{Staff: (2.7 staff years) *Mary Beth Algeo, *Jim Fowler, *KEVIN JURRENS, Mike Woodruff}

Project Objective and MEL Thrust Supported: The primary FY 94/95 objective for the RRM Intramural Project is to demonstrate that there exists a common set of manufacturing resource (MR) data which can be used to support the functions performed by a variety of computer aided engineering (CAE) software applications. In this context, manufacturing resource data may include characteristics of machine tools, manufacturing equipment, cutting tools, tool holders, tool adapters, collets, bushings, fixtures, cutting fluids, etc. Manufacturing System Integration.

Need Addressed: In the domain of mechanical design and manufacturing, information sharing between CAE applications is typically synonymous with product design data exchange. Other information elements which are relevant to and necessary for the functions performed by CAE applications are frequently overlooked. As an example, information describing machine tool capabilities is necessary for manufacturing planning and simulation purposes. Additionally, information describing specific process characteristics is required for manufacturing analysis and cost estimation. Each CAE vendor uses and maintains this information in subtly different ways which prevents application system integration. The problem is compounded because the originating sources of such information (e.g., machine and cutting tool manufacturers) do not provide equivalent characterizations of their products.

Several efforts have been initiated within industry to develop information constructs (e.g., databases, information models) that describe manufacturing resources. These efforts have typically resulted in company-specific data structures and system implementations. The implementations are typically applicable to only a single CAE application within the organization, resulting in multiple redundant stores of MR data and much duplicated effort to implement additional systems in other application areas.

Technical Approach: Information models which specify a common subset of manufacturing resource data will be developed, implemented, and tested to ensure that the requirements of targeted CAE applications are met. The initial focus of this project will be in the application areas of manufacturing cost estimating, manufacturing process planning, and NC toolpath generation. The completeness, validity, and usability of the information constructs will be evaluated by implementing the information models in a single database to supply MR data to multiple engineering applications in a multi-vendor environment.

It is expected that project results will provide a catalyst for a standardized and publicly available manufacturing resource data structure by providing proven results and a working strawman to appropriate standards organizations. Additionally, an accepted MR data structure will permit more seamless application system integration and allow CAE application vendors and research organizations to concentrate on application-specific problems as opposed to acquisition, representation, and maintenance of MR data. Standard MR information models could also be used by manufacturing resource providers (e.g., machine tool vendors) to disseminate specifications for their products and could facilitate the establishment of electronic MR "data books" and catalogs for use throughout the manufacturing industry.

\section{FY94 Accomplishments:}

- Formed collaborations with Martin Marietta Energy Systems, Texas Instruments, Allied-Signal Aerospace, Sandvik Corporation, SGS Tooling, Institute for Advanced Manufacturing Sciences, and others to review MR data needs from several perspectives.

- Established the scope and boundaries of the types of manufacturing resource data to be considered.

- Obtained and analyzed sample representations of MR data from tooling vendor documentation, 
manufacturing handbooks, technical journals and research literature, CAE application software data structures, industry resource databases, national and international standards documents, and application experts in the field of manufacturing equipment and tooling.

- Initiated development of the detailed requirements for a manufacturing resource data structure to accommodate multiple engineering applications.

- Selected and implemented a baseline set of engineering software systems for validation of the manufacturing resource information model (i.e., the Manufacturing Resource Test Environment).

\section{FY95 Plans:}

- Complete development of MR data requirements

- Model MR data requirements using Express language

- Implement Express model into database system

- Integrate process planning system with resource database

- Evaluate resource models in process planning context

- Develop cost models for machining operations

- Integrate cost estimating system with resource database

- Evaluate resource models in cost estimating context

- Demonstrate and report results

- Submit strawman proposal for standardization of MR data

Related Developments: The Rapid Response Manufacturing (RRM) Consortium is organized through the National Center for Manufacturing Sciences (NCMS). A principal objective of the RRM Intramural Project is to establish collaborations with the RRM Consortium to support RRM program efforts and to leverage NIST skills and technologies. With this support role in mind, activities of the RRM Intramural Project are selected based upon specific needs of consortium member companies.

\begin{tabular}{|c|c|c|c|c|c|}
\hline $\begin{array}{l}\text { RAPID RESPONSE MANUFACTURING (RRM) } \\
\begin{array}{l}\text { INTRAMURAL PROJECT } \\
\text { FISCAL YEARS }\end{array}\end{array}$ & 95 & 98 & 97 & 98 & 99 \\
\hline \multicolumn{6}{|l|}{ Complete development of MR data requirements [ATP] } \\
\hline \multicolumn{6}{|l|}{$\begin{array}{l}\text { Model MR data requirements using Express language } \\
\text { [ATP] }\end{array}$} \\
\hline \multicolumn{6}{|l|}{ Implement Express model into database system [ATP] } \\
\hline \multicolumn{6}{|l|}{$\begin{array}{l}\text { Evaluate resource models in process planning context } \\
\text { [ATP] }\end{array}$} \\
\hline \multicolumn{6}{|l|}{$\begin{array}{l}\text { Integrate process planning system with resource database } \\
\text { [ATP] }\end{array}$} \\
\hline \multicolumn{6}{|l|}{ Develop cost models for machining operations [ATP] } \\
\hline \multicolumn{6}{|l|}{$\begin{array}{l}\text { Integrate cost estimating system with resource database } \\
\text { [ATP] }\end{array}$} \\
\hline $\begin{array}{l}\text { Evaluate resource models in cost estimating context } \\
\text { [ATP] }\end{array}$ & & & & & \\
\hline
\end{tabular}




\begin{tabular}{|l|l|l|l|l|l||}
\hline $\begin{array}{l}\text { RAPID RESPONSE MANUFACTURING (RRM) } \\
\text { INTRAMURAL PROJECT }\end{array}$ FISCAL YEARS & 95 & 95 & 98 & 98 & 99 \\
\hline Demonstrate and report results [ATP] & & & & & \\
\hline $\begin{array}{l}\text { Submit strawman proposal for standardization of MR data } \\
\text { [ATP] }\end{array}$ & & & & & \\
\hline $\begin{array}{l}\text { Pursue standardization activities for the representation of } \\
\text { MR data [ATP] }\end{array}$ & & & & & \\
\hline $\begin{array}{l}\text { Integrate additional engineering applications with the } \\
\text { resource database [ATP] }\end{array}$ & & & & & \\
\hline $\begin{array}{l}\text { Supplement the integrated resource data environment with } \\
\text { STEP product data [ATP] }\end{array}$ & & & & & \\
\hline
\end{tabular}


Staff: (3.75 Staff Years) Hui-Min Huang, Tom Kramer, Alex Meystel, HARRY SCOTT, Kate Senehi, Nicholas Tarnoff

Project Objective and MEL Thrust Supported: This project has two primary objectives: 1) Develop a detailed design of Reference Model Architecture for intelligent control of manufacturing processes and 2) Demonstrate, validate and evaluate the NIST reference model architecture through analysis and performance measurements of a simulated and prototype implementation. Manufacturing System Integration.

Needs Addressed: The lack of a formal, consistent control architecture with a factory-wide scope is evidenced by characteristics of current implementations and their shortcomings. These include implementation of islands of automation exhibiting a low level of integration because of the absence of a common system architecture design model, functionality limited by the inability to integrate the components of multiple developers as the result of proprietary or non-standard interfaces, minimal reusable software components leading to higher cost, arbitrary differences in implementation techniques because a common model is not followed, and a lack of common development tools because of the differences among various architectural approaches. The development of the reference model architecture for intelligent control of manufacturing systems will directly address these needs. A common architecture will promote a higher level of integration and the standardization of subsystem interfaces. Further, since the architecture will no longer be a "moving target," the potential for software reuse is greater, as is the likelihood of creation of development tools that are useful across many applications. The results are cost savings in development and implementation of intelligent control systems for manufacturing.

Technical Approach: Following on a feasibility study completed in FY93 and the draft joint architecture design developed in FY94, the joint architecture will be refined and a manufacturing application implemented and demonstrated. A workshop on architecture issues is planned in FY95 and a consortia will be sought to identify architectural issues. Discussions will continue with potential industrial partners who have manufacturing facilities suitable for modeling and control under the joint architecture in simulation and as a prototype implementation. The selected facility will be modeled and operated under the joint architecture in simulation, using visualization methods developed under the HPCC Operator Interface Program, and using simulation tools, or extensions to existing tools, developed jointly by NIST and commercial tool vendors. Based on the study of Computer Aided Control System Engineering (CACSE) tools completed in FY94, development of the required tools will begin, and a first version of a CACSE tool will be demonstrated.

\section{FY94 Accomplishments:}

- Published feasibility study in which various architectures are reviewed and the concept of incorporating various aspects from them is considered.

- Produced draft document introducing an initial version of the architecture and addressing preliminary definitions, an overview of the architectural framework for the proposed architecture, a description of key aspects of the functioning of the architecture and a formal model of some portions of the architecture.

- Explored potential industry partnerships.

\section{FY95 Plans:}

- Complete detailed functional specification and architectural model using NGIS and EMC/Monarch systems as sources of specific implementation characteristics.

- Specify message suite for operation and startup/shutdown.

- Develop server controllers for material handling and tool management functions.

- Complete factory model and operational scenarios for first implementation.

- Implement factory model in simulation. 
- Host workshop on architecture issues.

- Build real-time, scheduled, and transition controller types. Develop required graphical support of controller user interfaces.

- Develop/integrate CASE components appropriate for joint architecture.

- Develop configuration management and scripts.

- Identify and implement application specific non-generic work elements.

- Integrate contractor-developed communication tool with implementation.

- Create process and production plans for first implementation.

- Develop/Integrate data base and create necessary resource files for first implementation.

- Integrate developed components in first implementation.

\begin{tabular}{|c|c|c|c|c|c|}
\hline $\begin{array}{l}\text { REFERENCE MODEL ARCHITECTURE/JOINT } \\
\begin{array}{l}\text { ARCHITECTURE } \\
\text { FISCAL YEARS }\end{array}\end{array}$ & 95 & 96 & 97 & 98 & 99 \\
\hline $\begin{array}{l}\text { Seek industrial partners with suitable factories for } \\
\text { emulation/control [OA] }\end{array}$ & & & & & \\
\hline $\begin{array}{l}\text { Host workshop on architecture issues and seek } \\
\text { consortium to work toward national/international standard } \\
\text { for reference model architecture }[O A]\end{array}$ & & & & & \\
\hline Develop design of first version of joint architecture [OA] & & & & & \\
\hline Determine factory application for first implementation [OA] & & & & & \\
\hline $\begin{array}{l}\text { Develop first, partial implementation and integrate with } \\
\text { factory emulation }[\mathrm{OA}]\end{array}$ & & & & & \\
\hline Develop data to support first implementation $[O A]$ & & & & & \\
\hline $\begin{array}{l}\text { Develop complete implementation of joint architecture } \\
\text { [OA] }\end{array}$ & & & & & \\
\hline $\begin{array}{l}\text { Integrate CASE components to support implementations } \\
\text { of joint architecture systems [OA] }\end{array}$ & & & & & \\
\hline $\begin{array}{l}\text { Document the initial implementation of the joint } \\
\text { architecture }[\mathrm{OA}]\end{array}$ & & & & & \\
\hline $\begin{array}{l}\text { Prepare report on the complete implementation of the joint } \\
\text { architecture }[\mathrm{OA}]\end{array}$ & & & & & \\
\hline $\begin{array}{l}\text { Prepare report on CASE support tools used and needed } \\
\text { [OA] }\end{array}$ & & & & & \\
\hline
\end{tabular}




\section{Title: SIMA PRODUCTION}

Staff: (2 staff years) ${ }^{*}$ Al Jones, *Swee Leong, *CHARLES MCLEAN, new hires

Project Objective and MEL Thrust Supported: The overall goal of the SIMA Production project is to address integration problems associated with production engineering, scheduling, and simulation systems. The project will develop process models, information models, and interface specifications, databases, and extensions to commercial production software which resolve facilitate system integration. Manufacturing Systems Integration.

Need Addressed: The world wide market for CAD/CAM/CAE software applications increased by more than $5 \%$ to $\$ 16.5$ billion dollars in 1993 . The computer professional services business which includes systems integrators is expected to grow to considerably in the coming years. The growth of the systems integration portion of the computer professional services business is highly dependent upon the growth of the CAD/CAM and CAE software market because data exchange formats and interface protocols between CAD/CAM/CAE software applications are incompatible. This incompatibility results in an increased business for professional integrators who create custom integration solutions to support data exchange between software applications. These solutions are expensive to implement, require a great deal of time to develop, are very inflexible, and lack the incorporation of standards. These custom solutions result in numerous problems that can be broken down into three major technical impediments: 1) the lack of understanding on what information and knowledge is required between design, planning, and production areas, 2) the lack of information exchange standards that support both product and process data exchnage between applications, and 3) the lack of interface standards which define interface protocols between applications. This project addresses this problem in the area of production engineering and production scheduling systems and interface standards.

Technical Approach: The project will assess industry needs, with respect to production engineering, production scheduling, and systems integration. The project will select and install software applications that are used to engineer production systems, perform production scheduling, and simulate production. The project will define requirements, develop information and process models, specify applications architectures, interfaces, and databases for integrating production software systems. Prototype integrated systems will be constructed from commercial products. The principal elements of the technical approach are: 1) Identify and address critical industrial needs through collaboration, 2) Develop solutions to production software integration problems, 3) Construct prototype environments using commercial products, 4) Validate results through industrial testing of system implementations, 5) Specify and promote needed industry standards, and 6) Facilitate the rapid commercialization of new technology.

\section{FY 94 Accomplishments:}

- Prepared SIMA project plan and work breakdown structure

- Contributed to and editted SIMA Background Study document

- Selected and procured simulation and scheduling software

- Initiated SIMA requirements analysis specification

- Prepared SIMA Applications projects briefings

\section{FY 95 Plans:}

- Arrange industrial collaboration

- Select test parts for baseline demonstration

- Define initial demonstration scenario

- Demonstrate baseline production system 
- Develop process models for production applications

- Develop information models for production applications

- Initiate implementation of Version 1 production applications system

Related Developments: There is related work in both scheduling and computer-aided manufacturing engineering in the Integration of Real-Time Scheduling and Shop Floor Data Collection Project.

\begin{tabular}{|c|c|c|c|c|c|}
\hline SIMA PRODUCTION & 95 & 96 & 97 & 98 & 99 \\
\hline \multicolumn{6}{|l|}{$\begin{array}{l}\text { Identify current production scheduling and production } \\
\text { engineering methodologies }\end{array}$} \\
\hline \multicolumn{6}{|l|}{ Establish baseline production systems environment } \\
\hline \multicolumn{6}{|l|}{ Develop production functional reference model } \\
\hline \multicolumn{6}{|l|}{ Assess state-of-the-art tools } \\
\hline \multicolumn{6}{|l|}{$\begin{array}{l}\text { Identify existing and needed production software } \\
\text { standards }\end{array}$} \\
\hline \multicolumn{6}{|l|}{ Document existing production engineering methods } \\
\hline \multicolumn{6}{|l|}{$\begin{array}{l}\text { Analyze current industry data format and integration } \\
\text { solutions }\end{array}$} \\
\hline \multicolumn{6}{|l|}{ Define architecture for production scheduling } \\
\hline \multicolumn{6}{|l|}{$\begin{array}{l}\text { Establish Version } 1 \text { interface and data exchange } \\
\text { specifications }\end{array}$} \\
\hline \multicolumn{6}{|l|}{ Implement Version 1 production systems prototype } \\
\hline \multicolumn{6}{|l|}{ Recommend new production scheduling methodologies } \\
\hline \multicolumn{6}{|l|}{ Implement production systems architecture } \\
\hline \multicolumn{6}{|l|}{ Support development of extensions to selected tools } \\
\hline \multicolumn{6}{|l|}{$\begin{array}{l}\text { Initiate and promote data exchange standard } \\
\text { specifications }\end{array}$} \\
\hline \multicolumn{6}{|l|}{ Implement Version 2 production systems prototype } \\
\hline \multicolumn{6}{|l|}{ Recommend new production engineering methodologies } \\
\hline \multicolumn{6}{|l|}{ Test prototype tools at selected sites } \\
\hline \multicolumn{6}{|l|}{ Support development and testing of standards } \\
\hline \multicolumn{6}{|l|}{ Conduct industry beta testing } \\
\hline Support and evaluate new commercial tools & & & & & \\
\hline
\end{tabular}




\begin{tabular}{||l|l|l|l|l|l||}
\hline SIMA PRODUCTION FISCAL YEARS & 95 & 96 & 97 & 98 & 99 \\
\hline Implement first commercial integrated implementation & & & & & \\
\hline Promote draft production interface standards & & & & & \\
\hline
\end{tabular}


Staff: *Allison Barnard, *Newton Breese, *MARY MITCHELL, *Lynn Rosenthal

Project Objective and MEL Thrust Supported: This project will accelerate the adoption of STEP by promoting the delivery of early high quality implementations of STEP Application Protocols. Manufacturing Systems Integration.

Need Addressed: The target customers are vendors of STEP products and early users who can invest in STEP pilots. Test laboratories will also use the results when product certification is of value. Past experience with standards has shown that vendor claims that a standard has been followed cannot be relied upon. The adoption of a standard may be delayed by years when early vendor products do not meet the requirements of the standard. The adoption of STEP will require considerable investment by both vendors and users of STEP products. An agreed upon means for confirming and certifying that a product conforms to the standard is a first step and one which requires the technical support from institutions like NIST. The world-wide interest in STEP is motivated by the following benefits: 1) enables concurrent engineering practices, making possible simultaneous development through the use of a shared data representations for tasks such as design, production planning, manufacturing, and maintenance; 2) facilitates multiple companies working together on new and improved product developments; and 3) makes possible the use of new and better approaches to increase the efficiency of revisions and upgrades to the design of a product.

Technical Approach: The approach is to provide a means by which STEP products can be measured for conformance with a standard. This is being done by developing a set of value-added software tools which will be made available for vendors to use during their product development process (i.e., build in conformance instead of testing it in at the end). This unique approach offers many advantages over traditional implementations of conformance testing. Required conformance testing is generally challenged by U.S. vendors. Under this approach, vendors can gain confidence that their product can successfully pass the testing, vendors have access to tools to improve the quality of their products and reduce the costs of software testing, and vendors gain in the expanded market that user confidence in a tested product brings.

Two additional strategies are also being pursued. (NIST is using the Industrial Technology Institute as a contractor.) The first is leveraging early implementation experience to validate the test system and test suites. NIST/ITI are providing testing support to a group of industry sponsored STEP pilot implementations that are organized by PDES, Inc.. A beta testing program will provide access to this means of testing to any early STEP implementation. The second is aggressive participation in the international standards effort related to testing methods and requirements on clients and test labs. The availability of a conformance testing program opens up the world market to U.S. developed STEP products. There has been competitive advantage experienced being the first country to provide a conformance testing service to its vendors. A U.S. based conformance testing service for STEP may improve our efforts to export both U.S. developed STEP products and competitive U.S. manufactured products to the rest of the world.

FY 94 Accomplishments:

- Developed prototype components of a Conformance Test System (CTS) including: Test Purpose Generator, which produces test purposes from (AIM) Express specification; Test Coverage Analyzer which determines which test purposes are supported by the test cases based on analysis of Part 21 files; Structure Checker, which valuates STEP products (pre-processors) for the structural consistency of Part 21 files produced and test system user interface which provides a user interface for control of the test execution including the management of test campaigns and test case selection

- Established Beta STEP testing program policy and procedures NISTIR

- Demonstrated CTS prototype in CASE Environment. 
- Completed guidelines for the Development of Test Purposes and ATSs.

- Developed Test Data for AP 203 - Configuration Controlled 3D Design (i.e., the 1st STEP application protocol approved as an international standard).

- Transferred conformance testing concepts to PDES, Inc. STEP migration team.

\section{FY 95 Plans:}

- Support testing of AP 203 products, as part of the beta testing program, to validate the test system and test procedures. It will also evaluate early implementations of STEP AP 203.

- Develop a Federal Information Processing Standard (FIPS) for STEP.

- Testing Harness: Enhance the test system: to automate the reporting/capture of test data, and to improve creation of test campaigns/installation of test cases.

- Upgrade Conformance Test System (CTS) Prototype with the following components: rule validator, Prototype ARM/AIM browser; enhanced version; enhanced coverage analyzer; prototype automated test case generator, and enhanced version; analyzer for STEP resource parts; and structure checker enhanced to include all informal propositions (constraints) specified in AP 203, initial and final release.

- Use Geometry Visualizer to simulate the functions of representing Part 21 geometric entities graphically so verdict criteria can be more easily evaluated by a test operator.

- Develop executable test cases for AP 207.

- Develop a test suite for Associative 3D Drafting.

- Prepare Abstract Test Suite for AP 203 for CD ballot.

- Support PDES, Inc. (U.S. industry) pilot implementations by incorporation of test data into the test system, developing implementors agreements, configuring test campaigns to correspond to agreements, technology transfer of the test system, methods, tools and etc.

- Resolve issues on Abstract Test Suite Guidelines and Abstract Test Methods. Produce and resolve issues with 1203 Committee Draft document. Maintain 12xx document template.

Related Developments: The testing methods are being standardized within ISO/TC184/SC4 Working Group 6 (WG6), Conformance Testing, through a consensus process. This will make the world-wide mutual recognition of test results possible. NIST and ITI must work with the testing activities of the ISO/TC184/SC4/WG6 and IGES/PDES Organization Testing project to achieve consensus. NIST is working with international partners from CADDETC, and ProSTEP and to a lesser extent GOSET and other ESPRIT CTS members which could also lead to the sharing of testing tools and executable test suites.

\begin{tabular}{|l|l|l|l|l|l|l||}
\hline STEP CONFORMANCE TESTING FISCAL YEARS & 95 & 95 & 97 & 98 & 99 \\
\hline $\begin{array}{l}\text { Software that automates test execution; prototype STEP } \\
\text { Conformance Test System; beta testing program }\end{array}$ & & & & & \\
\cline { 2 - 6 } $\begin{array}{l}\text { Vendor testing tools in CASE environment; generalized } \\
\text { STEP test suites; accreditation procedures for test labs }\end{array}$ & & & & & \\
\hline $\begin{array}{l}\text { Robust test system transferred to test laboratories; } \\
\text { additional STEP Implementation Methods supported; life } \\
\text { cycle interoperability testing method }\end{array}$ & & & & & \\
\hline $\begin{array}{l}\text { Technology transfer of interoperablity testing; establish } \\
\text { network of test centers to cover domain of applications }\end{array}$ & & & & & \\
\hline \begin{tabular}{l} 
Technology transfer to other standards applications \\
\hline
\end{tabular}
\end{tabular}




\section{Title: STEP IMPLEMENTATION PROTOTYPES}

Staff: *Allison Barnard, *Don Libes, *Josh Lubell, *MARY MITCHELL, *David Sauder, *Peter Wilson, New hire

Project Objective and MEL Thrust Supported: To accelerate the adoption of STEP by promoting development of industry consensus on "best practices" for product data communication, providing software tools to based on the STEP standard to facilitate implementations of STEP, and ensuring that STEP is responsive to the product data needs of US industry. Manufacturing Systems Integration

Need Addressed: For the above stated objective to be reached, several needs must be addressed. The initial customers are STEP Pilot Implementation projects, specifically those in the automotive industry who are advancing the state of the art in STEP data sharing applications. Now that the initial set of STEP specifications has been approved as an International Standard, US industry must implement real-life business scenarios to provide concrete information on the benefits and risks of full-up STEP implementations. To do this effectively, industry needs STEP expertise and STEP software tools. The success of these pilot implementations is key to the successful adoption of STEP. Additionally, implementation experience is needed within the STEP community as it will raise new issues for STEP and lead to improved methods. Discussion between industry users, vendors, and STEP developers needs to be facilitated in order to develop recommendations for the rapid resolution of problems related to the practical implementation of STEP.

Technical Approach: These needs will be addressed in several ways. NIST STEP software toolkits have been in wide use in the STEP community for several years. Under this project, existing toolkits will be upgraded to support the full functionality of the International Standard. These toolkits will be freely available to the public for use in STEP implementations.

A memorandum of understanding (MOU) is in place with PDES, Inc., an industry consortium formed to accelerate the development and implementation of STEP. The SIP plans to leverage work already going on in industry by forming a strategic partnership with a PDES, Inc. Pilot Project. An additional strategic partnership is planned with the Automotive Industry Action Group (AIAG) whose major members have agreement to adopt STEP throughout the supply chain. Once a strategic partnership has been formed with one or more pilot projects, expertise will be provided on STEP methodology, database access and testing to the pilot team. NIST-developed software will be extended where needed to meet the demands of the pilot implementations and this technology will be transferred to accelerate commercial implementations.

NIST is uniquely positioned to provide the needed interface between pilot implementation projects and the STEP development community. In accordance with it's traditional role, NIST will act as a neutral party to convene implementor forums between key industry users and the vendor community to develop recommendations for the rapid resolution of problems related to the practical implementation of STEP.

NIST will facilitate driving modifications to STEP and STEP methods by raising awareness of implementation issues and building consensus within the STEP community. Extending the STEP methods in support of implementations and by documenting implementation guidelines will accelerate the development and use of STEP as an advanced manufacturing technology and supporting the development and use of the STEP standard.

FY 94 Accomplishments: (seed project with CALS)

- Accelerated development of PAS-C Program Application Protocols

- Provided training on STEP Methods

- Provided training/user support for NIST software tools 
- Provided consulting on test design and concepts

\section{FY 95 Plans:}

- Collaborate with pilot implementation project(s)

Select STEP pilot implementation project(s) for collaboration

Define partner roles/project plan for collaboration

Identify high payback opportunities (process modeling)

Demonstrate potential for STEP data sharing

Document strategy and issue log

Provide STEP and software expertise to pilot team.

- Upgrade NIST STEP software toolkits

Upgrade NIST EXPRESS Toolkit to ISO 10303-11 International Standard

Extend STEP Class Library to ISO 10303-21 International Standard

Enhance/maintain documentation

Test and release software

Extend Express server to executed Test Suite Generation tools 6/95

- Establish STEP Implementor's Forum

Organize and conduct workshops for implementors

Develop Implementor's Forum operational structure

Establish E-mail exploder for implementors

- Transfer Technology

Provide STEP training to Electronic Commerce Resource Centers (train the trainer)

Related Developments: ISO 10303 "Product Representation and Exchange" published as International Standard December, 1994. The release of Abstract Test Suite Generation Tools to selected sites May, 1994 led to the circulation of the first Abstract Test Suite for STEP by an automotive Application Protocol. A major PDES Inc. Pilot and AIAG member, GM/EDS is one of 15 early release users of the NIST STEP Class Libraries (public release May 94).

\begin{tabular}{|c|c|c|c|c|c|}
\hline STEP IMPLEMENTATION PROTOTYPESFISCAL YEARS & 95 & 96 & 97 & 98 & 99 \\
\hline $\begin{array}{l}\text { Plan with STEP Pilot Implementation Project(s) for } \\
\text { Collaboration; release NIST Toolkit Software; document } \\
\text { issues and proposals documented and submit against } \\
\text { STEP documents; demonstrate Pilot Implementations }\end{array}$ & & & & & \\
\hline $\begin{array}{l}\text { Establish standardized implementors agreements; } \\
\text { produce summarized recommended practices within an } \\
\text { industry sector; demonstrate Pilot Implementations; } \\
\text { publish NISTIR on Guidelines for the Implementation of } \\
\text { STEP }\end{array}$ & & & & & \\
\hline
\end{tabular}


Program Objective and MEL Thrust Supported: In 1994, NIST initiated the SIMA program as part of a new federal government initiative on High Performance Computing and Communications (HPCC), which is described in the High Performance Computing Act of 1991 and Senate Bill S-4, "The National Competitiveness Act of 1993."

NIST's program for FY94 and beyond is included under the Information Infrastructure Technology Applications (IITA) program category of the HPCC initiative. The objectives of the SIMA program are: 1) to accelerate the development and deployment of HPCC technologies required for the National Information Infrastructure (NII), and 2) to apply and test these technologies in a manufacturing environment. Ultimately, these technologies will radically transform America's manufacturing environment, allowing individual companies to interact electronically as part of a "virtual enterprise" to produce world class products for the 21 st century.

The SIMA program will focus on technologies and standards that can improve computer systems integration and networking as applied to manufacturing. The program which involves all eight NIST laboratories, emphasizes both product data exchange for manufacturing, and electronic data interchange for electronic commerce. Manufacturing Systems Integration.

Need Addressed: American manufacturers need to recapture world leadership and respect. The specific technical goals are to exploit lean manufacturing (e.g. greater efficiency and lower cost), flexibility (e.g., variation in production runs to allow for consumer preferences), and agility (e.g., supporting small production runs, rapid retooling, and exploitation of electronic commerce services.

In addition, companies will be able to band together to jointly manufacture goods. This will require a integrated framework of software applications, and a rapid retooling, tailoring and composition of shared information services such as inventory control, work scheduling, collaborative design systems, planning and production systems, and product delivery. Potential machine tools vendors and other manufacturing support companies will be willing to provide simulations of new process-control and planning software to enable companies to test before they buy. In addition, software development companies will provide access to powerful computer-aided design tools that are currently too expensive for purchase by small companies. This is economically viable because a small company can access both the software and the human expertise that lies behind it, through integrated frameworks, data exchange standards, and online consulting services.

Technical Approach: Emphasis is on systems integration technologies that support flexible and rapid access to information for manufacturing applications. A standards-based data exchange effort for computer integrated manufacturing focuses on improving data exchange among design, planning and production activities. Prototype systems and interface repositories and pre-commercial prototype systems that can be installed by potential vendors for test and evaluation in NIST and industry supported Advanced Manufacturing Systems and Networking Testbeds. NIST will distribute standards reference data, technical information, and digital product data designs via digital library technologies.

NIST's manufacturing testbed will support R\&D in high performance manufacturing systems and testing computer and networking hardware and software in a manufacturing environment, and will be used to include applications in mechanical, electronics, construction, apparel, and chemical industries; electronic commerce applications in mechanical and electronic products: integration of materials performance data into computer aided design; harmonization of product data exchange and electronic data interchange standards; technology transfer of information for electronics and construction industries; and an integrated Standards Reference Data 
system. The testbed will serve as a demonstration site for use by industrial technology suppliers and users, and assist industry in the development and implementation of voluntary standards.

\section{FY 94 Accomplishments:}

- Installed and evaluated state-of-the-art manufacturing systems for design and planning of mechanical part production.

- Implemented a prototype application protocol development environment for product data exchange standards.

- Published report on reference architectures for manufacturing control systems and interface specifications for production systems.

- Provided electronic technology transfer capabilities for NIST's mfg project in response to industry request for online research information for advanced mfg systems.

- Established operational AMSANT for mechanical parts production applications, and established collaboration with other agencies and industry to leverage manufacturing developments that support systems integration need.

FY 95 Plans: The specific plans are included under the individual SIMA project descriptions.

Related Developments: The ARPA TRP program on National Industrial Information Infrastructure Protocols (NIIIP) Cycle one milestones which include a detailed architecture design and industry demonstrations. The DOE Technologies Enabling Agile Manufacturing (TEAM) program's strategic plan, which includes similar technology demonstrations for systems integration. The establishment of the PlantSTEP consortium to support AP development.

Additional related developments are defined in SIMA supported project plans. The SIMA program shares several STEP-related projects with the National PDES Testbed project.

\begin{tabular}{|c|c|c|c|c|c|}
\hline $\begin{array}{l}\text { SYSTEMS INTEGRATION FOR MANUFACTURING } \\
\begin{array}{ll}\text { APPLICATIONS (SIMA) PROGRAM } & \text { FISCAL YEARS }\end{array}\end{array}$ & 96 & 96 & 97 & 98 & 99 \\
\hline $\begin{array}{l}\text { Evaluate additional state-of-the-art software systems for } \\
\text { scheduling and production control of mechanical parts } \\
\text { production. [STRS] }\end{array}$ & $=$ & & & & \\
\hline $\begin{array}{l}\text { Publish: requirements for a CAM engineering tools } \\
\text { environment; a report on manufacturing systems } \\
\text { integration needs for industry, and a reference model for } \\
\text { process plant design. [STRS] }\end{array}$ & 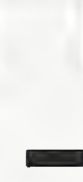 & & & & \\
\hline
\end{tabular}




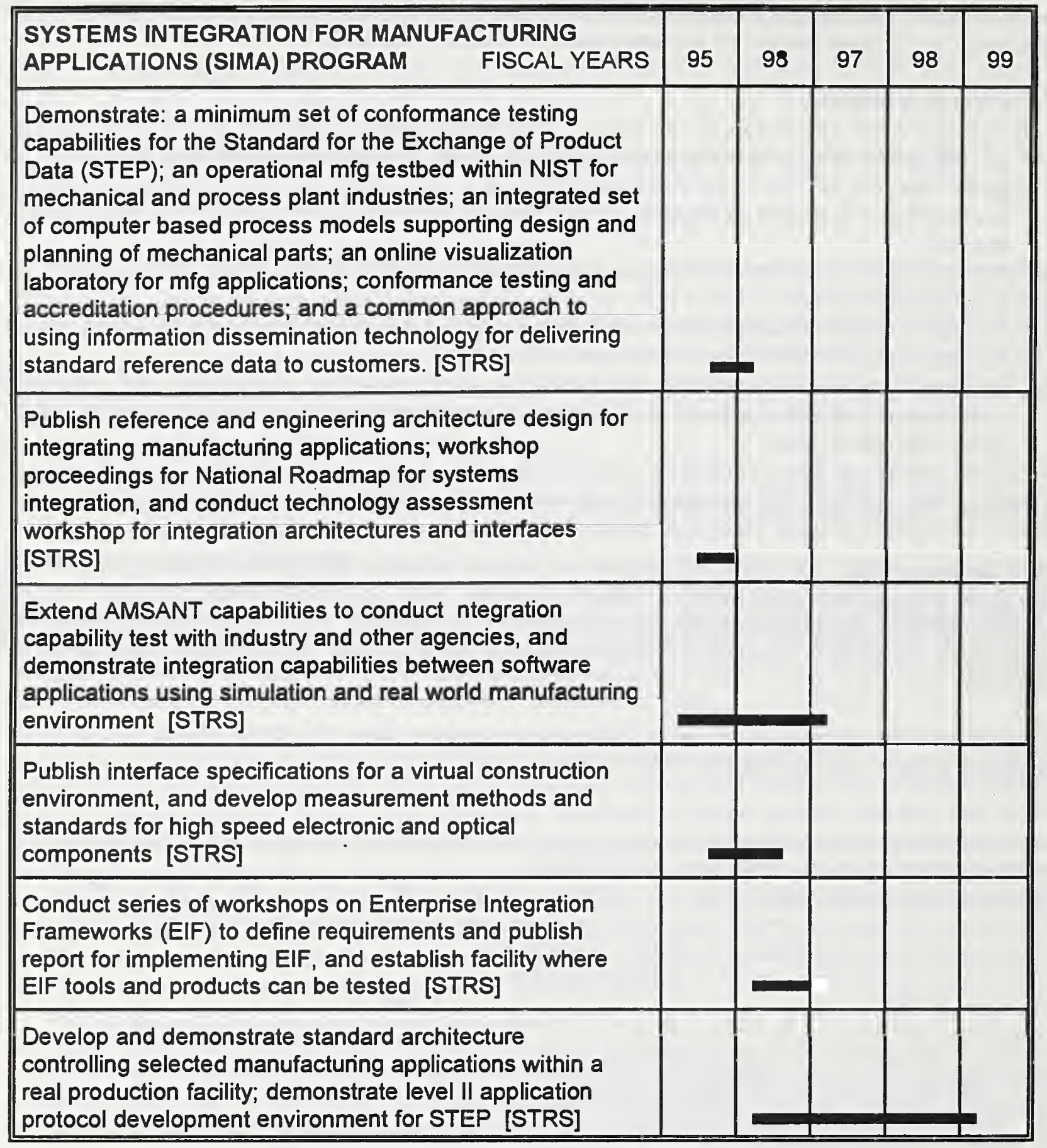


Title: SYSTEMS INTEGRATION FOR MANUFACTURING APPLICATIONS (SIMA): INTEGRATION PROJECT

Staff: (3.5 staff years) Edward Barkmeyer, NEIL CHRISTOPHER, Steve Osella, *Selden Stewart, Evan Wallace

Project Objective and MEL Thrusts Supported: The objective of the SIMA Integration Project is to contribute to U.S. industrial competitiveness by working with industry to develop standards for the integration of engineering design, planning, and production software systems. The Integration project will accomplish this objective by collaborating with related projects to develop system integration specifications, information models, and reference software implementations. The project will promote the results of its collaborations into formal standards processes. Manufacturing Systems Integration.

Need Addressed: U.S. Industry seeks to maintain manufacturing competitiveness by increasing the quality of its products, reducing product development times, and by increasing the agility of its operations. The SIMA Integration project will create standard models of manufacturing information to contribute to industry's quality goals. The system integration specifications and reference software implementations will contribute to reducing system development cycle time and the resulting integrated systems will contribute to reducing product development cycle times. The use of standards in manufacturing software systems integration will contribute to the ease of reconfiguring industrial systems in response to changing market demands.

Technical Approach: The SIMA Integration project is approaching its objectives through cycles of developments in manufacturing system integration specifications, software, and standards. The specifications, software, and standards developed in each cycle build on those developed in the previous cycle and contributes to those in subsequent development cycles. The result of these development cycles is a set of specifications which taken together form a manufacturing system architecture, a set of software prototypes and industry pilot implementations, and formal standards addressing many aspects of manufacturing systems integration. This project builds on NIST's existing body of knowledge in system architectures, specification languages, manufacturing data models, and software prototype development. This project collaborates with others working on related aspects of manufacturing systems integration.

\section{FY 94 Accomplishments:}

- Participated in the NIST sponsored three day "Conference on Manufacturing Technology Needs and Issues," the NCMS manufacturing industry workshop on "Principles of Responsible Agent Systems," and the Intelligent Manufacturing Systems - North American Symposium.

- Reviewed European progress in development of the CIM-OSA and related modeling and development tools through a CRADA with Loughborough University of Technology. Reviewed U.S. developments in manufacturing software system architectures and related modeling and development tools.

- Created EXPRESS language to Gbase conversion tool and C++ library for building objects out of EXPRESS data models.

- Participated in the development of the Draft International Standard ISO 11404 Language Independent Datatypes. Participated in the development of the Draft International Standard ISO 10303 Part 11, EXPRESS Language version 1.0. Participated in the development of the Draft International Standard ISO 10303 Part 21, Standard Data Access Interface (SDAI).

- Monitored and reviewed progress of manufacturing standards activities in ISO/TC184/SC5/WG1 and ISO/TC184/SC5/WG2.

- Published for review NISTIRs titled "Towards an Integrated Production Management Software System", MSI Models of Production Information", and "OSI Model of Common Memory Mechanism".

- Reviewed for publication numerous technical papers, program plans, and proposals related to manufacturing systems integration. 
FY 95 Plans:

- Create Cycle 1 specifications including activity models for design, planning, and production engineering processes, models of information used or created by the activity models, and an initial set of interface and integrating mechanism specifications.

- Create software prototypes to evaluate the suitability of integrating mechanisms which may be used by software implementations based on cycle i specifications. Among these prototypes will be evaluations of Object Request Brokers as potential integrating mechanisms.

- Participate in standards efforts including ISO 10303 Part 11, ISO/TC184/SC5/WG1, ISO/TC184/SC5/WG2, ISO TC /SC22/WG11, ISO/IEC JTC1/SC21/WG7, and the OMG ManSIG.

- Coordinate development and standardization activities with the NIIIP, Sematech CIM Framework, and DOE TEAM programs.

Related Developments: 1) Establishment of the SIMA Advanced Manufacturing Systems and Networking Testbed (AMSANT) and related efforts. ARPA TRP award of the National Industrial Information Infrastructure Protocol (NIIIP) project. Department of Energy establishment of the Technologies Enabling Agile Manufacturing (TEAM) program. Completion of the Sematech Computer Integrated Manufacturing (CIM) Application Framework Specification version 1.0. 2) Establishment of formal liaison between ISO/IEC JTC1/SC21/WG7 and the Object Management Group (OMG). Establishment of the OMG - Manufacturing Special Interest Group M(ManSIG) to accommodate the manufacturing industry's requirements of the Common Object Request Broker Architecture (CORBA). Emergence of initial versions of commercial Object Request Broker software products "conforming" to the OMG Common Object Request Broker Architecture.

\begin{tabular}{|c|c|c|c|c|c|}
\hline $\begin{array}{l}\text { SYSTEMS INTEGRATION FOR MANUFACTURING } \\
\text { APPLICATIONS (SIMA): } \\
\text { INTEGRATION PROJECT }\end{array}$ & 95 & 95 & 97 & 93 & 99 \\
\hline \multicolumn{6}{|l|}{$\begin{array}{l}\text { Create Cycle } 1 \text { Reference Architecture specifying design, } \\
\text { planning, and production engineering activities and } \\
\text { information sources [STRS] }\end{array}$} \\
\hline \multicolumn{6}{|l|}{$\begin{array}{l}\text { Create Cycle } 1 \text { Engineering Architecture specifying } \\
\text { functional subsystems, and initial set of integration } \\
\text { mechanisms [STRS] }\end{array}$} \\
\hline \multicolumn{6}{|l|}{$\begin{array}{l}\text { Determine suitability of Object Request Broker software as } \\
\text { an integrating mechanism by testing message passing } \\
\text { capabilities on both local area and wide area networks } \\
\text { [STRS] }\end{array}$} \\
\hline \multicolumn{6}{|l|}{$\begin{array}{l}\text { Prototype a simple distributed manufacturing software } \\
\text { application using an Object Request Broker as an } \\
\text { integrating mechanism [STRS, DOE TEAM in-kind } \\
\text { funding] }\end{array}$} \\
\hline $\begin{array}{l}\text { Integrate the Cycle } 1 \text { information models developed by the } \\
\text { SIMA Design, Planning, and Production projects [STRS] }\end{array}$ & & & & & \\
\hline
\end{tabular}




\begin{tabular}{|c|c|c|c|c|c|}
\hline $\begin{array}{l}\text { SYSTEMS INTEGRATION FOR MANUFACTURING } \\
\text { APPLICATIONS (SIMA): } \\
\text { INTEGRATION PROJECT }\end{array}$ & 98 & 96 & 97 & 98 & 99 \\
\hline $\begin{array}{l}\text { Demonstrate the capabilities of the STEP SDAI to OMG } \\
\text { CORBA IDL binding developed by the NIIIP program } \\
\text { through the use of this binding in a manufacturing } \\
\text { software prototype [STRS. NIIIP in-kind funding] }\end{array}$ & & & & & \\
\hline $\begin{array}{l}\text { Create Cycle } 2 \text { Reference Architecture, Engineering } \\
\text { Architecture, and additional integrated information models } \\
\text { [STRS, NIIIP in-kind, Sematech in-kind funding] }\end{array}$ & & & & & \\
\hline $\begin{array}{l}\text { Deploy Cycle } 2 \text { information models and architecture } \\
\text { specification in AMSANT for industry access and review. } \\
\text { [STRS] }\end{array}$ & & & & & \\
\hline $\begin{array}{l}\text { Create Cycle } 1 \text { implementation architecture in conjunction } \\
\text { with industry collaborators in preparation for industrial pilot } \\
\text { implementation [STRS, Industry in-kind funding]. }\end{array}$ & & & & & \\
\hline $\begin{array}{l}\text { Deploy industrial pilot implementation of SIMA } \\
\text { specifications and standards based on the Cycle } 1 \\
\text { implementation architecture. [STRS, Industry in-kind } \\
\text { funding] }\end{array}$ & & & & & \\
\hline $\begin{array}{l}\text { Contribute to the development of manufacturing system } \\
\text { integration standards, ISO } 10303 \text { Part } 11 \text { (EXPRESS), } \\
\text { ISO/TC184/ Advisory Group, OMG Common Object } \\
\text { Services Interface Definition Language (IDL), ISO/IEC } \\
\text { JTC1/SC21/WG7 Open Distributed Processing [STRS] }\end{array}$ & & & & & \\
\hline
\end{tabular}


Staff: (2.0 staff years) *Jesse Crusey, *Jeane Ford, HOWARD MONCARZ, *Tina Lee, *summer student

Project Objective and MEL Thrust Supported: The purpose of this project is to launch a nationwide $\mathrm{R} \& \mathrm{D}$ consortium-based program that will advance the technologies required, and the integration of those technologies, to provide Americans with affordable and quality, custom therapeutic footwear (CTF). This effort will enable the CTF (and ultimately the entire footwear) industry to enjoy the benefits from "open, modular, and reconfigurable integration of commercial software applications that support the design, planning and production of products within a Virtual Manufacturing Enterprise"-the SIMA vision.

This project helps the American footwear industry to potentially revolutionize its technology. In fact, the proposed program will enable the industry to supply a product to the market that can dramatically reduce health-care costs and have the potential for creating a new, large-volume market in custom footwear, thereby strengthening the American base of the industry. Furthermore, by the industry's own statement, without the government/industry collaboration as described here, the American CTF industry is in danger of failure. Success here can serve as a dramatic model for other sectors of American industry to follow. Integrated Machines and Systems.

Need Addressed: The U.S. domestic shoe market is $\$ 32$ billion a year at retail, which translates to over 1.5 billion pairs of shoes sold annually. Just 25 years ago, $80 \%$ of the shoes bought in this country were manufactured here. Now, however, that $80 \%$ figure has shrunk to only $12 \%$, with the number of domestic shoe manufacturers likewise reduced.

A very small part of the market, about $0.01 \%$, includes custom-manufactured shoes, where the shoe is manufactured to a specific individual's fit and, perhaps, other needs. In the custom shoe market less than 100,000 pairs of shoes are sold a year; those shoes are sold principally for health reasons. The low volume sold is due to the high labor content required, and results in a prohibitively high cost to the consumer. However, it is estimated that $10,000,000$ Americans could derive health benefits from custom footwear.

The separate technologies required for automated, and more efficient, custom-footwear manufacturing have reached the point where commercialization can be anticipated within the next several years. However, integration of those technologies to gain their maximum benefit through a nationwide, virtual enterprise must still be developed. This project will accelerate the process for American manufacturers to benefit from those technologies integrated to the national information infrastructure and thereby enable them to establish a firm foothold in the greatly expanded custom-footwear market anticipated. Furthermore, consumers with CTF needs will be able to afford quality, custom, therapeutic footwear.

Technical Approach: We are working to create a consortium to leverage the capabilities of the leading experts in this industry nationwide. Relevant technologies must be proven, developed, and/or advanced within an integrated, open-architecture environment; a proof-of-concept manufacturing cell must be demonstrated; and a pilot manufacturing operation, associated with a foot-health clinic, must be implemented. This will seed the commercialization of the technology for broad, nationwide dissemination.

We plan to obtain and integrate off-th shelf system components by implementing a portion of the CTF manufacturing cell, from automatic, 3D scanning of the foot through pre-production of the shoe, (i.e. generating the shoe patterns in electronic format). To integrate the other components required, we will collaborate with: 1) medical technologists who will research the accommodative and therapeutic corrections to the footwear required for patients with various foot problems; 2) with technologists who are developing 
automatic foot measurement devices; 3) with technologists who are developing rapid prototyping techniques for manufacturing lasts (shoe shape forms); and 4) with other laboratory sites who will receive shipment of the lasts and the electronic data patterns to produce the shoes.

Based on our experience with integrating all of the system components (some at the local site, others at remote sites) and in close collaboration with other consortium participants, we will develop specifications for an open architecture CTF manufacturing system.

Endorsing our program, Greg Alaimo, Vice President of Acor, a leading manufacturer of custom, therapeutic footwear wrote us a letter, stating "I feel that this team effort and an involvement by the Federal Government is the only viable way for us to obtain this technology. I fear that if this program does not move forward it just might signal the demise of our business."

\section{FY 94 Accomplishments:}

- Initiated and led workshop (co-hosted with SCRA) in Charleston, SC on March $10-11,1995$, to discuss the needs of the American footwear industry and to consider the creation of a nationwide research and development program to benefit that industry. Participants, comprised of top-level executives and leading technologists from the footwear industry, the health care industry, government, and academia. The need for an R \& D program to advance the technology for custom footwear manufacturing was firmly established, due to the tremendous impact on reducing health care costs, the military benefits possible, and also the possibility of creating a mainstream, custom-footwear industry. The participants agreed that the best strategy would be to concentrate initial efforts on advancing the technologies for CTF manufacturing because of the manageable size of that industry sector and because of the health-care benefits that could be obtained. (These conclusions were confirmed through numerous meetings and conversations, both before and after the workshop, with leaders from industry, the medical arena, academia, and government.)

- Published report, Program Requirements to Advance the Technology of Custom Footwear Manufacturing, October 1994, that documented the workshop and provided the initial "white paper" that articulated the need for the proposed R \& D program. Submitted an SBIR solicitation for technologies relevant to CTF manufacturing that was included in the last DoC SBIR solicitation booklet. This will enable us to expand our community of collaborators.

\section{FY 95 Plans:}

- Define vision for virtual CTF manufacturing enterprise (in collaboration with industry and medical experts) and help create consortium to accomplish it

- Specify the "As Is" and then begin specification of the "To Be" Architecture for the entire CTF Manufacturing Enterprise

- Implement a Pre-Production Cell for "As Is" CTF manufacturing with the objective to evolve it to the "To Be" vision

- Develop a simulation to demonstrate the "As Is" Architecture (and eventually the "To Be")

- Begin development of prototype Application Activity Models, Units of Functionality, and Application Reference Models for the STEP Application Protocols necessary for CTF Manufacturing

- Develop requirements for a virtual enterprise pilot implementation (i.e. physical pilot implementation, with separate components of it at distributed geographical sites). 


\begin{tabular}{|c|c|c|c|c|c|}
\hline $\begin{array}{l}\text { VIRTUAL ENTERPRISE FOR CUSTOM, THERAPEUTIC } \\
\text { FOOTWEAR MANUFACTURING }\end{array}$ & 95 & 96 & 97 & 95 & 99 \\
\hline $\begin{array}{l}\text { Establish buy-in of vision (created collaboratively) for } \\
\text { virtual, CTF manufacturing enterprise, and create } \\
\text { consortium to accomplish it [STRS] }\end{array}$ & & & & & \\
\hline $\begin{array}{l}\text { Publish the "To Be" CTF manfacturing architecture in } \\
\text { formal representation (e.g. IDEF) based on input } \\
\text { generated from NIST-initiated industry workshops [STRS] }\end{array}$ & & & & & \\
\hline $\begin{array}{l}\text { Implement a Pre-Production Cell for "To Be" CTF } \\
\text { manufacturing, integrated using prototype STEP } \\
\text { Application Protocols (APS), integrate to testbeds at other } \\
\text { sites (e.g. CTF production testbed), and conduct } \\
\text { proof-of-concept tests for new CTF manufaeturing } \\
\text { technologies across the virtual testbed [STRS] }\end{array}$ & & & & & \\
\hline $\begin{array}{l}\text { Provide simulation platform to demonstrate the "To Be" } \\
\text { architecture and update as architecture evolves during } \\
\text { course of project [STRS] }\end{array}$ & & & & & \\
\hline $\begin{array}{l}\text { Promote all ISO STEP APs ( } 25 \% \text { IS, } 25 \% \text { DIS, } 50 \% \text { in } \\
\text { development) necessary for the CTF virtual enterprise } \\
\text { [STRS] }\end{array}$ & & & & & \\
\hline $\begin{array}{l}\text { Deploy pilot for CTF virtual enterprise using commercial } \\
\text { sites for manufacturing and clinic sites for patient } \\
\text { assessments, utilizing STEP APs [STRS] }\end{array}$ & & & & & \\
\hline
\end{tabular}




\section{Cooperative Research and Development Agreements (CRADAs)}

\begin{tabular}{|l|l|}
\hline \multicolumn{2}{|c|}{ Office of Manufacturing Programs } \\
\hline Project Title & CRADA Partner CRADA Project Title \\
\hline Technology LearnIng Modules & $\begin{array}{l}\text { Industrial Modernization Center, A Mobile Shop of the 90's } \\
\text { Inc. }\end{array}$ \\
\hline
\end{tabular}

\begin{tabular}{|c|c|c|}
\hline \multicolumn{3}{|c|}{ Precision Engineering Division } \\
\hline Project Title & CRADA Partner & CRADA Project Title \\
\hline \multirow[t]{2}{*}{ CMM Calibration Artifacts } & Boeing Commercial Aircraft & $\begin{array}{l}\text { GCAG/NIST Interim Artifact } \\
\text { Test Program }\end{array}$ \\
\hline & Caterpillar Inc. & $\begin{array}{l}\text { Research on Artifacts for } \\
\text { Interim CMM Testing }\end{array}$ \\
\hline \multirow[t]{2}{*}{$\begin{array}{l}\text { Complex Form Dimensional } \\
\text { Metrology }\end{array}$} & $\begin{array}{l}\text { American Society of } \\
\text { Mechanicals Engineers } \\
\text { Consortium on Gear Metrology }\end{array}$ & $\begin{array}{l}\text { The Deployment of a National } \\
\text { Infrastructure for Gear } \\
\text { Metrology }\end{array}$ \\
\hline & Glastonbury Gage & Smart Dimensional Artifacts \\
\hline \multirow{4}{*}{$\begin{array}{l}\text { Development of Performance } \\
\text { Evaluation Methodologies for } \\
\text { Articulating Arm Coordinate } \\
\text { Measuring Machines }\end{array}$} & 2mm Program, Inc. & $\begin{array}{l}\text { Dexterous OCMM System for } \\
\text { Dimensional Control in } \\
\text { Automobile Body }\end{array}$ \\
\hline & Extrude Hone Corporation & $\begin{array}{l}\text { Capacitance Sensing System } \\
\text { for Dimensional Measurement }\end{array}$ \\
\hline & FARO Technologies, Inc. & Multi-Axis Articulating CMMs \\
\hline & Romer SupraTech, Inc. & Multi-Axis Articulating CMMs \\
\hline \multirow[t]{3}{*}{$\begin{array}{l}\text { Scanning Electron } \\
\text { Microscope Linewidth } \\
\text { Metrology }\end{array}$} & Anatech Ltd. & $\begin{array}{l}\text { Development of Cleaning } \\
\text { Procedures for Electron Beam } \\
\text { Induced Contamination }\end{array}$ \\
\hline & IVS & $\begin{array}{l}\text { Development of Submicrometer } \\
\text { Pitch Standards and Sharpness } \\
\text { Standards }\end{array}$ \\
\hline & Metrologix, Inc. & $\begin{array}{l}\text { Optimization of Electron Beam } \\
\text { Parameters for Automation } \\
\text { Linewidth }\end{array}$ \\
\hline
\end{tabular}




\begin{tabular}{|l|ll|}
\hline $\begin{array}{l}\text { Surface Finish and Microform } \\
\text { Measurements }\end{array}$ & MOXTEK & $\begin{array}{l}\text { Development of Holographically } \\
\text { Produced Pitch Standards }\end{array}$ \\
\cline { 2 - 3 } & $\begin{array}{l}\text { Optex Communications } \\
\text { Corporation }\end{array}$ & $\begin{array}{l}\text { Atomic Force Microscopy } \\
\text { Applied to Process Control }\end{array}$ \\
\cline { 2 - 3 } & Park Scientific Instruments & $\begin{array}{l}\text { CD Measurement for IC } \\
\text { Manufacturing Using AFM }\end{array}$ \\
\cline { 2 - 4 } & VLSI Standards, Inc. & $\begin{array}{l}\text { Development of SPM Calibration } \\
\text { Standards }\end{array}$ \\
\hline Wafer Flatness & Horizon Technology Group & $\begin{array}{l}\text { Advanced Manufacturing and } \\
\text { Metrology Methods for Ultra-flat } \\
\text { Electronic and Optical Substrates }\end{array}$ \\
\hline
\end{tabular}

\section{Automated Production Technology Division}

\begin{tabular}{|c|c|c|}
\hline Project Title & CRADA Partner & CRADA Project Title \\
\hline Acoustical Metrology Services & Horizon Technology Group & $\begin{array}{l}\text { Micromachined Acoustic Sensor } \\
\text { Technology }\end{array}$ \\
\hline \multirow[t]{2}{*}{ Precision Machining } & $\begin{array}{l}\text { National Center for Manufacturing } \\
\text { Sciences }\end{array}$ & $\begin{array}{l}\text { Real Time Error Compensation } \\
\text { ("RTEC") }\end{array}$ \\
\hline & Portsmouth Naval Shipyard & Portsmouth Fastener Workstation \\
\hline \multirow[t]{2}{*}{$\begin{array}{l}\text { Quality Control of Advanced } \\
\text { Materlals }\end{array}$} & The Boeing Company & $\begin{array}{l}\text { Laser Ultrasonic Inspection } \\
\text { System (LUIS) }\end{array}$ \\
\hline & ERIEZ Magnetics & $\begin{array}{l}\text { Ultrasonic Detection of } \\
\text { Contaminants in Flowing Fluids }\end{array}$ \\
\hline $\begin{array}{l}\text { Sensor Interface for Machine } \\
\text { Controller (SIMC) }\end{array}$ & Johnson Gage Company & Portsmouth Fastener Work Cell \\
\hline Spindle Characterization & Timken Company & $\begin{array}{l}\text { Effects of Work Spindle on the } \\
\text { Turning of Hard Materials }\end{array}$ \\
\hline
\end{tabular}




\section{Intelligent Systems Division}

\begin{tabular}{|l|ll|}
\hline Project Title & CRADA Partner & CRADA Project Title \\
\hline IMI Robocrane Project & Brigham Young University & $\begin{array}{l}\text { Fix Head Laser Scanner with Six- } \\
\text { Axis Motion }\end{array}$ \\
\cline { 2 - 3 } & Deneb Robotics, Inc & $\begin{array}{l}\text { Robo Crane Off-Line } \\
\text { Programming and Teleoperation }\end{array}$ \\
\cline { 2 - 3 } & Global Associates, Ltd. & $\begin{array}{l}\text { Integration of 10A Modular } \\
\text { Bridging System with the } \\
\text { Robocrane }\end{array}$ \\
\cline { 2 - 3 } & Helaman Ferguson & $\begin{array}{l}\text { String-Pot 2 Measurement } \\
\text { System }\end{array}$ \\
\cline { 2 - 3 } & Lehigh University & $\begin{array}{l}\text { Cable-Driven Steward Platform } \\
\text { Cranes in Conjunction with } \\
\text { ATLSS Connections }\end{array}$ \\
\cline { 2 - 3 } & Robotic Technology, Inc. & $\begin{array}{l}\text { Robotic Assembly of Innovtive } \\
\text { Ocean Structures }\end{array}$ \\
\cline { 2 - 3 } & SILMA, Inc. & $\begin{array}{l}\text { Visual Programming of Robot } \\
\text { Tasks for the Non-Specialist }\end{array}$ \\
\hline $\begin{array}{l}\text { Real-TIme Control System } \\
\text { Computer-Aided Control } \\
\text { System Englneerlng Tool } \\
\text { (RCT) }\end{array}$ & & \\
\hline
\end{tabular}

\section{Manufacturing Systems Integration Division}

\begin{tabular}{|l|ll|}
\hline Project Title & CRADA Partner & CRADA Project Title \\
\hline $\begin{array}{l}\text { Apparel Product Data } \\
\text { Exchange Standard/Customer- } \\
\text { Drlven Apparel Manufacturlng }\end{array}$ & Fashion Institute of Technology & Apparel Pattern Data Exchange \\
\hline $\begin{array}{l}\text { Computer-Alded Manufacturlng } \\
\text { Englneerlng }\end{array}$ & Black and Decker (pending) & $\begin{array}{l}\text { Computer-Aided Manufacturing } \\
\text { Engineering }\end{array}$ \\
\hline $\begin{array}{l}\text { Manufacturing Standards } \\
\text { Development }\end{array}$ & P.D.I.T. & STEP Integration Technology \\
\hline $\begin{array}{l}\text { Multl-Agent Manufacturing } \\
\text { Systems }\end{array}$ & $\begin{array}{l}\text { American Heuristics Corporation } \\
\text { (pending) }\end{array}$ & $\begin{array}{l}\text { Computer Aided Process } \\
\text { Planning and Cell Control }\end{array}$ \\
\hline $\begin{array}{l}\text { Natlonal PDES Testbed } \\
\text { Program Office }\end{array}$ & $\begin{array}{l}\text { International Business Machines } \\
\text { Corporation }\end{array}$ & PDES Testbed Project \\
\hline
\end{tabular}




\begin{tabular}{|l|ll|}
\hline Process Planning Appllcatlons & ADB, Inc & $\begin{array}{l}\text { Manufacturing Applications of } \\
\text { Object Oriented Databases }\end{array}$ \\
\cline { 2 - 3 } & American Heuristics Corporation & $\begin{array}{l}\text { Computer Aided Process } \\
\text { Planning and Cell Control }\end{array}$ \\
\cline { 2 - 3 } & International TechneGroup, Inc. & $\begin{array}{l}\text { Integration of Manufacturing } \\
\text { Engineering \& Planning Systems } \\
\text { for Product Life-Cycle } \\
\text { Applications }\end{array}$ \\
\hline $\begin{array}{l}\text { Persistent Object Base (POB) } \\
\text { Technology Evaluation For } \\
\text { Engineering }\end{array}$ & ADB, Inc & $\begin{array}{l}\text { Manufacturing Applications of } \\
\text { Object Oriented Databases }\end{array}$ \\
\hline $\begin{array}{l}\text { STEP Implementatlon } \\
\text { Prototypes }\end{array}$ & International Business Machines & PDES Testbed Project \\
\hline $\begin{array}{l}\text { Systems Integrating } \\
\text { Manufacturlng Applications } \\
\text { (SIMA): Integratlon Project }\end{array}$ & Lorporation & $\begin{array}{l}\text { Manufacturing System Model } \\
\text { Implementation }\end{array}$ \\
\hline
\end{tabular}




\section{Acronyms}

\begin{tabular}{|c|c|}
\hline $\begin{array}{l}\text { A\&E } \\
\text { AAMACS } \\
\text { ADACS } \\
\text { AE } \\
\text { AFB } \\
\text { AFM } \\
\text { AIAG } \\
\text { AMRF } \\
\text { AMSANT } \\
\text { AMTST } \\
\text { ANSI } \\
\text { AP } \\
\text { API } \\
\text { APTD } \\
\text { ARCMM } \\
\text { ARPA } \\
\text { ASA } \\
\text { ASME } \\
\text { ASTM } \\
\text { ATEP } \\
\text { ATL } \\
\text { ATM } \\
\text { ATP } \\
\text { ATS } \\
\text { BFRL } \\
\text { BIPM } \\
\text { C-AFM } \\
\text { CACSE } \\
\text { CAD } \\
\text { CAD/CAM } \\
\text { CAF } \\
\text { CAME } \\
\text { CAML } \\
\text { CASE } \\
\text { CCD } \\
\text { CIFP } \\
\text { CIM } \\
\text { CMM } \\
\text { CMS } \\
\text { CNC } \\
\text { CORBA } \\
\text { CRADA } \\
\text { DDA } \\
\text { DDE } \\
\text { DFA } \\
\text { DLA } \\
\text { DOC }\end{array}$ & $\begin{array}{l}\text { Architecture and engineering } \\
\text { Advanced Automated Master Angle Calibration System } \\
\text { Advanced Deburring and Chamfering System } \\
\text { Acoustical emission } \\
\text { Air Force base } \\
\text { Atomic force microscope } \\
\text { Automotive Industry Action Group } \\
\text { Automated Manufacturing Research Facility } \\
\text { Advanced Manufacturing Systems And Networking Testbed } \\
\text { Advanced Machine Tool Structures Testbed } \\
\text { American National Standards Institute } \\
\text { Application protocol (for STEP) } \\
\text { Application programming interface } \\
\text { Automated Production Technology Division } \\
\text { Articulating arm coordinate measuring machine } \\
\text { Advanced Research Projects Agency } \\
\text { Acoustical Society of America } \\
\text { American Society of Mechanical Engineers } \\
\text { American Society for Testing and Materials } \\
\text { Algorithm Testing and Evaluation Program } \\
\text { Advanced Technology Laboratory } \\
\text { Asynchronous transfer mode } \\
\text { Advanced Technology Program } \\
\text { Algorithm Testing System } \\
\text { Building and Fire Research Laboratory } \\
\text { Bureau International des Poids et Mesures (France) } \\
\text { Calibrated atomic force microscope } \\
\text { Computer aided control system engineering } \\
\text { Computer aided design } \\
\text { Computer aided design/computer aided manufacturing } \\
\text { Controlled ambient facility } \\
\text { Computer aided manufacturing engineering } \\
\text { Computing and Applied Mathematics Laboratory } \\
\text { Computer aided software engineering } \\
\text { Charge coupled device } \\
\text { Capital Improvement of Facilities Project } \\
\text { Computer integrated manufacturing } \\
\text { Coordinate measuring machine } \\
\text { Coordinate measuring systems } \\
\text { Computer numerical control } \\
\text { Common Object Request Broker Architecture } \\
\text { Cooperative Research and Development Agreement } \\
\text { Dynamic displacement artifact } \\
\text { Data description exchange } \\
\text { Design for assembly } \\
\text { Defense Logistics Agency } \\
\text { Department of Commerce }\end{array}$ \\
\hline
\end{tabular}




\begin{tabular}{|c|c|}
\hline $\begin{array}{l}\text { DOD } \\
\text { DOE }\end{array}$ & $\begin{array}{l}\text { Department of Defense } \\
\text { Department of Energy }\end{array}$ \\
\hline EEEL & Electronics and Electrical Engineering Laboratory \\
\hline EIF & Enterprise integration framework \\
\hline EMC & Enhanced Machine Controller \\
\hline ESAIM & Emulated Stepper Serial Image Measurement \\
\hline FCIM & Flexible computer integrated manufacturing \\
\hline FEA & Finite element analysis \\
\hline FTD & Factory Technology Division \\
\hline GUI & Graphical user interface \\
\hline HPCC & High Performance Computing and Communications \\
\hline IEC & Intemational Electrotechnical Commission \\
\hline IEEE & $\begin{array}{l}\text { Institute of Electrical and Electronics Engineers } \\
\text { Initial Graphics Exchanae Soecification }\end{array}$ \\
\hline IGES & $\begin{array}{l}\text { Initial Graphics Exchange Specification } \\
\text { Information Infrastructure Technology Applications }\end{array}$ \\
\hline $\begin{array}{l}\text { IITA } \\
\text { IPO }\end{array}$ & $\begin{array}{l}\text { Information Infrastructure Technology Applications } \\
\text { IGES/PDES Organization }\end{array}$ \\
\hline IPPD & Integrated Product/Process Design \\
\hline ISD & Intelligent Systems Division \\
\hline ISDN & Integrated Services Digital Network \\
\hline ISO & International Organization for Standardization \\
\hline ITA & Interim testing artifact \\
\hline ITS & $\begin{array}{l}\text { Industrial Technology Services (funding from NIST Advanced Technology Program and } \\
\text { Manufacturing Extension Partnership) }\end{array}$ \\
\hline JPL & Jet Propulsion Laboratory \\
\hline LAN & Local area network \\
\hline LSI & Linescale interferometer \\
\hline M3 & Molecular Measuring Machine \\
\hline MEL & Manufacturing Engineering Laboratory \\
\hline MITT & Manufacturing Information Technology Transfer \\
\hline MSEL & Materials Science and Engineering Laboratory \\
\hline MSID & Manufacturing Systems Integration Division \\
\hline NAMT & National Advanced Manufacturing Testbed \\
\hline NC & Numerically controlled (machine tools or equipment) \\
\hline NCMS & National Center for Manufacturing Sciences \\
\hline NCSL & National Conference of Standards Laboratories \\
\hline NGC & Next Generation Controller \\
\hline NGIS & Next Generation Inspection System \\
\hline NII & National Information Infrastructure \\
\hline NIIIIP & National Industrial Information Infrastructure Protocols \\
\hline NIST & National Institute of Standards and Technology \\
\hline NISTIR & National Institute of Standards and Technology Interagency/Internal Report \\
\hline NPL & National Physical Laboratory (U.K. and India) \\
\hline NRC & National Research Council \\
\hline NVLAP & National Voluntary Laboratory Accreditation Program \\
\hline$O A$ & Other (government) agencies \\
\hline OAI & Ohio Aerospace Institute \\
\hline OIML & International Organization for Legal Metrology \\
\hline OMG & Object Management Group \\
\hline OODB & Open Object Oriented Database \\
\hline ORCMT & Oak Ridge Centers for Manufacturing Technology \\
\hline OSRM & Office of Standard Reference Materials \\
\hline
\end{tabular}




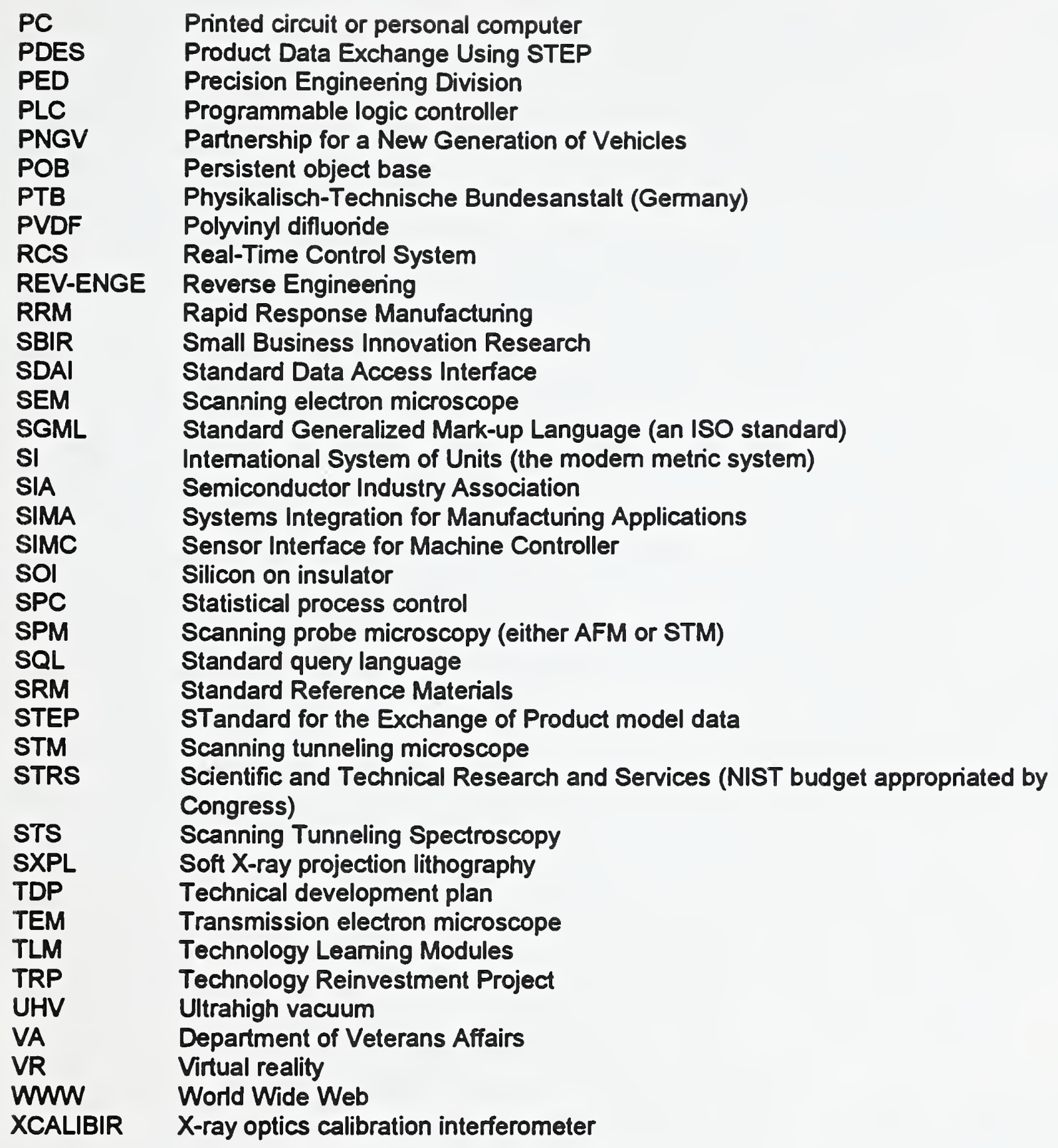



